Bond University

Research Repository

\title{
Chlorpromazine versus placebo for schizophrenia
}

Adams, Clive E.; Awad, George A.; Rathbone, John; Thornley, Ben; Soares-Weiser, Karla

Published in:

Cochrane Database of Systematic Reviews

DOI:

10.1002/14651858.CD000284.pub3

Licence:

Other

Link to output in Bond University research repository.

Recommended citation(APA):

Adams, C. E., Awad, G. A., Rathbone, J., Thornley, B., \& Soares-Weiser, K. (2014). Chlorpromazine versus placebo for schizophrenia. Cochrane Database of Systematic Reviews, 2014(1), [000284].

https://doi.org/10.1002/14651858.CD000284.pub3

\section{General rights}

Copyright and moral rights for the publications made accessible in the public portal are retained by the authors and/or other copyright owners and it is a condition of accessing publications that users recognise and abide by the legal requirements associated with these rights.

For more information, or if you believe that this document breaches copyright, please contact the Bond University research repository coordinator. 


\section{(E) Cochrane Library}

Cochrane Database of Systematic Reviews

\section{Chlorpromazine versus placebo for schizophrenia (Review)}

Adams CE, Awad GA, Rathbone J, Thornley B, Soares-Weiser K

Adams CE, Awad GA, Rathbone J, Thornley B, Soares-Weiser K.

Chlorpromazine versus placebo for schizophrenia.

Cochrane Database of Systematic Reviews 2014, Issue 1. Art. No.: CD000284.

DOI: 10.1002/14651858.CD000284.pub3.

www.cochranelibrary.com 
TABLE OF CONTENTS

HEADER . . . . . . . . . . . . . . . . . . . . . . . . . . . . . . . . . . . . . . . 1

ABSTRACT . . . . . . . . . . . . . . . . . . . . . . . . . . . . . . . . . . . . . . . . . . . . . . .

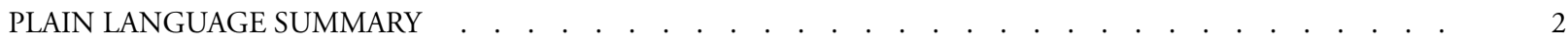

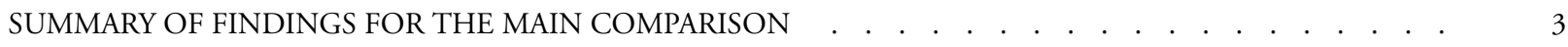

BACKGROUND . . . . . . . . . . . . . . . . . . . . . . . . . . . . . . . . . . . . . 6

OBJECTIVES . . . . . . . . . . . . . . . . . . . . . . . . . . . . . . . . . . . . . . . . . . . . . . . . .

METHODS . . . . . . . . . . . . . . . . . . . . . . . . . . . . . . . . . . . . . . 6

RESULTS . . . . . . . . . . . . . . . . . . . . . . . . . . . . . . . . . . . . . . . . . . .

Figure 1. . . . . . . . . . . . . . . . . . . . . . . . . . . . . . . . . . . . . .

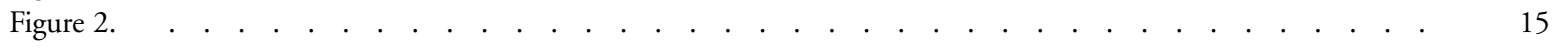

Figure 3. . . . . . . . . . . . . . . . . . . . . . . . . . . . . . . . . . . . . .

DISCUSSION . . . . . . . . . . . . . . . . . . . . . . . . . . . . . . . . . . . . . .

AUTHORS' CONCLUSIONS . . . . . . . . . . . . . . . . . . . . . . . . . . . . . . . . . . . . . .

ACKNOWLEDGEMENTS . . . . . . . . . . . . . . . . . . . . . . . . . . . . . . . . . . . . . . . . . . .

REFERENCES . . . . . . . . . . . . . . . . . . . . . . . . . . . . . . . . . . . . . . . . . . . .

CHARACTERISTICS OF STUDIES . . . . . . . . . . . . . . . . . . . . . . . . . . . . . . . . . . . . . . . . . . . 46

DATA AND ANALYSES . . . . . . . . . . . . . . . . . . . . . . . . . . . . . . . . . . . . . . . . . . . . . . . . . . .

Analysis 1.1. Comparison 1 CHLORPROMAZINE versus PLACEBO, Outcome 1 Death. . . . . . . . . . . 154

Analysis 1.2. Comparison 1 CHLORPROMAZINE versus PLACEBO, Outcome 2 Relapse. ..... . . . 155

Analysis 1.3. Comparison 1 CHLORPROMAZINE versus PLACEBO, Outcome 3 Global state: 1a. No overall improvement (psychiatrist-rated). . . . . . . . . . . . . . . . . . . . . . . . . . . . . . . . . . . . . . .

Analysis 1.4. Comparison 1 CHLORPROMAZINE versus PLACEBO, Outcome 4 Global state: 1b. No overall improvement (nurse-rated). . . . . . . . . . . . . . . . . . . . . . . . . . . . . . . . . . . . . . . 158

Analysis 1.5. Comparison 1 CHLORPROMAZINE versus PLACEBO, Outcome 5 Global state: 2. Average endpoint score - short term (CGI, high score=worse). . . . . . . . . . . . . . . . . . . . . . . . . . . . . . . . . 15

Analysis 1.6. Comparison 1 CHLORPROMAZINE versus PLACEBO, Outcome 6 Global state: 3a. Severity of illness, severely ill or worse (CGI 5+ points, psychiatrist-rated). . . . . . . . . . . . . . . . . . . . . . . . . . .

Analysis 1.7. Comparison 1 CHLORPROMAZINE versus PLACEBO, Outcome 7 Global state: 3b. Severity of illness, severely ill or worse - medium term (CGI 5+ points, nurse-rated). . . . . . . . . . . . . . . . . . . . . . . 161

Analysis 1.8. Comparison 1 CHLORPROMAZINE versus PLACEBO, Outcome 8 Leaving the study early. $\quad$. $\quad$. 162

Analysis 1.9. Comparison 1 CHLORPROMAZINE versus PLACEBO, Outcome 9 Mental state: 1 . Improved - short term (BPRS, 50\% change). . . . . . . . . . . . . . . . . . . . . . . . . . . . . . . . 164

Analysis 1.10. Comparison 1 CHLORPROMAZINE versus PLACEBO, Outcome 10 Mental state: 2. Average endpoint scores (BPRS, high score=worse). . . . . . . . . . . . . . . . . . . . . . . . . . . . . . . .

Analysis 1.11. Comparison 1 CHLORPROMAZINE versus PLACEBO, Outcome 11 Behaviour: 1. Deteriorated/ disturbed/un-cooperative. . . . . . . . . . . . . . . . . . . . . . . . . . . . . . . . . . . . . . . . . . 166

Analysis 1.12. Comparison 1 CHLORPROMAZINE versus PLACEBO, Outcome 12 Behaviour: 2. Unchanged. $\quad 167$

Analysis 1.13. Comparison 1 CHLORPROMAZINE versus PLACEBO, Outcome 13 Behaviour: 3. Average endpoint scores (RRS, high score=worse).

Analysis 1.14. Comparison 1 CHLORPROMAZINE versus PLACEBO, Outcome 14 Behaviour: 4. Average endpoint score - short term (PBRS, high score=good).

Analysis 1.15. Comparison 1 CHLORPROMAZINE versus PLACEBO, Outcome 15 Behaviour: 5 . Average endpoint scores - medium term (Fergus Falls Behavioural rating scale).

Analysis 1.16. Comparison 1 CHLORPROMAZINE versus PLACEBO, Outcome 16 Adverse effects: 1. Movement disorders.

Analysis 1.17. Comparison 1 CHLORPROMAZINE versus PLACEBO, Outcome 17 Adverse effects: 2. Movement disorders: Average endpoint scores (Extrapyramidal Bilan, high score=worse). . . . . . . . . . . . . .

Analysis 1.18. Comparison 1 CHLORPROMAZINE versus PLACEBO, Outcome 18 Adverse effects: 1. Central nervous system. . . . . . . . . . . . . . . . . . . . . . . . . . . . . . . . . . . . . 174

Analysis 1.19. Comparison 1 CHLORPROMAZINE versus PLACEBO, Outcome 19 Adverse effects: 3. Blood, skin, liver, eyes. . . . . . . . . . . . . . . . . . . . . . . . . . . . . . . . . . . . . . . . . . . . . . $\quad . \quad 176$

Chlorpromazine versus placebo for schizophrenia (Review)

Copyright @ 2015 The Cochrane Collaboration. Published by John Wiley \& Sons, Ltd. 
Analysis 1.20. Comparison 1 CHLORPROMAZINE versus PLACEBO, Outcome 20 Adverse effects: 4. Other. .

Analysis 1.21. Comparison 1 CHLORPROMAZINE versus PLACEBO, Outcome 21 SUBGROUP ANALYSIS: 1. MEN vs WOMEN: Behaviour: Deteriorated/disturbed/un-cooperative. . . . . . . . . . . . . . . . . . . . .

Analysis 1.22. Comparison 1 CHLORPROMAZINE versus PLACEBO, Outcome 22 SUBGROUP ANALYSIS: 2. ACUTE vs CHRONIC.

Analysis 1.23. Comparison 1 CHLORPROMAZINE versus PLACEBO, Outcome 23 SUBGROUP ANALYSIS: 3. HIGH v LOW DOSE. . . . . . . . . . . . . . . . . . . . . . . . . . . . . . . . . .

Analysis 1.24. Comparison 1 CHLORPROMAZINE versus PLACEBO, Outcome 24 SUBGROUP ANALYSIS: 4. DIAGNOSTIC CRITERIA vs NO DIAGNOSTIC CRITERIA. . . . . . . . . . . . . . . . . . . . . . . .

Analysis 1.25. Comparison 1 CHLORPROMAZINE versus PLACEBO, Outcome 25 SUBGROUP ANALYSIS: 5. STUDIES PRE-1990 vs STUDIES 1990-2007. . . . . . . . . . . . . . . . . . . . . . . Analysis 1.26. Comparison 1 CHLORPROMAZINE versus PLACEBO, Outcome 26 SENSITIVITY ANALYSIS: 1. RANDOMISATION. . . . . . . . . . . . . . . . . . . . . . . . . . . . . . . .

Analysis 1.27. Comparison 1 CHLORPROMAZINE versus PLACEBO, Outcome 27 SENSITIVITY ANALYSIS: 2. ASSUMPTIONS FOR LOST BINARY DATA. . . . . . . . . . . . . . . . . . . . . . . 196

ADDITIONAL TABLES . . . . . . . . . . . . . . . . . . . . . . . . . . . . . . . . . . . 196

APPENDICES . . . . . . . . . . . . . . . . . . . . . . . . . . . . . . . . . . . . . . . . . . . . . . 197

FEEDBACK . . . . . . . . . . . . . . . . . . . . . . . . . . . . . . . . . . . . . . . 200

WHAT'S NEW . . . . . . . . . . . . . . . . . . . . . . . . . . . . . . . . . . . . . 203

HISTORY . . . . . . . . . . . . . . . . . . . . . . . . . . . . . . . . . . . . . . . . 203

CONTRIBUTIONS OF AUTHORS . . . . . . . . . . . . . . . . . . . . . . . . . . . . . . . . . 204

DECLARATIONS OF INTEREST . . . . . . . . . . . . . . . . . . . . . . . . . . . . . . . . . . . . . . 204

SOURCES OF SUPPORT . . . . . . . . . . . . . . . . . . . . . . . . . . . . . . . . . . . . . . . . . . . . . . .

DIFFERENCES BETWEEN PROTOCOL AND REVIEW . . . . . . . . . . . . . . . . . . . . . . . . . . .

INDEX TERMS . . . . . . . . . . . . . . . . . . . . . . . . . . . . . . . . . . . . . . 205 


\title{
[Intervention Review]
}

\section{Chlorpromazine versus placebo for schizophrenia}

\author{
Clive E Adams ${ }^{1}$, George A Awad ${ }^{2}$, John Rathbone ${ }^{3}$, Ben Thornley ${ }^{4}$, Karla Soares-Weiser ${ }^{5}$ \\ ${ }^{1}$ Cochrane Schizophrenia Group, The University of Nottingham, Nottingham, UK. ${ }^{2}$ Department of Psychiatry, University of Toronto, \\ Toronto, Canada. ${ }^{3}$ Faculty of Health Sciences and Medicine, Bond University, Gold Coast, Australia. ${ }^{4}$ Marsh Gibbon, UK. ${ }^{5}$ Cochrane \\ Editorial Unit, Cochrane, London, UK \\ Contact address: Clive E Adams, Cochrane Schizophrenia Group, The University of Nottingham, Institute of Mental Health, Innovation \\ Park, Triumph Road,, Nottingham, NG7 2TU, UK. clive.adams@nottingham.ac.uk.
}

Editorial group: Cochrane Schizophrenia Group.

Publication status and date: Edited (no change to conclusions), published in Issue 11, 2015.

Citation: Adams CE, Awad GA, Rathbone J, Thornley B, Soares-Weiser K. Chlorpromazine versus placebo for schizophrenia. Cochrane Database of Systematic Reviews 2014, Issue 1. Art. No.: CD000284. DOI: 10.1002/14651858.CD000284.pub3.

Copyright (C 2015 The Cochrane Collaboration. Published by John Wiley \& Sons, Ltd.

\begin{abstract}
A B S T R A C T
Background

Chlorpromazine, formulated in the 1950s, remains a benchmark treatment for people with schizophrenia.
\end{abstract}

\section{Objectives}

To review the effects of chlorpromazine compared with placebo, for the treatment of schizophrenia.

\section{Search methods}

We searched the Cochrane Schizophrenia Group's Trials Register (15 May 2012). We also searched references of all identified studies for further trial citations. We contacted pharmaceutical companies and authors of trials for additional information.

\section{Selection criteria}

We included all randomised controlled trials (RCTs) comparing chlorpromazine with placebo for people with schizophrenia and nonaffective serious/chronic mental illness irrespective of mode of diagnosis. Primary outcomes of interest were death, violent behaviours, overall improvement, relapse and satisfaction with care.

\section{Data collection and analysis}

We independently inspected citations and abstracts, ordered papers, re-inspected and quality assessed these. We analysed dichotomous data using risk ratio (RR) and estimated the $95 \%$ confidence interval (CI) around this. We excluded continuous data if more than $50 \%$ of participants were lost to follow-up. Where continuous data were included, we analysed this data using mean difference (MD) with a $95 \%$ confidence interval. We used a fixed-effect model.

\section{Main results}

We inspected over 1100 electronic records. The review currently includes 315 excluded studies and 55 included studies. The quality of the evidence is very low. We found chlorpromazine reduced the number of participants experiencing a relapse compared with placebo during six months to two years follow-up ( $\mathrm{n}=512,3$ RCTs, RR 0.65 CI 0.47 to 0.90 ), but data were heterogeneous. No difference was found in relapse rates in the short, medium or long term over two years, although data were also heterogeneous. We found chlorpromazine provided a global improvement in a person's symptoms and functioning $(\mathrm{n}=1164,14 \mathrm{RCTs}$, RR 0.71 CI 0.58 to 0.86 ). Fewer people allocated to chlorpromazine left trials early ( $\mathrm{n}=1831,27$ RCTs, RR 0.64 CI 0.53 to 0.78$)$ compared with placebo. There are many adverse effects. Chlorpromazine is clearly sedating ( $\mathrm{n}=1627,23 \mathrm{RCTs}$, RR 2.79 CI 2.25 to 3.45$)$, it increases 
a person's chances of experiencing acute movement disorders ( $\mathrm{n}=942,5$ RCTs, RR 3.47 CI 1.50 to 8.03) and parkinsonism ( $\mathrm{n}=1468$, 15 RCTs, RR 2.11 CI 1.59 to 2.80). Akathisia did not occur more often in the chlorpromazine group than placebo. Chlorpromazine clearly causes a lowering of blood pressure with accompanying dizziness ( $\mathrm{n}=1488,18 \mathrm{RCTs}$, RR 2.38 CI 1.74 to 3.25) and considerable weight gain ( $\mathrm{n}=165,5$ RCTs, RR 4.92 CI 2.32 to 10.43 ).

\section{Authors' conclusions}

The results of this review confirm much that clinicians and recipients of care already know but aim to provide quantification to support clinical impression. Chlorpromazine's global position as a 'benchmark' treatment for psychoses is not threatened by the findings of this review. Chlorpromazine, in common use for half a century, is a well-established but imperfect treatment. Judicious use of this best available evidence should lead to improved evidence-based decision making by clinicians, carers and patients.

\section{PLAIN LANGUAGE SUMMARY}

\section{Chlorpromazine versus placebo for schizophrenia}

For previous plain language summary please see Appendix 3.

People with schizophrenia often hear voices or see things (hallucinations) and have strange beliefs (delusions). The main treatment for these symptoms of schizophrenia is antipsychotic drugs. Chlorpromazine was one of the first drugs discovered to be effective in the treatment of schizophrenia during the 1950s. It remains one of the most commonly used and inexpensive treatments even today. However, being an older drug ('typical' or first generation) it also has serious side effects, such as blurred vision, a dry mouth, tremors or uncontrollable shaking, depression, muscle stiffness and restlessness.

An update search was carried out in 2012 and the review now includes 55 studies that assess the effects of chlorpromazine in treating schizophrenia compared with no active treatment ('dummy' treatment or placebo). Evidence was, in the main, rated by the review authors as low quality. There is some evidence to suggest that chlorpromazine reduces relapse and improves people's mental health, symptoms and functioning. However, the side effects of chlorpromazine are severe and debilitating. Chlorpromazine causes sleepiness and sedation. It also causes movement disorders (such as tremors and uncontrollable shaking), considerable weight gain and lowering of blood pressure with accompanying dizziness.

Chlorpromazine is low-cost and widely available. Despite its many side effects, chlorpromazine is likely to remain a benchmark drug and one of the most widely used treatments for schizophrenia worldwide.

It should be noted that the quality of evidence from the 55 included studies was low and in addition to this, 315 studies were excluded because of flaws in the reporting of information or data and in research design and methods. Larger, better conducted and reported trials should focus on important outcomes such as quality of life, levels of satisfaction, relapse, hospital discharge or admission and number of violent incidents. 


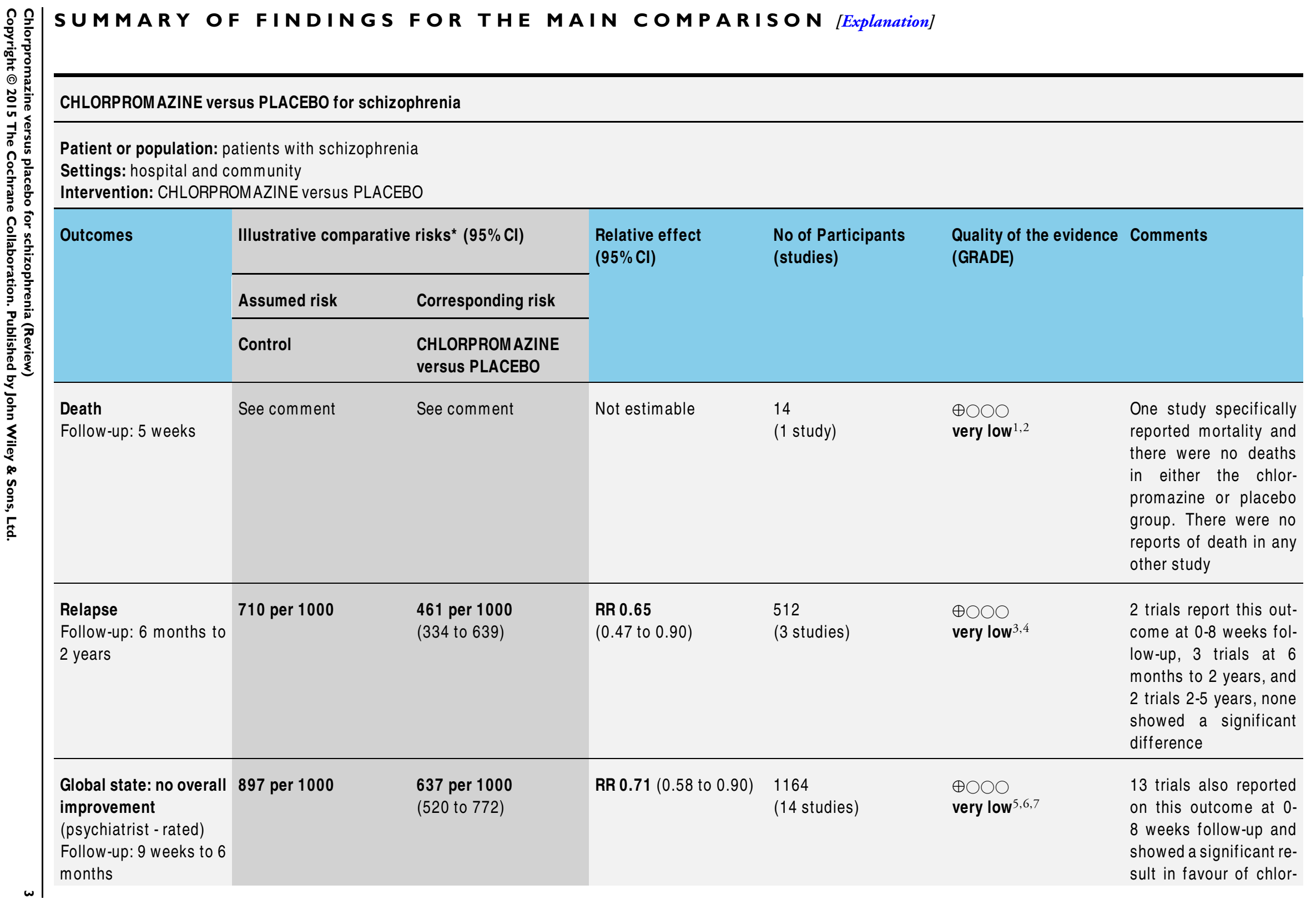




\begin{tabular}{|c|c|c|c|c|c|c|}
\hline & & & & & & promazine \\
\hline $\begin{array}{l}\text { Leaving the study early } \\
\text { Follow-up: } 9 \text { weeks to } 6 \\
\text { months }\end{array}$ & 200 per 1000 & $\begin{array}{l}128 \text { per } 1000 \\
(106 \text { to } 156)\end{array}$ & $\begin{array}{l}\text { RR } 0.64 \\
\text { ( } 0.53 \text { to } 0.78)\end{array}$ & $\begin{array}{l}1831 \\
\text { (27 studies) }\end{array}$ & $\begin{array}{l}\oplus \oplus \bigcirc \bigcirc \\
\text { low }^{8}\end{array}$ & $\begin{array}{l}17 \text { trials reported on } \\
\text { this outcome at } 0-8 \\
\text { weeks follow-up and } \\
\text { showed significant re- } \\
\text { sults in favour of chlor- } \\
\text { promazine. } 2 \text { trials re- } \\
\text { ported on this outcome } \\
\text { at } 6 \text { months to } 2 \text { years } \\
\text { follow-up, and } 1 \text { trial } \\
\text { at } 2-5 \text { years, and there } \\
\text { was no significant dif- } \\
\text { ference }\end{array}$ \\
\hline $\begin{array}{l}\text { Satisfaction with treat- } \\
\text { ment - not reported }\end{array}$ & See comment & See comment & Not estimable & - & See comment & $\begin{array}{l}\text { No studies reported on } \\
\text { this outcome. }\end{array}$ \\
\hline $\begin{array}{l}\text { Behaviour: dete- } \\
\text { riorated/ disturbed/un- } \\
\text { cooperative } \\
\text { Follow-up: } 9 \text { weeks to } 6 \\
\text { months }\end{array}$ & 471 per 1000 & $\begin{array}{l}231 \text { per } 1000 \\
\text { (113 to } 471)\end{array}$ & $\begin{array}{l}\text { RR } 0.49 \\
(0.24 \text { to } 1.00)\end{array}$ & $\begin{array}{l}1040 \\
\text { (8 studies) }\end{array}$ & $\begin{array}{l}\oplus \bigcirc \bigcirc \bigcirc \\
\text { very low } \text { low }^{4,9}\end{array}$ & $\begin{array}{l}2 \text { trials reported on this } \\
\text { outcome at } 0-8 \text { weeks } \\
\text { follow-up and found no } \\
\text { significant difference }\end{array}$ \\
\hline $\begin{array}{l}\text { Cost of care - not re- } \\
\text { ported }\end{array}$ & See comment & See comment & Not estimable & - & See comment & $\begin{array}{l}\text { No studies reported on } \\
\text { this outcome. }\end{array}$ \\
\hline
\end{tabular}

*The basis for the assumed risk (e.g. the median control group risk across studies) is provided in footnotes. The corresponding risk (and its $95 \%$ confidence interval) is based on the assumed risk in the comparison group and the relative effect of the intervention (and its $95 \% \mathrm{Cl}$ ).

Cl: Confidence interval; RR: Risk ratio

GRADE Working Group grades of evidence

High quality: Further research is very unlikely to change our confidence in the estimate of effect.

Moderate quality: Further research is likely to have an important impact on our confidence in the estimate of effect and may change the estimate.

Low quality: Further research is very likely to have an important impact on our confidence in the estimate of effect and is likely to change the estimate.

Very low quality: We are very uncertain about the estimate. 
${ }^{1}$ Serious risk of bias: the study had an unclear risk of bias for random sequence generation, allocation concealment and other bias as the drugs were provided by a pharmaceutical company.

${ }^{2}$ Very serious imprecision: there are very few participants and no events for this outcome.

${ }^{3}$ Serious risk of bias: all studies had an unclear risk of bias for random sequence generation, allocation concealment, blinding of assessors and incomplete data. One also had an unclear risk of other bias as the drugs were provided by a pharmaceutical company.

${ }^{4}$ Very serious inconsistency: there was very high heterogeneity in the pooled results.

${ }^{5}$ Serious risk of bias: one study had a high risk of bias for random sequence generation and in eleven studies it was unclear. Twelve studies had an unclear risk of bias for allocation concealment. Blinding of participants and personnel was unclear in seven studies and blinding of assessors was unclear in twelve. Four studies also had a high risk of other bias as they were funded by industry.

${ }^{6}$ Serious inconsistency: there was high heterogeneity in the pooled results.

7 Strongly suspected publication bias: the funnel plot suggests that there may be studies without statistically significant effects that have not been included in this analysis.

${ }^{8}$ Very serious risk of bias: twenty four of the studies had an unclear risk of bias for random sequence generation, and all but one for allocation concealment. Twelve studies had an unclear risk of bias for blinding of participants and personnel and in 23 studies it was unclear whether assessors were blinded. Six studies also had a high risk of other bias as they were partly funded by industry.

9 Serious risk of bias: all studies had an unclear risk of bias for random sequence generation, and all but one for allocation concealment. Three studies had an unclear risk of bias for blinding of participants and personnel, and in all studies it was unclear whether assessors were blinded. Two studies also had a high risk of other bias as they were partly funded by industry. 


\section{B A C K G R O U N D}

\section{Description of the condition}

Approximately 24 million people currently suffer from schizophrenia (WHO 1998), the majority of whom live in low- or middle-income countries. Chlorpromazine remains one of the most commonly used and inexpensive treatments for people with schizophrenia (Odejide 1982), despite its well-documented adverse effects and the advent of a new generation of antipsychotic drugs. It is one of the essential drugs listed by the World Health Organization (WHO 2003). Chlorpromazine is commonly prescribed in India, and in South East Asia, the older generation of antipsychotics are used to treat the majority of people with schizophrenia (Chong 2004). In 2003, chlorpromazine was the most frequently prescribed of the first generation 'typical' antipsychotic drugs in the UK at a time when the 'typical' group of antipsychotics accounted for $44 \%$ of all antipsychotic prescriptions (PPA, 2003).

\section{Description of the intervention}

Chlorpromazine, a drug developed in 1951 for reducing allergic reactions (an antihistamine) began to be used as part of a cocktail of drugs in order to induce a state of 'artificial hibernation' for surgical procedures (Laborit 1951). Its ability to reduce psychic stress led researchers to demonstrate its effectiveness for treating certain psychiatric disorders (Delay 1952). Chlorpromazine was hailed as a major discovery for schizophrenia, an illness for which few treatment options existed (Davis 1978). The impact of this drug has been so great, that according to one author, it has been heralded as the second revolution in psychiatry (the first being psychoanalysis) (Grozier 1973). Chlorpromazine is the first of many drugs to be classed as a 'neuroleptic' (literally translated: to grasp the nerve), a term coined by two of its first protagonists (Delay 1952). Early trials of chlorpromazine for schizophrenia indicated, that in comparison with placebo, it hastened clinical recovery, facilitated improvements in social functioning and was effective at preventing relapse.

\section{How the intervention might work}

The antipsychotic effect of chlorpromazine results from its action on particular areas within specific cells of the brain (Sedvall 1995). It is thought to affect how receptive these cells are to dopamine. However, chlorpromazine is not specific to one site of action within the body. Consequently, it is known to cause adverse effects ranging from dry mouth, blurred vision and urinary retention as well as restlessness, tremors, facial rigidity, shuffling gait and repetitive movements of the face and/or trunk which can be difficult to reverse (APA 1992). Chlorpromazine has also been linked to depressive symptoms that may be caused by the drug itself (neuroleptic dysphoria, Awad 1993). In addition, the use of chlorpromazine has been associated with a potentially fatal disturbance of blood pressure, temperature and muscle control (neuroleptic malignant syndrome, APA 1994).

\section{Why it is important to do this review}

There are questions relating to the differential response to drugs between certain groups of people with schizophrenia. For example, there may be differences in the effects of treatment for men and women (Hambrecht 1992; Kendler 1995; Szymanski 1995), for children, adults or the elderly (Kaplan 1990; Rosen 1990), or for people who are experiencing their first episode as opposed to those with a longer illness duration (Hill 1992; Szymanski 1996). When prescribing drugs for schizophrenia dosage is important in order to obtain optimal response with minimal adverse effects (Bollini 1994; Kane 1985). There also remains debate about the applicability of research findings to the 'real world' of clinicians (Jenicek 1990). For example, trials undertaken on highly selected groups of people with schizophrenia may be of very limited use in the 'everyday' situation. We attempted to investigate whether, for the primary outcomes of interest (see: Methods, Types of outcome measures), a real difference exists for those with diagnoses of schizophrenia made with operational 'checklists' as opposed to those with less rigorous diagnoses. A final question we posed was whether the effects of chlorpromazine were different between patients treated recently (1990-2002) to those treated in earlier decades (1951-1989).

New trials often use chlorpromazine as the 'benchmark' or 'control' drug rather than a placebo when a new treatment is being evaluated. The aim of this review is to evaluate this 'benchmark' in comparison to placebo. This is an update of a Cochrane Review first published in 1998, Issue 1 of The Cochrane Database of Systematic Reviews (Thornley 1998a) and updated in 2003 (Thornley 2003) and 2007 (Adams 2007).

\section{O B JE C T I VES}

To review the effects of chlorpromazine compared with placebo, for the treatment of schizophrenia.

It was expected that several subgroup analyses could be undertaken within this review (see Subgroup analysis and investigation of heterogeneity).

\section{METHODS}




\section{Criteria for considering studies for this review}

\section{Types of studies}

We sought all relevant randomised controlled trials. Where a trial was described as 'double blind' but it was implied that the study was randomised, we included these trials in a sensitivity analysis. If their inclusion did not result in a substantive difference, they remained in the analyses. If their inclusion did result in statistically significant differences, we did not add the data from these lower quality studies to the results of the better quality trials, but presented these within a subcategory. We excluded quasi-randomised studies, such as those allocating by alternate days of the week.

\section{Types of participants}

We included people with schizophrenia and other types of schizophrenia-like psychoses (schizophreniform and schizoaffective disorders) however diagnosed, irrespective of age, sex or severity of illness.

\section{Types of interventions}

\section{Chlorpromazine: any dose or mode of administration} (oral or by injection)

\section{Placebo (active or inactive) or no treatment}

\section{Types of outcome measures}

We categorised outcomes as short term (zero to eight weeks), medium term (nine weeks to six months) and long term (six months to two years).

\section{Primary outcomes}

We classified these outcomes as primary outcomes for the 2002 update to help minimise the potential for multiple statistical testing that could be undertaken within sensitivity analyses. We tried to choose these on the grounds of clinical importance and were helped in this by inclusion of a new co-reviewer, JR, who was not as familiar with the data as the previous authors. We have used the same outcomes but rearranged into new sub-headings for this 2012 update.

\section{Death - suicide and natural causes}

\section{Relapse - as defined by each study}

\section{Global state}

3.1 Overall improvement*

4. Leaving the study early

5. Satisfaction with treatment - participant/carer

\section{Behaviour}

6.1 Specific behaviours (e.g. aggressive or violent behaviour)

\section{Economic}

7.1 Cost of care

Secondary outcomes

\section{Global state}

1.1 Duration of hospital stay

1.2 Re-admission

1.3 Severity of Illness

\section{Mental state}

2.1 General symptoms

2.2 Specific symptoms

2.2.1 Positive symptoms (delusions, hallucinations, disordered thinking)

2.2.2 Negative symptoms (avolition, poor self-care, blunted affect)

2.2.3 Mood - depression

\section{Behaviour}

3.1 General behaviour

3.2 Social functioning

3.3 Employment status during trial (employed/unemployed)

3.4 Occurrence of violent incidents (to self, others or property)

\section{Adverse effects}

4.1 General

4.2 Specific

4.2.2 Movement disorders (extrapyramidal side effects, specifically tardive dyskinesia and neuroleptic malignant syndrome)

4.2.3 Sedation

4.2.4 Dry mouth 


\section{5. 'Summary of findings' table}

We used the GRADE approach to interpret findings (Schünemann 2008) and GRADE profiler (GRADEPRO) to import data from Review Manager 5 ( Review Manager) to create a 'Summary of findings' table. These tables provide outcome-specific information concerning the overall quality of evidence from each included study in the comparison, the magnitude of effect of the interventions examined, and the sum of available data on all outcomes we rate as important to patient-care and decision making. We have selected the following main outcomes for inclusion in the 'Summary of findings' table.

1. Death - suicide and natural causes

2. Overall improvement

3. Relapse - as defined by each study

4. Leaving the study early

5. Satisfaction with treatment - participant/carer

6. Specific behaviours (e.g. aggressive or violent behaviour)

7. Cost of care

\section{Search methods for identification of studies}

\section{Electronic searches}

For previous searches please see Appendix 2.

\section{Cochrane Schizophrenia Group Trials Register (May 20 I2)}

The Trials Search Co-ordinator searched the Cochrane Schizophrenia Group's Trials Register (15 May 2012).

The Cochrane Schizophrenia Group's Trials Register is compiled by systematic searches of major databases, handsearches of relevant journals and conference proceedings (see group module).

\section{Searching other resources}

\section{Reference searching}

We inspected the references of all identified studies for further studies.

\section{Personal contact}

For this update, we did not contact the first author of each included study for information regarding unpublished trials.

\section{Pharmaceutical companies}

In previous versions of this review, we contacted pharmaceutical companies for any unpublished and published trials. Approaches have been made to Rhone Poulenc Rorer, the original developers of chlorpromazine, for access to archive material. Dr R.A Pargiter of Hobart, Tasmania very kindly donated a series of reports from May and Baker (the pharmaceutical company which originally produced chlorpromazine) that listed presentations of work relevant to chlorpromazine and schizophrenia, dating from 1955 to 1973. We (BT, CEA and JR) handsearched these for further studies.

\section{Data collection and analysis}

Methods used in data collection and analysis for this 2012 update are below; for previous methods please see Appendix 3.

\section{Selection of studies}

For this 2012 update, the Cochrane Schizophrenia group provided Enhance Reviews a database of relevant abstracts; the Enhance Reviews team inspected full articles of the abstracts meeting the inclusion criteria.

\section{Data extraction and management}

\section{Extraction}

For this 2012 update, two members of the Enhance Reviews team extracted data from included studies. In addition, Jun Xia (JX) extracted data for all Chinese studies. We extracted data presented only in graphs and figures whenever possible. In the previous versions of the review, when further information was necessary, we contacted authors of studies in order to obtain missing data or for clarification. If studies were multi-centre, where possible, we extracted data relevant to each component centre separately.

\section{Management}

\subsection{Forms}

We extracted data onto standard, simple forms, created in a webbased software ( www.systematic-review.ca).

\subsection{Scale-derived data}

We included continuous data from rating scales only if: a. the psychometric properties of the measuring instrument have been described in a peer-reviewed journal (Marshall 2000); and b. the measuring instrument had not been written or modified by one of the trialists for that particular trial.

Ideally, the measuring instrument should either be i. a self-report or ii. completed by an independent rater or relative (not the therapist). We realise that this is not often reported clearly; we have noted whether or not this is the case in Description of studies. 


\subsection{Endpoint versus change data}

There are advantages of both endpoint and change data. Change data can remove a component of between-person variability from the analysis. On the other hand, calculation of change needs two assessments (baseline and endpoint), which can be difficult in unstable and difficult to measure conditions such as schizophrenia. We decided primarily to use endpoint data, and only use change data if the former were not available. We combined endpoint and change data in the analysis as we used mean differences (MD) rather than standardised mean differences throughout (Higgins 2011, Chapter 9.4.5.2).

\subsection{Skewed data}

Continuous data on clinical and social outcomes are often not normally distributed. To avoid the pitfall of applying parametric tests to non-parametric data, we aimed to apply the following standards to all data before inclusion:

a) standard deviations (SDs) and means are reported in the paper or obtainable from the authors;

b) when a scale starts from the finite number zero, the SD, when multiplied by two, is less than the mean (as otherwise the mean is unlikely to be an appropriate measure of the centre of the distribution (Altman 1996));

c) if a scale started from a positive value (such as the Positive and Negative Syndrome Scale (PANSS, Kay 1986) which can have values from 30 to 210 ), we modified the calculation described above to take the scale starting point into account. In these cases skew is present if $2 \mathrm{SD}>(\mathrm{S}-\mathrm{S} \mathrm{min})$, where $\mathrm{S}$ is the mean score and $\mathrm{S}$ min is the minimum score.

Endpoint scores on scales often have a finite start and end point and these rules can be applied. We entered skewed endpoint data from studies of fewer than 200 participants in additional tables rather than into an analysis. Skewed data pose less of a problem when looking at the mean if the sample size is large; we entered such endpoint data into syntheses.

When continuous data are presented on a scale that includes a possibility of negative values (such as change data), it is difficult to tell whether data are skewed or not, we entered skewed change data into analyses regardless of the size of the study.

\subsection{Common measure}

To facilitate comparison between trials, we intended to convert variables that can be reported in different metrics, such as days in hospital (mean days per year, per week or per month) to a common metric (e.g. mean days per month).

\subsection{Conversion of continuous to binary}

Where possible, we made efforts to convert outcome measures to dichotomous data. This can be done by identifying cut-off points on rating scales and dividing participants accordingly into 'clinically improved' or 'not clinically improved'. It is generally assumed that if there is a 50\% reduction in a scale-derived score such as the Brief Psychiatric Rating Scale (BPRS, Overall 1962) or the PANSS (Kay 1986), this could be considered as a clinically significant response (Leucht 2005; Leucht 2005a). If data based on these thresholds were not available, we used the primary cutoff presented by the original authors.

\subsection{Direction of graphs}

Where possible, we entered data in such a way that the area to the left of the line of no effect indicated a favourable outcome for chlorpromazine.

\section{Assessment of risk of bias in included studies}

For this 2012 update, two members of the Enhance Reviews team worked independently by using criteria described in the Cochrane Handbook for Systematic Reviews of Interventions (Higgins 2011) to assess trial quality for the new included studies and all previously included studies. This new set of criteria is based on evidence of associations between overestimate of effect and high risk of bias of the article such as sequence generation, allocation concealment, blinding, incomplete outcome data and selective reporting. Where inadequate details of randomisation and other characteristics of trials were provided, we did not contact authors of the studies in order to obtain additional information.

We have noted the level of risk of bias in both the text of the review and in the Summary of findings for the main comparison.

\section{Measures of treatment effect}

\section{Binary data}

For binary outcomes we calculated a standard estimation of the risk ratio (RR) and its $95 \%$ confidence interval (CI). It has been shown that RR is more intuitive (Boissel 1999) than odds ratios and that odds ratios tend to be interpreted as RR by clinicians (Deeks 2000).

\section{Continuous data}

For continuous outcomes we estimated mean difference (MD) between groups. We would prefer not to calculate effect size measures (standardised mean difference (SMD)). However, if scales of very considerable similarity were used, we presumed there was a small difference in measurement, and we would have calculated effect size and transformed the effect back to the units of one or more of the specific instruments. 


\section{Unit of analysis issues}

\section{Cluster trials}

Studies increasingly employ 'cluster randomisation' (such as randomisation by clinician or practice), but analysis and pooling of clustered data poses problems. Authors often fail to account for intra-class correlation in clustered studies, leading to a 'unit of analysis' error (Divine 1992) whereby P values are spuriously low, confidence intervals unduly narrow and statistical significance overestimated. This causes type I errors (Bland 1997; Gulliford 1999). We did not include any cluster trials in this review. If we had, where clustering was not accounted for in primary studies, we would have presented data in a table, with a $\left(^{*}\right)$ symbol to indicate the presence of a probable unit of analysis error. Where clustering was incorporated into the analysis of primary studies, we would have presented these data as if from a non-cluster randomised study, but adjusted for the clustering effect.

In subsequent versions of this review we will seek to contact first authors of studies to obtain intra-class correlation coefficients (ICC) for their clustered data and to adjust for this by using accepted methods (Gulliford 1999).

We have sought statistical advice and have been advised that the binary data as presented in a report should be divided by a 'design effect'. This is calculated using the mean number of participants per cluster $(\mathrm{m})$ and the ICC [Design effect $\left.=1+(\mathrm{m}-1)^{*} \mathrm{ICC}\right]$ (Donner 2002). If the ICC was not reported it was assumed to be 0.1 (Ukoumunne 1999).

If cluster studies have been appropriately analysed taking into account ICCs and relevant data documented in the report, synthesis with other studies would have been possible using the generic inverse variance technique.

\section{Cross-over trials}

A major concern of cross-over trials is the carry-over effect. It occurs if an effect (e.g. pharmacological, physiological or psychological) of the treatment in the first phase is carried over to the second phase. As a consequence, on entry to the second phase the participants can differ systematically from their initial state despite a wash-out phase. For the same reason cross-over trials are not appropriate if the condition of interest is unstable (Elbourne 2002). As both effects are very likely in severe mental illness, we only used data of the first phase of cross-over studies.

\section{Studies with multiple treatment groups}

Where a study involved more than two treatment arms, if relevant, we presented the additional treatment arms in the comparisons. If data were binary, we simply added these and combined within the two-by-two table. If data were continuous, we combined data following the formula in section 7.7.3.8 (Combining groups) of the Cochrane Handbook for Systemic reviews of Interventions (Higgins
2011). Where the additional treatment arms were not relevant, we did not reproduce these data.

\section{Dealing with missing data}

\section{Overall loss of credibility}

At some degree of loss of follow-up, data must lose credibility (Xia 2009). We chose that, for any particular outcome, should more than $50 \%$ of data be unaccounted for, we did not reproduce these data or use them within analyses. If, however, more than $50 \%$ of those in one arm of a study were lost, but the total loss was less than $50 \%$, we marked such data with $\left(^{*}\right)$ to indicate that such a result may well be prone to bias.

\section{Binary}

In the case where attrition for a binary outcome was between $0 \%$ and $50 \%$, we presented data for the total number of participants randomised for studies that used an intention-to-treat (ITT) analysis; where studies did not use an ITT analysis, we presented completer only data.

\section{Continuous}

\subsection{Attrition}

In the case where attrition for a continuous outcome was between $0 \%$ and $50 \%$, and data only from people who completed the study to that point were reported, we presented and used these data.

\subsection{Standard deviations}

If standard deviations (SDs) were not reported, we first tried to obtain the missing values from the authors. If not available, where there are missing measures of variance for continuous data, but an exact standard error (SE) and confidence intervals (CIs) available for group means, and either $\mathrm{P}$ value or $\mathrm{T}$ value available for differences in mean, we can calculate them according to the rules described in the Cochrane Handbook for Systemic reviews of Interventions (Higgins 2011). When only the SE is reported, SDs are calculated by the formula $\mathrm{SD}=\mathrm{SE}^{*}$ square root $(\mathrm{n})$. Chapters 7.7.3 and 16.1.3 of the Cochrane Handbook for Systemic reviews of Interventions (Higgins 2011) present detailed formulae for estimating SDs from $\mathrm{P}$ values, $\mathrm{T}$ or $\mathrm{F}$ values, CIs, ranges or other statistics. If these formulae do not apply, we would calculate the SDs according to a validated imputation method which is based on the SDs of the other included studies (Furukawa 2006). Although some of these imputation strategies can introduce error, the alternative would be to exclude a given study's outcome and thus to lose information. We did not impute any SDs, if we had we would have examined the validity of the imputations in a sensitivity analysis excluding imputed values. 


\subsection{Last observation carried forward}

We anticipated that in some studies the method of last observation carried forward (LOCF) would be employed within the study report. As with all methods of imputation to deal with missing data, LOCF introduces uncertainty about the reliability of the results (Leucht 2007). Therefore, where LOCF data have been used in the trial, if less than $50 \%$ of the data have been assumed, we reproduced these data and indicated that they are the product of LOCF assumptions.

\section{Assessment of heterogeneity}

\section{Clinical heterogeneity}

We considered all included studies initially, without seeing comparison data, to judge clinical heterogeneity. We simply inspected all studies for clearly outlying people or situations which we had not predicted would arise. When such situations or participant groups arose, we fully discussed these.

\section{Methodological heterogeneity}

We considered all included studies initially, without seeing comparison data, to judge methodological heterogeneity. We simply inspected all studies for clearly outlying methods which we had not predicted would arise. When such methodological outliers arose, we fully discussed these.

\section{Statistical heterogeneity}

\subsection{Visual inspection}

We visually inspected graphs to investigate the possibility of statistical heterogeneity.

\subsection{Employing the $\mathrm{I}^{2}$ statistic}

We investigated heterogeneity between studies by considering the $\mathrm{I}^{2}$ method alongside the $\mathrm{Chi}^{2} \mathrm{P}$ value. The $\mathrm{I}^{2}$ provides an estimate of the percentage of inconsistency thought to be due to chance (Higgins 2003). The importance of the observed value of $\mathrm{I}^{2}$ depends on i. magnitude and direction of effects and ii. strength of evidence for heterogeneity (e.g. P value from $\mathrm{Chi}^{2}$ test, or a confidence interval for $\mathrm{I}^{2}$ ). An $\mathrm{I}^{2}$ estimate greater than or equal to around $50 \%$ accompanied by a statistically significant $\mathrm{Chi}^{2}$ statistic was interpreted as evidence of substantial levels of heterogeneity (Higgins 2011). When substantial levels of heterogeneity were found in the primary outcome, we explored reasons for the heterogeneity (Subgroup analysis and investigation of heterogeneity). If data were heterogeneous we used a random-effects model.

\section{Assessment of reporting biases}

Reporting biases arise when the dissemination of research findings is influenced by the nature and direction of results (Egger 1997). These are described in Section 10 of the Cochrane Handbook for Systemic reviews of Interventions (Higgins 2011). We are aware that funnel plots may be useful in investigating reporting biases but are of limited power to detect small-study effects. We did not use funnel plots for outcomes where there were 10 or fewer studies, or where all studies were of similar sizes. In other cases, where funnel plots were possible, we sought statistical advice in their interpretation.

\section{Data synthesis}

We understand that there is no closed argument for preference for use of fixed-effect or random-effects models. The random-effects method incorporates an assumption that the different studies are estimating different, yet related, intervention effects. This often seems to be true to us and the random-effects model takes into account differences between studies even if there is no statistically significant heterogeneity. There is, however, a disadvantage to the random-effects model: it puts added weight onto small studies, which often are the most biased ones. Depending on the direction of effect, these studies can either inflate or deflate the effect size. We chose the fixed-effect model for all analyses. The reader is, however, able to choose to inspect the data using the randomeffects model.

\section{Subgroup analysis and investigation of heterogeneity}

\section{Subgroup analyses - only primary outcomes}

\subsection{Clinical state, stage or problem}

We proposed to undertake this review and provide an overview of the effects of chlorpromazine for people with schizophrenia in general. In addition, however, we tried to report data on subgroups of people in the same clinical state, stage and with similar problems. We also undertook subgroup analyses comparing the results for the following:

- men versus women; under 18 years of age versus 18-65 years old versus older than 65 ;

- acutely ill people (< one-month in duration) versus people who have been ill for longer;

- high dose (> $501 \mathrm{mg} /$ day) versus low doses (1-500 mg/day);

- people diagnosed according to any operational criteria versus those who have not been diagnosed using operational criteria;

- studies published before 1990 versus studies published between 1990 and the present. 


\section{Investigation of heterogeneity}

If inconsistency was high, we have reported this. First, we investigated whether data had been entered correctly. Second, if data were correct, we visually inspected the graph and successively removed outlying to see if homogeneity was restored.

When unanticipated clinical or methodological heterogeneity was obvious we simply stated hypotheses regarding these for future reviews or versions of this review. We do not anticipate undertaking analyses relating to these.

\section{Sensitivity analysis}

We applied sensitivity analyses to the primary outcomes of this review.

\section{Implication of randomisation}

We aimed to include trials in a sensitivity analysis if they were described in some way so as to imply randomisation. For the primary outcomes we included these studies and if there was no substantive difference when the implied randomised studies were added to those with better description of randomisation, then we entered all data from these studies.

\section{Assumptions for lost binary data}

Where assumptions had to be made regarding people lost to followup (see Dealing with missing data), we compared the findings of the primary outcomes when we use our assumption/s and when we used data only from people who completed the study to that point. A sensitivity analysis was undertaken to test how prone results were to change when completer-only data only were compared to the imputed data using the above assumption. If there was a substantial difference, we reported results and discussed them but continued to employ our assumption.

\section{Risk of bias}

We analysed the effects of excluding trials that were judged to be at high risk of bias across one or more of the domains of randomisation (implied as randomised with no further details available): allocation concealment, blinding and outcome reporting for the meta-analysis of the primary outcome. If the exclusion of trials at high risk of bias did not substantially alter the direction of effect or the precision of the effect estimates, then we included data from these trials in the analysis.

\section{Imputed values}

Had we included any cluster-randomised trials, we would have undertaken a sensitivity analysis to assess the effects of including data from trials where we used imputed values for ICC in calculating the design effect in cluster-randomised trials.

If we noted substantial differences in the direction or precision of effect estimates in any of the sensitivity analyses listed above, we did not pool data from the excluded trials with the other trials contributing to the outcome, but presented them separately.

\section{R E S U L T S}

\section{Description of studies}

Please see Characteristics of included studies and Characteristics of excluded studies.

\section{Results of the search}

The original searches in 1995 yielded over 600 references, and after initial appraisal we selected 201 studies for further inspection of the full papers. An additional 50 papers were also identified from the reference lists. We were able to include 45 relevant studies. For the July 2002 update, we found 106 citations and were able to include just one additional study, and four additional reports of already included studies. In addition, May and Baker's files of reports of chlorpromazine studies, kindly supplied by Dr Pargiter of Hobart, Tasmania, were handsearched by BT, CA and JR. These files yielded 37 more records that met the review criteria. Three of these reports were previously unknown studies that could be included. Thirty-four were excluded. We are very grateful to Dr Pargiter, who kept those files for so long and then, knowing that they could at last be usefully employed, donated them. For the January 2007 update search, we found 317 references from 142 studies. We were able to include one additional study (Xiong 1994).

The May 2012 update search identified a total of 21 new relevant studies. Five trials met the inclusion criteria for this review and there are now 55 studies included in the latest version of this review (see Figure 1). A total of 315 studies are now excluded. There are no studies awaiting assessment and no ongoing studies have been identified. 
Figure I. Study flow diagram.

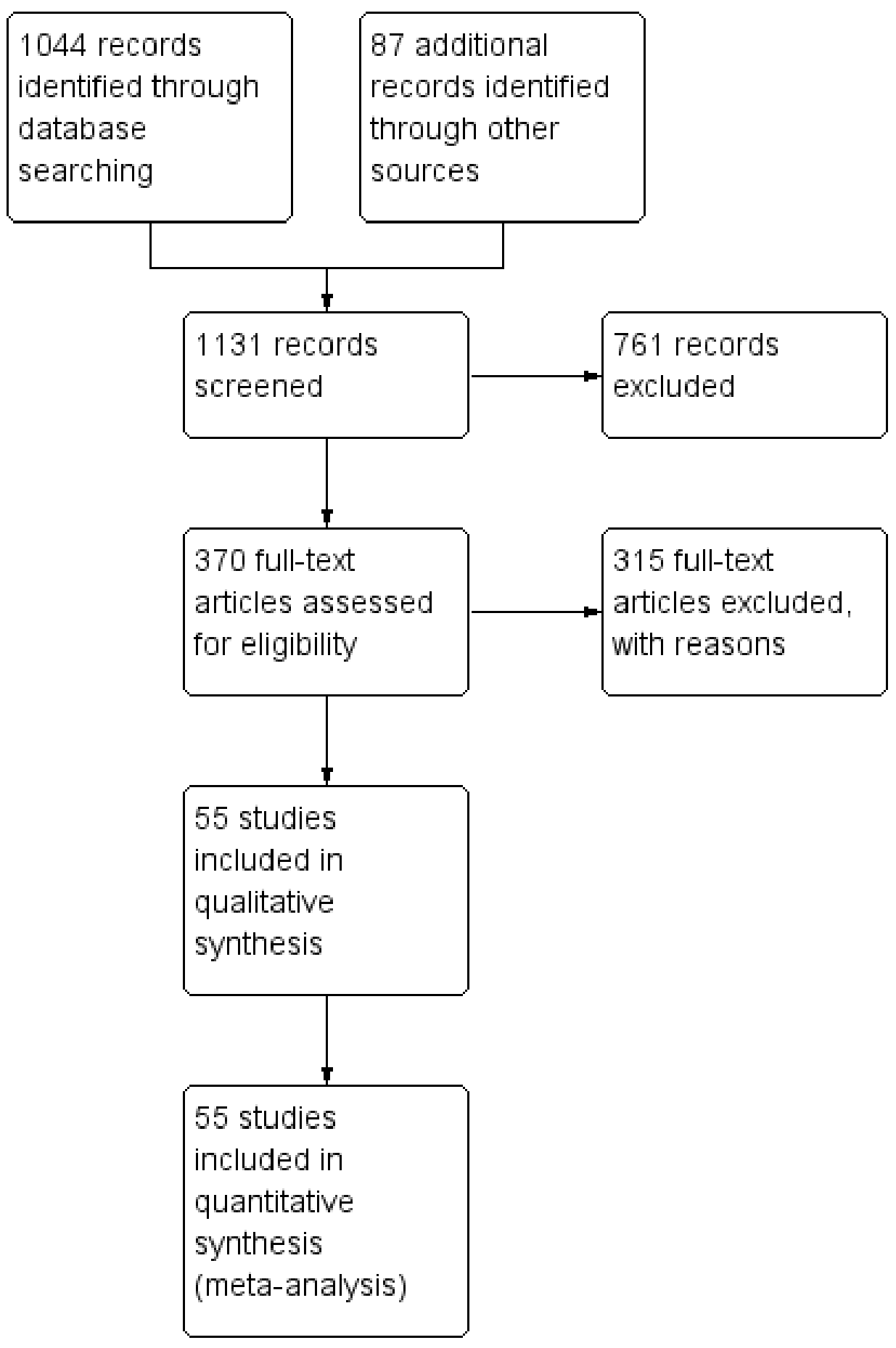




\section{Included studies}

We included 55 studies.

\section{Methods}

Four included studies were cross-over trials (Baker 1959; Letemendia 1967; Nishikawa 1982; Shepherd 1956), two had a factorial design (Hamilton 1960; Hogarty 1973), and the remainder were parallel studies. All studies were either stated to be randomised or implied randomisation.

\section{Length of trials}

The most common study length was six to 12 weeks but the range was considerable with two trials being just over 24 hours in duration, whilst the two longest were over a period of three years.

\section{Participants}

It was reported in all trials that the participants suffered from schizophrenia (with the exception of Vaughan 1955 who randomised people with mental illnesses who were 'chronic and intractable' with motor restlessness, psychomotor agitation, and excitement and Hankoff 1962 who did not clearly state the diagnoses but included psychiatric outpatients who were 'schizophrenic and non-schizophrenic', with the majority having schizophrenia). Only 14 of the 55 trials described the diagnostic criteria used, or the symptoms required for people to be included. Otherwise, entry to most included studies was on a clinical diagnosis of schizophrenia. A total of 5506 participants are now included in this review.

\section{Setting}

Most studies were hospital-based with only a few of the studies being undertaken in the community.

\section{Study size}

The mean number of participants was 99, ranging from 21 (Payne 1960) to 838 (Prien 1968).

\section{Intervention}

6.1 Chlorpromazine: The doses of chlorpromazine in these studies ranged from $25 \mathrm{mg} /$ day (Reschke 1974) to $2400 \mathrm{mg} /$ day (Dean 1958). The mean dose was $574 \mathrm{mg} /$ day (SD 446).

6.2 Placebo: All trials compared chlorpromazine with placebo or no treatment. Kurland 1961 used a 'positive' placebo (phenobarbital) and a 'negative' placebo, the results of which were combined in this review. Clark 1968a randomised participants to placebo and a no-drug group, which were also combined in this review. Prien 1968, however, randomised to a placebo group and a 'routine conventional hospital treatment' group. These groups were not combined because the latter had the opportunity to receive any medication that the treating physicians felt appropriate (presumably including chlorpromazine). Prien 1968 also included two arms, one with lower doses and the other with higher doses. We pooled data from these arms in the main analysis and conducted subgroup analyses.

6.3 Other drug treatment arms: Thirty-eight of the trials also included at least one more drug treatment arm in addition to placebo and chlorpromazine. Data were not included from these treatment arms.

\section{Outcomes}

The following outcomes were reported by the included studies: death, relapse, global impression, mental state, behaviour, leaving the study early and adverse effects. None of the included studies attempted to quantify levels of satisfaction, or quality of life and there is no evidence of any direct economic evaluation of chlorpromazine. Most outcomes analysed were dichotomous, and presented as such, or were ordinal data that could be dichotomised.

\subsection{Outcome scales}

The following scales provided continuous data for the analysis.

\subsubsection{Mental state}

i. Brief Psychiatric Rating Scale (Overall 1962)

A brief rating scale used to assess the severity of a range of psychiatric symptoms, including psychotic symptoms. The original scale has 16 items, but a revised 18-item scale is commonly used. Each item is defined on a seven-point scale varying from 'not present' to 'extremely severe', scoring from zero to six or one to seven. Scores can range from zero to 126 , with high scores indicating more severe symptoms. Tetreault 1969 reported data from this scale.

ii. Global impression

4.7.2.1 Clinical Global Impression (Guy 1976)

A rating instrument commonly used in studies on schizophrenia that enables clinicians to quantify severity of illness and overall clinical improvement. A seven-point scoring system is usually used with low scores indicating decreased severity and/or greater recovery. Borison 1991 reported data from this scale. 


\subsubsection{Behaviour}

i. Modified Rosenthal Rating Scale (Rosenthal 1963)

A scale for nurses to rate the behaviour of psychiatric patients. Lower scores indicate improved behaviour. Tetreault 1969 reported data from this scale.

ii. Parkside Behaviour Rating Scale (Schmidt 1957)

A rating scale in which six behavioural characteristics are rated on a five-point scale. The worst possible behaviour would carry a rating of six points, as against a maximum of 30 points for unproblematic behaviour. Baker 1959 reported data from this scale.

iii. Fergus Falls rating scale (Lucero 1951)

The L-M Fergus Falls Behavior Rating Scale is a method of rating the behaviour of patients in mental hospitals, which measures 11 aspects of behaviour, and the changes in one patient over a length of time. Ramu 1999a reported data from this scale.

\subsubsection{Adverse effects}

i. Extrapyramidal Bilan scale (Tetreault 1969a)

A nine-item rating scale for use by neurologists, to measure severity of symptoms such as facial mask, tremor, rigidity, akathisia, dystonia, dyskinesia and others. Each item can be scored from zero to three, such that the overall score can range from zero (no symptoms) to a possible 27 (severe symptoms of all types). Tetreault 1969 reported data from this scale.

\section{Excluded studies}

We have now excluded 315 studies. The studies listed in the 'Excluded studies' section had to be inspected in hard copy in order to make the final decision. Nearly half were not randomised, did not imply randomisation or did not describe the allocation procedure used. In several studies, participants were not suffering from schizophrenia. Another sizeable proportion of the trials did not compare chlorpromazine with placebo, but in combination with other treatments. A few were chlorpromazine withdrawal studies investigating the effects of instigation of treatment, which are not relevant to this review. We will include these withdrawal studies in a later review. Eighty-eight studies had no usable outcomes. Either data did not have clear clinical implications, for example EEG recordings, or genuinely relevant clinical data were not adequately reported. Frequently the numbers of participants in each group were not specified, means or standard deviations were not given or data were not reported from individual arms of cross-over studies.

\section{Awaiting assessment}

No studies are currently awaiting assessment.

\section{Ongoing studies}

We identified no ongoing studies.

\section{Risk of bias in included studies}

Please also see Figure 2 and Figure 3.

Figure 2. 'Risk of bias' graph: review authors' judgements about each 'Risk of bias' item presented as percentages across all included studies.

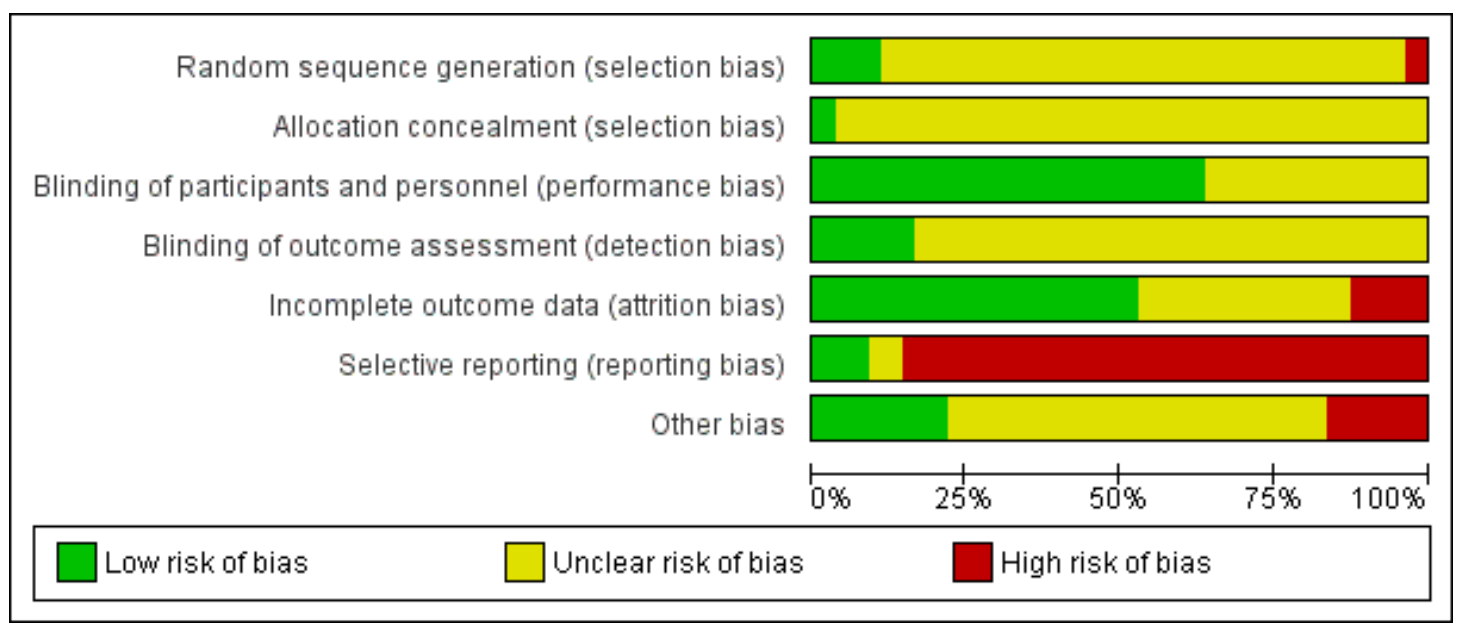

Chlorpromazine versus placebo for schizophrenia (Review) 
Figure 3. 'Risk of bias' summary: review authors' judgements about each 'Risk of bias' item for each included study.

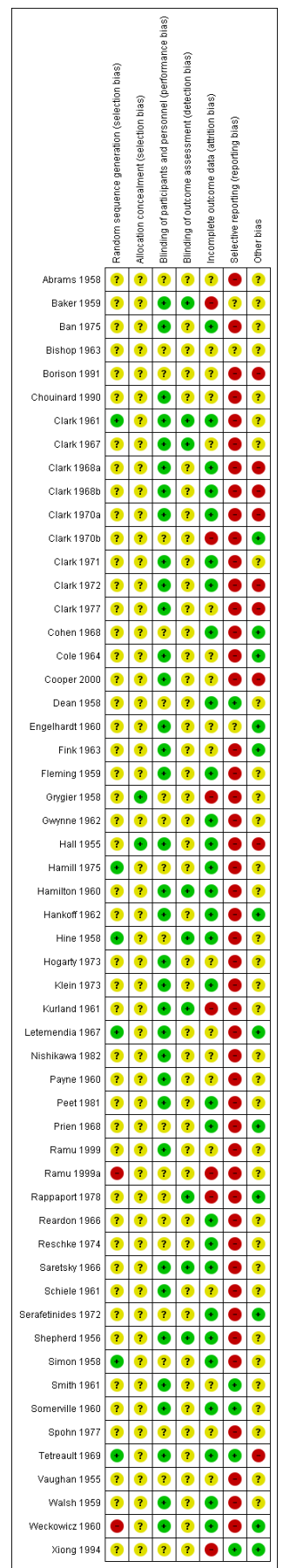




\section{Allocation}

Only four studies described the methods used to generate random allocation. Two studies (Hine 1958; Letemendia 1967) randomised by the toss of a coin, and two used tables of random numbers (Hamill 1975; Tetreault 1969a). Two studies (Cole 1964; Hall 1955) described some form of allocation concealment (sealed envelopes). For the other 53 studies, readers are given little assurance that bias was minimised during the allocation procedure, yet $24(24 / 53,45 \%)$ reported that the participants allocated to each treatment group were very similar. One study, Cooper 2000, reported that participants were randomly assigned in blocks of six and Weckowicz 1960 reported that participants were divided into three matched groups. For the remaining studies it is improbable that such equal numbers could have been obtained unless block randomisation was used, yet 24 out of 53 studies (45\%) had exactly the same numbers in the chlorpromazine and placebo groups.

\section{Blinding}

Thirty-five studies had a low risk of bias for performance bias and described the methods used to ensure blinding of participants and personnel. Twenty studies had an unclear risk of bias. Nine studies stated that outcome assessors were blinded and were rated a low risk of bias, the remainder had an unclear risk of bias. Two studies (Grygier 1958; Hall 1955) tested how successful their attempts at blinding were. Three studies (Clark 1970b; Hamill 1975; Simon 1958) gave no indication that blinding had been attempted.

\section{Incomplete outcome data}

Twenty-nine studies were rated as low risk of bias for incomplete outcome data and 19 studies had an unclear risk of bias. Seven studies were rated as having a high risk of bias.

\section{Selective reporting}

Only five studies had a low risk of bias for selective reporting. Three studies had an unclear risk of bias and 47 of the studies were rated as high risk of bias for selective reporting.

\section{Other potential sources of bias}

Eight trials were subject to other biases as they were either partly or fully funded by the pharmaceutical industry; in Borison 1991 two of the trialists are in prison for research fraud. Twelve studies were of low risk of bias for other potential sources of bias and the remainder had an unclear risk of bias.

\section{Effects of interventions}

See: Summary of findings for the main comparison CHLORPROMAZINE versus PLACEBO for schizophrenia We used risk ratios (RR) for dichotomous data and mean differences (MD) for continuous data, with their respective $95 \%$ confidence intervals (CIs) throughout.

\section{Comparison: CHLORPROMAZINE versus PLACEBO}

We categorised outcomes as short term (up to eight weeks), medium term (nine weeks to six months) and long term (six months to two years).

\section{I.I Death}

We found only one small trial $(n=14)$ that specifically reported mortality (Baker 1959); there were no deaths in either the chlorpromazine or placebo group (Analysis 1.1). We found no reports of death in any study and currently over 5506 people have been included in trials relating to this review (of which 1741 were given chlorpromazine).

\section{I.2 Relapse}

We found short-term ( $\mathrm{n}=74,2$ RCTs) and medium-term ( $\mathrm{n}=809$, 4 RCTs) data did not show a significant difference in rates of relapse (Analysis 1.2), but with significant heterogeneity $\left(\mathrm{I}^{2}=78 \%\right.$ and $96 \%$, respectively). Removing the studies with results that were causing this heterogeneity, as judged by visual inspection (Prien 1968; Spohn 1977) eliminates this heterogeneity. We found longer-term data (six months to two years) favoured the chlorpromazine group ( $\mathrm{n}=512,3$ RCTs, RR 0.65 CI 0.47 to 0.90 ), but the two long-term studies lasting two to five years (Hogarty 1973; Nishikawa 1982) showed no difference ( $\mathrm{n}=394,2$ RCTs), again with significant heterogeneity ( $\mathrm{I}^{2}=72 \%$ and $84 \%$, respectively). In this case, the larger trials (Hogarty 1973; Prien 1968) show a better effect for chlorpromazine and it may well be that the smaller trials are the outlying ones. However, Prien 1968 includes a highdose treatment arm $(2000 \mathrm{mg} /$ day of chlorpromazine $)$, which may explain some of the heterogeneity in the results, see the subgroup analysis (Analysis 1.23) below.

\section{I.3 Global state}

\subsubsection{No overall improvement}


We found short-term global state data ('no overall improvement' - psychiatrist-rated ; Analysis 1.3) significantly favoured chlorpromazine ( $\mathrm{n}=728,13$ RCTs, RR 0.61 CI 0.46 to 0.82 ) compared with placebo. Medium-term data up to six months also favoured chlorpromazine $(\mathrm{n}=1164,14$ RCTs, RR 0.71 CI 0.58 to 0.86). There was significant heterogeneity at both short term and medium term $\left(\mathrm{I}^{2}=69 \%\right.$ and $81 \%$, respectively). There were no obviously outlying trials for this outcome at short term, so none were removed from the analysis. For medium term, removal of the largest trial, Prien 1968, restores homogeneity, an effect that does not appear in the subgroup analysis for high versus low dose, see the subgroup analysis (Analysis 1.23) below, and again, it may be the smaller trials that are outliers.

Nurse-rated global state 'no overall improvement' scores (Analysis 1.4) were equivocal at short-term assessment in one small study (Weckowicz 1960) ( $\mathrm{n}=29$, RR 0.91 CI 0.65 to 1.27). However, scores from one research group (Clark 1970a; Clark 1972; Clark 1977) favoured chlorpromazine at medium-term assessment $(\mathrm{n}=$ 84, 3 RCTs, RR 0.48 CI 0.35 to 0.64). Similar data were recorded in continuous form in only one small study (Borison 1991) and results were equivocal ( $\mathrm{n}=19,1$ RCT; Analysis 1.5).

\subsubsection{Severity of illness}

We found estimates by psychiatrists for the severity of illness ( Analysis 1.6) were equivocal at short-term assessments $(n=44,1$ RCT) however, medium-term data showed significantly greater improvement in the chlorpromazine group $(n=694,3$ RCTs, RR 0.80 CI 0.74 to 0.86 ) compared with placebo. Nurse-rated severity of illness scores (Analysis 1.7) also favoured the chlorpromazine group (medium term, $\mathrm{n}=66,2$ RCTs, RR 0.63 CI 0.45 to 0.90 ) compared with placebo.

\section{I.4 Leaving the study early}

People allocated to chlorpromazine are more likely to remain in the study than participants given placebo (Analysis 1.8), in both short- ( $\mathrm{n}=1065$, 17 RCTs, RR 0.76 CI 0.63 to 0.92$)$ and mediumterm studies ( $\mathrm{n}=1831,27$ RCTs, RR 0.64 CI 0.53 to 0.78$)$. The short-term studies showed some heterogeneity $\left(\mathrm{I}^{2}=51 \%\right)$. When we analyse the data using random-effects, the result becomes nonsignificant ( $\mathrm{n}=1065,17$ RCTs, RR 0.80 CI0.58 to 1.10$)$. Removing the study with results that were causing this heterogeneity, as judged by visual inspection (Cole 1964, which used very high doses of chlorpromazine in one arm of the trial) eliminates this heterogeneity. However, we did not find any significant differences in attrition rates from the comparatively large studies (Engelhardt 1960, Hogarty 1973, $n=492$ ), which were conducted for up to two years. Also, longer-term data (Hogarty 1973) did not demonstrate a significant difference in retention rates.

\section{I.5 Mental state}

There are only a few studies with usable data relating to mental state.

\subsubsection{Improved ( $50 \%$ reduction in BPRS)}

We found no short-term difference in mental state using a cut-off point of at least a $50 \%$ decline in score to indicate 'improvement' (Cooper 2000, n=106; Analysis 1.9).

\subsubsection{Average endpoint score (BPRS)}

What continuous data there are favour chlorpromazine at short( $\mathrm{n}=49,2$ RCTs, MD -4.82 CI -8.48 to -1.15$)$ and medium-term assessments (Tetreault 1969, $\mathrm{n}=30, \mathrm{MD}-7.70 \mathrm{CI}-14.77$ to -0.63 ) (Analysis 1.10).

\subsubsection{Average change score (BPRS)}

See Table 1.

\section{I.6 Behaviour}

\subsubsection{Deteriorated/disturbed/un-cooperative}

We found participants did not differ significantly in experiencing a worsening in their behaviour (Analysis 1.11) at short-term assessment ( $\mathrm{n}=87,2$ RCTs), although data are heterogeneous (I ${ }^{2}=65 \%$ ). Medium-term data also did not differ significantly ( $\mathrm{n}=$ 1040,8 RCTs), but again, data are heterogeneous $\left(\mathrm{I}^{2}=90 \%\right)$. There are no obviously outlying studies as all confidence intervals overlap. Removing the possibly outlying studies, either Prien 1968 or Hall 1955, does not restore homogeneity, nor does their removal change the results.

\subsubsection{Unchanged}

Both short-term (Schiele 1961, $n=40)$ and medium-term ( $\mathrm{n}=68,2$ RCTs) dichotomous data did not reveal any significant differences between chlorpromazine and placebo when assessing change in participants behaviour (Analysis 1.12).

\subsubsection{Rosenthal Rating Scale}

Tetreault 1969 provided data from the Rosenthal Rating Scale ( Analysis 1.13) and we found short-term data were not significantly different $(n=30,1$ RCT) between chlorpromazine and the placebo group. Medium-term data were also not significantly different $(\mathrm{n}=$ 30, 1 RCT). 


\subsubsection{Parkside Behaviour Rating Scale}

Baker 1959 used the Parkside Behaviour Rating Scale (Analysis 1.14) to assess behaviour and we found that those given chlorpromazine had a significantly better rating in their behaviour compared with the placebo group (n=14, MD 6.00 CI 1.97 to 10.03).

\subsubsection{Fergus Falls Behavioural Rating Scale}

Ramu 1999a used the Fergus Falls Behavioural Rating Scale ( Analysis 1.15) to assess change in behaviour of participants and we found that behaviour was not significantly different $(n=42,1$ RCT) between chlorpromazine and the placebo group.

\section{I.7 Adverse effects}

\subsubsection{Extrapyramidal symptoms}

There is evidence that chlorpromazine increases a person's chances of experiencing acute movement disorders (dystonia) ( $\mathrm{n}=942,5$ RCTs, RR 3.47 CI 1.50 to 8.03), parkinsonism ( $\mathrm{n}=1468,15$ RCTs, RR 2.11 CI 1.59 to 2.80), tremor ( $n=392,7$ RCTs, RR 1.66 CI 1.01 to 2.73 ) and rigidity ( $\mathrm{n}=412,7$ RCTs, RR 2.24 CI 1.42 to 3.54). Akathisia (subjective feeling of restlessness that may lead to agitation) was dominated by one trial (Prien 1968) and did not occur more frequently in the chlorpromazine group than placebo ( $\mathrm{n}=1164,9$ RCTs), nor did tardive dyskinesia (Clark 1977, $\mathrm{n}=$ 18) nor ataxia (Hankoff 1962, $n=97$ ). We found extrapyramidal adverse effects were equivocal at both short- and medium-term assessments from one small scale study $(\mathrm{n}=30)$ by Tetreault 1969. (See Analysis 1.16; Analysis 1.17).

\subsubsection{Central nervous system}

Chlorpromazine is clearly sedating $(\mathrm{n}=1627,23$ RCTs, RR 2.79 CI 2.25 to 3.45 ). There is also evidence that chlorpromazine increases a person's chances of experiencing fits ( $n=695,3$ RCTs, RR 3.11 CI 1.05 to 9.18) and weakness ( $n=92,3$ RCTs, RR 3.33 CI 1.02 to 10.88). Convulsions did not occur more frequently in the chlorpromazine group than placebo (Gwynne 1962, n=52; Analysis 1.18).

\subsubsection{Blood, skin, liver and eyes}

We found no significant differences in blood problems such as agranulocytosis and leucopenia $(\mathrm{n}=394,7 \mathrm{RCTs})$, or rashes and itching ( $\mathrm{n}=1313,13 \mathrm{RCTs})$. Liver problems, mainly jaundice were also not significant ( $\mathrm{n}=249$, 4 RCTs). Further data from early trials suggest that chlorpromazine may well cause photosensitivity $(\mathrm{n}=$ 799, 6 RCTs, RR 6.04 CI 3.22 to 11.32), and eye opacities or pigment problems ( $\mathrm{n}=657,2$ RCTs, RR 3.09 CI 1.87 to 5.11) when large dosages of chlorpromazine are used. (See Analysis 1.19).

\subsubsection{Other}

Chlorpromazine clearly causes a lowering of blood pressure with accompanying dizziness $(\mathrm{n}=1488,18$ RCTs, RR 2.38 CI 1.74 to 3.25). Chlorpromazine is constipating, when compared with placebo ( $\mathrm{n}=1117,10 \mathrm{RCTs}$, RR 2.05 CI 1.33 to 3.15). We found data that urinary problems ( $\mathrm{n}=926,5 \mathrm{RCTs}$ ), and also blurred vision were not significantly different between chlorpromazine and placebo. We found that chlorpromazine does cause dry mouth ( $\mathrm{n}=1015,7$ RCTs, RR 4.56 CI 2.35 to 8.85). Chlorpromazine increases participants' weight $(\mathrm{n}=165,5$ RCTs, RR 4.92 CI 2.32 to 10.43 ). We found significantly more participants given chlorpromazine experienced nausea $(\mathrm{n}=1024,5$ RCTs, RR $2.07 \mathrm{CI}$ 1.14 to 3.73 ). Salivation occurred significantly more frequently in the chlorpromazine group ( $\mathrm{n}=830$, 3TCTs, RR 3.37 CI 1.07 to 10.57$)$. We found no clear evidence that chlorpromazine precipitates the frequency of amenorrhoea, menorrhagia or lactation problems. (See Analysis 1.20).

\section{Subgroup analyses}

\subsection{Men versus women}

Few studies reported outcomes for only men or women. The only primary outcome for which data were available for comparison is 'Behaviour deteriorated/disturbed/uncooperative' (Analysis 1.21). Schiele 1961 included only men $(n=40)$ and three studies report the same outcome for women alone (Clark 1970b; Fleming 1959; Somerville 1960, total $n=158$ ). Results of randomised trials were equally significant for the subgroups.

\subsection{Under 18 years of age versus 18-65 years old versus older than 65}

We could not perform this subgroup analysis as data were only available for people between the ages of 18 and 64 years.

\subsection{Acutely ill people (< one month in duration) versus people who have been ill for longer}

Limited data were available for a few primary outcomes (Analysis 1.22). We found that people who were chronically ill were more likely to have improved for short- and medium-term global improvement, and disturbed behaviour compared with those whose illnesses were acute. No difference was found for rates of relapse between acute and chronic participants. Results of randomised trials were equally significant for all subgroups. However, these analyses are severely limited by the lack of studies in the acutely ill groups and no firm conclusion can be made. 


\subsection{High dose (> $50 \mathrm{I} \mathrm{mg} /$ day) versus low doses ( $1-500$ $\mathrm{mg} /$ day)}

For the outcome of relapse between nine weeks and six months, the high-dose arm of Prien 1968 reports statistically significantly more favourable results for the chlorpromazine group, compared with the low-dose group of studies $(\mathrm{P}<0.005)$. However, for the low-dose subgroup there remains significant heterogeneity that is not explained by the exclusion of the high-dose arm of Prien 1968. For the short- and medium-term outcome 'no global improvement', there is no clear difference between studies using high-dose chlorpromazine to low dose. Higher dosages of chlorpromazine did not confer an advantage in reducing behavioural disturbances, compared with the low-dose group (Analysis 1.23).

2.5 People diagnosed according to any operational criteria versus those who have not been diagnosed using operational criteria

For relapse in short-term studies, the any operational criteria group had a better outcome but the sample size is too small to enable conclusions to be made. Relapse in medium-term studies favoured participants diagnosed with operational criteria $(\mathrm{P}<0.04)$. Global impression 'not improved' revealed no differences in the short and medium term. There were no apparent differences for severity of illness and behaviour (Analysis 1.24).

\subsection{Studies published before 1990 versus studies published between 1990 and the present}

Data were available for the outcomes of 'no overall improvement' in the short term and medium term, and 'behaviour deteriorated/ disturbed/uncooperative' (Analysis 1.25). Few studies were available in the 1990 to 2007 group limiting the analysis. Results of randomised trials were equally significant for all subgroups.

\section{Sensitivity analyses}

\section{I Implication of randomisation}

For the outcome 'no overall improvement' in the medium term, there were no differences in the results for one study (Ramu 1999a) that only implied randomisation and studies that explicitly stated that they were randomised (Analysis 1.26).

\subsection{Assumptions for lost binary data}

Two studies made assumptions regarding people lost to follow-up for the outcome 'no overall improvement' in the short term; no differences were found (Analysis 1.27).

\subsection{Risk of bias}

None of the studies had a high risk of bias for allocation concealment, or blinding of participants and outcome assessors (see Figure 2). Those that had a high risk of bias for randomisation were included in the sensitivity analysis above (Analysis 1.26).

\subsection{Imputed values}

We did not undertake a sensitivity analysis to assess the effects of including data from trials where we used imputed values for ICC as there were no cluster-randomised trials included in the review.

\subsection{Dishonest researchers}

It has come to our attention that Dr Richard Borison and Dr Bruce Diamond have been convicted of theft, making false statements and violations of state racketeering law in the USA. At this point, it seems that the crimes were to do with criminal diversion of funds, rather than falsifying study data (http://www.the-

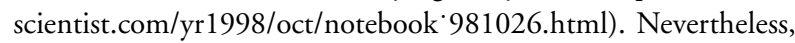
we temporarily removed studies with either of these authors from the analyses to see if this made a substantive difference to the findings. Borison 1991 presented usable data on mental state (average endpoint score on BPRS), the removal of this study did not result in a substantive change in the findings. Borison 1991 is the reports one unique outcome for global state (average endpoint score on Clinical Global Impression (CGI)), so removal of the study results in the deletion of the complete outcome.

\section{I S C U S S I O N}

\section{Summary of main results}

The summary below reflects the outcomes chosen for the Summary of findings for the main comparison, and considered the main findings of this review that can support evidence-based decision making.

\section{Death}

It may be surprising that there were no more deaths reported among over 5000 people with schizophrenia who were randomised to chlorpromazine or placebo. The lifetime incidence of suicide for people suffering from schizophrenia is $10 \%$ to $13 \%$ (Caldwell 1992). Furthermore, the use of large doses of neuroleptic has been associated with sudden death (Jusic 1994), but there are no records of such events within this review. The fact that there are none may reflect the fact that either trial-care is more vigilant than routine care or that death is an under-reported outcome. 


\section{Relapse}

Chlorpromazine reduced the number of participants experiencing a relapse compared with placebo during six months to two years follow-up, but not in the short, medium or long term over two years, although data were heterogeneous. The removal of Prien 1968 and Spohn 1977 did restore homogeneity in the short- and medium-term studies. The Prien 1968 study was different because of the very large dosages of chlorpromazine that were employed, although it had two arms, one with lower doses and another with higher doses, and these two arms were pooled in the analysis. An $86 \%$ efficacy was found for the high-dose arm in preventing relapse and a $68 \%$ efficacy for the low-dose arm; the confidence intervals only minimally overlap, so there is a potential impact of Prien 1968 on this outcome.

\section{Global state}

The best-quality data would need to be reported from six months onwards, and trials only reported on this outcome at short- and medium-term follow-ups. The efficacy of chlorpromazine for improving global state is $39 \%$ for short-term data and $29 \%$ for medium term, but the data are heterogenous. Considering that there was very little antipsychotic treatment that preceded the advent of chlorpromazine, such an efficacy can be considered nothing less than revolutionary for those with very serious mental illnesses.

\section{Leaving the study early}

The finding that using chlorpromazine results in more people staying in the study could be seen as heartening. Perhaps a genuine decrease in the distressing symptoms of schizophrenia leads to an increased concordance with medication despite the unpleasant side effects of this drug. On the other hand, this apparent willingness to comply may be due partly to sedation and hypotension. These effects (the former being linked to emotive terms such as the 'chemical straitjacket') may decrease a person's ability to make his/her own decisions.

\section{Mental state}

In spite of 45 years of research on this benchmark anti-psychotic treatment, very little can be said from trials regarding its direct effect on mental state in general or specific symptoms of schizophrenia.

\section{Satisfaction with care}

No studies reported on this outcome, so it is not possible to make any conclusions as to participants' satisfaction with chlorpromazine treatment.

\section{Behaviour}

There are more data regarding behaviour. No difference in the occurrence of behaviour judged to be disturbed or deteriorated was found in both short- and medium-term analyses, but the mediumterm result is based on heterogeneous data $\left(\mathrm{I}^{2}=90 \%\right)$. Other measures of behaviour 'unchanged' and the modified Rosenthal scale and the Fergus Falls scale did not result in any significant differences. Continuous endpoint data (Baker 1959) derived from the Parkside Behaviour Rating Scale did favour chlorpromazine but there were only seven participants in each group and we can have no real confidence in this finding.

\section{Adverse effects}

Clinicians will not be surprised that chlorpromazine produces acute movement disorders, parkinsonism, fits, tremor, rigidity, weakness and sleepiness. This Cochrane review, however, is a rare report of the best available and quantitative data on this compound that is now over half a century old. Estimates of the incidence of movement disorders such as tardive dyskinesia, however, are not available from this review, as these necessitate a long follow-up period that was only attempted in a few trials. Evidence supporting a link between chlorpromazine and akathisia is much less convincing than that for acute movement disorders, such as oculogyric crisis, and parkinsonism. This suggests that chlorpromazine may be less potent a cause of this unpleasant adverse effect than other compounds.

Taking chlorpromazine commonly causes people to become sleepy. This is an effect that, at times, may be welcomed by clinicians, but not necessarily by those with schizophrenia. Short-term sedation can be advantageous for clinicians trying to manage people with very disturbed behaviour. Sedation often helps to bring a difficult and dangerous situation under control and gives time for antipsychotic measures to be effective.

In addition, chlorpromazine has a tendency to cause other adverse effects such as jaundice, photosensitivity, eye opacities, low blood pressure, constipation, urinary retention, blurred vision and dry mouth. The worrying data regarding eye opacities is all derived from one trial (Prien 1968). This large trial, however, used up to two grams of chlorpromazine a day and it is likely that the lower doses more usual in current practice would result in less risk of this adverse effect. Chlorpromazine frequently causes weight increase.

\section{Cost of care}

Again, no studies reported on this outcome, so it is not possible to make any conclusions about the cost of chlorpromazine treatment.

\section{Subgroup analyses}

As was likely from the start, the power to detect a real difference between studies in any one of the subgroup analyses was very low. 
Only subsets of already limited lists of trials were available. The wide confidence intervals could be hiding true differences in effect between the groups. The only suggestions of statistically significant differences were for acutely ill versus chronically ill for the outcomes of global improvement and behaviour, and for highdose versus low-dose studies (relapse between nine weeks and six months). It is important to remember that this is now a non-randomised comparison between studies, rather than within a study, and that this is one of many statistical tests that were undertaken on this dataset. Further complicating matters is the fact that the other outcomes within this particular subgroup analysis did not clearly support or refute this difference between high and low doses. Prien 1968 is an unusual study. Using two grams of chlorpromazine per day would be unacceptable in most situations today, a view supported by some of the findings of this review ( $n=657,2$ RCTs, RR eye opacities from two grams chlorpromazine per day, 3.09 CI 1.9 to 5.1 ).

\section{Overall completeness and applicability of evidence}

\section{Applicability}

The 55 included studies in this version of this review include many people who would be recognisable in everyday practice. There are those with strictly diagnosed illnesses, very likely to suffer from schizophrenia, and people whose illness was diagnosed using less rigorous criteria. The results of the subgroup analyses on diagnostic rigour (see Effects of interventions section 2.5) also support the assertion that the results are widely applicable.

The dose of chlorpromazine in the studies included in this review could be considered high (mean $574.1 \mathrm{mg} /$ day SD 445) but, again, these levels are probably common for people with persistent schizophrenia across the globe.

Although the outcomes that have been used in this review are accessible to both clinicians and recipients of care, generalising to treatment in community settings, could be problematic. Most studies were undertaken in hospital, whereas the great majority of people with schizophrenia are in the community.

\section{Homogeneity}

Some results are difficult, or impossible, to interpret because of heterogeneity. The test for homogeneity is based on $\mathrm{I}^{2}$ analysis, and is often fairly weak, as the number of studies is small. However, the results of such tests, when statistically significant, suggest caution when adding trial data together.

\section{Quality of the evidence}

The quality of the current evidence is very low based on GRADE (Schünemann 2008). The majority of studies did not report the method of randomisation, and only two trials described method of allocation concealment. Although most studies were reported to be double blind, it was not clear in many whether or not the assessors were blinded to treatment group of participants. Fortyeight out of the 55 included studies were rated as high risk of bias for selective reporting. Studies frequently presented both dichotomous and continuous data in graphs, or just reported statistical measures of probability ( $\mathrm{P}$ values). This often made it impossible to acquire raw data for synthesis. It was also common to use $\mathrm{P}$ values as a measure of association between intervention and outcomes instead of showing the strength of the association. Although $P$ values are influenced by the strength of the association, they also depend on the sample size of the groups. It is sometimes possible to extract raw data from $P$ values, but their exact values are needed. In the reviewed studies this was not possible, because they were reported as ' $\mathrm{P}<0.05$ ' or ' $\mathrm{P}>0.05$ '. Frequently, continuous data were presented without providing standard deviations or standard errors (33/55 trials) or no data were presented at all (11/55 trials). In this way a lot of potentially informative data were lost. In some studies it seemed that attempts had been made to use the original trials as vehicles for answering a host of other questions about schizophrenia. As a consequence, data from the randomised parts of the studies became buried beneath copious subgroup analyses.

\section{Potential biases in the review process}

\section{Adding the old to the new}

This work includes studies that span nearly five decades of evaluative studies within psychiatry. It is possible that the rigour of these experiments has changed over time, as have the participants and even the formulation of the drug; it was thought that introduction of impurities in early formulations of chlorpromazine led to jaundice. There is some empirical evidence that the quality of schizophrenia trial reporting has not changed much over time (Thornley 1998) or, if it has changed, it may even have declined (Ahmed 1998). We have found no time-related differences in reporting of studies within this review and no suggestion of a change of the effect size over time. Synthesis of the results of studies seems justified.

\section{Failing to identify old trials}

We identified trials by meticulous searching, including handsearching old files (2002 update) that covered the drug's development over its first two decades. Nevertheless, for this compound formulated so long ago, publication biases may be difficult to avoid. We did not detect any overt asymmetry of the funnel plots. 
The strength of this review is that it presents up-to-date quantitative data for a benchmark treatment for schizophrenia that is used throughout the world.

\section{Sensitivity analyses on dishonest researchers}

We felt that it would be harsh to immediately delete all trial data associated with Drs Borison and Diamond without empirical data. That removal of their data makes no discernable difference to any outcome is reassuring.

\section{Agreements and disagreements with other studies or reviews}

We do not know of any other systematic reviews on this topic.

\section{AUTHORS' CONCLUSIONS}

\section{Implications for practice}

\section{For people with schizophrenia}

Many people with schizophrenia and their non-professional carers recognise psychotic symptoms as phenomena generated by a damaging and pernicious illness and may see the effect of chlorpromazine, as demonstrated within this review, as positive. Others may consider these data as supporting well-publicised objections to the use of drugs: drugs potent in their ability to cause unpleasant adverse effects, and to potentially erode a person's ability to make informed decisions.

\section{For clinicians}

This review will confirm much that clinicians already know, but it does provide some quantification to support clinical impression. Chlorpromazine is a sedating drug, prone to cause a variety of movement problems and increased weight. Evidence suggests that chlorpromazine reduces relapse and facilitates global improvement.

The adverse effect of sedation can, in certain clinical situations (especially in the short term), be a useful adjunct to any antipsychotic properties that chlorpromazine may have. For example, someone acutely disturbed and violent, perhaps because of false beliefs, may well benefit from a certain amount of sedation while the antipsychotic effects of treatment begin to work.

Chlorpromazine is a low-cost and widely available choice for the clinician. Despite its many adverse effects chlorpromazine is likely to remain one of the most widely used treatments for schizophrenia worldwide.

\section{For managers or policy makers}

Chlorpromazine is widely available and inexpensive. It is understandable that it remains one of the essential drugs listed by the WHO for treating people with serious mental illnesses. However, some of chlorpromazine's adverse effects could be expensive in terms of human suffering and cost of treatment. It could, therefore, prove better to use a more costly drug if the latter was equally potent, but had a more favourable adverse effects profile.

\section{Implications for research}

\section{More trials comparing chlorpromazine with placebo?}

Even though chlorpromazine has been used as an antipsychotic drug for decades, there are still a surprisingly small number of well-conducted randomised, placebo-controlled trials measuring its efficacy and potential to cause adverse effects. The use of chlorpromazine for millions of people is based on clinical experience rather than the poorly reported trials that involve, in total, only a few thousand participants. Clinicians and researchers are mainly satisfied with the current levels of understanding, and, therefore new studies evaluating chlorpromazine versus placebo will be very rare. However the chlorpromazine story is incomplete. Questions remain regarding the effect of this drug on mental state, longterm movement disorders and vision. One or more large, methodologically sound randomised, placebo-controlled trials could help answer these questions. With the advent of new drugs, however, the day for studies comparing chlorpromazine with placebo has passed.

\section{Placebo-controlled studies of other treatments}

Having shown that chlorpromazine is a benchmark treatment of psychotic symptoms, and knowing that allowing schizophrenia to go untreated may be damaging (Birchwood 1997), the question may well be raised as to whether any placebo-controlled studies of new antipsychotic drugs are justified. However, the marked level of improvement in the placebo groups in this review would seem to indicate that short-term studies of those with schizophrenia using a placebo group are justified and would be unlikely to be damaging to those with psychotic illnesses. Using a placebo comparison in the longer term would seem more problematic and difficult to justify.

\section{Future trials}

So much more could have been learnt about the effects of chlorpromazine if the studies in this review had clearly described the method of allocation, the integrity of blinding, especially for the more subjective outcomes, and the reasons for early withdrawal. Concrete and simple outcomes are of interest. For example, clearly reporting improvement, 'number of violent incidents', 'relapse' 
(giving some description of criteria), 'hospital discharge or admission', and 'presence of delusions or hallucinations' would have been helpful, and simple reporting of levels of satisfaction and quality of life would have been most informative. Chlorpromazine has been in use for decades, yet clinicians still have no trial-based data indicating how people with schizophrenia perceive the value of this drug in the short, medium and long term.

If rating scales are to be employed, a concerted effort should be made to agree on which measures are the most useful. Studies within this review reported on so many scales that, even if results had not been poorly reported, they would have been difficult to synthesise in a clinically meaningful way.

Further information on the standardisation of trial reporting can be found in the CONSORT statement (Moher 2001).

\section{ACKNOWLEDGEMENTS}

The Cochrane Schizophrenia Group now provide and maintain a template for the methods section of their reviews. We have used and adapted this template for use in the 2012 update.

Our thanks go to Theresa Flower and Prathap Tharyan for their work in the early stages of this review.

We thank Jacqueline Birks, Jon Deeks and Sarah Lewington for their help with data extraction and interpretation. (We look forward to further comments and criticisms with interest!)
Thank you to Kristian Wahlbeck and Stefan Leucht for excellent and thorough comments on all aspects of the review.

Thank you to Dr Mikhail F Denisov, for extracting data from Russian language papers.

Thanks to the staff of the Institute of Health Sciences Library, Oxford, UK, who regularly, efficiently and uncomplainingly dealt with our requests for articles (over 200 in all).

Several letters were sent by the review authors to authors, asking for extra information about their trials. Dr Steven Cooper (Belfast, UK), Dr Malcolm Peet (Sheffield, UK), Dr Nina Schooler (Glen Oaks, USA), and Professor Armand Loranger (New York, USA) were kind enough to respond, for which we are very grateful.

The help of Dr Muir Gray, our friend and supporter, is gratefully acknowledged.

As has already been acknowledged, the help of Dr Pargiter of Hobart, Tasmania was invaluable. We hope that Dr Pargiter feels that the eventual use of these data justified the decades of storage of these precious files. We are indebted to people such as Dr Pargiter, who see that people who agreed to be randomised so long ago did not agree to have their data lost or forgotten.

Enhance Reviews provided support for the 2012 update of this review in the data extraction, analysis and write-up of results.

Jun Xie screened full texts and extracted data for all Chinese studies.

\section{R E F E R E N C E S}

\section{References to studies included in this review}

Abrams 1958 \{published data only\}

Abrams J. Chlorpromazine in the treatment of chronic schizophrenia. Diseases of the Nervous System 1958;19:20-8.

Baker 1959 \{published data only\}

Baker JP. A controlled trial of ethylcrotonylurea. British

Journal of Psychiatry 1959;105:852-62.

Ban 1975 \{published data only\}

Ban TA, Lehmann HE, Sterlin C, Climan M. Comprehensive clinical studies with thiothixene. Diseases of the Nervous System 1975;36:473-7.

Bishop 1963 \{published data only\}

Bishop M, Gallant DM. Behavioral toxicity associated with benzquinamide (Quantril) therapy in schizophrenic patients. American Journal of Psychiatry 1963;120:180-1.

Borison 1991 \{published data only\}

* Borison RL, Diamond BI, Dren AT. Does sigma receptor antagonism predict clinical antipsychotic efficacy?. Psychopharmacology Bulletin 1991;27:103-6.

Borison RL, Dren AT, Diamond BI. Sigma receptor antagonism and antipsychotic actions in schizophrenic patients. European Journal of Pharmacology 1990;183:23.

Chouinard 1990 \{published data only\}

Chouinard G. A placebo-controlled clinical trial of remoxipride and chlorpromazine in newly admitted schizophrenic patients with acute exacerbation. Acta Psychiatria Scandinavica Supplementum 1990;358:111-9.

Clark 1961 \{published data only\}

* Clark ML, Ray T, Paredes A, Costiloe J, Chappell J, Hagans J, et al. Chlorpromazine in chronic schizophrenic women. I. Experimental design and effects at maximum point of treatment. Psychopharmacologia 1961;2:107-36. Clark ML, Ray TS, Ragland RE. Chlorpromazine in chronic schizophrenic women: rate of onset and rate of dissipation of drug effects. Psychosomatic Medicine 1963;25:212-7. Ray TS, Ragland RE, Clark ML. Chlorpromazine in chronic schizophrenic women: comparison of differential effects on various psychological modalities during and after treatment. Journal of Nervous and Mental Diseases 1964;138:348-53.

Clark 1967 \{published data only\}

Clark M, Dubowski K, Colmore J. The effect of chlorpromazine on serum cholesterol in chronic 
schizophrenic patients. Clinical Pharmacology and Therapeutics 1970;11:883-9.

* Clark ML, Ray TS, Paredes A, Ragland RE, Costiloe JP, Smith CW, et al. Chlorpromazine in women with chronic schizophrenia: the effect on cholesterol levels and cholesterol-behavior relationships. Psychosomatic Medicine 1967;29:634-42.

\section{Clark 1968a \{published data only\}}

Clark ML, Huber WK, Kyriakopoulos AA, Ray TS, Colmore JP, Ramsey HR. Evaluation of trifluperidol in chronic schizophrenia. Psychopharmacologia 1968;12: 193-203.

\section{Clark 1968b \{published data only\}}

Clark ML, Ray TS, Huber WK, Willis D, Ramsey HR. Evaluation of butaperazine in chronic schizophrenia. Clinical Pharmacology and Therapeutics 1968;97:57-64.

\section{Clark 1970a \{published data only\}}

* Clark M, Dubowski K, Colmore J. The effect of chlorpromazine on serum cholesterol in chronic schizophrenic patients. Clinical Pharmacology and Therapeutics 1970;11:883-9.

Clark ML, Huber WK, Sakata K, Fowles DC, Serafetinides EA. Molindone in chronic schizophrenia. Clinical Pharmacology and Therapeutics 1970;11:680-8. Serafetinides EA, Willis D, Clark ML. The EEG effects of chemically and clinically dissimilar antipsychotics: molindone vs. chlorpromazine. International Pharmacopsychiatry 1971;6:77-82.

\section{Clark 1970b \{published data only\}}

Clark M, Dubowski K, Colmore J. The effect of chlorpromazine on serum cholesterol in chronic schizophrenic patients. Clinical Pharmacology and Therapeutics 1970;11:883-9.

Clark M, Ramsey H, Rahhal D, Serafetinides E, Wood F, Costiloe J. Chlorpromazine in chronic schizophrenia. The effect of age and hospitalization on behavioral doseresponse relationships. Archives of General Psychiatry 1972; 27:479-83.

Clark ML, Ramsey HR, Ragland RE, Rahhal DK, Serafetinides EA, Costiloe JP. Chlorpromazine in chronic schizophrenia - behavioral dose-response relationships. Psychopharmacologia 1970;18:260-70.

Serafetinides EA, Willis D, Clark ML. EEG dose-response relationships of chlorpromazine in chronic schizophrenia: the effects on the various rhythms and on alpha blocking. Biological Psychiatry 1972;4:251-6.

Clark 1971 \{published data only\}

Clark. Phenothiazines in schizophrenics. Psychopharmacology Bulletin 1969;6(3):37-40.

* Clark ML, Huber WK, Charalampous KD, Serafetinides EA, Trousdale W, Colmore JP. Drug treatment in newly admitted schizophrenic patients. Archives of General Psychiatry 1971;25:404-9.

\section{Clark 1972 \{published data only\}}

* Clark ML, Huber WK, Sullivan J, Wood F, Costiloe JP. Evaluation of loxapine succinate in chronic schizophrenia. Diseases of the Nervous System 1972;33:783-91.

Serafetinides EA, Willis D, Clark ML. The EEG effects of dibenzoxazepines (loxapine succinate) as compared to CPZ: EEG changes as drug side effects. International Pharmacopsychiatry 1971;6:38-44.

Clark 1977 \{published data only\}

Clark ML, Paredes A, Costiloe JP, Wood F. Evaluation of butaclamol in chronic schizophrenic patients. Journal of Clinical Pharmacology 1977;17:529-36.

\section{Cohen 1968 \{published data only\}}

* Cohen M, Freedman N, Englehardt DM. Family interaction patterns, drug treatment, and change in social aggression. Archives of General Psychiatry 1968;19(1):50-6. Graupner OK, Kalman EV. Effects of various drugs on flicker fusion frequency. II. Phenothiazine derivatives (with reference to the dependence of the results on the chronological course of experiments [Die FlimmerVerschmelzung-Frequenz unter dem Einfluss verschiedener Pharmaka. II. Phenothiazinderivate (mit einem Hinweis auf die Abhangigkeit der Ergebnisse vom zeitlichen Verlauf der Versuche)]. Psychopharmacologia 1972;27(4):343-7. MEDLINE: 73085373

\section{Cole 1964 \{published data only\}}

* Cole JO, Goldberg SC, Klerman GL National Institute of Mental Health Psychopharmacology Service Center Collaborative Study Group. Phenothiazine treatment in acute schizophrenia. Archives of General Psychiatry 1964;10: 246-61.

Goldberg S, Klerman G, Cole J. Changes in schizophrenic psychopathology and ward behaviour as a function of phenothiazine treatment. British Journal of Psychiatry 1965; 111:120-33.

Goldberg SC, Mattsson NB. Schizophrenic subtypes defined by response to drugs and placebo. Diseases of the Nervous System 1968;29:153-8.

\section{Cooper 2000 \{published and unpublished data\}}

Cooper SJ, Butler A, Tweed J, Welch CP. Zotepine in the treatment of chronic schizophrenia. 10th ECNP (European College of Neuropsychopharmacology) Congress. Vienna, Austria. Vienna, Austria, September 13-17, 1997. Cooper SJ, Raniwalla J, Welch C. Zotepine in acute exacerbation of schizophrenia: a comparison versus chlorpromazine and placebo. XXth Collegium Internationale Neuro-psychopharmacologicum. Melbourne, Australia. Melbourne, Australia, 1996. * Cooper SJ, Tweed J, Raniwalla J, Butler A, Welch C. A placebo controlled comparison of zotepine versus chlorpromazine in patients with acute exacerbation of schizophrenia. Acta Psychiatrica Scandinavica 2000;101(3): 218-25. MEDLINE: 20184895

Cooper SJ, Tweed J, Raniwalla J, Welch C. A placebocontrolled comparison of zotepine versus chlorpromazine 
in patients with acute exacerbation of schizophrenia. Unpublished manuscript 1996.

Cooper SJ, Welch CP. A comparison of zotepine and chlorpromazine on BPRS subscores. 10th ECNP (European College of Neuropsychopharmacology) Congress. Vienna, Austria. Vienna, Austria, September 13-17, 1997.

Dean 1958 \{published data only\}

Dean EF, Buker S. Schizophrenia treated with and without chlorpromazine. Rocky Mountain Medical Journal 1958;55: $47-50$.

Engelhardt 1960 \{published data only\}

Engelhardt D, Freedman N, Rosen B, Mann D, Margolis R. Phenothiazines in prevention of psychiatric hospitalization. Archives of General Psychiatry 1964;11:162-9.

* Engelhardt DM, Freedman N, Glick BS, Hankoff LD, Mann D, Margolis R. Prevention of psychiatric hospitalization with use of psychopharmacological agents. JAMA 1960;173:147-9.

Engelhardt DM, Margolis RA, Rudorfer L, Paley HM. Physician bias and the double-blind. Archives of General Psychiatry 1969;20(3):315-20.

Engelhardt DM, Rosen B, Freedman N, Mann D, Margolis R. Phenothiazines in prevention of psychiatric hospitalization. II. Duration of treatment exposure. JAMA 1963;186:981-3.

Engelhardt DM, Rosen B, Freedman N, Margolis R. Phenothiazines in prevention of psychiatric hospitalization. IV. Delay or prevention of hospitalization - a reevaluation. Archives of General Psychiatry 1967;16:98-101.

Freedman N, Cutler R, Engelhardt DM, Margolis R. On the modification of paranoid symptomatology. Journal of Nervous and Mental Disease 1967;144:29-36.

Freedman N, Cutler R, Engelhardt DM, Margolis R. On the modification of paranoid symptomatology. II. Stylistic considerations and the effectiveness of phenothiazines. Journal of Nervous and Mental Disease 1970;150:68-76. Rosen B, Engelhardt DM, Freedman N. The hospitalization proneness scale as a predictor of response to phenothiazine treatment. Journal of Nervous and Mental Disease 1968;6: $476-80$.

Fink 1963 \{published data only\}

Belmont I, Pollack M, Willner A, Klein D, Fink M. The effects of imipramine and chlorpromazine on perceptual analytic ability, perceptual analytic responsivity and memory as revealed in rorschach responses. Journal of Nervous and Mental Disease 1963;137(1):42-50.

* Fink M, Pollack M, Klein DF, Blumberg AG, Belmont I, Karp E, et al. Comparative studies of chlorpromazine and imipramine. I. Drug discriminating patterns. Neuropsychopharmacology 1963;3:370-2.

Klein DF. Importance of psychiatric diagnosis in prediction of clinical drug effects. Archives of General Psychiatry 1967; 16:118-26.

Klein DF. Psychiatric diagnosis and a typology of clinical drug effects. Psychopharmacologia 1968;13:359-86.

Klein DF, Honigfeld G, Feldman S. Prediction of drug effect by diagnostic decision tree. Diseases of the Nervous
System 1968;29:159-87.

Levenstein S, Klein DF, Pollack M. Follow up study of formerly hospitalized voluntary psychiatric patients: the first two years. American Journal of Psychiatry 1966;122: 1102-8.

\section{Fleming 1959 \{published data only\}}

Fleming B, Spencer A, Whitelaw E. A controlled comparative investigation of the effects of promazine, chlorpromazine, and a placebo in chronic psychosis. British Journal of Psychiatry 1959;105:349-58.

\section{Grygier 1958 \{published data only\}}

Grygier P, Waters MA. Chlorpromazine used with an intensive occupational therapy program. A.M.A. Archives of Neurology and Psychiatry 1958;79:697-705.

Gwynne 1962 \{published data only\}

Gwynne P, Hundziak M, Kavtschitsch J, Lefton M, Pasamanick B. Efficacy of trifluoperazine on withdrawal in chronic schizophrenia. Journal of Nervous and Mental Disease 1962;134:451-5. MEDLINE: 13903283

Hall 1955 \{published data only\}

* Hall RA, Dunlap DJ. A study of chlorpromazine: methodology and results with chronic semi-disturbed schizophrenics. Journal of Nervous and Mental Disease 1955; 122:301-14.

Hollister LE, Hall RA. Phenothiazine derivatives and morphologic changes in the liver. American Journal of Psychiatry 1966;123:211-2.

Hamill 1975 \{published data only\} Hamill WT, Fontana AF. The immediate effects of chlorpromazine in newly admitted schizophrenic patients. American Journal of Psychiatry 1975;132:1023-6.

Hamilton 1960 \{published data only\} Hamilton M, Smith A, Lapidus HR, Cadogan EP. A controlled trial of Thiopropazate Dihydrochloride (Dartalan), Chlorpromazine and occupational therapy in chronic schizophrenics. British Journal of Psychiatry 1960; 106:40-55.

Hankoff 1962 \{published data only\} Hankoff LD, Rudorfer L, Paley HM. A reference study of ataraxics. A two-week double blind outpatient evaluation. Journal of New Drugs 1962;2:173-8. MEDLINE: 13904352

\section{Hine 1958 \{published data only\}}

Hine FR. Chlorpromazine in schizophrenic withdrawal and in the withdrawn schizophrenic. Journal of Nervous and Mental Diseases 1958;127:220-7.

\section{Hogarty 1973 \{published data only\}}

Goldberg S, Schooler N, Hogarty G, Roper M. Prediction of relapse in schizophrenic outpatients treated by drug and sociotherapy. Archives of General Psychiatry 1977;34: 171-84.

* Hogarty G, Goldberg S. Drug and sociotherapy in the aftercare of schizophrenic patients. One-year relapse rates. Archives of General Psychiatry 1973;28:54-64.

Hogarty G, Goldberg S, Schooler N. Drug and sociotherapy in the aftercare of schizophrenic patients. III. Adjustment of 
non relapsed patients. Archives of General Psychiatry 1974; 31:609-18.

Hogarty G, Goldberg S, Schooler N, Ulrich R. Drug and sociotherapy in the aftercare of schizophrenic patients. II. Two-year relapse rates. Archives of General Psychiatry 1974; 31:603-8.

Hogarty G, Ulrich R. Temporal effects of drug and placebo in delaying relapse in schizophrenic outpatients. Archives of General Psychiatry 1977;34:297-301.

Hogarty GE, Munetz MR. Pharmacogenic depression among outpatient schizophrenic patients - a failure to substantiate. Journal of Clinical Psychopharmacology 1984;4: $17-24$.

Klein 1973 \{published data only\}

Klein D, Rosen B. Premorbid asocial adjustment and response to phenothiazine treatment among schizophrenic inpatients. Archives of General Psychiatry 1973;29:480-5.

\section{Kurland 1961 \{published data only\}}

Kurland AA, Hanlon TE, Tatom MH, Ota KY, Simopoulos AL. The comparative effectiveness of six phenothiazine compounds, phenobarbital and inert placebo in the treatment of acutely ill patients: global measures of severity of illness. Journal of Nervous and Mental Disease 1961;133: 1-18.

Kurland AA, Hanlon TE, Tatom MH, Simopoulos AL. Comparative studies of the phenothiazine tranquilizers: methodological and logistical considerations. Journal of Nervous and Mental Disease 1961;132:61-74.

Kurland AA, Nilsson GL, Hanlon TE. Pre-admission drug treatment of state psychiatric hospital patients. American Journal of Psychiatry 1959;115:1028-9.

Kurland AA, Sutherland GF. The phenothiazine tranquilizers - their neurological complications and significance. Psychosomatics 1960;1:192-4.

Letemendia 1967 \{published data only\}

Letemendia F, Harris AD. Chlorpromazine and the untreated chronic schizophrenic: a long-term trial. British Journal of Psychiatry 1967;113:950-8.

Nishikawa 1982 \{published data only\}

Nishikawa T, Tsuda A, Tanaka M, Koga I, Uchida Y.

Prophylactic effect of neuroleptics in symptom-free schizophrenics. Psychopharmacology 1982;77:301-4.

Payne 1960 \{published data only\}

Payne P. A comparison of trifluopromazine, chlorpromazine and a placebo in twenty-one chronic schizophrenic patients. Manitoba Medical Review 1960:196-8.

Peet 1981 \{published data only\}

Peet M, Bethell M, Coates A, Khamnee A, Hall P, Cooper $S$, et al. Propranolol in schizophrenia. I. Comparison of propranolol, chlorpromazine and placebo. British Journal of Psychiatry 1981;139:105-11.

Prien 1968 \{published data only\}

Crane GE. Tardive dyskinesia in schizophrenic patients treated with psychotropic drugs. Agressologie 1968;2: 209-18.

De Long SL. Incidence and significance of chlorpromazine- induced eye changes. Diseases of the Nervous System 1968; 29:19-22.

Gardos G, Cole JO, LaBrie RA. A 12-year follow-up study of chronic schizophrenics. Hospital and Community Psychiatry 1982;33:983-4.

Mandel A, Gross M. Agranulocyctosis and phenothiazines. Diseases of the Nervous System 1968;29:32-6.

Prien R, Cole JO. High dose chlorpromazine therapy in chronic schizophrenia. Report of National Institute of Mental Health - psychopharmacology research branch collaborative study group. Archives of General Psychiatry 1968;18:482-95.

Prien R, DeLong S, Cole J, Levine J. Ocular changes occurring with prolonged high dose chlorpromazine therapy. Results from a collaborative study. Archives of General Psychiatry 1970;23:464-8.

Prien RF, Cole JO, Belkin NF. Relapse in chronic schizophrenics following abrupt withdrawal of tranquillizing medication. British Journal of Psychiatry 1968;115:679-86. Prien RF, Levine J, Cole JO. Indications for high dose chlorpromazine therapy in chronic schizophrenia. Diseases of the Nervous System 1970;31:739-45.

Ramu 1999 \{published data only\} Ramu MG, Chaturvedi DD, Venkataram BS, Shankara MR, Leelavathy S, Janakiramiah N, et al. A double blind controlled study on the role of brahmyadiyoga and tagara in navonmada (acute schizophrenia). Ayurvedic Management of Unmada (Schizophrenia). New Delhi: Central Council for Research in Ayurveda \& Siddha, 1999:59-76.

Ramu 1999a \{published data only\}

Ramu MG, Chaturvedi DD, Venkataram BS, Shankara MR, Leelavathy S, Janakiramiah N, et al. A DOUBLE BLIND controlled study on the role of brahmyadiyoga and tagara in jirnomada (chronic schizophrenia). Ayurvedic Management of Unmada (Schizophrenia). New Delhi: Central Council for Research in Ayurveda \& Siddha, 1999: $77-88$.

Rappaport 1978 \{published data only\}

Rappaport M, Hopkins HK, Hall K, Belleza T, Silverman J. Are there schizophrenics for whom drugs may be unnecessary or contraindicated?. International Pharmacopsychiatry 1978;13:100-11.

\section{Reardon 1966 \{published data only\}}

Reardon JD, Abrams S. Acute paranoid schizophrenia (treatment with chlorpromazine, trifluoperazine and placebo). Diseases of the Nervous System 1966;27:265-70.

\section{Reschke 1974 \{published data only\}}

Reschke RW. Parenteral haloperidol for rapid control of severe, disruptive symptoms of acute schizophrenia. Diseases of the Nervous System 1974;35:112-5.

Saretsky 1966 \{published data only\} Saretsky T. Effects of chlorpromazine on primary-process thought manifestations. Journal of Abnormal Psychology 1966;71:247-52. 
Schiele 1961 \{published data only\}

Schiele BC, Vestre ND, Stein KE. A comparison of thioridazine, chlorpromazine, and placebo: a double-blind controlled study on the treatment of chronic, hospitalized, schizophrenic patients. Journal of Clinical and Experiemental Psychopathology 1961;22:151-62.

Serafetinides 1972 \{published data only\} Serafetinides EA, Clark ML. Psychological effects of single dose antipsychotic medication. Biological Psychiatry 1973;7: 263-7.

Serafetinides EA, Collins S, Clark ML. Haloperidol, clopenthixol, and chlorpromazine in chronic schizophrenia. Chemically unrelated antipsychotics as therapeutic alternatives. Journal of Nervous and Mental Diseases 1972; 154:31-42.

Serafetinides EA, Willis D. A method of quantifying EEG for psychopharmacological research. International Pharmacopsychiatry 1973;8:245-7.

Serafetinides EA, Willis D, Clark ML. Haloperidol, clopenthixol, and chlorpromazine in chronic schizophrenia. II. The electroencephalographic effects of chemically unrelated antipsychotics. Journal of Nervous and Mental Diseases 1972;155:366-9.

Shepherd 1956 \{published data only\} Shepherd M, Watt DC. A controlled clinical study of chlorpromazine and reserpine. Journal of Neurology, Neurosurgery and Psychiatry 1956;19:232-5.

Simon 1958 \{published data only\} Simon W, Wirt AL, Wirt RD, Halloran AV. Long-term follow-up study of schizophrenic patients. Archives of General Psychiatry 1965;12:510-5.

* Simon W, Wirt R, Wirt A, Halloran A, Hinckley R, Lund $\mathrm{J}$, et al. A controlled study of the short-term differential treatment of schizophrenia. American Journal of Psychiatry 1958;114:1077-86.

Smith 1961 \{published data only\}

Smith ME. A clinical study of chlorpromazine and chlordiazepoxide. Connecticut State Medical Journal 1961; 25:153-7.

Somerville 1960 \{published data only\}

Somerville DM, Cohen PH, Graves GD. Phenothiazine side-effects. Comparison of two major tranquillizers. British Journal of Psychiatry 1960;106:1417-24.

Spohn 1977 \{published data only\}

Spohn H, Lacoursiere R, Thompson K, Coyne

L. Phenothiazine effects on psychological and

psychophysiological dysfunction in chronic schizophrenics. Archives of General Psychiatry 1977;34(6):633-44.

Tetreault 1969 \{published data only\}

Tetreault L. Comparative study of two drugs and a placebo in chronic schizophrenia [Etude comparative de deux medicaments et d'un placebo chez le schizophrene chronique]. Actualites Pharmacologiques 1969;22:221-8. Tetreault L, Bordeleau JM, Gauthier R, Vulpe M, Lapointe L. Comparative study of TPS-23, chlorpromazine and placebo in chronic schizophrenic patients. Diseases of the Nervous System 1969;30(2):74-84.

Vaughan 1955 \{published data only\}

Vaughan GF, Leiberman DM, Cook LC. Chlorpromazine in psychiatry. Lancet 1955;1:1083-7.

Walsh 1959 \{published data only\}

Walsh GP, Walton D, Black DA. The relative efficacy of "Vespral" and chlorpromazine in the treatment of a group of chronic schizophrenic patients. British Journal of Psychiatry 1959;105:199-209.

\section{Weckowicz 1960 \{published data only\}}

Weckowicz TE, Ward T. Clinical trial of RO 5-0690 and chlorpromazine on disturbed chronic schizophrenic patients. Diseases of the Nervous System 1960;21:527-8. MEDLINE: 13783681

Xiong 1994 \{published data only\}

Xiong, Hu. A double-blind comparative study of pheytoin and chlorpromazine in chronic schizophrenics. Medical Journal of Chinese Civil Administration 1994;6(4):160-1.

\section{References to studies excluded from this review}

Abse 1960 \{published data only\}

Abse WD, Dahlstrom WG, Tolley AG. Evaluation of tranquilizing drugs in the management of acute mental disturbance. American Journal of Psychiatry 1960;117: 973-80.

Acker 1965 \{published data only\} Acker CW. An exploration of the autonomic effects of phenothiazines. Psychopharmacologia 1965;7:150-8.

Affleck 1966 \{published data only\} Affleck DC, Eaton MT, Mansfield E. The action of a medication and the physician's expectations. Nebraska State Medical Journal 1966;51:331-4.

Agarwal 1985 \{published data only\}

Agarwal AK, Winny GC. Role of ECT phenothiazine combination in schizophrenia. Indian Journal of Psychiatry 1985;27:233-6.

Akimoto 1966 \{published data only\} Akimoto H, Shimazaki T, Shibata N, Sato Y, Takahashi R. Current status of pharmacotherapy in schizophrenia. Folia Psychiatrica et Neurologica Japonica 1966;20(1):1-8. MEDLINE: 67213329

Alpert 1966 \{published data only\} Alpert M, Hekimian LJ, Frosch WA. Evaluation of treatment with recorded interviews. American Journal of Psychiatry 1966;122:1258-64.

Alpert 1978 \{published data only\} Alpert M, Friedhoff A, Marcos L, Diamond F. Paradoxical reaction to L-dopa in schizophrenic patients. American Journal of Psychiatry 1978;135:1329-32.

Alson 1964 \{published data only\}

Alson E, Hastings K. The use of adjective check lists with psychotic patients: the problem of pseudo-responses. Journal of Clinical Psychology 1964;20(4):462-3. 
Aman 1985 \{published data only\}

Aman MG, Singh NN. Dyskinetic symptoms in profoundly retarded residents following neuroleptic withdrawal and during methylphenidate treatment. Journal of Mental Deficiency Research 1985;29(2):187-95. MEDLINE: 85293054

Amin 1977 \{published data only\}

Amin MM, Ban TA, Lehmann HE. A standard-controlled clinical study with benzquinamide in the treatment of chronic schizophrenic patients. Psychopharmacology Bulletin 1977;13:20-1

Ananth 1972 \{published data only\}

Ananth JV, Vacaflor L, Kekhwa G, Sterlin C, Ban TA. Nicotinic acid in the treatment of newly admitted schizophrenic patients: a placebo-controlled study. Internationale Zeitschrift Fur Klinische Pharmakologie Therapie und Toxikologie 1972;5(4):406-10. MEDLINE: 72239308

Andrews 1976 \{published data only\}

Andrews P, Hall JN, Snaith RP. A controlled trial of phenothiazine withdrawal in chronic schizophrenic patients. British Journal of Psychiatry 1976;128:451-5.

Ashcroft 1961 \{published data only\}

Ashcroft GW, MacDougall EJ, Barker PA. A comparison of tetrabenazine and chlorpromazine in chronic schizophrenia. Journal of Mental Science (British Journal of Psychiatry from 1963) 1961;107:287-93. MEDLINE: 72239308

Ayers 1984 \{published data only\}

Ayers T, Liberman RP, Wallace CJ. Subjective response to antipsychotic drugs: failure to replicate predictions of outcome. Journal of Clinical Psychopharmacology 1984;4: 89-93.

Azima 1954 \{published data only\} Azima H, Ogle W. Effects of Largactil in mental syndomes. Canadian Medical Association Journal 1954;71:116-21.

Bagadia 1981 \{published data only\}

Bagadia VN, Shah LP, Pradhan PV, Doshi J, Abhyankar R. Evaluation of cognitive effects of ECT: preliminary observations. Indian Journal of Psychiatry 1981;23:324-9.

Ban 1977 \{published data only\}

Ban TA, Lehmann HE, Deutsch M. Negative findings with megavitamins in schizophrenic patients - preliminary report. Communications in Psychopharmacology 1977;1:119-22. Hoffer, J. Megavitamin treatment of schizophrenia. Canadian Psychiatric Association Journal 1975;20:492-5.

Beech 1990 \{published data only\}

Beech A, Powell TJ, McWilliam J, Claridge GS. The effect of a small dose of chlorpromazine on a measure of 'cognitive inhibition'. Personality and Individual Differences 1990;11: $1141-5$.

Benaim 1960 \{published data only\}

Benaim S. The effect of chlorpromazine on the incidence of epileptic phenomena during insulin coma therapy: A statistical investigation. Journal of Mental Science 1960;106: $317-21$.
Bennett 1956 \{published data only\}

Bennett A, Ford F, Turk RE. Clinical investigation of chlorpromazine and reserpine in private psychiatric practice. American Journal of Psychiatry 1956;112:782-7.

Blumberg 1964 \{published data only\} Blumberg AG, Klein DF, Pollack M. Effects of chlorpromazine and imipramine on systolic blood pressure in psychiatric patients: Relationships to age, diagnosis and initial blood pressure. Journal of Psychiatric Research 1964;2 (1):51-60.

Blumberg 1969 \{published data only\} Blumberg AG, Klein DF. Chlorpromazine-procyclidine and imipramine: effects on thyroid function in psychiatric patients. Clinical Pharmacology and Therapeutics 1969;10: $350-4$.

\section{Boullin 1975 \{published data only\}}

Boullin DJ, Woods HF, Grimes RP, Grahame-Smith DG, Wiles D, Gelder MG, et al. Increased platelet aggregation responses to 5-hydroxytryptamine in patients taking chlorpromazine. British Journal of Clinical Pharmacology 1975;2:29-35.

Bowes 1956 \{published data only\} Bowes, HA. The ataractic drugs: the present position of chlorpromazine, frenquel, pacatal, and reserpine in the psychiatric hospital. American Journal of Psychiatry 1956; 113:530-9.

Bressler 1971 \{published data only\}

Bressler B, Friedel RO. A comparison between chlorpromazine and thiothixene in a Veterans Administration Hospital population. Psychosomatics 1971, 12:275-7.

Brizer 1985 \{published data only\} Brizer DA, Hartman N, Sweeney J, Millman RB. Effect of methadone plus neuroleptics on treatment-resistant chronic paranoid schizophrenia. American Journal of Psychiatry 1985;142(9):1106-7.

Burnett 1975 \{published data only\}

Burnett GB, Little SR, Graham N, Forrest AD. The assessment of thiothixene in chronic schizophrenia. A double-blind controlled trial. Diseases of the Nervous System 1975;36:625-9.

Cabrera Gomez 1994 \{published data only\} Cabrera Gomez JA, Cordero Gutierrez JR, Fernandez Lopez O, Reyes Gutierrez B, Romero Garcia K, Simon Consuegra J, et al. Treatment of schizophrenic disorder, paranoid type, with intramuscular recombinant alpha-2b interferon. Biotherapy 1994;7(1):27-37.

Caffey 1963 \{published data only\}

* Caffey E, Forrest I, Frank T, Klett CJ. Phenothiazine excretion in chronic schizophrenics. American Journal of Psychiatry 1963;120:578-82.

Caffey EM, Diamond LS, Frank TV, Grasberger JC, Herman L, Klett CJ, et al. Discontinuation or reduction of chemotherapy in chronic schizophrenics. Journal of Chronic Diseases 1964;17(4):347-58. 
Caffey 1975 \{published data only\}

Caffey EMJ, Prien RF. Practical considerations on treatment with antipsychotic preparations [Prakticheskie soobrazheniia o lechenii antipsikhoticheskimi preparatami]. Zhurnal Nevropatologii i Psikhiatrii 1975;75:1399-401.

\section{Campbell 1972 \{published data only\}}

* Campbell M, Fish B, Shapiro T, Floyd A. Acute responses of schizophrenic children to a sedative and a 'stimulating' neuroleptic: a pharmacologic yardstick. Current Therapeutic Research 1972;14:759-66.

Campbell M, Fish B, Shapiro T, Floyd A. Thiothixene in young disturbed children. A pilot study. Archives of General Psychiatry 1970;23:70-2.

Cardone 1969 \{published data only\}

Cardone S, Olson R. Chlorpromazine and body image. Effects on chronic schizophrenics. Archives of General Psychiatry 1969;20:576-82.

\section{Carrillo 1971 \{published data only\}}

Carrillo C. Pharmacologlal treatment of the emotionally unstable character disorder. Vth World Congress of Psychiatry. Ciudad de Mexico. 1971.

Casey 1960 \{published data only\} Casey JF, Bennet IF, Lindley CJ, Hollister LE, Gordon MH, Springer NN. Drug therapy in schizophrenia. A controlled study of the relative effectiveness of chlorpromazine, promazine, phenobarbital, and placebo. Archives of General Psychiatry 1960;2:210-20.

Casey 1961 \{published data only\}

Casey JF, Hollister LE, Klett CJ, Lasky JJ, Caffey EM. Combined drug therapy of chronic schizophrenics. Controlled evaluation of placebo, dextro-amphetamine, imipramine, isocarboxazid and trifluoperazine added to maintenance doses of chlorpromazine. American Journal of Psychiatry 1961;117:997-1003.

Chacon 1972 \{published data only\}

Chacon C, Harper P. Clinical and work performance variables in phenothiazine therapy of schizophrenia. Acta Psychiatrica Scandinavica 1973;49:65-76.

* Chacon Carlos, Harper P. Harvey GF. Work study in the assessment of the effects of phenothiazines in schizophrenia. Comprehensive Psychiatry 1972;13(6):549-54. MEDLINE: 73051431

Childers 1961 \{published data only\}

Childers RT, Therrien R. A comparison of the effectiveness of triluoperazine and chlorpromazine in schizophrenia. American Journal of Psychiatry 1961;118:552-4.

Chouinard 1977 \{published data only\} Chouinard G, Annable L, Kolivakis TN. Penfluridol in the maintenance treatment of schizophrenic patients newly discharged from a brief therapy unit. Journal of Clinical Pharmacology 1977;17(2-3):162-7. MEDLINE: 77094284

Chouinard-G 1983 \{published data only\}

Chouinard-G, Annable-L. Fluspirilene in the treatment of newly admitted schizophrenic patients. Psychopharmacology Bulletin. 1983;19(1):136-8.
Claghorn 1983 \{published data only\}

Claghorn J, Abuzzahab F, Wang R, Larson C, Gelenberg A, Klerman G, et al. The current status of clozapine. Psychopharmacology Bulletin 1983;19:138-40.

Clark 1970c \{published data only\} Clark ML, Serafetinides EA, Wise JB, Colmore JP. Ocular pigment deposits: drug-induced false-positives. JAMA 1970;214:2339.

Clark 1970d \{published data only\} Clark M, Dubowski K, Colmore J. The effect of chlorpromazine on serum cholesterol in chronic schizophrenic patients. Clinical Pharmacology and Therapeutics 1970;11:883-9.

Clark 1975 \{published data only\} Clark ML, Kaul PN. A preliminary report on clinical response and blood levels of chlorpromazine and its sulfoxide during chlorpromazine therapy in chronic schizophrenic patients. In: Gottschalk LA, Merlis S editor (s). Pharmacokinetics of Psychoactive Drugs. New York: Spectrum Publications, 1976:191-7.

* Clark ML, Kaul PN. A preliminary report on clinical response and blood levels of chlorpromazine and its sulfoxide during chlorpromazine therapy in chronic schizophrenic patients. Psychopharmacology Bulletin 1975; 11:28-30.

Clark ML, Kaul PN, Whitfield LR. Chlorpromazine kinetics and clinical response. Psychopharmacology Bulletin 1978;14:43-5.

Cobb 1956 \{published data only\}

Cobb W. Changes in the electroencephalogram, the electrodermogram, and the electromyogram provoked by chlorpromazine in man. Abstracts of World Medicine 1956; 20:177.

Cole 1967 \{published data only\}

Cole JO, Schooler NR. Differences in clinical effects of three phenothiazines in "acute" schizophrenia. Diseases of the Nervous System 1967;28:369-83.

\section{Coons 1962 \{published data only\}} Coons WH, Boyd BA, White JG. Chlorpromazine, trifluoperazine and placebo with long term mental hospital patients. Canadian Psychiatric Association Journal 1962;7: 159-63. MEDLINE: 62022417

\section{Cowden 1956 \{published data only\}}

Cowden RC, Zax M, Hague JR, Finney RC.

Chlorpromazine: alone and as an adjunct to group psychotherapy in the treatment of psychiatric patients. American Journal of Psychiatry 1956;4:898-902.

Crane 1970 \{published data only\} Crane GE. High doses of trifluperazine and tardive dyskinesia. Archives of Neurology 1970;22(2):176-80. MEDLINE: 70065772

\section{Crane 1971 \{published data only\}}

Crane GE. Persistence of neurological symptoms due to neuroleptic drugs. American Journal of Psychiatry 1971;127: 1407-10. 
Crow 1986 \{published data only\}

* Crow TJ, MacMillan JF, Johnson AL, Johnstone EC. The Northwick Park study of first episodes of schizophrenia. II. A randomised controlled trial of prophylactic neuroleptic treatment. British Journal of Psychiatry 1986;148:120-7. Johnstone EC, Crow TJ, Johnson AL, MacMillan JF. The Northwick Park study of first episodes of schizophrenia. I. Presentation of the illness and problems relating to admission. British Journal of Psychiatry 1986;148:115-20. MacMillan JF, Crow TJ, Johnson AL, Johnstone EC. The Northwick Park study of first episodes of schizophrenia. III. Short-term outcome in trial entrants and trial eligible patients. British Journal of Psychiatry 1986;148:128-33.

Curry 1972 \{published data only\} Curry SH, Adamson L. Double-blind trial of fluphenazine decanoate. Lancet 1972;2:543-4.

Cutler 1957 \{published data only\}

Cutler RP, Monroe JJ, Anderson TE. Effects of "tranquilizers" upon pathological activity in psychotic patients: II. Reserpine. Archives of Neurology and Psychiatry 1957;78:61-8.

Dally 1966 \{published data only\} Dally P, Sargant W. Treatment and outcome of anorexia nervosa. British Medical Journal 1966;2:793-5.

Danion 1992 \{published data only\} Danion JM, Peretti S, Grange D, Bilik M, Imbs JL, Singer L. Effects of chlorpromazine and lorazepam on explicit memory, repetition priming and cognitive skill learning in healthy volunteers. Psychopharmacology 1992;108(3): 345-51. MEDLINE: 92396807

Daston 1958 \{published data only\}

Daston PG. Stylus maze performance of chronic schizophrenics taking chlorpromazine. Journal of Consulting Psychology 1958;22(5):384.

Daston 1959 \{published data only\}

Daston PG. Effects of two phenothiazine drugs on concentrative attention span of chronic schizophrenics. Journal of Clinical Psychology 1959;15:106-9.

Davies 1973 \{published data only\}

Davies AL, O'Leary J. The use of chlorpromazine in schizophrenia. Nursing Times 1973;69:1694-5.

Dean 1967 \{published data only\}

Dean G. Mefenamic acid and chlorpromazine in porphyria variegata. South African Medical Journal 1967;41:925-7.

Denber 1955 \{published data only\}

Denber HCB, Merlis S. Studies on Mescaline. VI.

Therapeutic Aspects of the Mescaline-Chlorpromazine Combination. Journal of Nervous and Mental Diseases 1955; 122:463.

Denber 1956 \{published data only\}

Denber H, Bird EG. Chlorpromazine in the treatment of mental illness. III. The problem of depression. American Journal of Psychiatry 1956;112:1021.
Denber 1957 \{published data only\}

Denber HCB. Chlorpromazine-diethazine in the treatment of depression. Diseases of the Nervous System 1957;18:76-9.

Den Boer 2000 \{published data only\} Den Boer JA, Vahlne JO, Post P, Heck AH, Daubenton F, Olbrich R. Ritanserin as add on medication to neuroleptic therapy for patients with chronic or subchronic schizophrenia. Human Psychopharmacology 2000;15(3): 179-89.

Desager 1988 \{published data only\} Desager JP, Hulhoven R, Harvengt C, Hermann P, Guillet P, Thiercelin JF. Possible interactions between zolpidem, a new sleep inducer and chlorpromazine, a phenothiazine neuroleptic. Psychopharmacology Berlin 1988;96:63-6.

Douglas 1969 \{published data only\} Douglas KW, Hindley JP. A comparison of mesoridazine and chlorpromazine in chronic psychiatric patients. Journal of Clinical Pharmacology and The Journal of New Drugs 1969;9:176-82.

Downing 1963 \{published data only\} Downing RW, Ebert JN, Shubrooks SJ. Effect of phenothiazines on the thinking of acute schizophrenics. Perceptual and Motor Skills 1963;17(2):511-20.

Dube 1981 \{published data only\} Dube S, Sethi B. Efficacy of lithium in schizophrenia. Indian Journal of Psychiatry 1981;23(2):193-9.

Eitan 1991 \{published data only\} Eitan N, Levin Y, Ben-Artzi E, Levy A, Neumann M. Effects of antipsychotic drugs on memory functions of schizophrenic patients. Acta Psychiatrica Scandinavica 1992; 85:74-6.

Ekdawi 1966 \{published data only\} Ekdawi MY, Fowke R. A controlled trial of anti-parkinson drugs in drug-induced parkinsonism. British Journal of Psychiatry 1966;112(487):633-6.

Elkes $1954\{$ \{published data only\}

Elkes J, Elkes C. Effect of chlorpromazine on the behaviour of chronically overactive psychotic patients. British Medical Journal 1954;2:560-5.

Feldman 1956 \{published data only\} Feldman PE, Lacy BS, Walker AE, Garrez NJ. A controlled, blind study of effects of thorazine on psychotic behavior. Bulletin of the Menninger Clinic 1956;20:25-47.

Fink 1958 \{published data only\} Fink M, Shaw R, Gross GE, Coleman FS. Comparative study of chlorpromazine and insulin coma in therapy of psychosis. Journal of the American Medical Association 1958; 166(15):1846-50.

Fink 1965 \{published data only\} Fink M, Klein DF, Kramer JC. Clinical efficacy of chlorpromazine-procyclidine combination, imipramine and placebo in depressive disorders. Psychopharmacologia 1965; 7:27-36. 
Fleischhacker 1995 \{published data only\}

Fleischhacker W. Broadening treatment perspectives of schizophrenia: a clinical update on seroquel. 8th Congress of the European College of Neuropsychopharmacology; 1995 Sep 30 - Oct 4; Venice, Italy. 1995.

Fleming 1958 \{published data only\}

Fleming B, Currie J. Investigation of a new compound, B.W.203, and of Chlorpromazine in the treatment of psychosis. British Journal of Psychiatry 1958;104:749-57.

Foote 1958 \{published data only\}

Foote E. Combined Chlorpromazine and Reserpine in the treatment of chronic psychotics. British Journal of Psychiatry 1958;104:201-5.

Forrest 1967 \{published data only\}

Forrest GL, Bortner TW, Bakker CB. The role of personality variables in response to chlorpromazine, dextroamphetamine and placebo. Journal of Psychiatric Research 1967;5:281-8.

Freed 1956 \{published data only\}

Freed H, Peifer CA. Treatment of hyperkinetic emotionally disturbed children with prolonged administration of chlorpromazine. American Journal of Psychiatry 1956;113: 22.

Freedman 1965 \{published data only\}

Freedman N, Engelhardt D, Mann D, Margolis R, London $S$. Communication of body complaints and paranoid symptom change under conditions of phenothiazine treatment. Journal of Personality and Social Psychology 1965; 1(4):310-8.

Freeman 1956 \{published data only\}

Freeman H, Arnold AL, Cline HS. Effects of chlorpromazine and reserpine in chronic schizophrenic patients. Diseases of the Nervous System 1956;17:213-9.

Freeman H, Cline HS. Effects of chlorpromazine on chronic lobotomized schizophrenic patients. A.M.A. Archives of Neurology and Psychiatry 1956;76:500-7.

Freeman 1973 \{published data only\}

Freeman H. A double blind comparison of mesoridazine and chlorpromazine in chronic schizophrenics. Diseases of the Nervous System 1973;34(6):289-93. MEDLINE: 74114021

Friedhoff 1960 \{published data only\} Friedhoff A, Alpert M. The effect of chlorpromazine on the variability of motor task performance in schizophrenics. Journal of Nervous and Mental Disease 1960;131:110-6.

Fromm 1956 \{published data only\}

Fromm GH, Forsberg IA. Controlled study on the value of chlorpromazine in allaying anxiety. Diseases of the Nervous System 1956;17:16-9.

Gaitz 1955 \{published data only\}

Gaitz CM, Roy H, Thompson W, Kimbell I, Mullen AJ, Pokorny AD. Evaluation of Chlorpromazine in Comparison with other Methods of treatments of hospitalized psychiatric patients, using the lorr multidimensional scale for rating psychiatric patients. Psychiatric Research Reports 1955;1: 1984.
Galbrecht 1968 \{published data only\}

Galbrecht CR, Klett CJ. Predicting response to phenothiazines: the right drug for the right patient. Journal of Nervous and Mental Disease 1968;147:173-83.

Galdi 1988 \{published data only\}

Galdi J, Bonato RR. Relationship of adverse drug reactions to length of hospital-stay in genetically subgrouped schizophrenics. Canadian Journal of Psychiatry 1988;33: 816-8.

\section{Gallant 1963 \{published data only\}} Gallant D, Bishop M, Steele C, Noblin CD. The relationship between serotonin antagonism and tranquilizing activity. American Journal of Psychiatry 1963;119:882.

\section{Gallant 1967 \{published data only\}} Gallant DM, Bishop MP, O’Meallie L. BL-KR140: a controlled evaluation in chronic schizophrenic patients previously stabilized on chlorpromazine. Current Therapeutic Research 1967;9:447-50.

\section{Gardner 1955 \{published data only\}}

Gardner MJ, Hawkins HM, Judah LN, Murphree OD Objective measurement of psychiatric changes produced by chlorpromazine and reserpine in chronic schizophrenia. Psychiatric Research Reports 1955;1:77-83.

\section{Gardos 1968 \{published data only\}} Gardos G, Rapkin RM, DiMascio A. Trifluoperazine and chlorpromazine in combination and individually. Current Therapeutic Research Clinical and Experimental 1968;10 (12):609-12. MEDLINE: 69054114

\section{Gardos 1976 \{published data only\}}

Gardos G, Cole J O. Maintenance antipsychotic therapy: is the cure worse than the disease?. American Journal of Psychiatry 1976;133:32-6.

Garfield 1962 \{published data only\} Garfield SL, Helper MM, Wilcott RC, Muffly R. Effects of chlorpromazine on behaviour in emotionally disturbed children. Journal of Nervous and Mental Diseases 1962;135: 147-54.

Garmezy 1969 \{published data only\} Garmezy N. Effects of censure and chlorpromazine on visual discrimination behavior of schizophrenic and alcoholic patients. Proceedings of the Annual Convention of the American Psychological Association 1969;4(2):491-2.

Gauthier 1967 \{published data only\} Gauthier R, Hillel J, Bordeleau JM, Tetreault L. Comparative study of trifluperidol and trifluoperazine in the treatment of acute schizophrenia. Union Medicale $d u$ Canada 1967;96:936-43.

Gendron 1973 \{published data only\} Gendron JL, Zimmermann RL, Schiele BC. A double blind comparison of AL 1021 and chlorpromazine in hospitalized schizophrenics. Current Therapeutic Research 1973;15(6): 333-6.

Chlorpromazine versus placebo for schizophrenia (Review)

Copyright $(2015$ The Cochrane Collaboration. Published by John Wiley \& Sons, Ltd. 
Gibbs 1956 \{published data only\}

Gibbs JJ, Wilkens B, Lauterbach CG. A controlled clinical psychiatric study of chlorpromazine. Journal of Clinical and Experimental Psychopathology 1957;18:269-83.

* Gibbs JJ, Wilkens B, Lauterbach CG. A controlled clinical psychiatric study of the drug chlorpromazine. American Journal of Psychiatry 1956;113:254-5.

Gilgash 1957 \{published data only\}

Gilgash CA. Effects of Thorazine on Wechsler scores of adult catatonic schizophrenics. Psychological Reports 1957;3: $561-4$.

Goldberg 1968 \{published data only\} Goldberg SC, Mattsson NB. Schizophrenic subtypes defined by response to drugs and placebo. Diseases of the Nervous System 1968;29(5):S153-8. MEDLINE: 68399894

Goldberg 1970 \{published data only\} Goldberg GJ, Brooke G, Townsend HR, Brahma RK, Hill GB. A comparison of oxypertine and chlorpromazine in chronic schizophrenia. Acta Psychiatrica Scandinavica 1970; 46(2):126-35. MEDLINE: 71030938

Goldberg 1972 \{published data only\} Goldberg S, Frosch W, Drossman A, Schooler N, Johnson G. Prediction of response to phenothiazines in schizophrenia. A crossvalidation study. Archives of General Psychiatry 1972;26:367-73.

Goldman 1955 \{published data only\} Goldman D. Treatment of psychotic states with chlorpromazine. Journal of the American Medical Association 1955;157:1274-8.

Good 1958 \{published data only\}

* Good WW, Sterling M, Holtzman WH. Termination of chlorpromazine with schizophrenic patients. American Journal of Psychiatry 1958;115:443-8.

Mefferd RB, Labrosse EH, Gawienowski AM, Williams RJ. Influence of chlorpromazine on certain biochemical variables of chronic male schizophrenics. Journal of Nervous and Mental Diseases 1958;127:167-79.

Goodwin-Austin 1971 \{published data only\} Godwin-Austen RB, Clark T. Persistent phenothiazine dyskinesia treated with tetrabenazine. British Medical Journal 1971;4(778):25-6.

Goyne 1958 \{published data only\}

Goyne J B, Groebner E, Pueblita M. Clinical Research - Vesperin-Chlorpromazine Therapy. Scientific Papers of the 114th Annual Meeting of the American Psychiatric Association. 1958:104-5.

Graupner 1972 \{published data only\}

Graupner OK, Kalman EV. Effects of various drugs on flicker fusion frequency. II. Phenothiazine derivatives (with reference to the dependence of the results on the chronological course of experiments [Die FlimmerVerschmelzung-Frequenz unter dem Einfluss verschiedener Pharmaka. II. Phenothiazinderivate (mit einem Hinweis auf die Abhangigkeit der Ergebnisse vom zeitlichen Verlauf der Versuche)]. Psychopharmacologia 1972;27(4):343-7. MEDLINE: 73085373
Green 1996 \{published data only\}

Green JF, McElholm A, King DJ. A comparison of the sedative and amnestic effects of chlorpromazine and lorazepam. Psychopharmacology 1996;128(1):67-73.

\section{Green 1998 \{published data only\}}

Green JF, King DJ. Antisaccade and no-saccade distractibilty with chlorpromazine and lorazepam. Schizophrenia Research 1998;29(1,2):117.

Greenberg 1966 \{published data only\} Greenberg LM, Roth S. Differential effects of abrupt versus gradual withdrawal of chlorpromazine in hospitalized chronic schizophrenic patients. American Journal of Psychiatry 1966;123:221-6.

Griffiths 1979 \{published data only\} Griffiths RR, Bigelow G, Liebson I. Human drug selfadministration: double-blind comparison of pentobarbital, diazepam, chlorpromazine and placebo. Journal of Pharmacology and Experimental Therapeutics 1979;210: 301-10.

Guy 1978 \{published data only\}

Guy W, Petrie W, Cleary P. The incidence of treatment emergent symptoms under chlorpromazine and placebo conditions. Psychopharmacology Bulletin 1978;14:22-4.

Hammond 1978 \{published data only\} Hammond NV, Gruzelier JH. Laterality, attention and rate effects in the auditory temporal discrimination of chronic schizophrenics - the effect of treatment with chlorpromazine. Quarterly Journal of Experimental Psychology 1978;30:91-103.

Hamner 1996 \{published data only\} Hamner MB, Arvanitis LA, Miller BG, Link CGG, Hong WW. Plasma prolactin in schizophrenia subjects treated with seroquel (TM) (ICI 204,636). Psychopharmacology Bulletin 1996;32(1):107-10. MEDLINE: 96267998

\section{Hankoff 1960 \{published data only\}}

Hankoff L, Engelhardt D, Freedman N, Mann D, Margolis R. Denial of illness in schizophrenic outpatients: effects of psychopharmacological treatment. Archives of General Psychiatry 1960;3:657-64.

\section{Hanlon 1958 \{published data only\}} Hanlon TE, Kurland AA, Esquibel AJ, Ota KY. A comparative study of chlorpromazine and triflupromazine in the management of the chronic hospitalized psychotic patient. Journal of Nervous and Mental Diseases 1958;127: $17-20$.

Hanlon 1960 \{published data only\} Hanlon TE, Wiener G, Kurland AA. The psychiatric physician and the phenothiazine tranquilizers. Journal of Nervous and Mental Diseases 1960;130:67-71.

Harper 1976 \{published data only\} Harper P, Chacon C. Work performance versus clinical assessment in the evaluation of phenothiazine therapy. British Journal of Clinical Pharmacology 1976;3:50-5. 
Hartley 1978 \{published data only\}

Hartley L, Henry T, Couper-Smartt J. Chlorpromazine and serial reaction performance. British Journal of Psychology 1978;69:271-6.

Hartley 1987 \{published data only\} Hartley LR, Coxon L, Spencer J. Pharmacological effects on lateralized behavior. Current Psychology Research and Reviews 1987;6:301-12.

Hartley 1989 \{published data only\} Hartley LR, Strother N, Arnold PK, Mulligan B. Lateralization of emotional expression under a neuroleptic drug. Physiology and Behavior 1989;45:917-21.

Hartley 1991 \{published data only\} Hartley LR, Ireland LK, Arnold PK, Spencer J. Chlorpromazine and the lateralisation of the perception of emotion. Physiology and Behavior 1991;50:881-5.

Hartmann 1973 \{published data only\}

Hartmann E, Cravens J. The effects of long term administration of psychotrophic drugs on human sleep. IV. The effects of chlorpromazine. Psychopharmacologia 1973; 33:203-18.

Haskell 1974 \{published data only\} Haskell DS, McNair DM, Fisher S, Kahn RJ. A controlled outpatient trial of perphenazine-amitriptyline and chlorpromazine. Journal of Clinical Pharmacology 1974;14: 536- 42.

Heilizer 1959 \{published data only\}

${ }^{*}$ Heilizer F. The effects of chlorpromazine upon psychomotor and psychiatric behavior of chronic schizophrenic patients. Journal of Nervous and Mental Disease 1959;128:358-64.

Planansky K, Heilizer F. Weight changes in relation to the characteristics of patients on chlorpromazine. Journal of Clinical and Experimental Psychopathology 1959;20:53-7.

Hekimian 1967 \{published data only\}

Hekimian LJ, Friedhoff AJ. A controlled study of placebo, chlordiazepoxide and chlorpromazine with thirty male schizophrenic patients. Diseases of the Nervous System 1967; 28:675-8

\section{Herrera 1988 \{published data only\}}

Herrera JN, Sramek JJ, Costa JF, Roy S. High potency neuroleptics and violence in schizophrenics. Journal of Nervous and Mental Disease 1988;176(9):558-61.

Herrmann 1991a \{published data only\} Herrmann WM, Scharer E, Delini-Stula A. Predictive value of pharmaco electroencephalography in early human pharmacological evaluations of psychoactive drugs - first example - Savoxepine. Pharmacopsychiatry 1991;24: 196-205.

Herrmann 1991b \{published data only\} Herrmann WM, Scharer E, Wendt G, Delini-Stula A. Pharmaco EEG profile of maroxepine - third example to discuss the predictive value of pharmaco electroencephalography in early human pharmacological evaluations of psychoactive drugs. Pharmacopsychiatry 1991;24:214-24.
Herz 1991 \{published data only\}

Herz M, Glazer W, Mostert M, Sheard M, Szymanski H, Hafez $\mathrm{H}$, et al. Intermittent versus maintenance medication in schizophrenia. Two-year results. Archives of General Psychiatry 1991;48:333-9.

Hoffer 1975 \{published data only\}

Hoffer J. Megavitamin treatment of schizophrenia.

Canadian Psychiatric Association Journal 1975;20:492-5.

Hogarty 1976 \{published data only\}

Hogarty GE, Ulrich RF, Mussare F, Aristigueta N. Drug discontinuation among long term, successfully maintained schizophrenic outpatients. Diseases of the Nervous System 1976;37:494-500.

Hollis 1968 \{published data only\} Hollis JH. Chlorpromazine: direct measurement of differential behavioral effect. Science 1968;159:1487-9.

Hollister 1955 \{published data only\}

* Hollister LE, Jones KP, Brownfield B, Johnson F. Chlorpromazine alone and with reserpine. California Medicine 1955;83:218-21.

Hollister LE, Traub L, Beckman WG. Psychiatric use of reserpine and chlorpromazine: results of double-blind studies. In: Kline NS editor(s). Psychopharmacology. Washington DC: AAAS, 1956:65-74. [Publication Number 42]

\section{Holt 1984 \{published data only\}} Holt RJ. Neuroleptic drug-induced changes in platelet levels. Journal of Clinical Psychopharmacology 1984;4:130-2.

Hong 1996a \{published data only\}

Hong W, Arvanitis L. Reduction of the positive symptoms of schizophrenia by '(ICI 204,636): results from phase II and III clinical trials. 9th Congress of the European College of Neuropsychopharmacology; 1996 Sep 2125; Amsterdam, The Netherlands. 1996. MEDLINE: 78179482

Hong 1996b \{published data only\} Hong WW, Arvanitis LA. The atypical profile of '(ICI 204, 636) is supported by the lack of sustained elevation of plasma prolactin in schizophrenic patients. 9th Congress of the European College of Neuropsychopharmacology; 1996 Sep 21-25; Amsterdam, The Netherlands. 1996. MEDLINE: 68399894

Hopkin 1954 \{published data only\} Hopkin DA. Action of chlorpromazine and promethazine. British Medical Journal 1954;1:1036.

Hrushka 1966 \{published data only\} Hrushka M, Bruck M, Hsu JJ. Therapeutic effects of different modes of chlorpromazine administration. Diseases of the Nervous System 1966;27:522-7.

Huang 1967 \{published data only\} Huang CL, Hirano K. The effect of antipyretic analgesics on the metabolism of chlorpromazine in man. Biochemical Pharmacology 1967;16:2023-6. 
Hughes 1967 \{published data only\}

Hughes JS, Little JC. An appraisal of the continuing practice of prescribing tranquillizing drugs for long-stay psychiatric patients. British Journal of Psychiatry 1967;113:867-73.

Hurst 1960 \{published data only\}

Hurst L. Chlorpromazine and Pecazine in chronic schizophrenia. Journal of Mental Science (British Journal of Psychiatry from 1963) 1960;106:726-31.

Hurst 1996 \{published data only\}

Hurst BC, Link C. A comparison of the tolerance profile of seroquel with typical neuroleptics and placebo. Xth World Congress of Psychiatry. Madrid, Spain. Madrid, Spain, August 23-28, 1996.

Hussar 1969 \{published data only\}

Hussar AE, Bragg DG. The effect of chlorpromazine on the swallowing function in chronic schizophrenic patients. American Journal of Psychiatry 1969;126:570-3.

IRCT138811022935N32010 \{published data only\} IRCT138811022935N3. The effect of omega-3 on negative and positive symptoms in patients with chronic schizophrenia: A DOUBLE BLIND and PLACEBO controlled trial. http://www.irct.ir/ 2010.

Itil 1968 \{published data only\}

Itil T, Shapiro D, Fink M. Differentiation of psychotropic drugs by quantitative EEG analysis. Agressologie 1968;9: 267-80.

Itil 1971 \{published data only\} Itil TM, Ulett GA, Fukuda T. Quantitative pharmacoelectroencephalography in early evaluation of psychotropic drugs. Folia Psychiatrica et Neurologica Japonica 1971;25: 195-202.

Jia 2004 \{published data only\}

Jia H, Tang Y, Jiang Z. Clinical observation of the treatment of cognitive impairment in schizophrenia by the TCM therapy of enforcing spleen and nourishing kidney. Journal of Beijing University of TCM 2004;27(5):80-3.

Johnstone 1978 \{published data only\} Johnstone EC, Crow TJ, Frith CD, Carney MW, Price JS. Mechanism of the antipsychotic effect in the treatment of acute schizophrenia. Lancet 1978;1(8069):848-51. MEDLINE: 78155245

Jones 1969 \{published data only\} Jones IH. Drugs and motor activity in chronic schizophrenia. British Journal of Psychiatry 1969;115:851-6.

Jones 1971 \{published data only\}

Jones IH, Pikler N. Effects of chlorpromazine and trifluoperazine on the activity of chronic schizophrenics. British Journal of Psychiatry 1971;119:545-6.

Joseph 1979 \{published data only\}

Joseph MH, Baker HF, Johnstone EC, Crow TJ. 3Methoxy-4-hydroxyphenylglycol excretion in acutely schizophrenic patients during a controlled clinical trial of the isomers of flupenthixol. Psychopharmacology 1979;64 (1):35-40. MEDLINE: 80013695
Joshi 1980 \{published data only\}

Joshi VG, Nagesh R, Eswaran S, Nagesh R, Pai M, Mathews G, et al. Vitamins B1, B6, and B12 in the adjunctive treatment of schizophrenia - further studies to examine the effect of reduction of chlorpromazine dosage. Journal of Orthomolecular Psychiatry 1980;11:45-9.

Kabes 1982 \{published data only\}

Kabes J, Sikora J, Pisvejc J. Effect of piracetam on extrapyramidal side effects induced by neuroleptic drugs. International Pharmacopsychiatry 1982;17(3):185-92. MEDLINE: 83056096

Kammerer 1968 \{published data only\} Kammerer M, Wartel R, Gurfein L, Weil J, Wysoki V, Gelb F. Clinical experimentation with desipramine with statistical control [Experimentation clinique de la desipramine avec controle statistique]. Annales Medico-psychologiques 1968;1: 109-13.

Kaplan 1974 \{published data only\}

Kaplan J, Dawson S, Vaughan T, Green R, Wyatt RJ. Effect of prolonged chlorpromazine administration on the sleep of chronic schizophrenics. Archives of General Psychiatry 1974; 31:62-6.

Keskiner 1970 \{published data only\} Keskiner A, Itil TM, Todt N. A comparative study of butaperazine, chlorpromazine and placebo in chronic schizophrenics. Psychosomatics 1970;11:120-6.

Kim 1960 \{published data only\}

Kim K. Responses to treatment-refractory chronic schizophrenics to chlorpromazine with concurrent adrenocortical steroid. American Journal of Psychiatry 1960; 116:1023-4.

Kimbell 1971 \{published data only\} Kimbell I Jr, Winkelman GW, Hughes WM. Comparison of thioridazine and chlorpromazine in doctor's choice research design. Clinical Pharmacology and Therapeutics 1971;12:825-32.

King 1959 \{published data only\} King PD, Weinberger W. Comparison of proclorperazine and chlorpromazine in hospitalized chronic schizophrenics. American Journal of Psychiatry 1959;115:1026-7. MEDLINE: 69202908

King 1994 \{published data only\}

King DJ. Psychomotor impairment and cognitive disturbances induced by neuroleptics. Acta Psychiatrica Scandinavica Supplementum 1994;89(380):53-8.

Klein 1974 \{published data only\}

Klein RH, Lynn EJ, Axelrod H, Dluhy J. Self-administration of medication by psychiatric inpatients. Journal of Nervous and Mental Disease 1974;158:450-5.

Kopell 1968 \{published data only\} Kopell BS, Wittner WK. The effects of chlorpromazine and methamphetamine on visual signal-from-noise detection. Journal of Nervous and Mental Disease 1968;147:418-24.

Kordas 1968 \{published data only\}

Kordas S, Kazamias N, Georgas J, Papadokostakis J. Clopenthixol: a controlled trial in chronic hospitalised 
schizophrenic patients. British Journal of Psychiatry 1968; 114:833-6.

\section{Kornetsky 1957 \{published data only\}}

Kornetsky C, Humphries O. Relationship between effects of a number of centrally acting drugs and personality. Archives of Neurology and Psychiatry 1957;77:325-7.

Kornetsky C, Humphries O, Evarts EV. Comparison of psychological effects of certain centrally acting drugs in man. Archives of Neurology and Psychiatry 1957;77:318-24. Primac DW, Mirsky AF, Rosvold HE. Effects of centrally acting drugs on two tests of brain damage. Archives of Neurology and Psychiatry 1957;77:328-32.

Kornetsky 1958 \{published data only\}

* Kornetsky C, Humphries O. Psychological effects of centrally acting drugs in man. Journal of Mental Science 1958;104:1093-9.

Mirsky AF, Primac DW, Bates R. The effects of chlorpromazine and secobarbital on the C.P.T. Journal of Nervous and Mental Diseases 1959;128:12-7.

Kornetsky 1959 \{published data only\}

Kornetsky C, Pettit M, Wynne R, Evarts EV. A comparison of the psychological effects of acute and chronic administration of chlorpromazine and secobarbital (quinalbarbitone) in schizophrenic patients. Journal of Mental Science 1959;105:190-8.

Korol 1965 \{published data only\}

Korol B, Lang WJ, Brown ML, Gershon S. Effects of chronic chlorpromazine administration on systemic arterial pressure in schizophrenic patients: relationship of body position to blood pressure. Clinical Pharmacology and Therapeutics 1965;6:587-91.

Kovitz 1955 \{published data only\}

Kovitz B, Carter JT, Addison WP. A comparison of chlorpromazine and reserpine in chronic psychosis. Archives of Neurology and Psychiatry 1955;74:467-71.

Kramer 1975 \{published data only\} Kramer M, Roth T, Goldstein S, Ryan MS, Blackwell B. A double-blind evaluation of metiapine in hospitalized acute schizophrenics. Current Therapeutic Research 1975; 18:839-48.

Kugler 1980 \{published data only\} Kugler BT, Gruzelier JH. The influence of chlorpromazine and amylobarbitone on the recovery limb of the electrodermal response. Psychiatry Research 1980;2:75-84.

Kupfer 1971 \{published data only\} Kupfer DJ, Wyatt RJ, Synder F, Davis JM. Chlorpromazine and sleep in psychiatric patients. Archives of General Psychiatry 1971;24:185-9.

Kurland 1981 \{published data only\} Kurland AA, Nagaraju A. Viloxazine and the depressed schizophrenic - methodological issues. Journal of Clinical Pharmacology 1981;21(1):37-41. MEDLINE: 81168674

Lampe 1969 \{published data only\}

Lampe WT. A double blind study of clomacran. Current Therapeutic Research 1969;11:300-6.
Latz 1965 \{published data only\}

Latz A, Kornetsky C. The effects of chlorpromazine and secobarbital under two conditions of reinforcement on the performance of chronic schizophrenic subjects. Psychopharmacologia 1965;7:77-88.

Laurian 1981 \{published data only\} Laurian S, Le PK, Baumann P, Perey M, Gaillard JM. Relationship between plasma-levels of chlorpromazine and effects on EEG and evoked potentials in healthy volunteers. Pharmacopsychiatria 1981;14:199-204.

\section{Leff 1971 \{published data only\}}

Leff JP. Influence of selection of patients on results of clinical trials. British Medical Journal 1973;4:156-8.

* Leff JP, Wing JK. Trial of maintenance therapy in schizophrenia. British Medical Journal 1971;3:599-604.

Leszek 1991 \{published data only\}

Leszek J, Inglot AD, Cantell K, Wasik A. Natural human leukocyte interferon in the treatment of schizophrenia. European Journal of Psychiatry 1991;5(1):55-63.

\section{Levin 1959 \{published data only\}}

Levin ML. A comparison of the effects of phenobarbital, promethazine, chlorpromazine, and placebo upon mental hospital patients. Journal of Consulting Psychology 1959;23: $167-70$.

Levine 1997 \{published data only\}

Levine J, Caspi N, Laufer N. Immediate effects of chlorpromazine and perphenazine following neuroleptic washout on word association of schizophrenic patients. Schizophrenia Research 1997;26(1):55-63. MEDLINE: 98017426

Levita 1961 \{published data only\}

Levita E. Effects of chlorpromazine and promazine on perseveration. Journal of General Psychology 1961;65:181-7.

Lewis 1973 \{published data only\}

Lewis PJ, James NM. Haloperidol and chlorpromazine - a double-blind cross-over trial and clinical study in children and adolescents. Australian and New Zealand Journal of Psychiatry 1973;7:59-65.

Li 2006 \{published data only\} Li H-F, Xie S-P, Li M, Zhang M-L, Li J, Su B-H, et al. Ziprasidone in treatment of schizophrenia: a double blind, randomized, controlled, parallel group, and multicenter study

[齐拉西酮治疗精神分裂症的随机、双盲、双模拟、多中心研究]. Chinese Journal of New Drugs and Clinical Remedies

[中国 新药与临床杂志] 2006;25(10):747-52.

Liberman 1973 \{published data only\} Liberman RP, Davis J, Moon W, Moore J. Research design for analyzing drug-environment-behavior interactions. Journal of Nervous and Mental Diseases 1973;156:432-9.

Little 1958 \{published data only\} Little JC. A double-blind controlled comparison of the effects of Chlorpromazine, Barbiturate and a placebo in 142 chronic psychotic in-patients. British Journal of Psychiatry 1958;4:334-49. 
Loranger 1968 \{published data only\}

Loranger AW. Treatment of acute mental disorders with an adrenal steroid. British Journal of Psychiatry 1968;114: $843-4$.

Lorr 1961 \{published data only\}

Lorr M, McNair DM, Weinstein GJ, Michaux WW, Raskin A. Meprobamate and chlorpromazine in psychotherapy. Some effects on anxiety and hostility of outpatients. Archives of General Psychiatry 1961;4:381-9.

Lyberi 1956 \{published data only\} Lyberi G, Last SL. The use of chlorpromazine as an activating agent. Electroencephalography and Clinical Neurophysiology 1956;8:71-2.

Maculans 1964 \{published data only\} Maculans GA. Comparison of diazepam, chlorprothixine and chlorpromazine in chronic schizophrenic patients. Diseases of the Nervous System 1964;25:164-8.

Mahal 1976 \{published data only\}

Mahal AS, Ramu NG, Chaturvedi DD. Double blind controlled study of brahmyadiyoga and tagara in the management of various types of unmada (schizophrenia). Indian Journal of Psychiatry 1976;18(4):283-92.

Majewski 1968 \{published data only\}

Majewski J, Stempurska K. Results of treatment of schizophrenic psychoses with neuroleptics combined with subcomatic insulin [Wyniki leczenia psychoz schizofrenicznych neuroleptykami skojarzonymi z insulina podspiaczkowa]. Psychiatria Polska 1968;2(1):37-42. MEDLINE: 68366839

Marjerrison 1969 \{published data only\} Marjerrison G, Keogh RP. Integrated EEG variability drug effects in acute schizophrenics. Canadian Psychiatric Association Journal 1969;14:403-5.

Marrazzi 1972 \{published data only\}

Marrazzi AS, Woodruff S, Kennedy D. Perceptual challenge to measure illness and therapy. American Journal of Psychiatry 1972;128:886-90.

Mason-Browne 1957 \{published data only\} Mason-Browne NL. Perphenazine - a drug modifying consciousness. American Journal of Psychiatry 1957;114: $173-4$.

Mason-Browne NL, Borthwick JW. Effect of perphenazine (Trilafon) on modification of crude consciousness. Diseases of the Nervous System 1957;18:300-6.

Mathur 1981 \{published data only\}

Mathur S, Hall JN. Phenothiazine withdrawal in schizophrenics in a hostel (letter). British Journal of Psychiatry 1981;138:271-2.

Mattila 1994 \{published data only\}

Mattila MJ, Vanakoski J, Mattila Evenden ME, Karonen SL. Suriclone enhances the actions of chlorpromazine on human psychomotor performance but not on memory or plasma prolactin in healthy subjects. European Journal of Clinical Pharmacology 1994;46:215-20.
McClelland 1990 \{published data only\}

McClelland GR, Cooper SM, Pilgrim AJ. A comparison of the central nervous system effects of haloperidol, chlorpromazine and sulpiride in normal volunteers. British Journal of Clinical Pharmacology 1990;30:795-803.

Melnyk 1966 \{published data only\} Melnyk WT, Worthington AG, Laverty SG. Abrupt withdrawal of chlorpromazine and thioridazine from schizophrenic in-patients. Canadian Psychiatric Association Journal 1966;11(5):410-3.

Merry 1957 \{published data only\} Merry J, Pargiter MB, Munro H. Chlorpromazine and chronic neurotic tension. American Journal of Psychiatry 1957;113:988-90.

\section{Michaux 1966 \{published data only\}}

Kurland AA, Bethon GD, Michaux MH, Agallianos DD. Chlorpromazine-chlordiazepoxide and chlorpromazineimipramine treatment: side effects and clinical laboratory findings. Journal of New Drugs 1966;6:80-95.

* Michaux MH, Kurland AA, Agallianos DD. Chlorpromazine-chlordiazepoxide and chlorpromazineimipramine treatment of newly hospitalized, acutely ill psychiatric patients. Current Therapeutic Research, Clinical and Experimental 1966;8(supplement):117-52.

Millar 1963 \{published data only\} Millar J. A trial of fluphenazine in schizophrenia. British Journal of Psychiatry 1963;109:428-32. MEDLINE: 74100099

Milne 1960 \{published data only\} Milne H, Fowler DB. A clinical trial of Largactil (chlorpromazine), Stemeticl (prochlorperazine) and Veractil (methotrimeprazine). British Journal of Psychiatry 1960; 106:1105-10.

Milstein 1994 \{published data only\} Milstein V, Small JG, Brecher M, Kellams JJ, Small IF. Pharmaco-eeg studies of single doses of an atypical neuroleptic iloperidone, compared with chlorpromazine and PLACEBO in schizophrenic-patients. Biological Psychiatry 1994:35(9):671-.

Milton 1978 \{published data only\} Milton F, Patwa VK, Hafner RJ. Confrontation versus belief modification in persistently deluded patients. British Journal of Medical Psychology 1978;51:127-30.

Mitchell 1956 \{published data only\} Mitchell P. Chlorpromazine in the treatment of the chronic disturbed schizophrenic patient. British Journal of Psychiatry 1956;102:151-4.

Mitchell 1960 \{published data only\} Mitchell LE, Zax M. Psychological response to chlorpromazine in a group of psychiatric patients. Journal of Clinical Psychology 1960;16:440-2.

Monteleone 1999 \{published data only\} Monteleone P, Tortorella A, Borriello R, Cassandro P, Maj $M$. Prolactin hyperresponsiveness to $\mathrm{D}$ fenfluramine in drug free schizophrenic patients: a placebo controlled study. 
Biological Psychiatry 1999;45(12):1606-11. MEDLINE: 99304410

Morgenstern 1960 \{published data only\}

Morgenstern FV, Funk IC, Holt WL. Comparative short-term evaluation of triflupromazine hydrochloride, chlorpromazine hyrochloride, and placebo in acutely disturbed patients. New York State Journal of Medicine 1960; 60:254-8.

Morton 1968 \{published data only\}

Morton MR. A study of the withdrawal of chlorpromazine or trifluoperazine in chronic schizophrenia. American Journal of Psychiatry 1968;124:1585-8.

Moss 1958 \{published data only\}

Moss CS, Jensen RE, Morrow W, Freund HG. Specific behavioural changes produced by chlorpromazine in chronic schizophrenia. American Journal of Psychiatry 1958;115: 449-51.

Neal 1969 \{published data only\}

Neal CD, Collis MP, Imlah NW. A comparative trial of oxypertine and chlorpromazine in chronic schizophrenia. Current Therapeutic Research - Clinical and Experimental 1969;11:367-78.

Newbold 1956 \{published data only\}

Newbold HL, Steed WD. The use of chlorpromazine in psychotherapy. Journal of Nervous and Mental Diseases 1956; 123(3): $270-4$.

Okuma 1979 \{published data only\} Okuma T, Inanaga K, Otsuki S, Sarai K, Takahashi R, Hazama $\mathrm{H}$, et al. A preliminary double-blind study on the efficacy of carbamazepine in prophylaxis of manicdepressive illness. Psychopharmacology Berlin 1981;73:95-6.

Orzack 1969 \{published data only\}

Orzack MH, Taylor CL, Kornetsky C. A comparison of the behavioral effects of periodic administration of chlorpromazine and a "sustained-release" form of chlorpromazine. Clinical Pharamacology and Therapeutics 1969;10(2):258-64. MEDLINE: 69143232

Osmakova 1972 \{published data only\}

* Osmakova EI. Use of psychological methods for studying the particular psychotropic action of various psychopharmacologic drugs [Primenenie psikhologicheskikh metodik dlia issledovaniia sobstvenno psikhotropnogo deistviia nekotorykh psikhofarmakologic heskikh sredtsv]. Zhurnal Nevropatologii i Psikhiatrii 1972;72:1705-8. Rojo-Sierra M, Alonso J, Díez E, Giner J, Lloret E. [Aportación sobre el espectro psicofarmacoterápico del R P. 19366 y R P. 19 552]. 5th World Congress of Psychiatry; 1971 Nov 28 - Dec 4; Ciudad de Mexico, Mexico. 1971. MEDLINE: 79081577

Pai 2001 \{published data only\}

Pai Y-M, Yu S-C, Lin C-C. Risperidone in reducing tardive dyskinesia: a double-blind, placebo-controlled study. Annual Meeting of the American Psychiatric Association; 2001 May 5-10; LA, USA. Marathon Multimedia, 2001. MEDLINE: 98017426
Paredes 1966 \{published data only\}

Paredes A, Baumgold J, Pugh LA, Ragland R. Clinical judgment in the assessment of psychopharmacological effects. Journal of Nervous and Mental Disease 1966;142(2): 153-60.

Park 1981 \{published data only\}

Park S, Hardesty AS, Garcia E. Effects of triiodothyronine and chlorpromazine combination treatment in schizophrenia. Current Therapeutic Research-Clinical and Experimental 1981;29:929-35.

Pasamanick 1967 \{published data only\}

Pasamanick B, Scarpitti FR, Dinitz S. Schizophrenics in the Community: an Experimental Study in the Prevention of Hospitalization. New York: Appleton-Century-Crofts, 1967.

Patterson 1981 \{published data only\}

Patterson T, Venables PH. Bilateral skin conductance and the pupillary light dark reflex - manipulation by chlorpromazine, haloperidol, scopolamine, and placebo. Psychopharmacology 1981;73:63-9.

Peet 1980 \{published data only\}

Peet M, Middlemiss DN, Yates RA. Pharmacokinetic interaction between propranolol and chlorpromazine in schizophrenic patients [letter]. Lancet 1980;2:978.

Pennington 1957 \{published data only\} Pennington V. A two-year comparative study of ataraxics in neuropsychiatric patients. Journal of the American Geriatric Association 1957;5:42-9.

Pietzcker 1978 \{published data only\}

Pietzcker A. Long-term medication in schizophrenia [Langzeitmedikation bei schizophrenen Kranken]. Nervenarzt 1978;49:518-33.

Pigache 1973 \{published data only\}

Pigache RM. The clinical relevance of an auditory attention task (PAT) in a longitudinal study of chronic schizophrenia, with placebo substitution for chlorpromazine. Schizophrenia Research 1993;10:39-50.

* Pigache RM, Norris HN. Measurement of drug action in schizophrenia. Clinical Science 1973;44:28.

Pigache 1993 \{published data only\}

Pigache RM. Effects of placebo, orphenadrine, and rising doses of chlorpromazine, on PAT performance in chronic schizophrenia. A two-year longitudinal study. Schizophrenia Research 1993;10:51-9.

Platz 1967 \{published data only\} Platz AR, Klett CJ, Caffey EMJ. Selective drug action related to chronic schizophrenic subtype. (A comparative study of carphenazine, chlorpromazine, and trifluoperazine). Diseases of the Nervous System 1967;28:601-5.

Pleasure 1956 \{published data only\} Pleasure H. Chlorpromazine (Thorazine) for mental illness in the presence of pulmonary tuberculosis. Psychiatry Quarterly 1956;30:23-30. 
Pollack 1956 \{published data only\}

Pollack, B. The effect of chlorpromazine on the return rate of 250 patients released from the Rochester State Hospital. American Journal of Psychiatry 1956;112:937.

Pollard 1959 \{published data only\} Pollard JC. Combined effects of chlorpromazine and meprobamate in chronically disturbed psychotic patients. Diseases of the Nervous System 1959;20:427-9.

Quigley 1996 \{published data only\} Quigley N, Morgan D, Idzikowski C, King DJ. The effect of chlorpromazine and benzhexol on memory and psychomotor function in healthy volunteers. Journal of Psychopharmacology 1996;10:146-52.

Quinn 1960 \{published data only\}

Quinn PJG, Johnston J, Latner G, Kiloh LG. A comparative controlled trial of methotrimeprazine ('veractil') in chronic schizophrenia. British Journal of Psychiatry 1960;106: 161-70.

Raaska 2000 \{published data only\}

Raaska K, Neuvonen PJ. Ciprofloxacin increases serum clozapine and N-desmethylclozapine: a study in patients with schizophrenia. European Journal of Clinical Pharmacology 2000;56(8):585-9. MEDLINE: 21026257

Ragland 1968 \{published data only\} Ragland R, Clark ML, Ray TS, Paredes A, Costiloe JP, Segal B, et al. The evaluation of chlorpromazine therapy in chronic schizophrenic women. A replicated experiment. Journal of Chronic Diseases 1968;21:445-60.

Raja 2000 \{published data only\}

Raja M, Azzoni A. Second generation antipsychotics in the emergency care setting. A prospective naturalistic study. General Hospital Psychiatry 2000;22(2):107-14. MEDLINE: 20283566

Rappaport 1967 \{published data only\}

Rappaport M. Competing voice messages. Effects of message load and drugs on the ability of acute schizophrenics to attend. Archives of General Psychiatry 1967;17:97-103.

Rappaport 1968 \{published data only\}

Rappaport M. Attention to competing voice messages by nonacute schizophrenic patients. Effects of message load, drugs, dosage levels and patient background. Journal of Nervous and Mental Disease 1968;146:404-11.

Rathod 1958 \{published data only\}

Rathod N, Rees L. A controlled study of the prognostic significance of autonomic responses in the chlorpromazine treatment of disturbed psychotic patients. British Journal of Psychiatry 1958;104:705-12.

Raymond 1957 \{published data only\}

Raymond MJ, Lucas CJ, Beesley ML, O'Connell BA, Fraser Roberts JA. A trial of five tranquillizing drugs in psychoneurosis. British Medical Journal 1957;2:63-6.
Remr 1970 \{published data only\}

Remr J. The effects of chlorpromazine on fine psychomotor performance with a simultaneous secondary task in schizophrenics. Activitas Nervosa Superior 1971;13:179.

${ }^{*}$ Remr J. The effects of chlorpromazine on some components of psychomotor performance in schizophrenics. Activitas Nervosa Superior 1970;12:253-4.

Rifkin 1978 \{published data only\}

Rifkin A, Quitkin F, Kane J, Struve F, Klein DF. Are prophylactic antiparkinson drugs necessary? A controlled study of procyclidine withdrawal. Archives of General Psychiatry 1978;35(4):483-9. MEDLINE: 79081577

Rinaldi 1956 \{published data only\}

Rinaldi F, Rudy L, Himwich HE. Clinical evaluation of azacyclonol, chlorpromazine, and reserpine on a group of chronic psychotic patients. American Journal of Psychiatry 1956;112:678-83.

Rivera-Calimlim 1973 \{published data only\} Rivera Calimlim L, Castaneda L, Lasagna L. Effects of mode of management on plasma chlorpromazine in psychiatric patients. Clinical Pharmacology and Therapeutics 1973;14: 978-86.

Rojo-Sierra 1971 \{published data only\} Rojo-Sierra M, Alonso J, Díez E, Giner J, Lloret E. [Aportación sobre el espectro psicofarmacoterápico del R P. 19366 y R P. 19 552]. 5th World Congress of Psychiatry; 1971 Nov 28 - Dec 4; Ciudad de Mexico, Mexico. 1971: 495-6. MEDLINE: 79081577

Rosen 1972 \{published data only\}

Rosen B, Engelhardt DM, Freedman N, Margolis R, Rudorfer L, Paley HM. Prediction of psychiatric hospitalization. II. The Hospitalization Proneness Scale: a cross-validation. Journal of Nervous and Mental Disease 1972;80:271-4.

Rosenheck 2000 \{published data only\} Rosenheck R, Cramer J, Jurgis G, Perlick D, Xu W, Thomas J, et al. Clinical and psychopharmacologic factors influencing family burden in refractory schizophrenia. Journal of Clinical Psychiatry 2000;61(9):671-6.

Rosner 1955 \{published data only\} Rosner H, Levine S, Hess H, Kaye H. A comparative study of the effect on anxiety of chlorpromazine, reserpine, phenobarbital, and a placebo. Journal of Nervous and Mental Diseases 1955;122:505-12.

Rudy 1957 \{published data only\}

Rudy L, Himwich H, Tasher DC. Clinical evaluation of two phenothiazine compounds Promazine and Mepazine. American Journal of Psychiatry 1957;113:979-83.

Rudy 1958 \{published data only\} Rudy L, Rinaldi E, Himwich H, Tuteur W, Glotzer J. Trifluoperazine in the treatment of psychotic patients. American Journal of Psychiatry 1958;115:364-5.

Sainz 1955 \{published data only\} Sainz A. Chlorpromazine in psychiatric disorders. Prescriber 1955;2(2):14. MEDLINE: 20283566 
Saletu 1972 \{published data only\}

Saletu B, Saletu M, Itil T. Effect of minor and major tranquilizers on somatosensory evoked potentials. Psychopharmacologia 1972;24:347-58.

Salisbury 1957 \{published data only\}

Salisbury BJ, Hare EH. Ritalin and chlorpromazine in chronic schizophrenia: a controlled clinical trial. British Journal of Psychiatry 1957;103:830-4.

Schiele 1959 \{published data only\} Schiele BC, Mendelsohn RM, Penman AS, Schofield W. Comparison of low and high dosage procedures in chlorpromazine therapy. Psychiatric Quarterly 1959;33: 252-9.

\section{Schmidt 1957 \{published data only\}}

Schmidt KE. Combined treatment with chlorpromazine and reserpine: an attempt at quantitative assessments in chronic schizophrenic patients. British Journal of Psychiatry 1957;103:200-8.

Schooler 1976 \{published data only\}

Sakalis G, Chan TL, Sathananthan G, Schooler N, Goldberg S, Gershon S. Relationships among clinical response, extrapyramidal syndrome and plasma chlorpromazine and metabolite ratios. Communucations in Psychopharmacology 1977;1:157-66.

Schooler NR, Sakalis G, Chan TL. Chlorpromazine metabolism and clinical response in acute schizophrenia - a preliminary report. Psychopharmacology Bulletin 1975;11: 30-3.

* Schooler NR, Sakalis G, Chan TL, Gershon S, Goldberg SC, Collins P. Chlorpromazine metabolism and clinical response in acute schizophrenia - a preliminary report. Pharmacokinetics of Psychoactive Drugs. Unknown, 1976: 199-219.

Seager 1955 \{published data only\} Seager CP. Chlorpromazine in treatment of elderly psychotic women. British Medical Journal 1955;1:882-5.

Serafetinides 1973 \{published data only\}

Serafetinides EA. Consistency and similarity of drug EEG responses in chronic schizophrenic patients. International Pharmacopsychiatry 1973;8:214-6.

Shaskan 1975 \{published data only\}

Becker RE, Shaskan EG. Platelet monoamine oxidase activity in schizophrenic patients. American Journal of Psychiatry 1977;134:512-7.

Shaskan EG, Becker RE. Blood platelet monoamine oxidase activity in anergic schizophrenics. National Institute of Drug Abuse Research Monograph Services 1975;3:29-35.

Shaskan EG, Becker RE. Platelet monoamine oxidase in schizophrenics. Nature 1975;253:659-60.

Shawver 1959 \{published data only\}

Shawver JR, Gorham DR, Leskin LW, Good WW, Kabnick DE. Comparison of chlorpromazine and reserpine in maintenance drug therapy. Diseases of the Nervous System 1959;20:452-7.
Shopsin 1978 \{published data only\}

Shopsin B, Klein H, Aronson M. Clozapine: doubleblind control trial in the treatment of acute schizophrenia. Psychopharmacology Bulletin 1978;14:12-4.

Shopsin 1979 \{published data only\}

Honigfeld G, Patin J, Singer J. Clozapine: antipsychotic activity in treatment-resistant schizophrenics. Advances in Therapy 1984;1:77-97.

* Shopsin B, Klein H, Aaronson M, Collora M. Clozapine, chlorpromazine, and placebo in newly hospitalized, acutely schizophrenic patients. Archives of General Psychiatry 1979; 36:657-64.

\section{Silver 2000 \{published data only\}}

Silver H, Barash I, Aharon N, Kaplan A, Poyurovsky M. Fluvoxamine augmentation of antipsychotics improves negative symptoms in psychotic chronic schizophrenic patients: a placebo-controlled study. International Clinical Psychopharmacology 2000;15(5):257-61. MEDLINE: 20445223

Simopoulos 1971 \{published data only\} Simopoulos AM, Pinto A, Uhlenhuth EH, Mcgee J. Old wine in new bottles: decreased hostility in chronic psychotic inpatients treated with diphenylhydantoin (Dilantin). 5th World Congress of Psychiatry. Ciudad de Mexico. Ciudad de Mexico, 1971:abstract 1077.

Simpson 1974 \{published data only\} Simpson GM, Varga E, Reiss M, Cooper TB, Bergner $\mathrm{PE}$, Lee $\mathrm{JH}$. Bioequivalency of generic and brand-named chlorpromazine. Clinical Pharmacology and Therapeutics 1974;15:631-41.

Simpson 1980 \{published data only\}

Simpson GM, Cooper TB, Bark N, Sud I, Lee JH. Effect of antiparkinsonian medication on plasma levels of chlorpromazine. Archives of General Psychiatry 1980;37: 205-8.

Singh 1974 \{published data only\}

Singh MM. Dysphoric response to neuroleptic treatment in schizophrenia and its prognostic significance. Diseases of the Nervous System 1976;37:191-6.

* Singh MM. Dysphoric response to neuroleptic treatment in schizophrenia and its prognostic significance. Journal of the Bronx State Hospital 1974;2:173-83.

Singh MM, Kay SR. A comparative study of haloperidol and chlorpromazine in terms of clinical effects and therapeutic reversal with benzotropine in schizophrenia. Theoretical implications for potency differences among neuroleptics. Psychopharmacologia 1975;43:103-13.

Singh MM, Kay SR. Therapeutic reversal with benztropine in schizophrenics: practical and theoretical significance. Journal of Nervous and Mental Disease 1975;160:258-66.

Singh 1990 \{published data only\} Singh H, Hunt JI, Vitiello B, Simpson GM. Neuroleptic withdrawal in patients meeting criteria for supersensitivity psychosis. Journal of Clinical Psychiatry 1990;51:319-21. 
Small 1987 \{published data only\}

Small J, Milstein V, Small IF, Miller MJ, Kellams JJ, Corsaro CJ. Computerized EEG profiles of haloperidol, chlorpromazine, clozapine and placebo in treatment resistant schizophrenia. Clinical Electroencephalography 1987;18:124-35.

Smith 1958 \{published data only\}

Smith JA, Christian D, Rutherford A, Mansfield E. A comparison of triflupromazine (Vesprin), chlorpromazine and placebo in 85 chronic patients. American Journal of Psychiatry 1958;115:253-4.

Smith 1960 \{published data only\}

Smith ME. A comparative controlled study with chlordiazepoxide. American Journal of Psychiatry 1960;117: 362-3.

Smith 1967 \{published data only\}

Smith K, Surphlis WRP, Gynther MD, Shimkunas AM.

ECT-chlorpromazine and chlorpromazine compared in the treatment of schizophrenia. Journal of Nervous and Mental Disease 1967;144:284-90.

\section{Sommerness 1957 \{published data only\}}

Sommerness MD, Lucero RJ, Hamlon JS, Mahowald AM. Chlorpromazine: a controlled study with highly disturbed patients. Diseases of the Nervous System 1957;18:16-20.

South-East 1961 \{published data only\}

South-East Region (Scotland) Therapeutic Trials Committee. Controlled trial of Prochlorperazine (Stemetil) in schizophrenia. Journal of Mental Science (British Journal of Psychiatry from 1963) 1961;107:514-22. MEDLINE: 87204515

Soyka 1968 \{published data only\}

Soyka D. The effect of psychopharmacological drugs and other central nervous system effecting drugs on experimental nystagmus [Die Wirkung von Psychopharmaka und anderen zentral wirksamen substanzen auf den experimentellen Nystagmus]. Fortschritte Der Neurologie, Psychiatrie Und Ihrer Grenzgebiete 1968;36:526-39.

Spiegel 1967 \{published data only\} Spiegel DE, Keith-Spiegel P. The effects of carphenazine, trifluoperazine and chlorpromazine on ward behavior, physiological functioning and psychological test scores in chronic schizophrenic patients. Journal of Nervous and Mental Diseases 1967;144:111-6.

Spohn 1974 \{published data only\} Spohn HE, Lacoursiere RB, Williams RO. The effect of chlorpromazine on visual information processing in normal subjects. Journal of Nervous and Mental Disease 1974;159: 198-204.

Sugerman 1964 \{published data only\}

Pfeiffer CC, Goldstein L, Murphree HB, Sugerman AA. Time-series frequency analysis, and electrogenesis of the EEGs of normals and psychotics before and after drugs. American Journal of Psychiatry 1965;122:1147-55.

* Sugerman AA, Goldstein L, Murphree HB, Pfieffer CC, Jenney EH. EEG and behavioural changes in schizophrenia. Archives of General Psychiatry 1964;10:340-4.
Sun 2006 \{published data only\}

Sun Q-X, You H-F, Wang X-L. Venlafax-

ine combined with chlorpromazine in treat-

ing negative symptoms of schizophrenia

[文拉法辛合并氯丙嗪治疗精神分裂症阴性症状的临床研究]. Chinese Journal of Psychiatry 2006;39(2):90-3.

Syvalahti 1997 \{published data only\}

Syvalahti EK, Taiminen T, Saarijarvi S, Lehto H, Niemi H, Ahola V, et al. Citalopram causes no significant alterations in plasma neuroleptic levels in schizophrenic patients. Journal of International Medical Research 1997;25(1):24-32. MEDLINE: 97179384

Talbot 1964 \{published data only\}

Talbot DR. Are tranquilizer combinations more effective than a single tranquilizer?. American Journal of Psychiatry 1964;121:597-600.

Tang 2005 \{published data only\} Tang Y, Hongxiao J, Zhou F, Cao X, Yuan H, Zhang J. Improving the memory impairment of schizophrenia patients by strengthening the spleen and invigorating the kidney

[健脾补肾法治疗精神分裂症记忆损害的临床观察]. Chinese Journal of the Practical Chinese with Modern

Medicine (中华实用中西医杂志] 2005;18(12):1750-1.

Tang 2005a \{published data only\}

Tang YY, Jia HX, Jiang ZK, Cao XD, Yuan HN, Zhang JZ. Clinical observation of Jian-Pi-Bu-Shen (TCM) treating memory deterioration in patients with schizophrenia. Proceedings of the 8th Conference of Integrated Traditional Chinese Medicine and Western Medicine for Mental Health Problems. 2005:32-4.

Tang 2006 \{published data only\}

Tang Y-Y, Jia H-X, Zhou F, Cao X-D, Yuan H$\mathrm{N}$, Zhang J-Z. Attention impairment in patients with schizophrenia after the treatment of strengthening the spleen and invigorating the kidney

\section{[健脾补肾法治疗精神分裂症患者注意损害的效果评估]}

Modern Rehabilitation [现代康复] 2006;10(39):10-2.

Tassis 1959 \{published data only\}

Tassis JA. Full coma Insulin therapy, chlorpromazine and electoconvulsive treatment. A control study of 600 schizophrenic patients. Medical journal of Malaya 1959;14: 135-43.

Teja 1975 \{published data only\}

Teja JS, Grey WH, Clum JM, Warren C. Tranquilizers or anti-depressants for chronic schizophrenics: a long-term study. Australian and New Zealand Journal of Psychiatry 1975;9:241-7.

Tenenblatt 1956 \{published data only\} Tenenblatt SS, Spagno A. A controlled study of chlorpromazine therapy in chronic psychotic patients. Journal of Clinical \& Experimental Psychopathology 1956;17: 81-92. 
Terminska 1989 \{published data only\}

Terminska K, Mrowiec W. No English title available [Badanie porownawcze wplywu perazyny, flufenazyny, trifluoroperazyny, chloropromazny i haloperydolu na objawy pierwotne i deficytowe pierwszego zachorowania na schizofrenie paranoidalna]. Psychiatria Polska 1989;23: 24-30.

Tetreault 1969a \{published data only\} Tetreault L, Bordeleau JM, Albert JM, Rajotte P. Comparative study of fluphenazine ethanate, fluphenazine bichlorhydrate and placebos in chronic schizophrenics [Etude comparative de l'enanthate de fluphenazine, du bichlorhydrate de fluphenazine et du placebo chez le schizophrene chronique]. Canadian Psychiatric Association Journal 1969;14(2):191-8. MEDLINE: 69202908

Thorpe 1956 \{published data only\}

Thorpe J, Baker A. A research method to assess a new tranquillizing drug. British Journal of Psychiatry 1956;102: $790-5$.

Tourlentes 1958 \{published data only\} Tourlentes TL, Hunsicker AL, Hurd DE. Chlorpromazine and communication processes. A.M.A. Archives of Neurology and Psychiatry 1958;79:468-73.

Troshinsky 1962 \{published data only\}

Troshinsky CH, Aaronson HG, Stone RK. Maintenance phenothiazines in aftercare of schizophrenic patients. Pennsylvania Psychiatric Bulletin 1962;2:11-5.

Turner 1956 \{published data only\} Turner M, Berard, E, Turner N, Franco N. Changes in the electroencephalogram, the electrodermogram, and the electromyogram provoked by chlorpromazine in man. Abstracts of World Medicine 1956;20:177.

Turner 1966 \{published data only\}

Turner P. A comparison of fluphenazine and chlorpromazine on critical flicker fusion frequency. Journal of Pharmacy and Pharmacology 1966;18:836.

Urquhart 1959 \{published data only\}

Urquhart R, Forrest AD. Clinical trial of promazine hydrochloride and acetylpromazine in chronic schizophrenic patients. British Journal of Psychiatry 1959;105:260-4.

van Praag 1975 \{published data only\} van Praag HM, Dols LC, Schut T. Biochemical versus psychopathological action profile of neuroleptics. A comparative study of chlorpromazine and oxypertine in acute psychotic disorders. Comprehensive Psychiatry 1975; 16:255-63.

van Praag HM, Korf J. The dopamine hypothesis of schizophrenia. Some direct observations. In: van Praag HM editor(s). On the Origin of Schizophrenic Psychoses. Amsterdam: De Erven Bohn BV, 1975:81-98.

\section{Vestre 1961 \{published data only\}}

Vestre ND. An experimental study of the effects of chlorpromazine on association learning in schizophrenic patients. Dissertation Abstracts 1961:2374.
Vinar 1973 \{published data only\}

Vinar O. Whom do neuroleptic drugs help?. Psychopharmacology, Sexual Disorders and Drug Abuse. Amsterdam, Netherlands: North-Holland, 1973:247-56.

Vinar 1976 \{published data only\}

Vinar O, Taussigova D. Schizophrenic syndromes improving without neuroleptic drug treatment [Schizofrenni syndromy zlepsujici se bez neurolepticke lecby]. Ceskoslovenska Psychiatrie 1976;72(3):176-81. MEDLINE: 77001715

Volavka 1983 \{published data only\} Volavka J, Hui KS, Anderson B, Nemes Z, O’Donnell J, Lajtha A. Short-lived effect of (des-tyr)-gamma-endorphin in schizophrenia. Psychiatry Research 1983;10:243-52.

Warner 1996 \{published data only\} Warner JP, Barnes TR, Henry JA. Electrocardiographic changes in patients receiving neuroleptic medication. Acta Psychiatrica Scandinavica 1996;93:311-3.

Weir 1968 \{published data only\} Weir TW, Kernohan GA, MacKay DN. The use of pericyazine and chlorpromazine with disturbed mentally subnormal patients. British Journal of Psychiatry 1968;114: 111-2.

Welbel 1980 \{published data only\} Welbel L. No English title available [Roznice w dziallaniu klinicznym niektorych neuroleptykow]. Psychiatria Polska 1980;14:113-8.

Whitehead 1958 \{published data only\}

Whitehead WA, Thune LE. The effects of chlorpromazine on learning in chronic psychotics. Journal of Consulting Psychology 1958;22:379-83.

Wilcott 1962 \{published data only\} Wilcott RC, Helper MM, Garfield SL. Some psychophysiological effects of chlorpromazine on emotionally disturbed children. Journal of Nervous and Mental Diseases 1962;135:233-8.

Wilson 1961 \{published data only\} Wilson IC, McKay J, Sandifer MG. A double-blind trial to investigate the effects of thorazine (largactil, chlorpromazine), compazine (stemetil, prochlorperazine) and stelazine (trifluoperazine) in paranoid schizophrenia. British Journal of Psychiatry 1961;107:90-9.

Winkelman 1957 \{published data only\} Winkelman NW. An appraisal of chlorpromazine. General principles for administration of chlorpromazine, based on experience with 1,090 patients. American Journal of Psychiatry 1957;113(11):961-71.

Winter 1956 \{published data only\} Winter WD, Frederickson WK. The short-term effects of chlorpromazine on psychiatric patients. Journal of Consulting Psychology 1956;20:431-4.

Wode-Helgodt 1977 \{published data only\} Wode-Helgodt B, Eneroth P, Fyro B, Gullberg B, Sedvall G. Effect of chlorpromazine treatment on prolactin levels in cerebrospinal fluid and plasma of psychotic patients. Acta Psychiatrica Scandinavica 1977;56:280-93. 
Wold 1959 \{published data only\}

Wold PN. A long term evaluation of chlorpromazine in six chronic schizophrenic patients. American Journal of Psychiatry 1959;116:461-2.

Wolpert 1969 \{published data only\}

Wolpert A, Yaryura TJA, White L, Merlis S.

Triiodothyronine and phenothiazines in schizophrenia.

Diseases of the Nervous System 1969;30(7):487-9.

MEDLINE: 69288496

Wyatt 1997 \{published data only\}

Wyatt RJ, Green MF, Tuma AH. Long-term morbidity associated with delayed treatment of first admission schizophrenic patients: a re-analysis of the Camarillo State Hospital data. Psychological Medicine 1997;27:261-8.

Wykes 1994 \{published data only\}

Wykes T, Reeder C, Landau S, Everitt B, Knapp M, Patel A. Cognitive remediation therapy: predictive factors \& side effects. Unknown source. 1994.

Yan 2004 \{published data only\}

Yan M, Zhou Y, Wang A. Preventive effect of ferrous sulfate on extrapyramidal side effects of neuroleptics. Shandong

Archives of Psychiatry [山东精神医学] 2004;17(1):16-8.

Yang 2005 \{published data only\}

Yang R-1, Lv H-X, Lou F. The rehabilitation effect of group psychotherapy on chronic schizophrenic patient

[小组心理治疗对慢性精神分裂症患者的康复作用].

Occupation and Health [职业与健康] 2005;21(6):936.

Yorkston 1977 \{published data only\}

Yorkston NJ, Zaki SA, Pitcher DR, Gruzelier JH, Hollander

$\mathrm{D}$, Sergeant HG. Propranolol as an adjunct to the treatment of schizophrenia. Lancet 1977;2:575-8.

Yuan-guang 1994 \{published data only\}

Yuan-Guang C, Guang-Rong X, Jing Ping Z. A study on the relationship between the chlorprmazine plasma levels and clinical response to chlorpromazine administrations in the schizophrenics. Chinese Journal of Neurology and Psychiatry 1994;27(3):153-5.

Zeller 1956 \{published data only\}

Zeller WW, Graffagnino PN, Cullen CF, Rietman HJ. Use of chlorpromazine and reserpine in the treatment of emotional disorders. Journal of the American Medical Association 1956;160:179-84.

王强, 1995 \{published data only\}

王强, 袁风来, 艾莉, 尹定富, 肖迎光. [only Chinese Title available]

[氯丙嗪合并碳酸锂治疗难治性精神分裂症随机双盲交叉试验]. Journal of Clinical Psychological Medicine

临床精神医学杂志] 1995;5(3):185.

金建烽, 2008 \{published data only\}

金建峰，巢亚琴，徐乐平，宋梓样，郡亚琴. [Ti-

tle only available in Chinese characters]
[合并小剂量阿立哌唑改善氯丙嗪所致高催乳素血症的临床研究].

Shandong Archives of Psychiatry (山东精神医学] 2008;21

(6):455-6.

\section{Additional references}

\section{Ahmed 1998}

Ahmed I, Soares K, Seifas R, Adams CE. Randomised controlled trials in Archives of General Psychiatry (19591995): a prevalence study. Archives of General Psychiatry 1998;55(8):754-5.

\section{Altman 1996}

Altman DG, Bland JM. Detecting skewness from summary information. BMJ 1996;313:1200. [CHLO020600]

APA 1992

American Psychiatric Association. Tardive dyskinesia: a task force report of the American Psychiatric Association. Washington DC: American Psychiatric Association, 1992.

\section{APA 1994}

American Psychiatric Association. Diagnostic and Statistical Manual of Mental Disorders. Fourth. Washington DC: American Psychiatric Association, 1994.

\section{Awad 1993}

Awad AG. Subjective response to neuroleptics in schizophrenia. Schizophrenia Bulletin 1993;19:609-18.

\section{Birchwood 1997}

Birchwood M, McGorry P, Jackson H. Early interventions in schizophrenia. British Journal of Psychiatry 1997;170: $2-5$.

Bland 1997

Bland JM. Statistics notes. Trials randomised in clusters. BMJ 1997;315:600

Boissel 1999

Boissel JP, Cucherat M, Li W, Chatellier G, Gueyffier F, Buyse M, et al. The problem of therapeutic efficacy indices. 3. Comparison of the indices and their use. Therapie 1999; 54(4):405-11.

Bollini 1994

Bollini P, Pampallona S, Orza MJ, Adams ME, Chalmers TC. Antipsychotic drugs: is more worse? A meta-analysis of the published randomized control trials. Psychological Medicine 1994;24:307-16.

\section{Caldwell 1992}

Caldwell CB, Gottesman II. Schizophrenia - a high-risk factor for suicide: clues to risk reduction. Suicide and LifeThreatening Behavior 1992;22:479-93.

\section{Chong 2004}

Chong MY, Tan CH, Fujii S, Yang S, Ungvari GS, Si T, et al. Antipsychotic drug prescription for schizophrenia in East Asia: rationale for change. Psychiatry and Clinical Neuroscience 2004;58:61-7.

\section{Davis 1978}

Davis JM, Garver DL. Neuroleptics: clinical use in psychiatry. In: Iverson A, Iverson B, Snyder C editor(s). 
Handbook of Psychopharmacology. New York and London: Plenum, 1978.

\section{Deeks 2000}

Deeks J. Issues in the selection for meta-analyses of binary data. Abstracts of 8th International Cochrane Colloquium; 2000 Oct 25-28th; Cape Town, South Africa. 2000.

\section{Delay 1952}

Delay J, Deniker P. [Le traitement des Psychoses par une Methode neuroleptique derivee de l'Hibernotherapie]. CR Congres des Medicins alienistes et neurologistes de France. Luxembourg. 1952:479.

\section{Divine 1992}

Divine GW, Brown JT, Frazier LM. The unit of analysis error in studies about physicians' patient care behavior. Journal of General Internal Medicine 1992;7(6):623-9.

\section{Donner 2002}

Donner A, Klar N. Issues in the meta-analysis of cluster randomized trials. Statistics in Medicine 2002;21:2971-80.

\section{Egger 1997}

Egger M, Davey Smith G, Schneider M, Minder C. Bias in meta-analysis detected by a simple, graphical test. $B M J$ 1997;315:629-34.

\section{Elbourne 2002}

Elbourne D, Altman DG, Higgins JPT, Curtina F, Worthingtond HV, Vaile A. Meta-analyses involving crossover trials: methodological issues. International Journal of Epidemiology 2002;31(1):140-9.

\section{Furukawa 2006}

Furukawa TA, Barbui C, Cipriani A, Brambilla P, Watanabe $\mathrm{N}$. Imputing missing standard deviations in meta-analyses can provide accurate results. Journal of Clinical Epidemiology 2006;59(7):7-10.

\section{Grozier 1973}

Grozier L. The third revolution in psychiatry: fluphenazine decanoate. In: Ayd FJ editor(s). The Future of Pharmacotherapy: Drug Delivery Systems. Baltimore: International Drug Therapy Newsletter, 1973:97.

\section{Gulliford 1999}

Gulliford MC. Components of variance and intraclass correlations for the design of community-based surveys and intervention studies: data from the Health Survey for England 1994. American Journal of Epidemiology 1999;149: 876-83.

\section{Guy 1976}

Guy W. Early Clinical Drug Evaluation (ECDEU) Assessment Manual for Psychopharmacology. Washington DC: National Institute of Mental Health, 1976. [Publication No.76-338]

\section{Hambrecht 1992}

Hambrecht T, Maurer K, Hafner H, Sartorius N. Transnational stability of gender differences in schizophrenia? An analysis based on the WHO study on determinants of outcome of severe mental disorders. European Archives of Psychiatry and Clinical Neuroscience 1992;242:6-12.

\section{Higgins 2003}

Higgins JP, Thompson SG, Deeks JJ, Altman DG. Measuring inconsistency in meta-analyses. BMJ 2003;327: 557-60.

\section{Higgins 2005}

Higgins JPT, Green S (editors). Cochrane Handbook for Systematic Reviews of Interventions 4.2.5 [updated May 2005]. The Cochrane Library. Chichester: John Wiley \& Sons, Ltd, 2005, issue Issue 3.

\section{Higgins 2011}

Higgins JPT, Green S (editors). Cochrane Handbook for Systematic Reviews of Interventions Version 5.0.2 [updated September 2011]. The Cochrane Collaboration, 2011. Available from www.cochrane-handbook.org.

\section{Hill 1992}

Hill C, Keks NA, Jackson H, Kulkarni J, Hannah D, Copolov D, et al. Symptomatic response to antipsychotics differs between recent onset and recurrent chronic schizophrenic patients. Australian and New Zealand Journal of Psychiatry 1992;26:417-22.

\section{Jadad 1996}

Jadad AR, Moore RA, Carroll D, Jenkinson C, Reynolds DJM, Gavaghan DJ, et al. Assessing the quality of reports of randomized clinical trials: is blinding necessary?. Controlled Clinical Trials 1996;17:1-12.

\section{Jenicek 1990}

Jenicek M, Berthelette D, Breton J, Croteau N, Leduc N, Pineault R. Content and methods of studies on the prevention and treatment of mental disorders in selected psychiatric journals. Revue d'Epidemiologie et de Sante Publique 1990;38:357-64.

\section{Jusic 1994}

Jusic N, Lader M. Post-mortem antipsychotic drug concentrations and unexplained deaths. British Journal of Psychiatry 1994;165:787-91.

\section{Kane 1985}

Kane JM, Rifkin A, Woerner M, Reardon G, Kreisman D, Blumenthal R, et al. High-dose versus low-dose strategies in the treatment of schizophrenia. Psychopharmacological Bulletin 1985;21:533-7.

\section{Kaplan 1990}

Kaplan MJ, Lazoff M, Kelly K, Lukin R, Garver DL. Enlargement of cerebral third ventricle in psychotic patients with delayed response to neuroleptics. Biological Psychiatry 1990;27:205-14.

\section{Kay 1986}

Kay SR, Opler LA, Fiszbein A. Positive and Negative Syndrome Scale (PANSS) Manual. North Tonawanda (NY): Multi-Health Systems, 1986.

\section{Kendler 1995}

Kendler KS, Walsh D. Gender and schizophrenia. Results of an epidemiologically-based family study. British Journal of Psychiatry 1995;167:184-92. 


\section{Laborit 1951}

Laborit H, Huguenard P. no English title available [L'Hibernation artificielle par Moyens pharmacodynamiques et physiques]. Presse Medicale 1951;59:1329.

\section{Leucht 2005}

Leucht S, Kane JM, Kissling W, Hamann J, Etschel E, Engel RR. What does the PANSS mean?. Schizophrenia Research 2005;79(2-3):231-8. [PUBMED: 15982856]

\section{Leucht 2005a}

Leucht S, Kane JM, Kissling W, Hamann J, Etschel E, Engel R. Clinical implications of Brief Psychiatric Rating Scale Scores. British Journal of Psychiatry 2005;187:366-71.

\section{Leucht 2007}

Leucht S, Engel RR, Bauml J, Davis JM. Is the superior efficacy of new generation antipsychotics an artifact of LOCF?. Schizophrenia Bulletin 2007;33(1):183-91. [PUBMED: 16905632]

\section{Lucero 1951}

Lucero RJ, Meyer BT. A behavior rating scale suitable for use in mental hospitals. Journal of Clinical Psychology 1951; 7:250-4. DOI: 10.1002/1097

\section{Marshall 2000}

Marshall M, Lockwood A, Bradley C, Adams C, Joy C, Fenton M. Unpublished rating scales: a major source of bias in randomised controlled trials of treatments for schizophrenia. British Journal of Psychiatry 2000;176: $249-52$.

\section{Moher 2001}

Moher D, Schulz KF, Altman D. The CONSORT statement: revised recommendations for improving the quality of reports of parallel-group randomized trials. JAMA 2001;285:1987-91.

\section{Odejide 1982}

Odejide AO, Ban TA. Psychotropic drug prescription pattern in a developing country (Nigeria). The need for an essential psychotherapeutic drug list. International Pharmacopsychiatry 1982;17:163-9.

\section{Overall 1962}

Overall JE, Gorham DR. The Brief Psychiatric Rating Scale. Psychological Reports 1962;10:799-812.

\section{PPA, 2003}

Prescription Pricing Authority: NHS 2003. http:// www.ppa.org.uk/index.htm.

\section{Rosen 1990}

Rosen J, Bohon S, Gershon S. Antipsychotics in the elderly. Acta Psychiatrica Scandinavica Supplement 1990;358:170-5.

\section{Rosenthal 1963}

Rosenthal D. Ratings of disturbance in various categories of behavior during hospitalization. In: Rosenthal D editor (s). The Gerain Quadruplets: a Study of Heredity and Environment in Schizophrenia. New York: Basic Books, 1963.

Schulz 1995

Schulz KF, Chalmers I, Hayes RJ, Altman DG. Empirical evidence of bias: dimensions of methodological quality associated with estimates of treatment effects in controlled trials. JAMA 1995;273:408-12.

\section{Schünemann 2008}

Schünemann HJ, Oxman AD, Vist GE, Higgins JPT, Deeks JJ, Glasziou P, et al. Chapter 12: Interpreting results and drawing conclusions. In: Higgins JPT, Green S editor(s). Cochrane Handbook for Systematic Reviews of Interventions. The Cochrane Collaboration, 2008:359-83.

\section{Sedvall 1995}

Sedvall G, Farde L. Chemical brain anatomy in schizophrenia. Lancet 1995;346:743-9.

\section{Szymanski 1995}

Szymanski S, Lieberman JA, Alvir JM, Mayerhoff D, Loebel A, Geisler S, et al. Gender differences in onset of illness, treatment response, course, and biologic indexes in first-episode schizophrenic patients. American Journal of Psychiatry 1995;152:698-703.

\section{Szymanski 1996} Szymanski SR, Cannon TD, Gallacher F, Erwin RJ, Gur RE. Course of treatment response in first-episode and chronic schizophrenia. American Journal of Psychiatry 1996; 153:519-25.

\section{Thornley 1998}

Thornley B, Adams CE. Content and quality of 2000 controlled trials in schizophrenia over 50 years. BMJ 1998; 317:1181-4.

\section{Ukoumunne 1999}

Ukoumunne OC, Gulliford MC, Chinn S, Sterne JAC, Burney PGJ. Methods for evaluating area-wide and organistation-based intervention in health and health care: a systematic review. Health Technology Assessment 1999;3(5): $1-75$.

\section{WHO 1998}

WHO: Global Health Statistics Online, 1998. WHO: Global Health Statistics Online, 1998. WWHO: Global Health Statistics Online, 1998. http://w3.whosea.org/en/ section1174/section1199/section1567_6744.htm.

\section{WHO 2003}

WHO: Essential Medicines 13th edition, WHO Model List 2003. http://www.who.int/hac/techguidance/pht/ essentialmed/en/.

\section{Xia 2009}

Xia J, Adams CE, Bhagat N, Bhagat V, Bhoopathi P, ElSayeh H, et al. Loss to outcomes stakeholder survey: the LOSS study. Psychiatric Bulletin 2009;33(7):254-7.

\section{References to other published versions of this review}

\section{Adams 2007}

Adams CE, Awad G, Rathbone J, Thornley B. Chlorpromazine versus placebo for schizophrenia. Cochrane Database of Systematic Reviews 2007, Issue 2. DOI: 10.1002/14651858.CD000284.pub2 


\section{Thornley 1998a}

Thornley B, Adams CE, Awad G. Chlorpromazine versus placebo for those with schizophrenia. Cochrane Database of Systematic Reviews 1998, Issue 1. DOI: 10.1002/14651858

Thornley 2003

B Thornley, J Rathbone, CE Adams, G Awad.

Chlorpromazine versus placebo for schizophrenia. Cochrane Database of Systematic Reviews 2003, Issue 2. DOI: 10.1002/14651858.CD000284

* Indicates the major publication for the study 


\section{CHARACTERISTICSOFSTUDIES}

\section{Characteristics of included studies [ordered by study ID]}

\section{Abrams 1958}

Methods

Allocation: 'divided at random' - no further description.

Blinding: medications 'same size, shape and colour'.

Duration: 4 months.

Design: parallel.

Country: not reported.

\begin{tabular}{|c|c|c|}
\hline Participants & \multicolumn{2}{|c|}{$\begin{array}{l}\text { Diagnosis: schizophrenia. } \\
\text { History: in hospital } 2+\text { years, 'treatment resistant'. } \\
\mathrm{N}=40 \text {. } \\
\text { Sex: } 40 \mathrm{~F} \text {. } \\
\text { Age: range } 20-55 \text { years. } \\
\text { Setting: hospital. }\end{array}$} \\
\hline Interventions & \multicolumn{2}{|c|}{$\begin{array}{l}\text { 1. Chlorpromazine: dose } 200 \mathrm{mg} / \text { day rising to } 600 \mathrm{mg} / \text { day. } \mathrm{N}=20 \text {. } \\
\text { 2. Placebo. } \mathrm{N}=20 \text {. } \\
\text { Medication given in fixed-dose regimen. }\end{array}$} \\
\hline Outcomes & \multicolumn{2}{|c|}{$\begin{array}{l}\text { Leaving study early. } \\
\text { Unable to use - } \\
\text { Mental state: MSRPP (no SD). } \\
\text { Adverse effects (no usable data). } \\
\text { Cognitive functioning: Weschler Bellvue Intelligence Scale, Rorschach tests (no SD) }\end{array}$} \\
\hline Notes & \multicolumn{2}{|c|}{ MSRPP reported with SE of differences. SDs calculated but data implausible } \\
\hline \multicolumn{3}{|l|}{ Risk of bias } \\
\hline Bias & Authors' judgement & Support for judgement \\
\hline $\begin{array}{l}\text { Random sequence generation (selection } \\
\text { bias) }\end{array}$ & Unclear risk & $\begin{array}{l}\text { "Divided, at random, into two groups" no } \\
\text { further details reported }\end{array}$ \\
\hline Allocation concealment (selection bias) & Unclear risk & No information reported. \\
\hline $\begin{array}{l}\text { Blinding of participants and personnel } \\
\text { (performance bias) } \\
\text { All outcomes }\end{array}$ & Unclear risk & $\begin{array}{l}\text { "The experimental group received chlor- } \\
\text { promazine under the name of "Thoraxine } \\
\text { A“, "The control group, received a placebo, } \\
\text { the same size, shape and colour as the chlor- } \\
\text { promazine. As a differentiation from the } \\
\text { chlorpromazine, the placebo was known as } \\
\text { "Thorazine B" }\end{array}$ \\
\hline
\end{tabular}




\begin{tabular}{|c|c|c|}
\hline $\begin{array}{l}\text { Blinding of outcome assessment (detection } \\
\text { bias) } \\
\text { All outcomes }\end{array}$ & Unclear risk & No information reported. \\
\hline $\begin{array}{l}\text { Incomplete outcome data (attrition bias) } \\
\text { All outcomes }\end{array}$ & Unclear risk & $\begin{array}{l}\text { "During the course of the experiment sev- } \\
\text { eral patients had to be eliminated from both } \\
\text { groups for various reasons so that the final } \\
\text { chlorpromazine group consisted of } 18 \text { pa- } \\
\text { tients while the final placebo group con- } \\
\text { sisted of } 16 \text { patients". Reasons for leaving } \\
\text { the study early not reported }\end{array}$ \\
\hline Selective reporting (reporting bias) & High risk & $\begin{array}{l}\text { No SDs reported for MSRPP, Weschler } \\
\text { Bellvue Intelligence Scale or Rorschach } \\
\text { tests. No useable data for adverse effects }\end{array}$ \\
\hline Other bias & Unclear risk & Source of funding not reported. \\
\hline
\end{tabular}

Baker 1959

\begin{tabular}{|c|c|}
\hline Methods & $\begin{array}{l}\text { Allocation: 'order determined by random selection'. } \\
\text { Blinding: double, matching tablets in envelopes. } \\
\text { Design: cross-over - first arm data used. } \\
\text { Duration: } 5 \text { weeks (preceded by } 1 \text { week washout). } \\
\text { Country: UK. }\end{array}$ \\
\hline Participants & $\begin{array}{l}\text { Diagnosis: psychosis (schizophrenia } \mathrm{N}=21 \text {, involutional melancholia } \mathrm{N}=2 \text {, manic de- } \\
\text { pressive } \mathrm{N}=1 \text {, senile psychosis } \mathrm{N}=1 \text { ). } \\
\text { History: 'chronic', in hospital } 2+\text { years. } \\
\mathrm{N}=25^{*} \text {. } \\
\text { Sex: } 25 \mathrm{~F} \text {. } \\
\text { Age: range } 33-79 \text { years. } \\
\text { Setting: hospital. }\end{array}$ \\
\hline Interventions & $\begin{array}{l}\text { 1. Chlorpromazine: dose mean } 200 \mathrm{mg} / \text { day, range } 150-300 \mathrm{mg} / \text { day. } \mathrm{N}=7 \text {. } \\
\text { 2. Placebo (lactulose): dose } 1.95 \mathrm{~g} / \text { day to } 3.9 \mathrm{~g} / \text { day. } \mathrm{N}=7 \text {. } \\
\text { 3. Ethylcrotonylurea: dose range } 600-1200 \mathrm{mg} / \text { day. } \mathrm{N}=8 \text {. } \\
\text { Medication given in fixed-dose regimen. }\end{array}$ \\
\hline Outcomes & $\begin{array}{l}\text { Leaving study early. } \\
\text { Death. } \\
\text { Behaviour. BPRS } \\
\text { Adverse effects. } \\
\text { Unable to use - } \\
\text { Mental state: BPRS (no usable data). } \\
\text { Physiological measures (no usable data). }\end{array}$ \\
\hline
\end{tabular}


Baker 1959 (Continued)

$\begin{array}{ll}\text { Notes } & \text { *hree participants not accounted for. } \\ & \text { Only data for those with schizophrenia and senile psychosis used }(\mathrm{N}=22)\end{array}$

Risk of bias

\begin{tabular}{|c|c|c|}
\hline Bias & Authors' judgement & Support for judgement \\
\hline $\begin{array}{l}\text { Random sequence generation (selection } \\
\text { bias) }\end{array}$ & Unclear risk & $\begin{array}{l}\text { "Order determined by random selection" } \\
\text { no further details reported }\end{array}$ \\
\hline Allocation concealment (selection bias) & Unclear risk & No information reported. \\
\hline $\begin{array}{l}\text { Blinding of participants and personnel } \\
\text { (performance bias) } \\
\text { All outcomes }\end{array}$ & Low risk & "Matching tablets" were used. \\
\hline $\begin{array}{l}\text { Blinding of outcome assessment (detection } \\
\text { bias) } \\
\text { All outcomes }\end{array}$ & Low risk & $\begin{array}{l}\text { "The total number of tablets for each five- } \\
\text { week period (378) were put in a separate } \\
\text { envelope, labelled "A", "B", or "C" } C^{\text {" and a }} \\
\text { code was kept showing which tablets any } \\
\text { patient was taking during any given period } \\
\text { [...] It was thus possible to keep the han- } \\
\text { dling and the knowledge of the identity of } \\
\text { the tablets under the control of a person } \\
\text { other than the psychiatric assessor of results } \\
\text { until the trial was completed." }\end{array}$ \\
\hline $\begin{array}{l}\text { Incomplete outcome data (attrition bias) } \\
\text { All outcomes }\end{array}$ & High risk & $\begin{array}{l}\text { "There were no deaths in this group, but } \\
\text { one patient (Case } 120 \text { ) was so uncoopera- } \\
\text { tive in taking tablets that it was decided to } \\
\text { abandon the attempt, in her case". Three } \\
\text { participants are not accounted for in the } \\
\text { analysis }\end{array}$ \\
\hline Selective reporting (reporting bias) & Unclear risk & Unable to use BPRS data. \\
\hline Other bias & Unclear risk & $\begin{array}{l}\text { "These three substances were supplied in } \\
\text { matching tablets by Messrs. Smith \& } \\
\text { Nephew, the sponsors of the new drug" }\end{array}$ \\
\hline
\end{tabular}

Chlorpromazine versus placebo for schizophrenia (Review) 
Setting: hospital.

Outcomes
$\begin{aligned} & \text { Leaving study early. } \\ & \text { Global impression. CGI. } \\ & \text { Unable to use - } \\ & \text { Adverse effects (not given per individual). } \\ & \text { Mental state: BPRS (no mean/SD). }\end{aligned}$

Notes

\section{Risk of bias}

\begin{tabular}{|c|c|c|}
\hline Bias & Authors' judgement & Support for judgement \\
\hline $\begin{array}{l}\text { Random sequence generation (selection } \\
\text { bias) }\end{array}$ & Unclear risk & "Randomised" no further details reported. \\
\hline Allocation concealment (selection bias) & Unclear risk & No information reported. \\
\hline $\begin{array}{l}\text { Blinding of participants and personnel } \\
\text { (performance bias) } \\
\text { All outcomes }\end{array}$ & Low risk & $\begin{array}{l}\text { "Double-blind" } \\
\text { "All medication was supplied in capsules } \\
\text { identical in appearance, taste and smell" }\end{array}$ \\
\hline $\begin{array}{l}\text { Blinding of outcome assessment (detection } \\
\text { bias) } \\
\text { All outcomes }\end{array}$ & Unclear risk & "Double-blind" no further details reported. \\
\hline $\begin{array}{l}\text { Incomplete outcome data (attrition bias) } \\
\text { All outcomes }\end{array}$ & Low risk & There were no losses to follow-up. \\
\hline Selective reporting (reporting bias) & High risk & No means and SDs reported for BPRS. \\
\hline Other bias & Unclear risk & $\begin{array}{l}\text { Supported in part by PHS Grant from the } \\
\text { National Institute of Mental Health, Rock- } \\
\text { well, Maryland }\end{array}$ \\
\hline
\end{tabular}


Bishop 1963

\begin{tabular}{|c|c|c|}
\hline Methods & \multicolumn{2}{|c|}{$\begin{array}{l}\text { Allocation: randomly assigned, stratified by age, sex, history - no further description. } \\
\text { Blinding: double - no further description. } \\
\text { Duration: } 10 \text { weeks (preceded by } 60 \text { days washout). } \\
\text { Design: parallel. } \\
\text { Country: not reported. }\end{array}$} \\
\hline Participants & \multicolumn{2}{|c|}{$\begin{array}{l}\text { Diagnosis: schizophrenia (criteria not specified). } \\
\text { History: 'chronic'. } \\
\text { N=30. } \\
\text { Sex: both (proportions not given). } \\
\text { Age: unknown. } \\
\text { Setting: hospital. }\end{array}$} \\
\hline Interventions & \multicolumn{2}{|c|}{$\begin{array}{l}\text { 1. Chlorpromazine: dose } 800 \mathrm{mg} / \text { day max. (dose discretionary). } \mathrm{N}=10 \text {. } \\
\text { 2. Placebo. } \mathrm{N}=10 \text {. } \\
\text { 3. Benzquinamide (Quantril): dose } 1200 \mathrm{mg} / \text { day max. (dose discretionary). } \mathrm{N}=10\end{array}$} \\
\hline Outcomes & \multicolumn{2}{|c|}{$\begin{array}{l}\text { Leaving study early. } \\
\text { Global impression. } \\
\text { Unable to use - } \\
\text { Mental state: Lorr Scale, BPRS (no data reported). } \\
\text { Psychological tests: Tulane Research Battery (no data reported) }\end{array}$} \\
\hline \multicolumn{3}{|l|}{ Notes } \\
\hline \multicolumn{3}{|l|}{ Risk of bias } \\
\hline Bias & Authors' judgement & Support for judgement \\
\hline $\begin{array}{l}\text { Random sequence generation (selection } \\
\text { bias) }\end{array}$ & Unclear risk & $\begin{array}{l}\text { "Divided at random" no further details re- } \\
\text { ported. }\end{array}$ \\
\hline Allocation concealment (selection bias) & Unclear risk & No information reported. \\
\hline $\begin{array}{l}\text { Blinding of participants and personnel } \\
\text { (performance bias) } \\
\text { All outcomes }\end{array}$ & Unclear risk & "Double blind" no further details reported. \\
\hline $\begin{array}{l}\text { Blinding of outcome assessment (detection } \\
\text { bias) } \\
\text { All outcomes }\end{array}$ & Unclear risk & "Double blind" no further details reported. \\
\hline
\end{tabular}


Bishop 1963 (Continued)

\begin{tabular}{l|l|l}
\hline $\begin{array}{l}\text { Incomplete outcome data (attrition bias) } \\
\text { All outcomes }\end{array}$ & Unclear risk & $\begin{array}{l}\text { No losses to follow-up in the chlorpro- } \\
\text { mazine or placebo groups }\end{array}$ \\
\hline Selective reporting (reporting bias) & Unclear risk & $\begin{array}{l}\text { No data reported for the BPRS, Lorr scale } \\
\text { or Tulane Research Battery }\end{array}$ \\
\hline Other bias & Unclear risk & $\begin{array}{l}\text { Study supported by PHS Grant MY- } \\
3701 \text { (Psychopharmacology Service Cen- } \\
\text { tre - NIMII). Benzquinamide supplied by } \\
\text { Charles Pfizer and Company, Inc, New } \\
\text { York }\end{array}$ \\
\hline
\end{tabular}

Borison 1991

Methods

Allocation: randomly assigned - no further description.

Blinding: double - no further description.

Duration: 4 weeks (preceded by 1 week placebo washout).

Design: parallel.

Country: USA.

$\begin{array}{ll}\text { Participants } & \text { Diagnosis: schizophrenia (DSM-III criteria). } \\ \text { History: acutely ill, physically healthy. } \\ \mathrm{N}=30 . \\ \text { Sex: } 30 \mathrm{M} . \\ \text { Age: mean } 35.6 \text { yrs, range } 22-58 . \\ \text { Setting: hospital. }\end{array}$

Interventions

1. Chlorpromazine: dose 400-1600 mg/day (variable dose regimen). $\mathrm{N}=9$.

2. Placebo. $\mathrm{N}=10$.

3. Rimcazole: dose $20-400 \mathrm{mg} /$ day (variable dose regimen). $\mathrm{N}=11$

\begin{tabular}{|c|c|c|}
\hline Outcomes & \multicolumn{2}{|c|}{$\begin{array}{l}\text { Global impression. CGI. } \\
\text { Mental state. BPRS. } \\
\text { Unable to use - } \\
\text { Adverse effects: SAS (no data). }\end{array}$} \\
\hline Notes & \multicolumn{2}{|c|}{ Those leaving early 'analysed [in paper] using last observation carried forward' } \\
\hline \multicolumn{3}{|l|}{ Risk of bias } \\
\hline Bias & Authors' judgement & Support for judgement \\
\hline $\begin{array}{l}\text { Random sequence generation (selection } \\
\text { bias) }\end{array}$ & Unclear risk & $\begin{array}{l}\text { "Subjects were assigned on a double-blind, } \\
\text { random basis" no further details reported }\end{array}$ \\
\hline Allocation concealment (selection bias) & Unclear risk & No information reported. \\
\hline
\end{tabular}

Chlorpromazine versus placebo for schizophrenia (Review)

Copyright ( 2015 The Cochrane Collaboration. Published by John Wiley \& Sons, Ltd. 
Borison 1991 (Continued)

Blinding of participants and personnel Unclear risk

"Double blind” no further details reported.

(performance bias)

All outcomes

Blinding of outcome assessment (detection Unclear risk

“Double blind” no further details reported. bias)

All outcomes

Incomplete outcome data (attrition bias) Unclear risk

"Early terminators from treatment were

All outcomes analysed using last observation carried forward"

Selective reporting (reporting bias) High risk

Use of SAS not pre-specified in methods. No data reported for adverse effects

Other bias

High risk

Borison and Diamond in prison for research fraud.

Chouinard 1990

\begin{tabular}{|c|c|}
\hline Methods & $\begin{array}{l}\text { Allocation: randomly assigned - no further description. } \\
\text { Blinding: double, identical capsules. } \\
\text { Duration: } 4 \text { weeks (preceded by 3-7 days washout). } \\
\text { Design: parallel. } \\
\text { Country: Canada. }\end{array}$ \\
\hline Participants & $\begin{array}{l}\text { Diagnosis: schizophrenia (DSM-III criteria } \&>18 \text { on BPRS). } \\
\text { History: newly admitted. } \\
\mathrm{N}=62 \text {. } \\
\text { Sex: } 39 \mathrm{M}, 23 \mathrm{~F} \text {. } \\
\text { Age: mean } 39.7 \text { yrs, range } 19-62 \text {. } \\
\text { Setting: hospital inpatients, admitted through emergency room }\end{array}$ \\
\hline Interventions & $\begin{array}{l}\text { 1. Chlorpromazine: dose } 300-1200 \mathrm{mg} / \text { day (variable dose regimen). } \mathrm{N}=21 \text {. } \\
\text { 2. Placebo. } \mathrm{N}=21 \text {. } \\
\text { 3. Remoxipride: dose } 150-600 \mathrm{mg} / \mathrm{day} \text { (variable dose regimen). } \mathrm{N}=20 \\
\text { Chloral hydrate/clonazepam for sedation as requested; procyclidine for parkinsonism as } \\
\text { requested }\end{array}$ \\
\hline Outcomes & $\begin{array}{l}\text { Leaving study early. } \\
\text { Global improvement (> } 50 \% \text { reduction of BPRS score). } \\
\text { Adverse effects (as measured by requiring procyclidine). } \\
\text { Requiring sedation. } \\
\text { Unable to use - } \\
\text { Mental state: BPRS (no SD). } \\
\text { Global impression: CGI (no SD) } \\
\text { Adverse effects (no usable data). }\end{array}$ \\
\hline
\end{tabular}


Chouinard 1990 (Continued)

Notes

Risk of bias

\begin{tabular}{|c|c|c|}
\hline Bias & Authors' judgement & Support for judgement \\
\hline $\begin{array}{l}\text { Random sequence generation (selection } \\
\text { bias) }\end{array}$ & Unclear risk & $\begin{array}{l}\text { "Randomly assigned" no further details re- } \\
\text { ported. }\end{array}$ \\
\hline Allocation concealment (selection bias) & Unclear risk & No information reported. \\
\hline $\begin{array}{l}\text { Blinding of participants and personnel } \\
\text { (performance bias) } \\
\text { All outcomes }\end{array}$ & Low risk & $\begin{array}{l}\text { "Double blind", "The trial drugs were pro- } \\
\text { vided in the form of identical white opaque } \\
\text { gelatin capsules" }\end{array}$ \\
\hline $\begin{array}{l}\text { Blinding of outcome assessment (detection } \\
\text { bias) } \\
\text { All outcomes }\end{array}$ & Unclear risk & "Double blind" no further details reported. \\
\hline $\begin{array}{l}\text { Incomplete outcome data (attrition bias) } \\
\text { All outcomes }\end{array}$ & Unclear risk & $\begin{array}{l}\text { Patients that did not complete the four } \\
\text { week trial "were included in the statistical } \\
\text { analyses by using their endpoint scores at } \\
\text { time of discontinuation" } \\
\text { "Four chlorpromazine-treated patients } \\
\text { failed to complete the trial: } 3 \text { on account } \\
\text { of side effects ( } 1 \text { case of leucopenia and } 2 \\
\text { of hypotension) and } 1 \text { on account of in- } \\
\text { efficacy. Seven placebo-treated patients did } \\
\text { not complete the clinical trial ( } 1 \text { case of ab- } \\
\text { normal liver function, } 5 \text { of inefficacy, and } \\
1 \text { patient for administrative reasons)." Last } \\
\text { observation carried forward method used }\end{array}$ \\
\hline Selective reporting (reporting bias) & High risk & $\begin{array}{l}\text { No SDs reported for BPRS and CGI. No } \\
\text { useable data reported for adverse effects }\end{array}$ \\
\hline Other bias & Unclear risk & Source of funding not reported. \\
\hline
\end{tabular}




\begin{tabular}{|c|c|c|}
\hline Participants & \multicolumn{2}{|c|}{$\begin{array}{l}\text { Diagnosis: schizophrenia (Diagnostic Manual of APA, 1952). } \\
\text { History: 'chronic', in hospital > } 5 \text { years, physically healthy. } \\
\mathrm{N}=60 \text {. } \\
\text { Sex: } 60 \text { F. } \\
\text { Age: mean } 43 \text { yrs, range } 26-52 \text {. } \\
\text { Setting: hospital. }\end{array}$} \\
\hline Interventions & \multicolumn{2}{|c|}{$\begin{array}{l}\text { 1. Chlorpromazine: dose } 200-800 \mathrm{mg} / \text { day. } \mathrm{N}=20 \text {. } \\
\text { 2. Placebo (lactose): dose } 6-8 \text { capsules per day. } \mathrm{N}=20 \text {. } \\
\text { 3. Phenobarbital: dose } 120-480 \mathrm{mg} / \text { day. } \mathrm{N}=20 \\
\text { Medication given in variable dose regimen. }\end{array}$} \\
\hline Outcomes & \multicolumn{2}{|c|}{$\begin{array}{l}\text { Global improvement. } \\
\text { Adverse effects. } \\
\text { Unable to use - } \\
\text { Behaviour: OBRS (no data). } \\
\text { Psychological tests (no usable data). }\end{array}$} \\
\hline Notes & \multicolumn{2}{|c|}{$\begin{array}{l}\text { One in CPZ group withdrawn (agranulocytosis, week 12). Her other 'triplets' also with- } \\
\text { drawn, therefore, } N=57 \text { except side effects }(\mathrm{N}=60)\end{array}$} \\
\hline \multicolumn{3}{|l|}{ Risk of bias } \\
\hline Bias & Authors' judgement & Support for judgement \\
\hline $\begin{array}{l}\text { Random sequence generation (selection } \\
\text { bias) }\end{array}$ & Low risk & $\begin{array}{l}\text { Participants "individually matched into } \\
\text { triplets. Random assignment of triplet } \\
\text { members to treatment groups“, "drawn by } \\
\text { a table of random numbers" }\end{array}$ \\
\hline Allocation concealment (selection bias) & Unclear risk & No information reported. \\
\hline $\begin{array}{l}\text { Blinding of participants and personnel } \\
\text { (performance bias) } \\
\text { All outcomes }\end{array}$ & Low risk & $\begin{array}{l}\text { "Double-blind", "neither the patients nor } \\
\text { the personnel involved in the care or evalu- } \\
\text { ation of the subjects were informed of any } \\
\text { individual's medication until the end of the } \\
\text { study. Medications were dispensed in indi- } \\
\text { vidually labeled bottles so that identifica- } \\
\text { tion by code was not possible" }\end{array}$ \\
\hline
\end{tabular}


Clark 1961 (Continued)

\begin{tabular}{|c|c|c|}
\hline $\begin{array}{l}\text { Blinding of outcome assessment (detection } \\
\text { bias) } \\
\text { All outcomes }\end{array}$ & Low risk & $\begin{array}{l}\text { "Double-blind", "'neither the patients nor } \\
\text { the personnel involved in the care or evalu- } \\
\text { ation of the subjects were informed of any } \\
\text { individual's medication until the end of the } \\
\text { study" }\end{array}$ \\
\hline $\begin{array}{l}\text { Incomplete outcome data (attrition bias) } \\
\text { All outcomes }\end{array}$ & Low risk & $\begin{array}{l}\text { One participant in the chlorpromazine } \\
\text { group was withdrawn due to agranulocy- } \\
\text { tosis, along with the other two participants } \\
\text { in her "triplet" }\end{array}$ \\
\hline Selective reporting (reporting bias) & High risk & $\begin{array}{l}\text { No data reported for OBRS, and no useable } \\
\text { data reported for psychological tests }\end{array}$ \\
\hline Other bias & Unclear risk & $\begin{array}{l}\text { Supported, in part, by USPHS Grant M- } \\
1600 \text { from the National Institute of Mental } \\
\text { Health, National Institutes of Health, De- } \\
\text { partment of Health, Education, and Wel- } \\
\text { fare } \\
\text { Medications supplied by Dr Fred Alexan- } \\
\text { der of Smith, Kline, and French Laborato- } \\
\text { ries }\end{array}$ \\
\hline
\end{tabular}

Clark 1967

Methods

Allocation: randomised - table of random numbers.

Blindness: double - identical capsules.

Duration: 10 weeks.*

Design: parallel.

Setting: inpatients.

Country: USA.

\begin{tabular}{ll} 
Participants & Diagnosis: schizophrenia. \\
& History: duration ill > 5 years. \\
& N=72. \\
Sex: 72 F. \\
Age: $25-55$ years. \\
Setting: hospital. \\
\hline Interventions & 1. Chlorpromazine: dose mean 678 mg/day. N=51. \\
& 2. Placebo. N=21. \\
\hline \multirow{2}{*}{ Outcomes } & Leaving the study early. \\
& Unable to use - \\
& Mental state: BPRS, PRS (no data). \\
& Behaviour: OBRS (no data). \\
Cognitive function: Perdue Pegboard test, Digit Symbol Test (no data). \\
Physiological measures (no usable data).
\end{tabular}




\section{Risk of bias}

\begin{tabular}{l|l|l}
\hline Bias & Authors' judgement & Support for judgement \\
\hline $\begin{array}{l}\text { Random sequence generation (selection } \\
\text { bias) }\end{array}$ & Unclear risk & $\begin{array}{l}\text { "Assigned at random" no further details re- } \\
\text { ported. }\end{array}$ \\
\hline $\begin{array}{l}\text { Allocation concealment (selection bias) } \\
\text { Blinding of participants and personnel } \\
\text { (performance bias) } \\
\begin{array}{l}\text { All outcomes } \\
\text { Low risk }\end{array}\end{array}$ & Unclear risk & No information reported. \\
\hline
\end{tabular}

Blinding of outcome assessment (detection Low risk

bias)

All outcomes

Incomplete outcome data (attrition bias) Unclear risk All outcomes
"Double-blind procedure in which neither the investigators nor the subjects knew who was receiving chlorpromazine"

"Seventy subjects meeting all physical and selection criteria completed both cycles of study 1 year apart. During the course of the second cycle, 2 subjects were found to be abnormal in regard to cholesterol metabolism [...] and their data were deleted from this report"

"11 subjects taking chlorpromazine were unable to tolerate the full $800 \mathrm{mg}$ over the 10-week trial"

Selective reporting (reporting bias) High risk

No data reported for BPRS, PRS, OBRS, Perdue Pegboard test, Digit Symbol Test and physiological measures

Other bias

Unclear risk
Chlorpromazine and placebo were supplied by Smith Kline \& French Laboratories, Philadelphia, $\mathrm{Pa}$

Supported by Grant MH-04260 from the US Public Health Service 


\begin{tabular}{|c|c|c|}
\hline Methods & \multicolumn{2}{|c|}{$\begin{array}{l}\text { Allocation: randomly assigned - no further description. } \\
\text { Blinding: double, identical capsules. } \\
\text { Duration: } 14 \text { weeks (preceded by } 12 \text { week washout). } \\
\text { Design: parallel. } \\
\text { Country: USA. }\end{array}$} \\
\hline Participants & \multicolumn{2}{|c|}{$\begin{array}{l}\text { Diagnosis: chronic schizophrenia (criteria not specified). } \\
\text { History: >2 yrs of illness. } \\
\text { N=72. } \\
\text { Sex: } 72 \text { F. } \\
\text { Age: mean } 42 \text { yrs, range } 20-60 . \\
\text { Setting: hospital. }\end{array}$} \\
\hline Interventions & \multicolumn{2}{|c|}{$\begin{array}{l}\text { 1. Chlorpromazine: dose } 1000 \mathrm{mg} / \text { day max. } \mathrm{N}=18 \text {. } \\
\text { 2. Placebo. } \mathrm{N}=18 \text {. } \\
\text { 3. Trifluperidol: dose } 10 \mathrm{mg} / \text { day } \max . \mathrm{N}=18 \text {. } \\
\text { 4. No drug group. } \mathrm{N}=18 \text {. } \\
\text { Barbiturates or chloral hydrate for sedation as required. }\end{array}$} \\
\hline Outcomes & \multicolumn{2}{|c|}{$\begin{array}{l}\text { Leaving study early. } \\
\text { Global improvement. } \\
\text { Adverse effects. } \\
\text { Unable to use - } \\
\text { Behaviour: Oklahoma Rating Scale (no SD). } \\
\text { Psychological tests (no SD). } \\
\text { Physiological tests (no data). }\end{array}$} \\
\hline Notes & \multicolumn{2}{|c|}{ Groups 3 and 4 combined for purposes of review. } \\
\hline \multicolumn{3}{|l|}{ Risk of bias } \\
\hline Bias & Authors' judgement & Support for judgement \\
\hline $\begin{array}{l}\text { Random sequence generation (selection } \\
\text { bias) }\end{array}$ & Unclear risk & $\begin{array}{l}\text { "Randomly assigned" no further details re- } \\
\text { ported. }\end{array}$ \\
\hline Allocation concealment (selection bias) & Unclear risk & No information reported. \\
\hline $\begin{array}{l}\text { Blinding of participants and personnel } \\
\text { (performance bias) } \\
\text { All outcomes }\end{array}$ & Low risk & $\begin{array}{l}\text { "Identically appearing capsules from each } \\
\text { subject's individually labelled stock bottle } \\
\text { to meet the double-blind requirements of } \\
\text { the study" }\end{array}$ \\
\hline $\begin{array}{l}\text { Blinding of outcome assessment (detection } \\
\text { bias) } \\
\text { All outcomes }\end{array}$ & Unclear risk & "Double-blind" no further details reported. \\
\hline
\end{tabular}


Clark 1968a (Continued)

\begin{tabular}{l|l|l}
\hline $\begin{array}{l}\text { Incomplete outcome data (attrition bias) } \\
\text { All outcomes }\end{array}$ & Low risk & $\begin{array}{l}\text { "Sixty six patients completed the study. } \\
\text { Two patients were dropped from the CPZ } \\
\text { group because of skin rashes and a third } \\
\text { because of a severe behavioural reaction", } \\
\text { "Three were dropped form the no drug } \\
\text { group [...] one patient in TRP group com- } \\
\text { pleted only 13 weeks before undergoing } \\
\text { surgery" }\end{array}$ \\
\hline Selective reporting (reporting bias) & High risk & $\begin{array}{l}\text { No SDs reported for Oklahoma Rating } \\
\text { Scale and psychological tests. No data re- } \\
\text { ported for physiological tests }\end{array}$ \\
\hline Other bias & High risk & $\begin{array}{l}\text { Supported by grants from the National In- } \\
\text { stitute of Mental Health, US Public Health } \\
\text { Service and McNeil Laboratories Inc, Fort } \\
\text { Washington, Pennsylvania }\end{array}$ \\
\hline
\end{tabular}

\section{Clark 1968b}

Methods

Allocation: randomised - no further details.

Blinding: double - identical tablets.

Duration: 16 weeks.

Design: parallel.

Country: USA.

Diagnosis: schizophrenia.
History: duration ill $\sim 20$ years, in hospital $\sim 16$ years.
N=69.
Sex: all women.
Age: $20-60$ years, mean 45.
Setting: hospital.

Interventions

1. Chlorpromazine: dose max $1000 \mathrm{mg} /$ day. $\mathrm{N}=23$.

2. Placebo: dose 10 tablets. $\mathrm{N}=23$.

3. Butaperazine: dose $\max 100 \mathrm{mg} /$ day. $\mathrm{N}=23$.

Barbiturates, chloral hydrate, benztropine as required.

Outcomes

Leaving the study early.

Adverse effects.

Unable to use -

Global improvement (no usable data).

Behaviour: OBRS (no usable data).

Personality inventory: IMPS (modified, no usable data).

Cognitive function: Perdue Pegboard, Digit Symbol test (no usable data).

Physiological tests (no data).

Notes

Chlorpromazine versus placebo for schizophrenia (Review)

Copyright ( 2015 The Cochrane Collaboration. Published by John Wiley \& Sons, Ltd. 
Clark 1968b （Continued)

Risk of bias

\begin{tabular}{|c|c|c|}
\hline Bias & Authors' judgement & Support for judgement \\
\hline $\begin{array}{l}\text { Random sequence generation (selection } \\
\text { bias) }\end{array}$ & Unclear risk & "Randomly assigned" no further details. \\
\hline Allocation concealment (selection bias) & Unclear risk & No information reported. \\
\hline $\begin{array}{l}\text { Blinding of participants and personnel } \\
\text { (performance bias) } \\
\text { All outcomes }\end{array}$ & Low risk & $\begin{array}{l}\text { Double-blind", "All medications were } \\
\text { identical in appearance" }\end{array}$ \\
\hline $\begin{array}{l}\text { Blinding of outcome assessment (detection } \\
\text { bias) } \\
\text { All outcomes }\end{array}$ & Unclear risk & Double-blind" no further details reported. \\
\hline $\begin{array}{l}\text { Incomplete outcome data (attrition bias) } \\
\text { All outcomes }\end{array}$ & Low risk & $\begin{array}{l}\text { "Sixty seven patients completed the study. } \\
\text { One patient was dropped from the CPZ } \\
\text { group because of agranulocytosis; one was } \\
\text { lost form the BPZ group when she eloped. } \\
\text { " }\end{array}$ \\
\hline Selective reporting (reporting bias) & High risk & $\begin{array}{l}\text { No useable data was reported for global } \\
\text { improvement, OBRS, IMPS, Perdue Peg- } \\
\text { board, Digit Symbol test and physiological } \\
\text { tests }\end{array}$ \\
\hline Other bias & High risk & $\begin{array}{l}\text { Supported by grants from US Public Heath } \\
\text { Service and AH Robins Company }\end{array}$ \\
\hline
\end{tabular}

Clark 1970a

\begin{tabular}{ll} 
Methods & Allocation: randomly assigned 'by sex'. \\
& Blinding: double, identical capsules. \\
& Duration: 12 weeks (preceded by 12-week washout). \\
& Design: parallel. \\
& Country: USA. \\
\hline Participants & Diagnosis: schizophrenia (criteria not specified). \\
& History: 'chronic'. \\
N=44. \\
Sex: 7 M, 37 F. \\
Age: mean 39.7 yrs, range 22-55. \\
Setting: hospital.
\end{tabular}


Clark 1970a (Continued)

\begin{tabular}{ll}
\hline Interventions & 1. Chlorpromazine: dose $200-1000 \mathrm{mg} /$ day. $\mathrm{N}=15$. \\
& 2. Molindone: dose $20-100 \mathrm{mg} / \mathrm{day} . \mathrm{N}=15$. \\
& 3. Placebo: dose $2-10$ capsules/day. $\mathrm{N}=14$. \\
& Medication given in variable dose regimen. \\
\hline Outcomes & Leaving study early. \\
& Global improvement. \\
& Severity of illness. \\
& Cooperativeness (those who agreed to EEG tests). \\
& Adverse effects. \\
& Unable to use - \\
& Mental state: BPRS (no SD). \\
Behaviour: NOSIE (no SD). & Various psychological tests (no SD). \\
\hline Notes & Drugs to combat EPS not used. \\
\hline
\end{tabular}

Risk of bias

\begin{tabular}{|c|c|c|}
\hline Bias & Authors' judgement & Support for judgement \\
\hline $\begin{array}{l}\text { Random sequence generation (selection } \\
\text { bias) }\end{array}$ & Unclear risk & $\begin{array}{l}\text { "Randomly assigned by sex" no further de- } \\
\text { tails reported. }\end{array}$ \\
\hline Allocation concealment (selection bias) & Unclear risk & No information reported. \\
\hline $\begin{array}{l}\text { Blinding of participants and personnel } \\
\text { (performance bias) } \\
\text { All outcomes }\end{array}$ & Low risk & $\begin{array}{l}\text { "Identically appearing capsules", "double- } \\
\text { blind, with medications dispensed from in- } \\
\text { dividual stock bottles labelled only with the } \\
\text { patient's name" }\end{array}$ \\
\hline $\begin{array}{l}\text { Blinding of outcome assessment (detection } \\
\text { bias) } \\
\text { All outcomes }\end{array}$ & Unclear risk & "Double-blind" no further details reported. \\
\hline $\begin{array}{l}\text { Incomplete outcome data (attrition bias) } \\
\text { All outcomes }\end{array}$ & Low risk & $\begin{array}{l}\text { "One subject was dropped form the } \mathrm{CPZ} \\
\text { group because of abnormal liver function } \\
\text { tests; another subject on } \mathrm{CPZ} \text { was termi- } \\
\text { nated } 2 \text { weeks early because of surgery" }\end{array}$ \\
\hline Selective reporting (reporting bias) & High risk & $\begin{array}{l}\text { No SDs reported for BPRS, NOSIE and } \\
\text { the various psychological tests }\end{array}$ \\
\hline Other bias & High risk & $\begin{array}{l}\text { Supported in part by US Public Health } \\
\text { Service Grant, Research Scientist Devel- } \\
\text { opment Award from National Institute of } \\
\text { Mental Health. Endo Laboratories pro- } \\
\text { vided the medication and partial support }\end{array}$ \\
\hline
\end{tabular}

Chlorpromazine versus placebo for schizophrenia (Review) 
Clark 1970b

\begin{tabular}{|c|c|}
\hline Methods & $\begin{array}{l}\text { Allocation: randomly assigned by block - no further description. } \\
\text { Blinding: not described. } \\
\text { Duration: } 24 \text { weeks (preceded by } 12 \text { week washout). } \\
\text { Design: parallel. } \\
\text { Country: USA. }\end{array}$ \\
\hline Participants & $\begin{array}{l}\text { Diagnosis: schizophrenia - criteria not specified. } \\
\text { History: "chronic". } \\
\text { N=71. } \\
\text { Sex: } 71 \text { F. } \\
\text { Age: mean } 43.7 \text { yrs, range } 21-60 . \\
\text { Setting: hospital. }\end{array}$ \\
\hline Interventions & $\begin{array}{l}\text { 1. Chlorpromazine: dose } 150 \mathrm{mg} / \text { day. } \mathrm{N}=17 .^{*} \\
\text { 2. Chlorpromazine: dose } 300 \mathrm{mg} / \text { day. } \mathrm{N}=18 .^{*} \\
\text { 3. Chlorpromazine: dose } 600 \mathrm{mg} / \text { day. } \mathrm{N}=18 .^{*} \\
\text { 4. Placebo. } \mathrm{N}=18 .^{*} \\
\text { Medication given in fixed dose regimen; benztropine for EPS, chloral hydrate, pheno- } \\
\text { barbitone or sodium amytal for sedation, as required }\end{array}$ \\
\hline Outcomes & $\begin{array}{l}\text { Leaving study early. } \\
\text { Adverse effects. } \\
\text { Behavioural disturbance (requiring more medication on }>5 \text { occasions) } \\
\text { Unable to use - } \\
\text { Global Impression: CGI (no SD). } \\
\text { Mental state: BPRS, IMPS (no SD). } \\
\text { Behaviour: OBRS (no SD). }\end{array}$ \\
\hline Notes & $\begin{array}{l}{ }^{*} \text { Withdrawals partially described }(\mathrm{N}=4) \text { - initial group unclear. Assumed one from each } \\
\text { group (these amended numbers appear above) }\end{array}$ \\
\hline
\end{tabular}

\section{Risk of bias}

\begin{tabular}{l|l|l}
\hline Bias & Authors' judgement & Support for judgement \\
\hline $\begin{array}{l}\text { Random sequence generation (selection } \\
\text { bias) }\end{array}$ & Unclear risk & $\begin{array}{l}\text { "Subjects were assigned by block randomi- } \\
\text { sation" no further details reported }\end{array}$ \\
\hline $\begin{array}{l}\text { Allocation concealment (selection bias) } \\
\text { Blinding of participants and personnel } \\
\text { (performance bias) } \\
\text { All outcomes }\end{array}$ & Unclear risk & No information reported. \\
\hline $\begin{array}{l}\text { Blinding of outcome assessment (detection } \\
\text { bias) } \\
\text { All outcomes }\end{array}$ & Unclear risk & No information reported. \\
\hline
\end{tabular}

Chlorpromazine versus placebo for schizophrenia (Review) 
Clark 1970b (Continued)

\begin{tabular}{l|l|l}
\hline $\begin{array}{l}\text { Incomplete outcome data (attrition bias) } \\
\text { All outcomes }\end{array}$ & High risk & $\begin{array}{l}\text { "During the course of the study one subject } \\
\text { was dropped because of rash and anaemia, } \\
\text { one because of agranulocytosis, two be- } \\
\text { cause of elopement from the hospital, and } \\
\text { two because of requisite surgery". Study } \\
\text { does not report which from groups the } \\
\text { losses to follow-ups occurred }\end{array}$ \\
\hline Selective reporting (reporting bias) & High risk & No SDs reported for CGI, BPRS, IMPS, \\
\hline Other bias & Low risk & and OBRS. \\
\hline
\end{tabular}

\section{Clark 1971}

Methods Allocation: randomly assigned, blocks of 4 - no further description.

Blinding: double, identical capsules.

Duration: 4 weeks.

Design: parallel.

Country: USA.

Diagnosis: schizophrenia (minimum of 2 symptoms from list).
History: mean no. admissions CPZ group=2.4, placebo group=3.6.
N=86.
Sex: male and female (numbers unclear).
Age: mean 33 years, range 21-45.
Setting: hospital.

Interventions

1. Chlorpromazine: dose 200-1000 mg/day. $\mathrm{N}=23$.

2. Placebo (lactulose). $\mathrm{N}=21$.

3. Fluphenazine: dose $2-10 \mathrm{mg} /$ day. $\mathrm{N}=20$.

4. Thioridazine: dose $200-1000 \mathrm{mg} /$ day. $\mathrm{N}=22$.

Medication given in variable dose regimen; usual night-time sedation permitted

Outcomes

Leaving study early.

Global impression. CGI.

Adverse effects.

Unable to use -

Mental state: BPRS (no SD).

Behaviour: NOSIE (no SD).

Psychological tests (no SD).

Notes

Risk of bias

Bias

Authors' judgement

Support for judgement

Chlorpromazine versus placebo for schizophrenia (Review)

Copyright @ 2015 The Cochrane Collaboration. Published by John Wiley \& Sons, Ltd. 
Clark 1971 (Continued)

Random sequence generation (selection Unclear risk bias)
"Patients were assigned to treatment randomly in blocks of four" no further details reported

\begin{tabular}{|c|c|c|}
\hline Allocation concealment (selection bias) & Unclear risk & No information reported. \\
\hline $\begin{array}{l}\text { Blinding of participants and personnel } \\
\text { (performance bias) } \\
\text { All outcomes }\end{array}$ & Low risk & $\begin{array}{l}\text { "Double-blind", "identical appearing med } \\
\text { ication was administered from a bottle la } \\
\text { belled only with the patient's name" }\end{array}$ \\
\hline
\end{tabular}

Blinding of outcome assessment (detection Unclear risk

"Double-blind" no further details reported. bias)

All outcomes

Incomplete outcome data (attrition bias) Low risk All outcomes
"Of the 75 subjects completing the study, one placebo subject was terminated because of behavioural deterioration after only three weeks observation and one subject taking fluphenazine was discharged from the hospital as markedly improved after only two weeks observation. In both instances, final measures were obtained and their data were retained for the final analysis. Eleven additional subjects were started in the study but were dropped without obtaining final measures for a variety of reasons: in the placebo group there was one subject absent without permission (AWOL), one on convalescent leave, and one subject transferred to another hospital; in the thioridazine group there were two AWOL subjects and one with medication intolerance; in the chlorpromazine group there was one AWOL and two subjects who refused oral medication; in the fluphenazine group there was one administrative transfer and one AWOL.”

No SDs reported for BPRS, NOSIE and the psychological tests.

Supported by Public Health Service grant and Research Scientist Award. Medication provided by Smith Kline \& French Laboratories, Sandoz Inc and ER SQuibb \& Sons 
Clark 1972

\begin{tabular}{|c|c|}
\hline Methods & $\begin{array}{l}\text { Allocation: randomly assigned - no further description. } \\
\text { Blinding: double, identical capsules. } \\
\text { Duration: } 12 \text { weeks (preceded by } 12 \text { weeks washout). } \\
\text { Design: parallel. } \\
\text { Country: USA. }\end{array}$ \\
\hline Participants & $\begin{array}{l}\text { Diagnosis: schizophrenia (criteria not specified). } \\
\text { History: 'chronic', } 2+\text { yrs ill. } \\
\mathrm{N}=55 \text {. } \\
\text { Sex: } 24 \mathrm{M}, 31 \mathrm{~F} \text {. } \\
\text { Age: CPZ group mean } 42 \text { yrs, placebo group mean } 40 \text { yrs, range 21-60. } \\
\text { Setting: hospital. }\end{array}$ \\
\hline Interventions & $\begin{array}{l}\text { 1. Chlorpromazine: dose } 1000 \mathrm{mg} / \text { day. } \mathrm{N}=19 \text {. } \\
\text { 2. Placebo. } \mathrm{N}=18 \text {. } \\
\text { 3. Loxapine: dose } 10 \mathrm{mg} / \text { day. } \mathrm{N}=18 \text {. } \\
\text { Medication increasing to fixed dose; antiparkinson medication as required }\end{array}$ \\
\hline Outcomes & $\begin{array}{l}\text { Leaving study early. } \\
\text { Global impression. CGI. } \\
\text { Global severity of illness. CGI. } \\
\text { Adverse effects. } \\
\text { Unable to use - } \\
\text { Mental state: BPRS (no SD). } \\
\text { Behaviour: NOSIE (no SD). } \\
\text { Weight gain (no SD). } \\
\text { Physical tests: EKG, urine, blood (no data reported). }\end{array}$ \\
\hline Notes & \\
\hline
\end{tabular}

\section{Risk of bias}

\begin{tabular}{|c|c|c|}
\hline Bias & Authors' judgement & Support for judgement \\
\hline $\begin{array}{l}\text { Random sequence generation (selection } \\
\text { bias) }\end{array}$ & Unclear risk & $\begin{array}{l}\text { "Allocation to treatment was random, but } \\
\text { provided for balancing of groups by sex and } \\
\text { age" no further details reported }\end{array}$ \\
\hline Allocation concealment (selection bias) & Unclear risk & No information reported. \\
\hline $\begin{array}{l}\text { Blinding of participants and personnel } \\
\text { (performance bias) } \\
\text { All outcomes }\end{array}$ & Low risk & $\begin{array}{l}\text { "Double-blind", identical appearing med- } \\
\text { ication in capsule form was administered } \\
\text { orally to each subject rom his individual } \\
\text { stock bottle labelled only with his name" }\end{array}$ \\
\hline Blinding of outcome assessment (detection & Unclear risk & "Double-blind" no further details reported. \\
\hline
\end{tabular}
bias)

All outcomes

Chlorpromazine versus placebo for schizophrenia (Review)

Copyright ( 2015 The Cochrane Collaboration. Published by John Wiley \& Sons, Ltd. 
Clark 1972 (Continued)

\begin{tabular}{l|l|l}
\hline $\begin{array}{l}\text { Incomplete outcome data (attrition bias) } \\
\text { All outcomes }\end{array}$ & Low risk & $\begin{array}{l}\text { "Five patients were lost from the study: } 2 \\
\text { from the PL group because of a grand mal } \\
\text { seizure in one, and a cardiac arrhythmia } \\
\text { in the second; } 2 \text { from the CPZ group be- } \\
\text { cause of abnormal liver function in one and } \\
\text { a severe allergic reaction dermatitis with } \\
\text { photo-sensitivity on the other; } 1 \text { from the } \\
\text { LOX group because of a hip fracture" }\end{array}$ \\
\hline Selective reporting (reporting bias) & High risk & $\begin{array}{l}\text { No SDs reported for BPRS, NOSIE and } \\
\text { weight gain. No data reported for physical }\end{array}$ \\
\hline tests
\end{tabular}

Clark 1977

\begin{tabular}{|c|c|}
\hline Methods & $\begin{array}{l}\text { Allocation: randomly assigned 'by sex' - no further description. } \\
\text { Blinding: double, identical capsules. } \\
\text { Duration: } 12 \text { weeks (preceded by } 8 \text { week wash-out). } \\
\text { Design: parallel. } \\
\text { Country: USA. }\end{array}$ \\
\hline Participants & $\begin{array}{l}\text { Diagnosis: schizophrenia (criteria not specified). } \\
\text { History: 'chronic'. } \\
\text { N=27. } \\
\text { Sex: } 13 \mathrm{M}, 14 \mathrm{~F} \text {. } \\
\text { Age: mean } 43.2 \text { yrs, range } 23-61 \text {. } \\
\text { Setting: hospital. }\end{array}$ \\
\hline Interventions & $\begin{array}{l}\text { 1. Chlorpromazine: dose } 1000 \mathrm{mg} / \text { day. } \mathrm{N}=9 \text {. } \\
\text { 2. Placebo. } \mathrm{N}=9 \text {. } \\
\text { 3. Butaclamol: dose } 50 \mathrm{mg} / \text { day. } \mathrm{N}=9 \text {. } \\
\text { Medication increasing to fixed dose; antiparkinson medication for EPS as required; } \\
\text { sodium amytal and chloral hydrate for behaviour control as required }\end{array}$ \\
\hline Outcomes & $\begin{array}{l}\text { Leaving study early. } \\
\text { Global impression. CGI. } \\
\text { Adverse effects. } \\
\text { Unable to use - } \\
\text { Mental state: BPRS (no SD). } \\
\text { Global impression: CGI (no SD). } \\
\text { Behaviour: NOSIE (no SD). } \\
\text { Physical tests: EKG, urine, blood (no data). }\end{array}$ \\
\hline
\end{tabular}

Notes

Chlorpromazine versus placebo for schizophrenia (Review) 
Clark 1977 (Continued)

\section{Risk of bias}

\begin{tabular}{|c|c|c|}
\hline Bias & Authors' judgement & Support for judgement \\
\hline $\begin{array}{l}\text { Random sequence generation (selection } \\
\text { bias) }\end{array}$ & Unclear risk & $\begin{array}{l}\text { "Allocation to treatment by sex was ran- } \\
\text { dom" no further details reported }\end{array}$ \\
\hline Allocation concealment (selection bias) & Unclear risk & No information reported \\
\hline $\begin{array}{l}\text { Blinding of participants and personnel } \\
\text { (performance bias) } \\
\text { All outcomes }\end{array}$ & Low risk & $\begin{array}{l}\text { "Placebo tablets identical to the white buta- } \\
\text { clamol and to the brown CPZ preparations } \\
\text { were taken by all subjects during the dry- } \\
\text { out period and by the placebo group dur- } \\
\text { ing treatment" } \\
\text { "Each patient received his/her medication } \\
\text { from individual stock bottles" } \\
\text { "Double-blind". }\end{array}$ \\
\hline $\begin{array}{l}\text { Blinding of outcome assessment (detection } \\
\text { bias) } \\
\text { All outcomes }\end{array}$ & Unclear risk & "Double-blind" no further details reported. \\
\hline $\begin{array}{l}\text { Incomplete outcome data (attrition bias) } \\
\text { All outcomes }\end{array}$ & Unclear risk & $\begin{array}{l}\text { "Of the } 27 \text { subjects who started, three failed } \\
\text { to complete the full } 12 \text { weeks of study: one } \\
\text { female subject in the butaclamol group be- } \\
\text { came excited and agitated during the } 4 \text { th } \\
\text { week of treatment, exacerbated a labile hy- } \\
\text { pertension, and was dropped at the end of } \\
\text { the } 4 \text { th week as treatment failure. Two male } \\
\text { subjects in the placebo group also mani- } \\
\text { fested clinical deterioration, one at the } 8 \text { th } \\
\text { week and one at the } 11 \text { th week of treat- } \\
\text { ment, and were terminated as treatment } \\
\text { failures. In each instance, final rating were } \\
\text { obtained and their data were retained in the } \\
\text { analysis". Last observation carried forward } \\
\text { method used }\end{array}$ \\
\hline Selective reporting (reporting bias) & High risk & $\begin{array}{l}\text { No SDs reported for BPRS, CGI and } \\
\text { NOSIE, and no data reported for physical } \\
\text { tests }\end{array}$ \\
\hline Other bias & High risk & $\begin{array}{l}\text { Supported in part by a USPHS grant and a } \\
\text { grant-in-aid from Ayerst Laboratories, NY }\end{array}$ \\
\hline
\end{tabular}

Chlorpromazine versus placebo for schizophrenia (Review)

Copyright () 2015 The Cochrane Collaboration. Published by John Wiley \& Sons, Ltd. 
Cohen 1968

\begin{tabular}{|c|c|}
\hline Methods & $\begin{array}{l}\text { Allocation: randomised. } \\
\text { Blinding: "using a double-blind procedure". } \\
\text { Duration: } 3 \text { months. } \\
\text { Design: parallel. } \\
\text { Country: USA. }\end{array}$ \\
\hline Participants & $\begin{array}{l}\text { Diagnosis: schizophrenia. } \\
\text { History: participants had symptoms of schizophrenia for at least 1-year. } \\
\mathrm{N}=126 . \\
\text { Sex: } 54 \text { M } 72 \mathrm{~F} \text {. } \\
\text { Age: range } 18-42 \text {. } \\
\text { Setting: community outpatients clinic. }\end{array}$ \\
\hline Interventions & $\begin{array}{l}\text { 1. Chlorpromazine: dose } 180 \mathrm{mg} / \text { day. } \mathrm{N}=42 \text {. } \\
\text { 2. Placebo. } \mathrm{N}=42 \text {. } \\
\text { 3. Promazine: dose } 180 \mathrm{mg} / \text { day. } \mathrm{N}=42 \text {. }\end{array}$ \\
\hline Outcomes & $\begin{array}{l}\text { Leaving the study early. } \\
\text { Unable to use - } \\
\text { Mean change in social aggression (no SD). } \\
\text { Manifest anxiety state (no SD). }\end{array}$ \\
\hline Notes & \\
\hline
\end{tabular}

\section{Risk of bias}

\begin{tabular}{l|l|l}
\hline Bias & Authors' judgement & Support for judgement \\
\hline $\begin{array}{l}\text { Random sequence generation (selection } \\
\text { bias) }\end{array}$ & Unclear risk & $\begin{array}{l}\text { "Randomly assigned” no further details re- } \\
\text { ported. }\end{array}$ \\
\hline Allocation concealment (selection bias) & Unclear risk & No information reported. \\
\hline $\begin{array}{l}\text { Blinding of participants and personnel } \\
\text { (performance bias) } \\
\text { All outcomes }\end{array}$ & Unclear risk & "Double-blind" no further details reported. \\
\hline
\end{tabular}

Blinding of outcome assessment (detection Unclear risk bias)

All outcomes

\begin{tabular}{l|l|l}
\hline $\begin{array}{l}\text { Incomplete outcome data (attrition bias) } \\
\text { All outcomes }\end{array}$ & Low risk & No losses to follow-up reported. \\
\hline Selective reporting (reporting bias) & High risk & $\begin{array}{l}\text { No SDs reported for social aggression and } \\
\text { manifest anxiety state }\end{array}$ \\
\hline Other bias & Low risk & $\begin{array}{c}\text { Supported by grants from the National } \\
\text { Institute of Mental Health, Public Health }\end{array}$ \\
\hline
\end{tabular}


Cohen 1968 (Continued)

Service

Cole 1964

Methods
Allocation: randomly assigned, sealed envelopes, stratified by sex and race (no further
description).
Blinding: double, oral medication 'prepared as standard No. 2 pink capsules', IM from
'1 cc glass ampules' with sterile saline for placebo.
Duration: 6 weeks.
Design: parallel.
Country: USA.

Participants

Diagnosis: schizophrenia (presence of specific symptoms/behaviours).

History: newly admitted, recent onset illness.

$\mathrm{N}=463$.

Sex: male and female (proportions not given).

Age: $16-45$ yrs.

Setting: hospital.

Exclusions: childhood autism or schizophrenia, brain syndrome, learning disability, alcoholism, epilepsy, drug abuse

Interventions

1. Chlorpromazine: dose 200-1600 mg/day or 50-400 mg/day (IM). N=112.

2. Placebo: dose 2-16 doses/day or 2-16 injections/day (IM). $\mathrm{N}=125$.

3. Fluphenazine: dose $2-16 \mathrm{mg} /$ day or $1-8 \mathrm{mg} /$ day (IM). $\mathrm{N}=115$.

4. Thioridazine: dose 200-1600 mg/day or 50-400 mg/day (IM). $\mathrm{N}=111$

Medication given in discretionary dose regimen; antiparkinsonian medication for EPS as required

Outcomes

Leaving study early.

Adverse effects.

Unable to use -

Global impression: Global Rating of Severity of Mental Illness \& Global Rating of Improvements (data not reported by group).

Mental state: IMPS (data not reported by group).

Behaviour: Burdock Ward Behaviour Rating Scale (data not reported by group)

Notes

Risk of bias

Bias

Random sequence generation (selection Unclear risk bias)

Allocation concealment (selection bias) Unclear risk

\section{Support for judgement}

"Stratified by sex with randomised assignment to drug treatment within each sex group" no further details reported

No information reported. 


\section{Cole 1964 (Continued)}

Blinding of participants and personnel Low risk (performance bias)

All outcomes
"Double-blind" oral medication "prepared as standard No. 2 pink capsules”, IM from " 1 cc glass ampules" with sterile saline for placebo

"Double-blind" no further details reported.

bias)

All outcomes

Incomplete outcome data (attrition bias) Unclear risk All outcomes
119 out of 463 participants were lost to follow-up. Reasons for loss to follow-up were balanced across groups, apart from treatment failure where "the majority of patients who were dropped because of treatment failure were on placebo"

Data was not reported by group for Global Rating of Severity of Mental Illness \& Global Rating of Improvements, IMPS and Burdock Ward Behaviour Rating Scale

Supported by NIMH grants.

Cooper 2000

Methods

Allocation: randomly assigned in blocks of 6 - no further description.

Blinding: "double dummy technique ... used to maintain blinding".

Duration: 8 weeks.

Design: parallel.

Country: Multi-centre (Belgium, UK., Ireland and Poland)

Participants

Diagnosis: schizophrenia (DSM-III-R \& > moderately ill on CGI).

History: acute exacerbation or sub chronic/chronic.

$\mathrm{N}=159$.

Sex: 115 M, 44 F.

Age: mean -39 yrs, range 18-65.

Setting: inpatients and outpatients.

Interventions

1. Chlorpromazine: dose $600 \mathrm{mg} /$ day. $\mathrm{N}=53$.

2. Placebo. $\mathrm{N}=53$.

3. Zotepine: dose $300 \mathrm{mg} /$ day. $\mathrm{N}=53$.

Benzodiazepines or chloral hydrate for sleeplessness as required; anticholinergic medication for EPS as required

Outcomes

Leaving study early.

Global improvement (50\% reduction in BPRS).

Global impression: CGI (no improvement psychiatrist rated).

Unable to use - 
Adverse effects (unclear if data includes withdrawals).

Mental state: BPRS, SANS (unsure of data).

Global impression: CGI (unsure of data).

Adverse effects: AIMS, COSTART, EPMS, Simpson and Angus (no means, SD)

Notes

Unclear if data for 'leaving study early' and 'improvement' include 1 person omitted

from 'ITT' analysis. Author contacted, replied, and further data awaited

\section{Risk of bias}

$\begin{array}{ll}\text { Bias Authors' judgement } & \text { Audgents }\end{array}$

Random sequence generation (selection Unclear risk bias)

\section{Support for judgement}

"All eligible patients were allocated a study number and randomly assigned in blocks of six" no further details reported

No information reported.

"Double-blind"

"A double-dummy technique was used to maintain blinding because of differences in capsule and tablet appearances, i.e. patients received active zotepine plus placebo chlorpromazine or placebo zotepine plus active chlorpromazine or double placebo."

"Double-blind" no further details reported.

Blinding of outcome assessment (detection Unclear risk bias)

All outcomes

Incomplete outcome data (attrition bias) Unclear risk All outcomes

"ITT analysis"

"A total of 89 patients completed the full 8-week study." "Sixty-nine patients withdrew from the study" Reasons for leaving the study not fully described

Selective reporting (reporting bias) High risk

For adverse effects it is unclear if data includes withdrawals. We are unsure of the data reported for BPRS, SANS, CGI, AIMS, COSTART and EPMS. No means and SDs were reported for Simpson and Angus

Other bias

High risk
Funded by Knoll Pharmaceuticals. Data analysis was by Knoll in conjunction with Dr Cooper 


$\begin{array}{ll}\text { Methods } & \text { Allocation: randomised. } \\ & \text { Blinding: double blind. } \\ & \text { Duration: } 15 \text { weeks. } \\ \text { Design: parallel. } \\ \text { Country: USA. }\end{array}$

Participants

Diagnosis: schizophrenia.

History: chronic schizophrenia.

$\mathrm{N}=18$.

Sex: female.

Age: mean 37, range 26-47.

Setting: hospital.

Interventions

1. Chlorpromazine: dose mean $2400 \mathrm{mg} /$ day, $2000-3000 \mathrm{mg} /$ day . $\mathrm{N}=9$.

2. Placebo. $\mathrm{N}=9$.

Outcomes

Leaving the study early.

Adverse effects (jaundice, skin reactions).

Unable to use -

Ward evaluation (unpublished scale).

Notes

Risk of bias

\begin{tabular}{|c|c|c|}
\hline Bias & Authors' judgement & Support for judgement \\
\hline $\begin{array}{l}\text { Random sequence generation (selection } \\
\text { bias) }\end{array}$ & Unclear risk & No information reported. \\
\hline Allocation concealment (selection bias) & Unclear risk & No information reported. \\
\hline $\begin{array}{l}\text { Blinding of participants and personnel } \\
\text { (performance bias) } \\
\text { All outcomes }\end{array}$ & Unclear risk & $\begin{array}{l}\text { "Those patients on placebo were given } \\
\text { tablets which were identical in appearance } \\
\text { with chlorpromazine." } \\
\text { "Until the patients were receiving } 1000 \\
\text { mg of chlorpromazine a day, the hospital } \\
\text { pharmacist was was the only person who } \\
\text { knew which patients were receiving place- } \\
\text { bos. At the } 1000 \text { mg level the ward physi- } \\
\text { cian checked the master list to determine } \\
\text { who was on the placebos" }\end{array}$ \\
\hline
\end{tabular}

Blinding of outcome assessment (detection Unclear risk bias)

No information reported.

All outcomes

Incomplete outcome data (attrition bias) Low risk All outcomes

There were no losses to follow-up.

Chlorpromazine versus placebo for schizophrenia (Review)

Copyright $(2015$ The Cochrane Collaboration. Published by John Wiley \& Sons, Ltd. 
Dean 1958 (Continued)

\begin{tabular}{|c|c|c|}
\hline Selective reporting (reporting bias) & Low risk & All expected outcomes reported. \\
\hline Other bias & Unclear risk & $\begin{array}{l}\text { Chlorpromazine supplied by Smith Kline } \\
\& \text { French Laboratories } \\
\text { Source of funding not reported. }\end{array}$ \\
\hline
\end{tabular}

\section{Engelhardt 1960}

\begin{tabular}{|c|c|c|}
\hline Methods & \multicolumn{2}{|c|}{$\begin{array}{l}\text { Allocation: randomly assigned - no further description. } \\
\text { Blinding: double, identical capsules. } \\
\text { Duration: } 18 \text { months. } \\
\text { Design: parallel. } \\
\text { Country: USA. }\end{array}$} \\
\hline Participants & \multicolumn{2}{|c|}{$\begin{array}{l}\text { Diagnosis: schizophrenia (criteria not specified). } \\
\text { History: illness }>1 \text { yr. } \\
\mathrm{N}=173 \text {. } \\
\text { Sex: not reported. } \\
\text { Age: range } 18-40 \text { yrs. } \\
\text { Setting: outpatients department. }\end{array}$} \\
\hline Interventions & \multicolumn{2}{|c|}{$\begin{array}{l}\text { 1. Chlorpromazine: dose } 50-800 \mathrm{mg} / \text { day (variable dose regimen). } \mathrm{N}=62 \text {. } \\
\text { 2. Placebo. } \mathrm{N}=56 \text {. } \\
\text { 3. Promazine: dose } 50-800 \mathrm{mg} / \text { day (variable dose regimen). } \mathrm{N}=55\end{array}$} \\
\hline Outcomes & \multicolumn{2}{|c|}{$\begin{array}{l}\text { Leaving study early. } \\
\text { Relapse (hospitalisation). }\end{array}$} \\
\hline Notes & \multicolumn{2}{|c|}{$\begin{array}{l}\text { Above data extracted from Engelhardt (JAMA 1960;173:147-9). } \\
\text { Other reports have greater 'N' (of which the } 173 \text { above are assumed to be an unbiased } \\
\text { sub-sample) but no data is usable from these papers }\end{array}$} \\
\hline \multicolumn{3}{|l|}{ Risk of bias } \\
\hline Bias & Authors' judgement & Support for judgement \\
\hline $\begin{array}{l}\text { Random sequence generation (selection } \\
\text { bias) }\end{array}$ & Unclear risk & $\begin{array}{l}\text { "Drug assignment was random" no further } \\
\text { details reported. }\end{array}$ \\
\hline Allocation concealment (selection bias) & Unclear risk & No information reported. \\
\hline $\begin{array}{l}\text { Blinding of participants and personnel } \\
\text { (performance bias) } \\
\text { All outcomes }\end{array}$ & Low risk & $\begin{array}{l}\text { "Double-blind" } \\
\text { "The medication was in the form of pink } \\
\text { capsules containing either placebo, pro- } \\
\text { mazine hydrochloride or chlorpromazine } \\
\text { hydrochloride" } \\
\text { "The treating psychiatrist did not know }\end{array}$ \\
\hline
\end{tabular}


Engelhardt 1960 (Continued)

which agent the patient received"

\begin{tabular}{l|l|l}
\hline $\begin{array}{l}\text { Blinding of outcome assessment (detection } \\
\text { bias) } \\
\text { All outcomes }\end{array}$ & Unclear risk & "Double-blind” no further details reported. \\
\hline $\begin{array}{l}\text { Incomplete outcome data (attrition bias) } \\
\text { All outcomes }\end{array}$ & Unclear risk & “The overall drop-out rate was $36.4 \%$ (63 \\
& & $\begin{array}{l}\text { out of } 173 \text { patients), while for individual } \\
\text { agents the rates were as follows: placebo, 33. } \\
9 \% \text {; and chlorpromazine, } 40.3 \% ” \\
\text { for loss to follow-up not reported }\end{array}$ \\
\hline Selective reporting (reporting bias) & Unclear risk & $\begin{array}{l}\text { No outcomes pre-specified in methods. } \\
\text { Other reports have greater 'N' (of which } \\
\text { the 173 above are assumed to be an unbi- } \\
\text { ased sub-sample) but no data is usable from } \\
\text { these papers }\end{array}$ \\
\hline & Low risk & $\begin{array}{l}\text { Study supported in part by a grant from } \\
\text { National Institute of Mental Health, US } \\
\text { Public Health Service }\end{array}$ \\
\hline
\end{tabular}

Fink 1963

Methods

Allocation: randomly assigned - no further description.

Blinding: used " $40 \mathrm{cc}$ of highly flavoured liquid“.

Duration: 6 weeks, follow-up 2-3 yrs.

Design: parallel.

Country: USA.

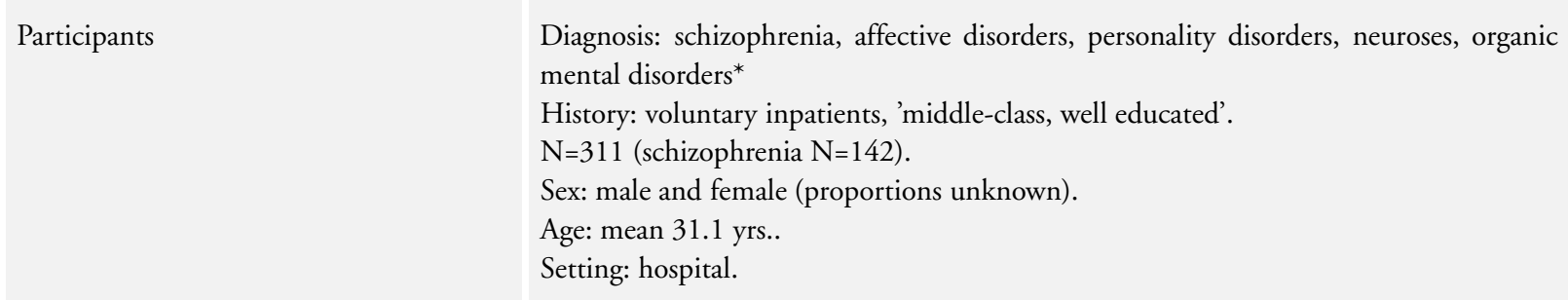

Interventions $\quad$ 1. Chlorpromazine: dose $1200 \mathrm{mg} / \mathrm{day} . \mathrm{N}=51$.

2. Placebo. $\mathrm{N}=44$.

3. Imipramine: dose $300 \mathrm{mg} /$ day. $\mathrm{N}=47$.

Medication increasing to fixed dose; group 1 given procyclidine to prevent EPS: dose max. $15 \mathrm{mg} /$ day

Outcomes

Global improvement.

Leaving the study early (Belmont 1963, N=19)

Unable to use -

Mental state: MSRPP (no usable data). 
Fink 1963 (Continued)

Memory: Rorschach tests (no SD).

\begin{tabular}{ll}
\hline Notes & *Review uses schizophrenia data only. \\
& Another 33 participants in Klein, Honigfeld, and Feldman report (1968) but no data. \\
& Belmont 1963 reported data on a subgroup of 19 people with schizophrenia
\end{tabular}

\section{Risk of bias}

\begin{tabular}{|c|c|c|}
\hline Bias & Authors' judgement & Support for judgement \\
\hline $\begin{array}{l}\text { Random sequence generation (selection } \\
\text { bias) }\end{array}$ & Unclear risk & $\begin{array}{l}\text { "Randomly assigned" no further details re- } \\
\text { ported. }\end{array}$ \\
\hline Allocation concealment (selection bias) & Unclear risk & No information reported. \\
\hline $\begin{array}{l}\text { Blinding of participants and personnel } \\
\text { (performance bias) } \\
\text { All outcomes }\end{array}$ & Low risk & $\begin{array}{l}\text { "Double-blind" } \\
\text { "Each medication was dissolved in a highly } \\
\text { flavoured liquid vehicle and each patient } \\
\text { received } 40 \mathrm{ml} \text { per day from individually la- } \\
\text { belled bottles" }\end{array}$ \\
\hline $\begin{array}{l}\text { Blinding of outcome assessment (detection } \\
\text { bias) } \\
\text { All outcomes }\end{array}$ & Unclear risk & "Double-blind" no further details reported. \\
\hline $\begin{array}{l}\text { Incomplete outcome data (attrition bias) } \\
\text { All outcomes }\end{array}$ & Unclear risk & $\begin{array}{l}\text { "Of the } 173 \text { patients starting medication, } \\
19 \text { did not complete the study because of } \\
\text { psychiatric reasons }[\ldots] 5 \text { for medical com- } \\
\text { plications }[\ldots] 5 \text { patients received an active } \\
\text { placebo in a methodological substudy and } \\
\text { are not included in this analysis }\end{array}$ \\
\hline Selective reporting (reporting bias) & High risk & $\begin{array}{l}\text { No useable data reported for the MSRPP } \\
\text { and no SDs reported for Rorschach tests }\end{array}$ \\
\hline Other bias & Low risk & $\begin{array}{l}\text { Partly funded by National Institute of } \\
\text { Mental Health, USPHS }\end{array}$ \\
\hline
\end{tabular}

Fleming 1959

Methods

Allocation: randomly assigned - no further description.

Blinding: double, identical capsules.

Duration: 6 months (preceded by 'several weeks' washout).

Design: parallel.

Country: Ireland. 
Fleming 1959 (Continued)

\begin{tabular}{|c|c|}
\hline Participants & $\begin{array}{l}\text { Diagnosis: schizophrenia (criteria not specified). } \\
\text { History: 'chronic', mean duration ill } 21 \text { yrs. } \\
\mathrm{N}=63 \text {. } \\
\text { Sex: } 63 \mathrm{~F} \text {. } \\
\text { Age: mean } 57.6 \text { yrs. } \\
\text { Setting: hospital. }\end{array}$ \\
\hline Interventions & $\begin{array}{l}\text { 1. Chlorpromazine: dose } 75 \mathrm{mg} / \text { day increasing to } 300 \mathrm{mg} / \text { day max. } \mathrm{N}=21 \text {. } \\
\text { 2. Placebo. } \mathrm{N}=21 \text {. } \\
\text { 3. Promazine: dose } 75 \mathrm{mg} / \text { day increasing to } 300 \mathrm{mg} / \text { day max. } \mathrm{N}=21\end{array}$ \\
\hline Outcomes & $\begin{array}{l}\text { Leaving study early. } \\
\text { Disturbed behaviour (“noisy, aggressive or disturbed incidents”). } \\
\text { Adverse effects. } \\
\text { Unable to use - } \\
\text { Mental state: Powick Psychiatric Rating Scale (no SD). }\end{array}$ \\
\hline Notes & \\
\hline
\end{tabular}

Risk of bias

\begin{tabular}{|c|c|c|}
\hline Bias & Authors' judgement & Support for judgement \\
\hline $\begin{array}{l}\text { Random sequence generation (selection } \\
\text { bias) }\end{array}$ & Unclear risk & $\begin{array}{l}\text { "Patients were sub-divided, upon a random } \\
\text { basis, into } 3 \text { equal groups" no further details } \\
\text { reported }\end{array}$ \\
\hline Allocation concealment (selection bias) & Unclear risk & No information reported. \\
\hline $\begin{array}{l}\text { Blinding of participants and personnel } \\
\text { (performance bias) } \\
\text { All outcomes }\end{array}$ & Low risk & $\begin{array}{l}\text { "Double-blind" } \\
\text { "the tablets of the } 3 \text { treatments were iden- } \\
\text { tical in appearance, the hospital dispenser } \\
\text { alone knowing to which treatment any par- } \\
\text { ticular patient had been assigned at the out- } \\
\text { set" }\end{array}$ \\
\hline
\end{tabular}

Blinding of outcome assessment (detection Unclear risk

“Double-blind" no further details reported.

bias)

All outcomes

Incomplete outcome data (attrition bias) Low risk

All outcomes
"12 patients who failed to complete the trial was as follows: 6 patient received ECT; 2 patients developed severe extrapyramidal symptoms (chlorpromazine); 1 patient developed agranulocytosis (chlorpromazine); and 3 patients were withdrawn for miscellaneous physical considerations (promazine) 
Fleming 1959 (Continued)

"The loss of patients was equally distributed"

\begin{tabular}{|c|c|c|}
\hline Selective reporting (reporting bias) & High risk & $\begin{array}{l}\text { No SD reported for Powick Psychiatric Rat- } \\
\text { ing Scale. }\end{array}$ \\
\hline Other bias & Unclear risk & $\begin{array}{l}\text { John Wyeth \& Bro. supplied the pro- } \\
\text { mazine, Messrs, May \& Baker Ltd supplied } \\
\text { chlorpromazine and placebo tablets }\end{array}$ \\
\hline
\end{tabular}

\section{Grygier 1958}

Methods

Allocation: randomly assigned - pairs matched (on age, duration of illness, intelligence, and aptitude for OT), and 'pharmacist decided at random' - no further description.

Blinding: not described but raters asked to guess which participants were on which medication.

Duration: 24 weeks.

Design: parallel.

Country: UK.

Participants

Diagnosis: chronic schizophrenia (criteria not specified).

History: 'chronic', mean duration ill 19.6 yrs.

$\mathrm{N}=30$.

Sex: $30 \mathrm{~F}$.

Age: mean 49.8 yrs, SD 10.7 yrs.

Setting: hospital.

Interventions

Outcomes
1. Chlorpromazine: dose $150 \mathrm{mg} /$ day. $\mathrm{N}=15$.

2. Placebo. $\mathrm{N}=15$.

Global improvement.

Unable to use -

Behaviour: Albany Behavioral Rating Scale (no SD).

Leaving study early (both members of a pair removed from analysis when one left).

Adverse effects (both members of a pair removed from analysis when one developed a serious side effect e.g. granulocytosis, jaundice)

Notes

\section{Risk of bias}

\begin{tabular}{|c|c|c|}
\hline Bias & Authors' judgement & Support for judgement \\
\hline $\begin{array}{l}\text { Random sequence generation (selection } \\
\text { bias) }\end{array}$ & Unclear risk & $\begin{array}{l}\text { "selected two groups, matching them as } \\
\text { closely as possible", "pharmacist decided at } \\
\text { random" no further details reported }\end{array}$ \\
\hline
\end{tabular}




\section{Grygier 1958 (Continued)}

\begin{tabular}{|c|c|c|}
\hline Allocation concealment (selection bias) & Low risk & $\begin{array}{l}\text { "The pharmacist decided at random which } \\
\text { group would receive chlorpromazine and } \\
\text { which inert tablets, and only she had this } \\
\text { information at any time" }\end{array}$ \\
\hline $\begin{array}{l}\text { Blinding of participants and personnel } \\
\text { (performance bias) } \\
\text { All outcomes }\end{array}$ & Unclear risk & No information reported. \\
\hline $\begin{array}{l}\text { Blinding of outcome assessment (detection } \\
\text { bias) } \\
\text { All outcomes }\end{array}$ & Unclear risk & $\begin{array}{l}\text { "At the end of the experiment both raters } \\
\text { were asked to "guess" the composition of } \\
\text { the chlorpromazine group" no further de- } \\
\text { tails reported, implies assessors were blind } \\
\text { for treatment allocation }\end{array}$ \\
\hline $\begin{array}{l}\text { Incomplete outcome data (attrition bias) } \\
\text { All outcomes }\end{array}$ & High risk & $\begin{array}{l}\text { "if any patient had to discontinue the pro- } \\
\text { gram, her "pair" could also be omitted" } \\
\text { "Three pairs were lost: one due to death } \\
\text { from unassociated causes; two due to ma- } \\
\text { jor side-effects". Both members of a pair re- } \\
\text { moved from analysis when one left }\end{array}$ \\
\hline Selective reporting (reporting bias) & High risk & $\begin{array}{l}\text { No SDs reported for Albany Behavioral } \\
\text { Rating Scale. }\end{array}$ \\
\hline Other bias & Unclear risk & Source of funding not reported. \\
\hline
\end{tabular}

\section{Gwynne 1962}

\begin{tabular}{ll} 
Methods & Allocation: randomised. \\
Blinding: unclear. & Duration: 4 months. \\
& Design: parallel. \\
& Setting: inpatients. \\
& Country: not reported. \\
\hline Participants & Diagnosis: schizophrenia. \\
& \begin{tabular}{l} 
N=78. \\
Age: average 49 years. \\
Sex: M 38 F 38. \\
History: Hospital record diagnosis of schizophrenia for a least 5 years, history of with- \\
drawal for at least one year. \\
Exclusions: not reported. \\
Setting: hospital. \\
\hline 1. Chlorpromazine: dose 7 days on $100 \mathrm{mg} /$ day, $200 \mathrm{mg} / \mathrm{day}, 300 \mathrm{mg} / \mathrm{day}$, and $400 \mathrm{mg} /$ \\
\hline day until maximum improvement or side-effects intervened. $\mathrm{N}=26$. \\
2. Trifluoperazine: dose 7 days on $10 \mathrm{mg} /$ day, $20 \mathrm{mg} / \mathrm{day}, 30 \mathrm{mg} / \mathrm{day}$, and $40 \mathrm{mg} / \mathrm{day}$
\end{tabular} \\
\hline
\end{tabular}


Gwynne 1962 (Continued)

until maximum improvement or side-effects intervened. $\mathrm{N}=26$.

3. Placebo. $\mathrm{N}=26$.

Benztropine methanesulfonate $(2 \mathrm{mg})$ as required.

\begin{tabular}{ll}
\hline Outcomes & $\begin{array}{l}\text { Adverse effects*. } \\
\text { Leaving the study early. } \\
\text { Unable to use - } \\
\text { Mental state: MRSPP (no means and SDs reported) }\end{array}$ \\
\hline Notes & $* \mathrm{~N}$ not reported, assumed to be N randomised. \\
\hline
\end{tabular}

\section{Risk of bias}

\begin{tabular}{|c|c|c|}
\hline Bias & Authors' judgement & Support for judgement \\
\hline $\begin{array}{l}\text { Random sequence generation (selection } \\
\text { bias) }\end{array}$ & Unclear risk & $\begin{array}{l}\text { "Three groups of } 26 \text { patients each ( } 13 \text { males } \\
\text { and } 13 \text { females) were formed by random } \\
\text { selection from the basic group" no further } \\
\text { details reported }\end{array}$ \\
\hline Allocation concealment (selection bias) & Unclear risk & No information reported. \\
\hline $\begin{array}{l}\text { Blinding of participants and personnel } \\
\text { (performance bias) } \\
\text { All outcomes }\end{array}$ & Unclear risk & $\begin{array}{l}\text { "All drugs and placebo were identical in } \\
\text { appearance and taste." No further details } \\
\text { reported }\end{array}$ \\
\hline $\begin{array}{l}\text { Blinding of outcome assessment (detection } \\
\text { bias) } \\
\text { All outcomes }\end{array}$ & Unclear risk & No information reported. \\
\hline $\begin{array}{l}\text { Incomplete outcome data (attrition bias) } \\
\text { All outcomes }\end{array}$ & Low risk & $\begin{array}{l}\text { In the placebo group, one participant left } \\
\text { the study early due to adverse effects and } \\
\text { two due to unmanageability. There were no } \\
\text { losses to follow-up in the chlorpromazine } \\
\text { group }\end{array}$ \\
\hline Selective reporting (reporting bias) & High risk & No means and SDs reported for MSRPP. \\
\hline Other bias & Unclear risk & $\begin{array}{l}\text { Drugs provided by Smith, Kline and } \\
\text { French, and Merck, Sharp \& Dohme } \\
\text { Source of funding not reported. }\end{array}$ \\
\hline
\end{tabular}



drugs]. In turn, these code letters ... assigned in serial fashion to patients on each ward, thus insuring randomised and unknown assignment of drug and placebo'.

Blinding: double, identical capsules and blindness tested (see notes).

Duration: 66 days (preceded by 32 day washout).

Design: parallel.

Country: USA.

\begin{tabular}{|c|c|}
\hline Participants & $\begin{array}{l}\text { Diagnosis: schizophrenia (criteria not specified). } \\
\text { History: 'chronic', 'semi-disturbed'. } \\
\mathrm{N}=175 \text {. } \\
\text { Sex: } 54 \mathrm{M}, 121 \mathrm{~F} \text {. } \\
\text { Age: range } 20-59 \text { yrs. } \\
\text { Setting: hospital. }\end{array}$ \\
\hline Interventions & $\begin{array}{l}\text { 1. Chlorpromazine: dose variable up to } 750 \mathrm{mg} / \text { day (discretionary). } \mathrm{N}=87 \text {. } \\
\text { 2. Placebo (terra alba). } \mathrm{N}=88 \text {. }\end{array}$ \\
\hline Outcomes & $\begin{array}{l}\text { Leaving study early. } \\
\text { Global improvement. } \\
\text { Behaviour. Modified Fergus Falls Behavior Rating Sheet. } \\
\text { Adverse effects. } \\
\text { Unable to use - } \\
\text { Specific symptoms (no usable data). } \\
\text { Liver biopsy data (non-random subset of participants). }\end{array}$ \\
\hline Notes & $\begin{array}{l}\text { Blindness testing. Psychiatrists guessed } 22 / 50 \mathrm{CPZ} \text { group correctly, and } 56 / 61 \text { placebo } \\
\text { group correctly. Psychologists guessed } 31 / 50 \mathrm{CPZ} \text { group correctly, and } 53 / 63 \text { placebo } \\
\text { group correctly - side effects=main source of unblinding }\end{array}$ \\
\hline
\end{tabular}

Risk of bias

\begin{tabular}{|c|c|c|}
\hline Bias & Authors' judgement & Support for judgement \\
\hline $\begin{array}{l}\text { Random sequence generation (selection } \\
\text { bias) }\end{array}$ & Unclear risk & $\begin{array}{l}\text { "Randomised selection" no further details } \\
\text { reported. }\end{array}$ \\
\hline
\end{tabular}

Allocation concealment (selection bias) Low risk
Blinding of participants and personnel Low risk (performance bias)

All outcomes
"The drug manufacturer supplied the material in 10 coded batches. Half of the batches contained drug, and half placebo (terra alba), and code letters were assigned at random to these batches. In turn, these codes letters were assigned in serial fashion to

"Double-blind"

"identical-appearing placebo" 


\section{Hall 1955 (Continued)}

\begin{tabular}{l|l}
$\begin{array}{l}\text { Blinding of outcome assessment (detection } \\
\text { bias) }\end{array}$ & Unclear risk \\
All outcomes & $\begin{array}{l}\text { "Double-blind“, "the participating tech- } \\
\text { nicians, psychiatrists and psychologist } \\
\text { recorded their judgments as the whether } \\
\text { the patient received drug or placebo", "the } \\
\text { psychiatrists and psychologist were neither } \\
\text { completely "blind" nor completely "un- } \\
\text { blind" }\end{array}$ \\
\hline
\end{tabular}

Incomplete outcome data (attrition bias) Low risk All outcomes

Selective reporting (reporting bias)

Other bias

High risk
"The three patients who developed jaundice were eliminated from the project"

There were no useable data for specific symptoms and liver biopsy data was only reported for a non-random subset of participants

Smith, Kline \& French Laboratories provided chlorpromazine, partly supported the study with a grant for statistical analysis and provided other assistance

Hamill 1975

Methods

Allocation: assigned 'using a table of random numbers'.

Blinding: unclear.

Duration: 5 days.

Design: parallel.

Country: USA.

Participants

Diagnosis: schizophrenia (presence of $>2$ symptoms from checklist).

History: newly admitted.

$\mathrm{N}=44$.

Sex: 33\% M, 67\% F.

Age: range $18-55$ yrs.

Setting: hospital.

Interventions

1. Chlorpromazine: dose 306-475 mg/day. $\mathrm{N}=22$.

2. Placebo. $\mathrm{N}=22$.

Medication given in variable dose regimen.

Outcomes

Leaving study early.

Unable to use -

Mental state: BPRS (no mean, N, or SD).

Global improvement: CGI (no SD).

Behaviour: NOSIE (no mean, N, or SD).

Notes

Chlorpromazine versus placebo for schizophrenia (Review) 


\section{Hamill 1975 (Continued)}

\section{Risk of bias}

\begin{tabular}{|c|c|c|}
\hline Bias & Authors' judgement & Support for judgement \\
\hline $\begin{array}{l}\text { Random sequence generation (selection } \\
\text { bias) }\end{array}$ & Low risk & $\begin{array}{l}\text { "Assignment of patients to the chlorpro- } \\
\text { mazine or the placebo group was deter- } \\
\text { mined using a table of random numbers" }\end{array}$ \\
\hline Allocation concealment (selection bias) & Unclear risk & $\begin{array}{l}\text { "Patients were given a number from } 1 \text { to } 44 \\
\text { according to the randomisation and with- } \\
\text { out the participation of the research psy- } \\
\text { chiatrist" }\end{array}$ \\
\hline $\begin{array}{l}\text { Blinding of participants and personnel } \\
\text { (performance bias) } \\
\text { All outcomes }\end{array}$ & Unclear risk & No information reported. \\
\hline $\begin{array}{l}\text { Blinding of outcome assessment (detection } \\
\text { bias) } \\
\text { All outcomes }\end{array}$ & Unclear risk & No information reported. \\
\hline $\begin{array}{l}\text { Incomplete outcome data (attrition bias) } \\
\text { All outcomes }\end{array}$ & Low risk & $\begin{array}{l}\text { "Of the } 44 \text { patients evaluated, } 11 \text { were } \\
\text { dropped from the study during the } 5 \text { day } \\
\text { period. OF the } 111 \text { dropped patients, } 6 \\
\text { were in the drug group and } 5 \text { in the placebo } \\
\text { group." Reasons for leaving the study early } \\
\text { balanced across groups }\end{array}$ \\
\hline Selective reporting (reporting bias) & High risk & $\begin{array}{l}\text { No useable data reported for the BPRS and } \\
\text { NOSIE and no SDs reported for CGI }\end{array}$ \\
\hline Other bias & Unclear risk & $\begin{array}{l}\text { Source of funding not reported. Placebo } \\
\text { provided by Smith Kline \& French Labo- } \\
\text { ratories, Philadelphia, Pa }\end{array}$ \\
\hline
\end{tabular}

Hamilton 1960

\begin{tabular}{ll} 
Methods & Allocation: block randomisation into six groups. \\
& Blinding: double, 'placebo tablets .... indistinguishable \\
& Design: factorial $(2 \times 3)$. \\
& Duration: 8 weeks. \\
& Country: UK. \\
\hline Participants & Diagnosis: schizophrenia (no specified criteria). \\
& History: 'chronic'; all liable to overactivity/aggression. \\
& N=54. \\
& Sex: $54 \mathrm{M}$. \\
& Age: mean 38 yrs.
\end{tabular}


Hamilton 1960 (Continued)

Setting: hospital.

Interventions

1. Chlorpromazine: dose $300 \mathrm{mg} /$ day. $\mathrm{N}=18$.

2. Placebo. $\mathrm{N}=18$.

3. Thiopropazate: dose $30 \mathrm{mg} /$ day. $\mathrm{N}=18$.

Medication given in fixed dose regime; factored to:

A. Occupational therapy. $\mathrm{N}=27$.

B. No occupational therapy. $\mathrm{N}=27$.

\begin{tabular}{ll}
\hline Outcomes & Leaving study early. \\
& Adverse effects. \\
& Unable to use - \\
& Mental state: Lorr (no mean, SD). \\
& Behaviour: nurse-rated scale (no mean, SD). \\
\hline Notes & \\
\hline
\end{tabular}

Risk of bias

\begin{tabular}{|c|c|c|}
\hline Bias & Authors' judgement & Support for judgement \\
\hline $\begin{array}{l}\text { Random sequence generation (selection } \\
\text { bias) }\end{array}$ & Unclear risk & $\begin{array}{l}\text { "The patients were randomly allotted to } 6 \\
\text { groups of } 9 \text { patients each" } \\
\text { "Each of these } 3 \text { groups was randomly cou- } \\
\text { pled with another group, and the names of } \\
\text { the patients in the } 3 \text { pairs of groups given } \\
\text { to the hospital pharmacist. He randomly } \\
\text { selected one pair of no further details re- } \\
\text { ported }\end{array}$ \\
\hline Allocation concealment (selection bias) & Unclear risk & $\begin{array}{l}\text { "Pharmacist }[\ldots] \text { randomly selected" } \\
\text { groups, no further details reported }\end{array}$ \\
\hline $\begin{array}{l}\text { Blinding of participants and personnel } \\
\text { (performance bias) } \\
\text { All outcomes }\end{array}$ & Low risk & $\begin{array}{l}\text { "Form the point of view of the patients, } \\
\text { nurses and physicians, there were } 27 \text { pa- } \\
\text { tients receiving one kind of tablet and } \\
27 \text { patients receiving the other kind, but } \\
\text { only the pharmacist knew which of the pa- } \\
\text { tients were receiving active and which in- } \\
\text { ert tablets. All the tablets were sugar-coated } \\
\text { nad the placebo tablets were indistinguish- } \\
\text { able from the active drugs." }\end{array}$ \\
\hline $\begin{array}{l}\text { Blinding of outcome assessment (detection } \\
\text { bias) } \\
\text { All outcomes }\end{array}$ & Low risk & $\begin{array}{l}\text { "Form the point of view of the patients, } \\
\text { nurses and physicians, there were } 27 \text { pa- } \\
\text { tients receiving one kind of tablet and } \\
27 \text { patients receiving the other kind, but } \\
\text { only the pharmacist knew which of the pa- } \\
\text { tients were receiving active and which inert }\end{array}$ \\
\hline
\end{tabular}

Chlorpromazine versus placebo for schizophrenia (Review)

Copyright () 2015 The Cochrane Collaboration. Published by John Wiley \& Sons, Ltd. 
Hamilton 1960 (Continued)

tablets."

"The patients were assessed on Behaviour in the ward by the charge nurses and on Symtoms by the physician"

\begin{tabular}{l|l|l} 
Incomplete outcome data (attrition bias) Low risk There were no losses to follow-up.
\end{tabular} All outcomes

Selective reporting (reporting bias) High risk

No means and SDs reported for mental state and a nurse-rated behaviour scale

Other bias

Unclear risk

Source of funding not reported.

Hankoff 1962

Methods

Allocation: randomised.

Blinding: double.

Duration: 2 weeks.

Design: parallel.

Country: USA.

\section{Participants}

Diagnosis: schizophrenia and non-schizophrenia.

$\mathrm{N}=174$.

Age: mean 39 years.

Sex: M 70, F 64

History: not reported.

Exclusions: not reported.

Setting: community.

Interventions

1. Chlorpromazine: dose $150 \mathrm{mg} /$ day. $\mathrm{N}=25$.

2. Chlordiazepoxide: dose $30 \mathrm{mg} /$ day. $\mathrm{N}=27$.

3. Meprobamate: dose $600 \mathrm{mg} /$ day. $\mathrm{N}=27$.

4. Placebo. $\mathrm{N}=72$.

Doses adjusted at one week intervals as necessary.

Outcomes

Global improvement.

Leaving the study early.

Adverse effects.

Unable to use -

Manifest Anxiety (no SDs reported).

Affect Adjective Checklist (no SDs reported).

Notes

\section{Risk of bias}

Bias

Authors' judgement

Support for judgement 
Hankoff 1962 (Continued)

\begin{tabular}{|c|c|c|}
\hline $\begin{array}{l}\text { Random sequence generation (selection } \\
\text { bias) }\end{array}$ & Unclear risk & $\begin{array}{l}\text { "Patients were randomly assigned to treat- } \\
\text { ment groups" no further details reported }\end{array}$ \\
\hline Allocation concealment (selection bias) & Unclear risk & No information reported. \\
\hline $\begin{array}{l}\text { Blinding of participants and personnel } \\
\text { (performance bias) } \\
\text { All outcomes }\end{array}$ & Low risk & $\begin{array}{l}\text { "Double-blind" } \\
\text { "All the drugs and their placebos were ad- } \\
\text { ministered in pink No. } 2 \text { capsules" }\end{array}$ \\
\hline $\begin{array}{l}\text { Blinding of outcome assessment (detection } \\
\text { bias) } \\
\text { All outcomes }\end{array}$ & Unclear risk & "Double-blind" no further details reported. \\
\hline $\begin{array}{l}\text { Incomplete outcome data (attrition bias) } \\
\text { All outcomes }\end{array}$ & Low risk & $\begin{array}{l}\text { "Of } 174 \text { patients starting in the project, } \\
134 \text { completed the two-week drug trial. } \\
\text { The } 40 \text { patients who failed to complete the } \\
\text { study usually did not return for appoint- } \\
\text { ments. An occasional patient in this total } \\
\text { of } 40 \text { was dropped for reasons of protocol } \\
\text { violation" }\end{array}$ \\
\hline Selective reporting (reporting bias) & High risk & $\begin{array}{l}\text { No SDs reported for Manifest Anxiety and } \\
\text { Affect Adjective Checklist }\end{array}$ \\
\hline Other bias & Low risk & $\begin{array}{l}\text { Supported by a grant from the US Public } \\
\text { Health Service. }\end{array}$ \\
\hline
\end{tabular}

Hine 1958

Methods

Allocation: matched on level of withdrawal symptoms and assigned at 'the toss of a coin'. Blinding: double, 'corresponding tablets or solution'.

Duration: 20 weeks (preceded by 11 week baseline period).

Design: parallel.

Country: USA.

Participants $\quad$ Diagnosis: schizophrenia (criteria unspecified).

History: 'chronic', 'more withdrawn than usual', continuously hospitalised for $>5 \mathrm{yrs}$.

$\mathrm{N}=22$.

Sex: $22 \mathrm{~F}$.

Age: range 30-50 yrs.

Setting: hospital.

Interventions

1. Chlorpromazine: dose increasing to max. tolerable level or $750 \mathrm{mg} / \mathrm{day} . \mathrm{N}=11$.

2. Placebo. $\mathrm{N}=11$.

Outcomes

Leaving study early.

Adverse effects. weakness, skin rash.

Improvement. change in hospital status, such as grounds privileges 
Hine 1958 (Continued)

Unable to use -

Withdrawal: Southeast Louisiana Hospital Behavior Rating Scale (no data)

Notes

Risk of bias

\begin{tabular}{|c|c|c|}
\hline Bias & Authors' judgement & Support for judgement \\
\hline $\begin{array}{l}\text { Random sequence generation (selection } \\
\text { bias) }\end{array}$ & Low risk & $\begin{array}{l}\text { "Matched pairs" based on withdrawal } \\
\text { symptoms "and one member of this pair } \\
\text { was assigned to the treatment group by the } \\
\text { toss of a coin }\end{array}$ \\
\hline Allocation concealment (selection bias) & Unclear risk & No information reported. \\
\hline $\begin{array}{l}\text { Blinding of participants and personnel } \\
\text { (performance bias) } \\
\text { All outcomes }\end{array}$ & Unclear risk & $\begin{array}{l}\text { "Double-blind" } \\
\text { "The results of this assignment were not } \\
\text { known to the judges, raters or other ward } \\
\text { personnel" } \\
\text { "corresponding placebo tablets or solution" } \\
\text { no further details reported }\end{array}$ \\
\hline $\begin{array}{l}\text { Blinding of outcome assessment (detection } \\
\text { bias) } \\
\text { All outcomes }\end{array}$ & Low risk & $\begin{array}{l}\text { "Double-blind" } \\
\text { "The results of this assignment were not } \\
\text { known to the judges, raters or other ward } \\
\text { personnel" }\end{array}$ \\
\hline $\begin{array}{l}\text { Incomplete outcome data (attrition bias) } \\
\text { All outcomes }\end{array}$ & Low risk & $\begin{array}{l}\text { "It was necessary to discontinue medication } \\
\text { during the third week on one patient in the } \\
\text { treatment group because of the develop- } \\
\text { ment of severe angioneurotic edema. This } \\
\text { patient was eliminated from the project" }\end{array}$ \\
\hline Selective reporting (reporting bias) & High risk & $\begin{array}{l}\text { No data reported for the Southeast } \\
\text { Louisiana Hospital Behavior Rating Scale }\end{array}$ \\
\hline Other bias & Unclear risk & $\begin{array}{l}\text { Drugs provided by Smith Kline \& French } \\
\text { Laboratories }\end{array}$ \\
\hline
\end{tabular}




\begin{tabular}{|c|c|}
\hline Methods & $\begin{array}{l}\text { Allocation: stratified by sex and randomly assigned - no further description. } \\
\text { Blinding: double, "identical looking tablets". } \\
\text { Design: factorial }(2 \times 2) \text {. } \\
\text { Duration: } 3 \text { years (preceded by } 2 \text { months CPZ-stabilisation period) } \\
\text { Country: USA. }\end{array}$ \\
\hline Participants & $\begin{array}{l}\text { Diagnosis: schizophrenia (no specified criteria). } \\
\text { History: recently discharged. } \\
\mathrm{N}=374 \text {. } \\
\text { Sex: } 43 \% \mathrm{M}, 57 \% \mathrm{~F} \text {. } \\
\text { Age: mean } 34 \text { yrs, range } 18-53 \text {. } \\
\text { Setting: community. }\end{array}$ \\
\hline Interventions & $\begin{array}{l}\text { 1. Chlorpromazine: dose variable } \mathrm{min} .100 \mathrm{mg} / \text { day, mean } 270 \mathrm{mg} / \text { day. } \mathrm{N}=192 \text {. } \\
\text { 2. Placebo. } \mathrm{N}=182 \text {. } \\
\text { Factored to: } \\
\text { A. Major role therapy. } \mathrm{N}=190 \text {. } \\
\text { B. Rehabilitation counseling. } \mathrm{N}=184 \text {. }\end{array}$ \\
\hline Outcomes & $\begin{array}{l}\text { Leaving study early. } \\
\text { Relapse. } \\
\text { Unable to use - } \\
\text { Death (N given, but not by group). } \\
\text { Trouble with police (N given, but not by group). } \\
\text { Mental state: BPRS, Symptom Checklist, IMPS, Springfield Symptom Inventory (no } \\
\text { SD). } \\
\text { Social functioning: Major Role Adjustment Inventory, Katz Adjustment Scale, Casework } \\
\text { Evaluation Schedule (no SD). } \\
\text { Carer morbidity: Family Distress Scale (no SD). }\end{array}$ \\
\hline Notes & $\begin{array}{l}\text { Assumption re 'leaving study early': One report states - } 27 \text { people 'terminated' during } \\
\text { month } 1-10,3 \text { due to side effects of CPZ. No data on remaining } 24 \text { - group of allocation } \\
\text { unknown. However, by } 2 \text { yrs 'terminations'=31 (Table } 3 \text {, 'II. Two-year relapse rates' } \\
\text { paper), } 13 \text { from CPZ, } 18 \text { from placebo group. This allowed calculation of group of } \\
\text { allocation of the original } 24 \text { at } 10 \text { months }(10+3 \text { already known=CPZ group, } 14= \\
\text { placebo group) }\end{array}$ \\
\hline
\end{tabular}

Risk of bias

\begin{tabular}{l|ll}
\hline Bias & Authors' judgement & Support for judgement \\
\hline $\begin{array}{l}\text { Random sequence generation (selection } \\
\text { bias) }\end{array}$ & Unclear risk & $\begin{array}{l}\text { "Randomly assigned" no further details re- } \\
\text { ported. }\end{array}$ \\
\hline $\begin{array}{l}\text { Allocation concealment (selection bias) } \\
\begin{array}{l}\text { Blinding of participants and personnel } \\
\text { (performance bias) } \\
\text { All outcomes }\end{array}\end{array}$ & Low risk & No information reported. \\
\hline
\end{tabular}

Chlorpromazine versus placebo for schizophrenia (Review)

Copyright (๑) 2015 The Cochrane Collaboration. Published by John Wiley \& Sons, Ltd. 
Hogarty 1973 (Continued)

\begin{tabular}{|c|c|c|}
\hline $\begin{array}{l}\text { Blinding of outcome assessment (detection } \\
\text { bias) } \\
\text { All outcomes }\end{array}$ & Unclear risk & "Double-blind" no further details reported. \\
\hline $\begin{array}{l}\text { Incomplete outcome data (attrition bias) } \\
\text { All outcomes }\end{array}$ & Unclear risk & $\begin{array}{l}\text { Losses to follow-up not clearly reported. } \\
\text { Reasons for leaving the study early re- } \\
\text { ported, but not according to group }\end{array}$ \\
\hline Selective reporting (reporting bias) & High risk & $\begin{array}{l}\text { Number of deaths and number of partic- } \\
\text { ipants in trouble with police not reported } \\
\text { by group } \\
\text { No SDs reported for BPRS, Symptom } \\
\text { Checklist, IMPS, Springfield Symptom In- } \\
\text { ventory, Major Role Adjustment Inventory, } \\
\text { Katz Adjustment Scale, Casework Evalua- } \\
\text { tion Schedu }\end{array}$ \\
\hline Other bias & Unclear risk & $\begin{array}{l}\text { Supported by grants from the Psychophar- } \\
\text { macology Research Branch, National Insti- } \\
\text { tute of Mental Health (NIMH) } \\
\text { Chlorpromazine was supplied by Smith } \\
\text { Kline \& French Laboratories, Philadelphia }\end{array}$ \\
\hline
\end{tabular}

\section{Klein 1973}

$\begin{array}{ll}\text { Methods } & \text { Allocation: randomly assigned - no further description. } \\ \text { Blinding: double, used 'highly flavoured liquid placebo', a constant } 40 \mathrm{ml} \text { per day from } \\ \text { individually labelled bottles. } \\ \text { Duration: } 6 \text { weeks. } \\ \text { Design: parallel. } \\ \text { Country: USA. }\end{array}$

\section{Notes}

Chlorpromazine versus placebo for schizophrenia (Review)

Copyright ( 2015 The Cochrane Collaboration. Published by John Wiley \& Sons, Ltd. 
Klein 1973 (Continued)

\section{Risk of bias}

\begin{tabular}{|c|c|c|}
\hline Bias & Authors' judgement & Support for judgement \\
\hline $\begin{array}{l}\text { Random sequence generation (selection } \\
\text { bias) }\end{array}$ & Unclear risk & $\begin{array}{l}\text { "Randomly assigned" no further details re- } \\
\text { ported. }\end{array}$ \\
\hline Allocation concealment (selection bias) & Unclear risk & No information reported. \\
\hline $\begin{array}{l}\text { Blinding of participants and personnel } \\
\text { (performance bias) } \\
\text { All outcomes }\end{array}$ & Low risk & $\begin{array}{l}\text { "Double-blind" } \\
\text { "Medication was administered in a highly } \\
\text { flavoured liquid placebo, and each patient } \\
\text { received a constant } 40 \mathrm{ml} / \text { day from indi- } \\
\text { vidually labelled bottles" }\end{array}$ \\
\hline $\begin{array}{l}\text { Blinding of outcome assessment (detection } \\
\text { bias) } \\
\text { All outcomes }\end{array}$ & Unclear risk & "Double-blind" no further details reported. \\
\hline $\begin{array}{l}\text { Incomplete outcome data (attrition bias) } \\
\text { All outcomes }\end{array}$ & Low risk & There were no losses to follow-up. \\
\hline Selective reporting (reporting bias) & High risk & No SDs reported for MSRPP. \\
\hline Other bias & Unclear risk & $\begin{array}{l}\text { Supported in part by grants from the Pub- } \\
\text { lic Health Service of the National Institue } \\
\text { of Mental Health } \\
\text { Smith Kline \& French Laboratories and } \\
\text { Wellcome and Co supplied the drugs }\end{array}$ \\
\hline
\end{tabular}

Kurland 1961

\begin{tabular}{ll} 
Methods & Allocation: assigned by “predetermined random selection”. \\
& Blinding: double, "standard unmarked capsules", "coloured pink to mask all identifying \\
& consistencies and colours of drugs". \\
& Duration: 6 weeks. \\
& Design: parallel. \\
& Country: USA. \\
\hline Participants & Diagnosis: 'predominantly schizophrenic in character'. \\
& History: newly admitted, target symptoms of hyperactivity, anxiety, tension, overt ag- \\
& gression. \\
& N=277. \\
& Sex: $1: 2$ ratio M:F. \\
Age: mean 31 yrs, range $18-61$. \\
Setting: hospital.
\end{tabular}


Kurland 1961 (Continued)

Interventions
1. Chlorpromazine: dose $25 \mathrm{mg} /$ day IM (days 1-2) then min. $300 \mathrm{mg} /$ day (no max.). $\mathrm{N}=33$.

2. 'Positive' placebo (phenobarbital): dose $65 \mathrm{mg} /$ day IM (days 1-2) then min. $97.5 \mathrm{mg} /$ day (no max.). $\mathrm{N}=37$.

3. 'Negative' placebo (saline/lactose): dose IM (days 1-2) then oral. $N=37$.

4. Promazine: dose $50 \mathrm{mg} /$ day IM (days 1-2) then $\mathrm{min} .300 \mathrm{mg} /$ day (no max.). N=32.

5. Mepazine: dose $25 \mathrm{mg} /$ day IM (days 1-2) then $\mathrm{min} .75 \mathrm{mg} /$ day (no max.). $\mathrm{N}=34$.

6. Triflupromazine: dose $25 \mathrm{mg} /$ day IM (days 1-2) then $\mathrm{min} .75 \mathrm{mg} /$ day (no max.). $\mathrm{N}=$ 36.

7. Prochlorperazine: dose $5 \mathrm{mg} /$ day IM (days $1-2$ ) then $\mathrm{min} .30 \mathrm{mg} /$ day (no max.). $\mathrm{N}=$ 32.

8. Perphenazine: dose $5 \mathrm{mg} /$ day (days $1-2$ ) then $\min .24 \mathrm{mg} /$ day (no $\max$.). $\mathrm{N}=36$
Leaving study early.

Adverse effects.

Global improvement.

Unable to use -

Mental state: MSRPP, Psychotic Reaction Profile, Psychiatric Scale of Target Symptoms (no SD)

\section{Notes}

\section{Risk of bias}

Bias

Random sequence generation (selection Unclear risk bias)

\section{Support for judgement}

"The choice of the particular drug to be used in any case was based on a predetermined random selection" no further details reported

No information reported.

"Double-blind"

"The drugs were dispensed in standard unmarked capsules [...] coloured pink to mask all identifying consistencies and colours of the drugs"

"Double-blind"

"Ratings were blind, in that raters did not know which drug the patients was receiving"

"Those patients whom data were incomplete, together with those not receiving medication for at least ten days, were excluded from the study" 
Kurland 1961 (Continued)

\begin{tabular}{|c|c|c|}
\hline & & $\begin{array}{l}\text { "Of the } 238 \text { patients who met all popu- } \\
\text { lation restrictions, } 187 \text { remained in the } \\
\text { project at least } 10 \text { days [...] Fifty-nine pa- } \\
\text { tients completed the prescribed six-week } \\
\text { treatment course." }\end{array}$ \\
\hline Selective reporting (reporting bias) & High risk & $\begin{array}{l}\text { No SDs reported for the MSRPP, Psychotic } \\
\text { Reaction Profile and Psychiatric Scale of } \\
\text { Target Symptoms }\end{array}$ \\
\hline Other bias & Unclear risk & $\begin{array}{l}\text { Funded by a research grant from the Na- } \\
\text { tional Advisory Mental Health Council, } \\
\text { National Institute of Health, US Public } \\
\text { Health Service } \\
\text { Drugs provided by Smith Kline \& French } \\
\text { Laboratories, Squibb Laboratories, Shering } \\
\text { Corporation and Warner-Chilcott Labora- } \\
\text { tories }\end{array}$ \\
\hline
\end{tabular}

Letemendia 1967

Methods

Allocation: matched (age, length of hospitalisation \& severity) then assigned by toss of a coin.

Blinding: double, "medication dispensed in uniform amber-coloured capsules".

Design: cross-over.

Duration: 9 months per arm of cross-over.

Country: UK.

Participants

Diagnosis: schizophrenia $(\mathrm{N}=26$ - criteria not specified), deluded $(\mathrm{N}=2)$, concurrent learning difficulties $(\mathrm{N}=2)$.

History: > 5 yrs continuous hospitalisation, physically healthy.

$\mathrm{N}=28$.

Sex: $28 \mathrm{M}$.

Age: $<65$ years.

Setting: hospital.

Interventions 1 . Chlorpromazine: dose $300 \mathrm{mg} /$ day. $\mathrm{N}=14$.

2. Placebo. $\mathrm{N}=14$.

Outcomes

Leaving study early.

Unable to use -

Mental state \& behaviour (authors' own scale - no SD).

Notes

2 people dropped out - unsure if before/after randomisation.

\section{Risk of bias}

Bias

Authors' judgement

Support for judgement

Chlorpromazine versus placebo for schizophrenia (Review)

Copyright $\odot 2015$ The Cochrane Collaboration. Published by John Wiley \& Sons, Ltd. 


\begin{tabular}{|c|c|c|}
\hline $\begin{array}{l}\text { Random sequence generation (selection } \\
\text { bias) }\end{array}$ & Low risk & $\begin{array}{l}\text { Groups matched according to age, length } \\
\text { of hospital stay and severity, "The designa- } \\
\text { tion of the two groups was determined by } \\
\text { tossing a coin" }\end{array}$ \\
\hline Allocation concealment (selection bias) & Unclear risk & No information reported. \\
\hline $\begin{array}{l}\text { Blinding of participants and personnel } \\
\text { (performance bias) } \\
\text { All outcomes }\end{array}$ & Low risk & $\begin{array}{l}\text { "Double-blind" } \\
\text { "Neither patients, doctors, nor nurses knew } \\
\text { which patients were being given chlorpro- } \\
\text { mazine and which placebo. All medication } \\
\text { was dispensed in uniform amber-coloured } \\
\text { capsules. Each patient was supplied from } \\
\text { a separated bottle, replenished weekly ac- } \\
\text { cording to the design by an independent } \\
\text { party" }\end{array}$ \\
\hline $\begin{array}{l}\text { Blinding of outcome assessment (detection } \\
\text { bias) } \\
\text { All outcomes }\end{array}$ & Unclear risk & "Double-blind" no further details reported. \\
\hline $\begin{array}{l}\text { Incomplete outcome data (attrition bias) } \\
\text { All outcomes }\end{array}$ & Unclear risk & $\begin{array}{l}\text { "Of the } 30 \text { patients who initially fulfilled } \\
\text { out conditions, one died from a cerebrovas- } \\
\text { cular accident during the period of prelim- } \\
\text { inary observations, and a second was elim- } \\
\text { inated because of slow phasic changes in } \\
\text { mental state". Two losses to follow-up, but } \\
\text { unclear is before or after randomisation }\end{array}$ \\
\hline Selective reporting (reporting bias) & High risk & $\begin{array}{l}\text { No SDs reported for mental state and be- } \\
\text { haviour scale }\end{array}$ \\
\hline Other bias & Low risk & $\begin{array}{l}\text { Supported by a grant from the Rockefeller } \\
\text { foundation. }\end{array}$ \\
\hline
\end{tabular}

\section{Nishikawa 1982}

Methods

Allocation: randomly assigned - no further description.

Blinding: double, drug appearance (colour, taste, volume) identical.

Design: cross-over, data reported for first arm only.

Duration: up to 3 years (or relapse, if sooner).

Country: Japan.

\section{Participants}

Diagnosis: schizophrenia (criteria not specified).

History: remitted illness, but $>1$ relapses.

$\mathrm{N}=55$.

Sex: $37 \mathrm{M}, 18 \mathrm{~F}$.

Age: mean 33.3 yrs, SD 8.0. 
Nishikawa 1982 (Continued)

Setting: outpatients department.

\begin{tabular}{ll}
\hline Interventions & 1. Chlorpromazine: dose $75 \mathrm{mg} /$ day. $\mathrm{N}=10$. \\
& 2. Placebo. $\mathrm{N}=10$. \\
& 3. Diazepam: dose $15 \mathrm{mg} / \mathrm{day} . \mathrm{N}=13$. \\
& 4. Imipramine: dose $50 \mathrm{mg} / \mathrm{day} . \mathrm{N}=12$. \\
& 5. Haloperidol: dose $3 \mathrm{mg} /$ day. $\mathrm{N}=10$. \\
& Medication given in fixed-dose regimen; nitrazepam $10 \mathrm{mg} /$ day for insomnia as required; \\
& biperiden $3 \mathrm{mg} /$ day for EPS as required \\
\hline \multirow{2}{*}{ Outcomes } & Relapse. \\
& Unable to use - \\
& Symptom-free days (survival data not supported by RevMan). \\
\hline \multirow{2}{*}{ Notes } & \\
\hline
\end{tabular}

\section{Risk of bias}

\begin{tabular}{|c|c|c|}
\hline Bias & Authors' judgement & Support for judgement \\
\hline $\begin{array}{l}\text { Random sequence generation (selection } \\
\text { bias) }\end{array}$ & Unclear risk & $\begin{array}{l}\text { "Randomly assigned" no further informa- } \\
\text { tion reported. }\end{array}$ \\
\hline Allocation concealment (selection bias) & Unclear risk & No information reported. \\
\hline $\begin{array}{l}\text { Blinding of participants and personnel } \\
\text { (performance bias) } \\
\text { All outcomes }\end{array}$ & Low risk & $\begin{array}{l}\text { "Double-blind" } \\
\text { "Drug appearance, with respect to powder } \\
\text { colour, taste and volume, was made iden- } \\
\text { tical by adding a kind of stomachics }\end{array}$ \\
\hline $\begin{array}{l}\text { Blinding of outcome assessment (detection } \\
\text { bias) } \\
\text { All outcomes }\end{array}$ & Unclear risk & "Double-bind" no further details reported. \\
\hline $\begin{array}{l}\text { Incomplete outcome data (attrition bias) } \\
\text { All outcomes }\end{array}$ & Unclear risk & $\begin{array}{l}\text { "Then nine patients were dropped from } \\
\text { the study for various reasons. These reasons } \\
\text { included: failure to report to the hospital } \\
\text { for scheduled appointments }(\mathrm{N}=3) \text {; admis- } \\
\text { sions to other hospitals }(\mathrm{N}=2) \text {; strong re- } \\
\text { quests from the patient not to change the } \\
\text { previous drugs }(\mathrm{N}=3) \text {; and a suicide after } \\
\text { admission to the hospital }(\mathrm{N}=1) \text { ". Number } \\
\text { of participants and reasons for leaving the } \\
\text { study early not reported by groups }\end{array}$ \\
\hline Selective reporting (reporting bias) & High risk & Not all expected outcomes reported. \\
\hline Other bias & Unclear risk & Drugs provided by SMP (Sankyo, Japan). \\
\hline
\end{tabular}

Chlorpromazine versus placebo for schizophrenia (Review)

Copyright () 2015 The Cochrane Collaboration. Published by John Wiley \& Sons, Ltd. 


\begin{tabular}{|c|c|}
\hline Methods & $\begin{array}{l}\text { Allocation: "double blind technique employed". } \\
\text { Blinding: double blind. } \\
\text { Duration: } 6 \text { weeks. } \\
\text { Design: parallel. } \\
\text { Country: Canada. }\end{array}$ \\
\hline Participants & $\begin{array}{l}\text { Diagnosis: schizophrenia. } \\
\text { History: chronic, hospitalised for an average of } 12.7 \text { years. } \\
\mathrm{N}=21 . \\
\text { Sex: } 21 \mathrm{M} \text {. } \\
\text { Age: } 23-73 \text { ( } 41.9 \text { average). } \\
\text { Setting: hospital. }\end{array}$ \\
\hline Interventions & $\begin{array}{l}\text { 1. Chlorpromazine: dose } 25 \mathrm{mg} / \mathrm{tds} \text { increasing to } 100 \mathrm{mg} / \mathrm{tds} \text {. } \mathrm{N}=7 \text {. } \\
\text { 2. Placebo. } \mathrm{N}=7 \text {. } \\
\text { 3. Vesprin: dose } 25 \mathrm{mg} / \mathrm{td} \text { increasing to } 100 \mathrm{mg} / \mathrm{tds} \text {. } \mathrm{N}=7 \text {. }\end{array}$ \\
\hline Outcomes & $\begin{array}{l}\text { Adverse effects. } \\
\text { Unable to use - } \\
\text { Categories of improved, much improved and unimproved (no usable data) }\end{array}$ \\
\hline Notes & Withdrawals not described. \\
\hline
\end{tabular}

Risk of bias

\begin{tabular}{|c|c|c|}
\hline Bias & Authors' judgement & Support for judgement \\
\hline $\begin{array}{l}\text { Random sequence generation (selection } \\
\text { bias) }\end{array}$ & Unclear risk & $\begin{array}{l}\text { "The patients were divided into three } \\
\text { groups of seven persons" no further details } \\
\text { reported }\end{array}$ \\
\hline Allocation concealment (selection bias) & Unclear risk & No information reported. \\
\hline $\begin{array}{l}\text { Blinding of participants and personnel } \\
\text { (performance bias) } \\
\text { All outcomes }\end{array}$ & Low risk & $\begin{array}{l}\text { "Double-blind" } \\
\text { "All three types of tablet were exactly the } \\
\text { same colour, size and shape. Each patient's } \\
\text { medication was supplied to the wards in } \\
\text { identical containers bearing the patient's } \\
\text { name only. The physician and ward per- } \\
\text { sonnel were unaware of which patient was } \\
\text { receiving which tablet; the latter being } \\
\text { known only to the pharmacist and not di- } \\
\text { vulged until the completion of the investi- } \\
\text { gation" }\end{array}$ \\
\hline
\end{tabular}

Blinding of outcome assessment (detection Unclear risk bias)

All outcomes
"Double-blind" no further information reported. 
Payne 1960 (Continued)

\begin{tabular}{l|l|l}
\hline $\begin{array}{l}\text { Incomplete outcome data (attrition bias) } \\
\text { All outcomes }\end{array}$ & Unclear risk & Did not report any losses to follow-up. \\
\hline Selective reporting (reporting bias) & High risk & $\begin{array}{l}\text { Results for categories of 'improved', 'much } \\
\text { improved' and 'unimproved' not fully re- } \\
\text { ported }\end{array}$ \\
\hline Other bias & Unclear risk & $\begin{array}{l}\text { Drugs supplied by ER Squibb and Sons of } \\
\text { Canada, Limited. } \\
\text { Source of funding not reported. }\end{array}$ \\
\hline
\end{tabular}

\section{Peet 1981}

Methods Allocation: randomly assigned - no further description.

Blinding: double, used 'capsules of identical external appearance'.

Duration: 3 months.

Design: parallel.

Country: UK.

\begin{tabular}{|c|c|}
\hline Participants & $\begin{array}{l}\text { Diagnosis: schizophrenia (Feighner's criteria). } \\
\text { History: unclear. 'with a diagnosis of chronic schizophrenia'. } \\
\text { N=53. } \\
\text { Sex: } 40 \mathrm{M}, 13 \mathrm{~F} \text {. } \\
\text { Age: mean } 51.3 \text { yrs. } \\
\text { Setting: hospital. } \\
\text { Exclusions: heart disease, asthma, liver disease, diabetes, alcoholism, drug abuse, other } \\
\text { regularly prescribed psychotropic drugs }\end{array}$ \\
\hline Interventions & $\begin{array}{l}\text { 1. Chlorpromazine: dose max. } 400 \mathrm{mg} / \text { day. } \mathrm{N}=16 \text {. } \\
\text { 2. Placebo: dose max. } 8 \text { capsules/day. } \mathrm{N}=18 \text {. } \\
\text { 3. Propranolol: dose max. } 640 \mathrm{mg} / \text { day. } \mathrm{N}=19 \text {. } \\
\text { Medication given in discretionary dose regimen; diazepam used as required }\end{array}$ \\
\hline Outcomes & $\begin{array}{l}\text { Leaving study early. } \\
\text { Relapse. } \\
\text { Adverse effects. tremor, drowsiness. } \\
\text { Unable to use - } \\
\text { Mental state: BPRS (no mean, N, or SD). } \\
\text { Behaviour: NOSIE (no mean, N, or SD). }\end{array}$ \\
\hline & \\
\hline
\end{tabular}

\section{Risk of bias}

\begin{tabular}{|c|c|c|}
\hline Bias & Authors' judgement & Support for judgement \\
\hline $\begin{array}{l}\text { Random sequence generation (selection } \\
\text { bias) }\end{array}$ & Unclear risk & $\begin{array}{l}\text { "Randomly assigned" no further details re- } \\
\text { ported. }\end{array}$ \\
\hline
\end{tabular}

Chlorpromazine versus placebo for schizophrenia (Review)

Copyright ( 2015 The Cochrane Collaboration. Published by John Wiley \& Sons, Ltd. 
Peet 1981 (Continued)

\begin{tabular}{l|l|l}
\hline Allocation concealment (selection bias) & Unclear risk & No information reported. \\
\hline $\begin{array}{l}\text { Blinding of participants and personnel } \\
\text { (performance bias) } \\
\text { All outcomes }\end{array}$ & Low risk & $\begin{array}{l}\text { "Double-blind" } \\
\text { "Capsules of identical appearance" }\end{array}$ \\
\hline $\begin{array}{l}\text { Blinding of outcome assessment (detection } \\
\text { bias) } \\
\text { All outcomes }\end{array}$ & Unclear risk & "Double-blind" no further details reported. \\
\hline $\begin{array}{l}\text { Incomplete outcome data (attrition bias) } \\
\text { All outcomes }\end{array}$ & Low risk & $\begin{array}{l}\text { 6 patients left the study early from the } \\
\text { propanolol and chlorpromazine groups, } \\
\text { and 9 from the placebo group. Reasons for } \\
\text { loss evenly distributes across groups }\end{array}$ \\
\hline $\begin{array}{l}\text { Selective reporting (reporting bias) } \\
\text { Other bias }\end{array}$ & High risk & $\begin{array}{l}\text { No means or SDs reported for IMPS, } \\
\text { NOSIE and Discharge Readiness Inven- } \\
\text { tory }\end{array}$ \\
\hline
\end{tabular}

Prien 1968

\begin{tabular}{|c|c|}
\hline Methods & $\begin{array}{l}\text { Allocation: randomly assigned - no further description. } \\
\text { Blinding: double - no further description. } \\
\text { Duration: } 24 \text { weeks (preceded by } 8 \text { weeks 'routine hospital medication') } \\
\text { Design: parallel. } \\
\text { Country: USA. }\end{array}$ \\
\hline Participants & $\begin{array}{l}\text { Diagnosis: schizophrenia (specified criteria). } \\
\text { History: 'chronic'. } \\
\text { N=838. } \\
\text { Sex: male and female (proportions not given). } \\
\text { Age: mean } 41 \text { yrs, range } 19-55 \text {. } \\
\text { Setting: hospital. }\end{array}$ \\
\hline Interventions & $\begin{array}{l}\text { 1. Chlorpromazine: dose } 2000 \mathrm{mg} / \text { day ("high dose"). } \mathrm{N}=208 \text {. (Permanent dose reduction } \\
\text { to } 1500 \mathrm{mg} \text { permitted to control side effects). } \\
\text { 2. Chlorpromazine: dose } 300 \mathrm{mg} / \text { day ("low dose"). } \mathrm{N}=208 \text {. } \\
\text { 3. Placebo. } \mathrm{N}=212 \text {. } \\
\text { 4. 'Routine conventional hospital treatment'. } \mathrm{N}=210 \text {. }\end{array}$ \\
\hline Outcomes & $\begin{array}{l}\text { Leaving study early. } \\
\text { Behaviour deterioration. } \\
\text { Global improvement (own 7-point rating scale). } \\
\text { Global severity of illness (own 7-point rating scale). } \\
\text { Adverse effects. } \\
\text { Relapse. }\end{array}$ \\
\hline
\end{tabular}


Prien 1968 (Continued)

Unable to use -

Mental state: IMPS (no mean or SD).

Behaviour: NOSIE (no mean or SD).

Social function: Discharge Readiness Inventory (no mean or SD)

Notes $\quad$ Blood problems reported from just one centre $(\mathrm{N}=58)$.

Tardive dyskinesia side-effects- extracted from a sub-study by Crane (1968)

\section{Risk of bias}

\begin{tabular}{|c|c|c|}
\hline Bias & Authors' judgement & Support for judgement \\
\hline $\begin{array}{l}\text { Random sequence generation (selection } \\
\text { bias) }\end{array}$ & Unclear risk & $\begin{array}{l}\text { "Randomly assigned" no further details re- } \\
\text { ported. }\end{array}$ \\
\hline Allocation concealment (selection bias) & Unclear risk & No information reported. \\
\hline $\begin{array}{l}\text { Blinding of participants and personnel } \\
\text { (performance bias) } \\
\text { All outcomes }\end{array}$ & Unclear risk & "Double-blind" no further details reported. \\
\hline $\begin{array}{l}\text { Blinding of outcome assessment (detection } \\
\text { bias) } \\
\text { All outcomes }\end{array}$ & Unclear risk & No information reported. \\
\hline $\begin{array}{l}\text { Incomplete outcome data (attrition bias) } \\
\text { All outcomes }\end{array}$ & Low risk & $\begin{array}{l}\text { "The placebo group had the highest per- } \\
\text { centage of dropout }(38 \%) \text {, followed by the } \\
\text { high dose group }(25 \%) \text {, and the low dose } \\
\text { group }(15 \%) \text {. Terminations due to side ef- } \\
\text { fects were most frequent in the high dose } \\
\text { group, while the placebo group had the } \\
\text { highest incidence of dropouts due to dete- } \\
\text { riorated behavior." Losses to follow-up bal- } \\
\text { anced across intervention groups, with sim- } \\
\text { ilar reasons for missing data }\end{array}$ \\
\hline Selective reporting (reporting bias) & High risk & $\begin{array}{l}\text { No SD for IMPS, NOSIE, Discharge } \\
\text { Readiness Inventory. }\end{array}$ \\
\hline Other bias & Low risk & $\begin{array}{l}\text { The study appears to be free of other } \\
\text { sources of bias. }\end{array}$ \\
\hline
\end{tabular}




\begin{tabular}{|c|c|}
\hline Methods & $\begin{array}{l}\text { Allocation: randomised. } \\
\text { Blinding: double. } \\
\text { Duration: } 2 \text { months. } \\
\text { Design: parallel. } \\
\text { Country: India. }\end{array}$ \\
\hline Participants & $\begin{array}{l}\text { Diagnosis: schizophrenia (in accordance with National Institute of Mental Health, Psy- } \\
\text { chopharmacological service centre, collaborative study group) } \\
\mathrm{N}=136 . \\
\text { Age: } 15-45 \text { years. } \\
\text { Sex: male and female. } \\
\text { History: significant hospitalisation during previous } 12 \text { months. Acute episode of chronic } \\
\text { schizophrenia. } \\
\text { Exclusions: stuporous and exclusively withdrawn patients. } \\
\text { Setting: outpatients. }\end{array}$ \\
\hline Interventions & $\begin{array}{l}\text { 1. Chlorpromazine: dose } 200 \mathrm{mg} / \text { day in month } 1 \text { and } 300 \mathrm{mg} / \text { day in month } 2 . \mathrm{N}=27^{*} \text {. } \\
\text { 2. Placebo. } \mathrm{N}=27^{*} \text {. } \\
\text { 3. Brahmadiyoga. } \mathrm{N}=27^{*} \text {. } \\
\text { 4. Tagara. } \mathrm{N}=27^{*} \text {. }\end{array}$ \\
\hline
\end{tabular}

Outcomes

Global impression: no global improvement.

Adverse effects.

Unable to use -

Psychotic rating scale (unclear whether a validated scale).

Spiral after effect (not a validated scale).

Notes $\quad{ }^{*} \mathrm{~N}$ randomised to each group not reported; $\mathrm{N}$ after losses to follow-up

\section{Risk of bias}

\begin{tabular}{|c|c|c|}
\hline Bias & Authors' judgement & Support for judgement \\
\hline $\begin{array}{l}\text { Random sequence generation (selection } \\
\text { bias) }\end{array}$ & Unclear risk & $\begin{array}{l}\text { "Randomly allocated" no further details re- } \\
\text { ported. }\end{array}$ \\
\hline Allocation concealment (selection bias) & Unclear risk & No information reported. \\
\hline $\begin{array}{l}\text { Blinding of participants and personnel } \\
\text { (performance bias) } \\
\text { All outcomes }\end{array}$ & Low risk & $\begin{array}{l}\text { "Double-blind" } \\
\text { "The medicines and placebo were admin- } \\
\text { istered in the form of identical tablets" }\end{array}$ \\
\hline $\begin{array}{l}\text { Blinding of outcome assessment (detection } \\
\text { bias) } \\
\text { All outcomes }\end{array}$ & Unclear risk & "Double-blind" no further details reported. \\
\hline $\begin{array}{l}\text { Incomplete outcome data (attrition bias) } \\
\text { All outcomes }\end{array}$ & Unclear risk & $\begin{array}{l}\text { "Out of } 136 \text { patients } 108 \text { who have com- } \\
\text { pleted the treatment for a period of } 2 \\
\text { months were taken for final assessment. }\end{array}$ \\
\hline
\end{tabular}


The remaining 28 were dropouts for reasons of escape and leaving without medical advice". Number randomised to each group not reported. Number lost from each group not reported

Selective reporting (reporting bias) High risk

Not all expected outcomes reported.

Unclear which rating scales are reported in the results tables

\begin{tabular}{|c|c|c|}
\hline Other bias & Unclear risk & Source of funding not reported. \\
\hline
\end{tabular}

Ramu 1999a

\begin{tabular}{|c|c|}
\hline Methods & $\begin{array}{l}\text { Allocation: not stated. } \\
\text { Blinding: double. } \\
\text { Duration: } 11 \text { weeks. } \\
\text { Design: parallel. } \\
\text { Country: India. }\end{array}$ \\
\hline Participants & $\begin{array}{l}\text { Diagnosis: schizophrenia (WHO glossary of mental disorders) } \\
\text { N=78. } \\
\text { Age: average }-32 \text { (SD 7) for chlorpromazine and placebo groups. } \\
\text { Sex: M 30, F } 35 \text {. } \\
\text { History: Chronic schizophrenia between } 2 \text { and } 6 \text { years. } \\
\text { Exclusions: not reported. } \\
\text { Setting: not reported. }\end{array}$ \\
\hline Interventions & $\begin{array}{l}\text { 1. Chlorpromazine: dose } 300 \mathrm{mg} / \text { day up to day } 30 \text { and } 450 \mathrm{mg} / \text { day up to day } 75 . \mathrm{N}= \\
22^{*} \text {. } \\
\text { 2. Brahmyadiyoga: } 12 \mathrm{~g} / \text { day up to day } 30 \text { and } 16 \mathrm{~g} / \text { day up to day } 75 . \mathrm{N}=23^{*} \text {. } \\
\text { 3. Placebo. } \mathrm{N}=20^{*} \text {. }\end{array}$ \\
\hline Outcomes & $\begin{array}{l}\text { No global improvement. } \\
\text { Behaviour: Fergus Falls rating scale**. } \\
\text { Adverse effects: drowsiness**. } \\
\text { Unable to use - } \\
\text { Psychiatric symptoms rating scale (not a validated scale). }\end{array}$ \\
\hline Notes & $\begin{array}{l}{ }^{*} \mathrm{~N} \text { randomised to each group not reported; } \mathrm{N} \text { after losses to follow-up. } \\
{ }^{* *} \mathrm{~N} \text { not reported, assumed to be the number reported in each group after losses to } \\
\text { follow-up }\end{array}$ \\
\hline
\end{tabular}

\section{Risk of bias}

Bias

Authors' judgement

Support for judgement 


\begin{tabular}{|c|c|c|}
\hline $\begin{array}{l}\text { Random sequence generation (selection } \\
\text { bias) }\end{array}$ & High risk & No information reported. \\
\hline Allocation concealment (selection bias) & Unclear risk & No information reported. \\
\hline $\begin{array}{l}\text { Blinding of participants and personnel } \\
\text { (performance bias) } \\
\text { All outcomes }\end{array}$ & Unclear risk & $\begin{array}{l}\text { "Double-blind" } \\
\text { "Sugar coated uniform tablets of the trial } \\
\text { drugs" no further details reported }\end{array}$ \\
\hline $\begin{array}{l}\text { Blinding of outcome assessment (detection } \\
\text { bias) } \\
\text { All outcomes }\end{array}$ & Unclear risk & "Double-blind" no further details reported. \\
\hline $\begin{array}{l}\text { Incomplete outcome data (attrition bias) } \\
\text { All outcomes }\end{array}$ & High risk & $\begin{array}{l}\text { " } 78 \text { cases were taken for the study. Of them, } \\
13 \text { cases were dropped out for various rea- } \\
\text { sons" N randomised to each group not re- } \\
\text { ported. Reasons for losses and number of } \\
\text { losses to follow-up per group not reported }\end{array}$ \\
\hline Selective reporting (reporting bias) & High risk & $\begin{array}{l}\mathrm{N} \text { not reported for psychiatric rating scale. } \\
\text { Total scores not reported for final assess- } \\
\text { ment of psychiatric rating scale } \\
\mathrm{N} \text { reported for global improvement differs } \\
\text { from } \mathrm{N} \text { reported in each group }\end{array}$ \\
\hline Other bias & Unclear risk & $\begin{array}{l}\text { Drugs supplied by } \mathrm{M} / \mathrm{s} \text { Eros Pharma, Ban- } \\
\text { galore. }\end{array}$ \\
\hline
\end{tabular}

\section{Rappaport 1978}

Methods

Allocation: randomly assigned - no further description.

Blinding: single, staff'remained blind as to whether the patient was receiving medication or placebos'.

Duration: unclear, mean hospitalisation $=43$ days, follow up at 1-36 months after discharge

Design: parallel.

Country: USA.

Participants

Diagnosis: schizophrenia (no specified criteria).

History: 'acute' illness.

$\mathrm{N}=127$.

Sex: 127 M.

Age: range 16-40 yrs.

Setting: hospital.

Interventions

1. Chlorpromazine: dose variable $300-900 \mathrm{mg} /$ day. $\mathrm{N}=53$

2. Placebo. $\mathrm{N}=74$. 


\begin{tabular}{|c|c|c|}
\hline Outcomes & \multicolumn{2}{|c|}{$\begin{array}{l}\text { Leaving study early. } \\
\text { Relapse (rehospitalisation). }\end{array}$} \\
\hline Notes & \multicolumn{2}{|c|}{$\begin{array}{l}\text { N's at allocation unbalanced - integrity of randomisation unclear. } \\
\text { Unclear when outcomes recorded - assumed 'medium-term' in all cases (to reflect mode } \\
\text { outcome period in review) }\end{array}$} \\
\hline \multicolumn{3}{|l|}{ Risk of bias } \\
\hline Bias & Authors' judgement & Support for judgement \\
\hline $\begin{array}{l}\text { Random sequence generation (selection } \\
\text { bias) }\end{array}$ & Unclear risk & $\begin{array}{l}\text { "Assigned randomly" no further details re- } \\
\text { ported. }\end{array}$ \\
\hline Allocation concealment (selection bias) & Unclear risk & No information reported. \\
\hline $\begin{array}{l}\text { Blinding of participants and personnel } \\
\text { (performance bias) } \\
\text { All outcomes }\end{array}$ & Unclear risk & $\begin{array}{l}\text { "physician }[\ldots] \text { and the nursing staff re- } \\
\text { mained blind as to whether the patient was } \\
\text { receiving medication or placebos" no fur- } \\
\text { ther details reported }\end{array}$ \\
\hline $\begin{array}{l}\text { Blinding of outcome assessment (detection } \\
\text { bias) } \\
\text { All outcomes }\end{array}$ & Low risk & $\begin{array}{l}\text { "Ratings were made by a trained research } \\
\text { assistant who was unaware as to what the } \\
\text { patient's medication condition was while } \\
\text { he was hospitalised" }\end{array}$ \\
\hline $\begin{array}{l}\text { Incomplete outcome data (attrition bias) } \\
\text { All outcomes }\end{array}$ & High risk & $\begin{array}{l}\text { "The } 80 \text { patients in this study represented } \\
63 \% \text { of the total sample (127) studied while } \\
\text { in the hospital. It was noted that during the } \\
\text { follow-up period, there was a significantly } \\
\text { larger attrition of subjects from the group } \\
\text { assigned to placebo while in the hospital } \\
\text { than the group assigned to chlorpromazine } \\
\text { ( } 45 \% \text { vs } 26 \%) . "\end{array}$ \\
\hline Selective reporting (reporting bias) & High risk & $\begin{array}{l}\text { Unclear when outcomes recorded. Not all } \\
\text { expected outcomes reported }\end{array}$ \\
\hline Other bias & Low risk & $\begin{array}{l}\text { Supported California Department of Men- } \\
\text { tal Hygiene and the National Institute of } \\
\text { Mental Health and from the Wickes Foun- } \\
\text { dation and Esalen Institute }\end{array}$ \\
\hline
\end{tabular}


Methods

(a)

Allocation: randomly assigned - no further description.

Blinding: 'neither the ward personnel nor the investigator knew which drug the patient received'.

Duration: min. 4 weeks, max. 12 weeks.

Design: parallel.

Country: USA.

Interventions
$\begin{aligned} & \text { 1. Chlorpromazine: dose } 300 \mathrm{mg} / \text { day (week } 1), 600 \mathrm{mg} / \text { day thereafter. } \mathrm{N}=11 . \\ & \text { 2. Placebo: dose } 2-4 \mathrm{cc} / \text { day (week } 1), 5-10 \mathrm{cc} / \text { day thereafter. } \mathrm{N}=12 .\end{aligned}$
$\begin{aligned} & \text { 3. Trifluoperazine: dose } 20 \mathrm{mg} / \mathrm{day} \text { (week } 1 \text { ), } 40 \mathrm{mg} / \text { day thereafter. } \mathrm{N}=11 \\ & \text { Medication given in fixed-dose regimen; artane: } 10 \mathrm{mg} / \text { day given to all to reduce side } \\ & \text { effects }\end{aligned}$

Outcomes

Leaving study early.

Global improvement (lack of previously observed delusions and hallucinations)

Unable to use -

Mental state: MMPI (no means or SD).

Notes

\section{Risk of bias}

\begin{tabular}{ll|l}
\hline Bias & Authors' judgement & Support for judgement \\
\hline $\begin{array}{l}\text { Random sequence generation (selection } \\
\text { bias) }\end{array}$ & Unclear risk & $\begin{array}{l}\text { "Randomly assigned" no further details re- } \\
\text { ported. }\end{array}$ \\
\hline Allocation concealment (selection bias) & Unclear risk & $\begin{array}{l}\text { "Randomly assigned trifluorop- } \\
\text { erazine, chlorpromazine or placebo by the } \\
\text { pharmacy" no further details reported }\end{array}$ \\
\hline
\end{tabular}

Blinding of participants and personnel Unclear risk (performance bias)

All outcomes

Blinding of outcome assessment (detection Unclear risk bias)

All outcomes

Incomplete outcome data (attrition bias) Low risk All outcomes
"Neither the ward personnel nor the investigator knew which drug the patient received" no further details reported

"Neither the ward personnel nor the investigator knew which drug the patient received" no further details reported

"Six patients had to be excluded from the investigation as they were given ECT. Of these subjects two were on trifluoroper- 


\begin{tabular}{|c|c|c|}
\hline & & $\begin{array}{l}\text { azine, one on chlorpromazine and three } \\
\text { were controls" } \\
\text { "An additional three subjects, one from } \\
\text { each group, had to be removed from the } \\
\text { study because of transfer or home leave" }\end{array}$ \\
\hline Selective reporting (reporting bias) & High risk & $\begin{array}{l}\text { No means or SDs reported for the MMPI. } \\
\text { Not all expected outcomes reported }\end{array}$ \\
\hline Other bias & Unclear risk & $\begin{array}{l}\text { Smith Kline and French provided drugs. } \\
\text { Source of funding not reported. }\end{array}$ \\
\hline
\end{tabular}

\section{Reschke 1974}

\begin{tabular}{|c|c|}
\hline Methods & $\begin{array}{l}\text { Allocation: randomly assigned - no further description. } \\
\text { Blinding: double - no further description. } \\
\text { Duration: approximately } 25 \text { hours. } \\
\text { Design: parallel. } \\
\text { Country: not reported. }\end{array}$ \\
\hline Participants & $\begin{array}{l}\text { Diagnosis: schizophrenia (no specified criteria). } \\
\text { History: severe agitation. } \\
\mathrm{N}=50 \text {. } \\
\text { Sex: } 2 \mathrm{M}, 48 \mathrm{~F} \text {. } \\
\text { Age: mean } 35.9 \text { yrs, range } 19-57 \text {. } \\
\text { Setting: hospital. }\end{array}$ \\
\hline Interventions & $\begin{array}{l}\text { 1. Chlorpromazine: dose } 25 \mathrm{mg} \mathrm{IM} . \mathrm{N}=10 \text {. } \\
\text { 2. Placebo. } \mathrm{N}=11 \text {. } \\
\text { 3. Haloperidol: dose } 5 \mathrm{mg} \mathrm{IM} . \mathrm{N}=10 \text {. } \\
\text { 4. Haloperidol: dose } 2 \mathrm{mg} \mathrm{IM} . \mathrm{N}=11 \text {. } \\
\text { 5. Haloperidol: dose } 1 \mathrm{mg} \mathrm{IM} . \mathrm{N}=8 \text {. } \\
\text { Max. of } 4 \text { injections administered at min. intervals of } 30 \text { minutes }\end{array}$ \\
\hline Outcomes & $\begin{array}{l}\text { Leaving study early. } \\
\text { Global improvement (own 5-point rating scale). } \\
\text { Adverse effects. } \\
\text { Unable to use - } \\
\text { Mental state: BPRS and own target symptoms scale (no mean or SD) }\end{array}$ \\
\hline Notes & \\
\hline
\end{tabular}

\section{Risk of bias}

\begin{tabular}{|c|c|c|}
\hline Bias & Authors' judgement & Support for judgement \\
\hline $\begin{array}{l}\text { Random sequence generation (selection } \\
\text { bias) }\end{array}$ & Unclear risk & $\begin{array}{l}\text { "Randomly assigned" no further details re- } \\
\text { ported. }\end{array}$ \\
\hline
\end{tabular}


Reschke 1974 (Continued)

\begin{tabular}{l|l|l}
\hline Allocation concealment (selection bias) & Unclear risk & No information reported. \\
\hline $\begin{array}{l}\text { Blinding of participants and personnel } \\
\text { (performance bias) } \\
\text { All outcomes }\end{array}$ & Unclear risk & "Double-blind" no further details reported. \\
\hline $\begin{array}{l}\text { Blinding of outcome assessment (detection } \\
\text { bias) } \\
\text { All outcomes }\end{array}$ & Unclear risk & “Double-blind” no further details reported. \\
\hline $\begin{array}{l}\text { Incomplete outcome data (attrition bias) } \\
\text { All outcomes }\end{array}$ & Low risk & There were no losses to follow-up. \\
\hline $\begin{array}{l}\text { Selective reporting (reporting bias) } \\
\text { Other bias }\end{array}$ & High risk & No means and SDs reported for BPRS. \\
\hline
\end{tabular}

\section{Saretsky 1966}

\begin{tabular}{|c|c|}
\hline Methods & $\begin{array}{l}\text { Allocation: randomly assigned - no further description. } \\
\text { Blinding: double, 'two kinds of pills ... identical in size, shape, colour, and taste'. } \\
\text { Duration: } 3 \text { months. } \\
\text { Design: parallel. } \\
\text { Country: USA. }\end{array}$ \\
\hline Participants & $\begin{array}{l}\text { Diagnosis: schizophrenic reaction (no criteria stated). } \\
\text { History: newly admitted. } \\
\mathrm{N}=40 \text {. } \\
\text { Sex: } 40 \mathrm{M} . \\
\text { Age: }<55 \text { yrs. } \\
\text { Setting: hospital. }\end{array}$ \\
\hline Interventions & $\begin{array}{l}\text { 1. Chlorpromazine: dose } 400 \mathrm{mg} / \text { day. } \mathrm{N}=20 \text {. } \\
\text { 2. Placebo (lactose): dose } 4 \text { pills/day. } \mathrm{N}=20 \text {. } \\
\text { Medication given in fixed-dose regimen. }\end{array}$ \\
\hline Outcomes & $\begin{array}{l}\text { Leaving study early. } \\
\text { Unable to use - } \\
\text { Mental state: MSRPP (mean appears erroneous). }\end{array}$ \\
\hline Notes & \\
\hline
\end{tabular}

\section{Risk of bias}

Bias

Authors' judgement

Support for judgement 
Saretsky 1966 (Continued)

\begin{tabular}{|c|c|c|}
\hline $\begin{array}{l}\text { Random sequence generation (selection } \\
\text { bias) }\end{array}$ & Unclear risk & $\begin{array}{l}\text { "Randomly assigned" no further details re- } \\
\text { ported. }\end{array}$ \\
\hline Allocation concealment (selection bias) & Unclear risk & No information reported. \\
\hline $\begin{array}{l}\text { Blinding of participants and personnel } \\
\text { (performance bias) } \\
\text { All outcomes }\end{array}$ & Low risk & $\begin{array}{l}\text { "The drugs were packaged in individual } \\
\text { bottles with only the patient's name printed } \\
\text { on them as a means of identification." } \\
\text { "Throughout the experiment, whether the } \\
\text { patient received the drug or a placebo was } \\
\text { not known to anyone connected with the } \\
\text { experiment." } \\
\text { "The two kinds of pills were identical in } \\
\text { size, shape, colour, and taste." }\end{array}$ \\
\hline $\begin{array}{l}\text { Blinding of outcome assessment (detection } \\
\text { bias) } \\
\text { All outcomes }\end{array}$ & Low risk & $\begin{array}{l}\text { "Throughout the experiment, whether the } \\
\text { patient received the drug or a placebo was } \\
\text { not known to anyone connected with the } \\
\text { experiment." }\end{array}$ \\
\hline $\begin{array}{l}\text { Incomplete outcome data (attrition bias) } \\
\text { All outcomes }\end{array}$ & Low risk & There were no losses to follow-up. \\
\hline Selective reporting (reporting bias) & High risk & Not all expected outcomes reported. \\
\hline Other bias & Unclear risk & Source of funding not reported. \\
\hline
\end{tabular}

Schiele 1961

Methods

Allocation: randomly assigned - no further description.

Blinding: double - no further description.

Duration: 16 weeks.

Design: parallel.

Country: USA.

Participants

Diagnosis: schizophrenia (no criteria stated).

History: all had been hospitalised for an average of 10 years.

$\mathrm{N}=80$.

Sex: $80 \mathrm{M}$.

Age: 40.6 years (average).

Setting: hospital.

Interventions

1. Chlorpromazine: dose 200-1000 mg/day. $\mathrm{N}=20$.

2. Placebo: $\mathrm{N}=20$.

3. Thioridazine: dose $200-1000 \mathrm{mg} /$ day. $\mathrm{N}=20$.

4. Trifluoperazine: dose $10-50 \mathrm{mg} /$ day. $\mathrm{N}=20$. 
Schiele 1961 (Continued)

\begin{tabular}{|c|c|c|}
\hline Outcomes & \multicolumn{2}{|c|}{$\begin{array}{l}\text { Leaving the study early. } \\
\text { Mental state. MMPI. } \\
\text { Global estimate of clinical change - via ward staff. } \\
\text { Adverse effects. } \\
\text { Unable to use - } \\
\text { Behaviour: MBS (no SD). }\end{array}$} \\
\hline Notes & \multicolumn{2}{|l|}{ Withdrawals described. } \\
\hline \multicolumn{3}{|l|}{ Risk of bias } \\
\hline Bias & Authors' judgement & Support for judgement \\
\hline $\begin{array}{l}\text { Random sequence generation (selection } \\
\text { bias) }\end{array}$ & Unclear risk & $\begin{array}{l}\text { "Randomly assigned" no further details re- } \\
\text { ported. }\end{array}$ \\
\hline Allocation concealment (selection bias) & Unclear risk & No information reported. \\
\hline $\begin{array}{l}\text { Blinding of participants and personnel } \\
\text { (performance bias) } \\
\text { All outcomes }\end{array}$ & Low risk & $\begin{array}{l}\text { "During the first } 16 \text { weeks, the study was } \\
\text { carried out under strict double-blind con- } \\
\text { ditions. Each patient had his individual } \\
\text { bottle of medication; the capsules were } \\
\text { identical in appearance, and only the hos- } \\
\text { pital pharmacist had the code for determin- } \\
\text { ing which patient was receiving each kind } \\
\text { of medication" }\end{array}$ \\
\hline $\begin{array}{l}\text { Blinding of outcome assessment (detection } \\
\text { bias) } \\
\text { All outcomes }\end{array}$ & Unclear risk & "Double-blind" no further details reported. \\
\hline $\begin{array}{l}\text { Incomplete outcome data (attrition bias) } \\
\text { All outcomes }\end{array}$ & Unclear risk & $\begin{array}{l}\text { "Only } 2 \text { patients were dropped }[. . .] \text { because } \\
\text { their psychiatric condition became and re- } \\
\text { mained worse." } \\
\text { "During the thirteenth week. a third pa- } \\
\text { tient who was in the trifluoperazine group } \\
\text { eloped from the hospital." Only } 43 \text { partic- } \\
\text { ipants took the MMPI three times }\end{array}$ \\
\hline Selective reporting (reporting bias) & High risk & No SD reported for the MBS. \\
\hline Other bias & Unclear risk & Source of funding not reported. \\
\hline
\end{tabular}


Serafetinides 1972

\begin{tabular}{|c|c|}
\hline Methods & $\begin{array}{l}\text { Allocation: randomly assigned - no further description. } \\
\text { Blinding: double, used 'identically appearing capsules'. } \\
\text { Duration: } 12 \text { weeks (preceded by } 12 \text { week dry-out period). } \\
\text { Design: parallel. } \\
\text { Country: USA. }\end{array}$ \\
\hline Participants & $\begin{array}{l}\text { Diagnosis: schizophrenia (criteria not specified). } \\
\text { History: > } 2 \text { yrs ill. } \\
\mathrm{N}=57^{*} \text {. } \\
\text { Sex: } 25 \mathrm{M}, 32 \mathrm{~F} \text {. } \\
\text { Age: range } 21-61 \text { yrs. } \\
\text { Setting: hospital. }\end{array}$ \\
\hline Interventions & $\begin{array}{l}\text { 1. Chlorpromazine: dose max. } 1000 \mathrm{mg} / \text { day. } \mathrm{N}=14 \text {. } \\
\text { 2. Placebo: dose max. } 10 \text { capsules/day. } \mathrm{N}=13 \text {. } \\
\text { 3. Haloperidol: dose max. } 15 \mathrm{mg} / \text { day. } \mathrm{N}=14 \text {. } \\
\text { 4. Clopenthixol: dose max. } 250 \mathrm{mg} / \text { day. } \mathrm{N}=15 \text {. } \\
\text { Medication given in variable dose regimen' medication for EPS or insomnia as required }\end{array}$ \\
\hline Outcomes & $\begin{array}{l}\text { Leaving study early. } \\
\text { Global improvement. CGI. } \\
\text { Adverse effects. } \\
\text { Liver function. } \\
\text { Unable to use - } \\
\text { Global improvement: CGI (discrepancy with group totals). } \\
\text { Mental state: BPRS, Venables-O'Conner scale (no SD). } \\
\text { Behaviour: NOSIE, OBRS (no SD). } \\
\text { Psychological function: test battery (no data). }\end{array}$ \\
\hline Notes & *One participant not accounted for. \\
\hline
\end{tabular}

Risk of bias

\begin{tabular}{|c|c|c|}
\hline Bias & Authors' judgement & Support for judgement \\
\hline $\begin{array}{l}\text { Random sequence generation (selection } \\
\text { bias) }\end{array}$ & Unclear risk & $\begin{array}{l}\text { "Randomly assigned" no further details re- } \\
\text { ported. }\end{array}$ \\
\hline Allocation concealment (selection bias) & Unclear risk & No information reported. \\
\hline $\begin{array}{l}\text { Blinding of participants and personnel } \\
\text { (performance bias) } \\
\text { All outcomes }\end{array}$ & Unclear risk & $\begin{array}{l}\text { "All medications were prepared in identi- } \\
\text { cally appearing capsules" no further details } \\
\text { reported }\end{array}$ \\
\hline
\end{tabular}

Blinding of outcome assessment (detection Unclear risk bias)

All outcomes

No information reported. 


\begin{tabular}{l|l|l}
\hline $\begin{array}{l}\text { Incomplete outcome data (attrition bias) } \\
\text { All outcomes }\end{array}$ & Low risk & $\begin{array}{l}\text { "Four of the } 57 \text { subjects, three on CPZ, and } \\
\text { one on PL,failed to complete the 12 weeks } \\
\text { of study. The PL subject and one CPZ sub- } \\
\text { ject were terminated because of behavioural } \\
\text { deterioration after } 4 \text { and } 8 \text { weeks respec- } \\
\text { tively. The other two CPZ subjects devel- } \\
\text { oped intestinal obstruction secondary to } \\
\text { massive fecal impactions and were termi- } \\
\text { nated in the 7th week of study." }\end{array}$ \\
\hline Selective reporting (reporting bias) & High risk & $\begin{array}{l}\text { No SDs were reported for the CGI, NOSIE } \\
\text { and the OBPRS. } \\
\text { No data was reported for the psychological } \\
\text { function tests. }\end{array}$ \\
\hline Other bias & Low risk & $\begin{array}{l}\text { Supported in part by a US Public Health } \\
\text { Service Grant. }\end{array}$ \\
\hline
\end{tabular}

\section{Shepherd 1956}

Methods

Participants

Interventions

1. Chlorpromazine: dose $300 \mathrm{mg} /$ day. $\mathrm{N}=8$.

2. Placebo. $\mathrm{N}=8$. [see notes].

3. Reserpine: dose $15 \mathrm{mg}$ (reduced to) $10 \mathrm{mg} /$ day. $\mathrm{N}=8$. [see notes]

Medication given in fixed-dose regimen.

Outcomes

Improvement.

Leaving study early.

Unable to use -

Adverse effects (not reported for individual arm of cross-over)

Notes

Before first cross-over reserpine group inadvertently given $0.75 \mathrm{mg} /$ day (not $15 \mathrm{mg} /$ day) . This group therefore regarded as placebo group by trialists and reviewers (hence $\mathrm{N}$ for placebo=16) 
Shepherd 1956 (Continued)

Risk of bias

\begin{tabular}{|c|c|c|}
\hline Bias & Authors' judgement & Support for judgement \\
\hline $\begin{array}{l}\text { Random sequence generation (selection } \\
\text { bias) }\end{array}$ & Unclear risk & $\begin{array}{l}\text { The } 24 \text { patients were divided into three } \\
\text { groups of eight (A,B, and } \mathrm{C}) \text { by random } \\
\text { selection" no further details reported }\end{array}$ \\
\hline Allocation concealment (selection bias) & Unclear risk & No information reported. \\
\hline $\begin{array}{l}\text { Blinding of participants and personnel } \\
\text { (performance bias) } \\
\text { All outcomes }\end{array}$ & Low risk & $\begin{array}{l}\text { Two kinds of inert substances were em- } \\
\text { ployed, one indistinguishable from reser- } \\
\text { pine, the other from chlorpromazine. No- } \\
\text { body but the ward doctor allocating the } \\
\text { drugs and the dispenser knew which pa- } \\
\text { tients were receiving drugs and which pa- } \\
\text { tients were on placebo" }\end{array}$ \\
\hline $\begin{array}{l}\text { Blinding of outcome assessment (detection } \\
\text { bias) } \\
\text { All outcomes }\end{array}$ & Low risk & $\begin{array}{l}\text { "Weekly clinical assessments were carried } \\
\text { out by one of us (DCW) who was unaware } \\
\text { of the nature of individual prescriptions" }\end{array}$ \\
\hline $\begin{array}{l}\text { Incomplete outcome data (attrition bias) } \\
\text { All outcomes }\end{array}$ & Low risk & There were no losses to follow-up. \\
\hline Selective reporting (reporting bias) & High risk & $\begin{array}{l}\text { Adverse effects were not reported for each } \\
\text { individual arm. }\end{array}$ \\
\hline Other bias & Unclear risk & $\begin{array}{l}\text { Messrs Ciba supplied serpasil and dummy } \\
\text { tablets, Messrs May and Baker supplied } \\
\text { dummy tablets }\end{array}$ \\
\hline
\end{tabular}

Simon 1958

$\begin{array}{ll}\text { Methods } & \text { Allocation: by list of random numbers. } \\ & \text { Blinding: unclear. } \\ & \text { Duration: } 30 \text { days. } \\ \text { Design: parallel. } \\ \text { Country: USA. }\end{array}$

Participants

Diagnosis: schizophrenia (78), schizoaffective (2).

History: treatment naive, duration treated -33 days.

$\mathrm{N}=80$

Sex: not reported.

Age: mean -31 years.

IQ: mean -103 .

Setting: hospital. 


\begin{tabular}{|c|c|c|}
\hline Interventions & \multicolumn{2}{|c|}{$\begin{array}{l}\text { 1. Chlorpromazine: dose mean } 400 \mathrm{mg} / \text { day, range } 200-1200 \mathrm{mg} / \text { day. } \mathrm{N}=20 \text {. } \\
\text { 2. Reserpine: dose mean } \mathrm{mg} / \text { day, range } 2-\mathrm{mg} / \text { day. } \mathrm{N}=20 \text {. } \\
\text { 3. Clinical judgement: any treatment - could include chlorpromazine. } \mathrm{N}=20 \text {. } \\
\text { 4. Hospital routine: admission but no specific treatment, no drugs. } \mathrm{N}=20\end{array}$} \\
\hline Outcomes & \multicolumn{2}{|c|}{$\begin{array}{l}\text { Leaving the study early. } \\
\text { Unable to use - } \\
\text { Personality profile: MMPI (no means, no SD). } \\
\text { Social functioning: Scale of Occupational Adjustment (no data reported) }\end{array}$} \\
\hline Notes & \multicolumn{2}{|c|}{ Withdrawals described. } \\
\hline \multicolumn{3}{|l|}{ Risk of bias } \\
\hline Bias & Authors' judgement & Support for judgement \\
\hline $\begin{array}{l}\text { Random sequence generation (selection } \\
\text { bias) }\end{array}$ & Low risk & $\begin{array}{l}\text { "Assigned to one of } 4 \text { treatment groups on } \\
\text { a random basis [...] the staff was kept igno- } \\
\text { rant of the order within the random list" }\end{array}$ \\
\hline Allocation concealment (selection bias) & Unclear risk & No information reported. \\
\hline $\begin{array}{l}\text { Blinding of participants and personnel } \\
\text { (performance bias) } \\
\text { All outcomes }\end{array}$ & Unclear risk & No information reported. \\
\hline $\begin{array}{l}\text { Blinding of outcome assessment (detection } \\
\text { bias) } \\
\text { All outcomes }\end{array}$ & Unclear risk & No information reported. \\
\hline $\begin{array}{l}\text { Incomplete outcome data (attrition bias) } \\
\text { All outcomes }\end{array}$ & Low risk & There were no losses to follow-up. \\
\hline Selective reporting (reporting bias) & High risk & $\begin{array}{l}\text { Means and SDs were not reported for the } \\
\text { MMPI. } \\
\text { No data was reported for the Scale of Oc- } \\
\text { cupational Adjustment }\end{array}$ \\
\hline Other bias & Unclear risk & Source of funding not reported. \\
\hline
\end{tabular}



symptom.

Blinding: double.

Duration: 14 weeks.

Design: parallel.

Country: not reported.

\begin{tabular}{ll}
\hline Participants & Diagnosis: schizophrenia. \\
& History: chronic. \\
& N=41. \\
& $\begin{array}{l}\text { Sex: male and female. } \\
\text { Age: } 42.21 \text { years (average). } \\
\text { Setting: research unit. }\end{array}$ \\
\hline Interventions & $\begin{array}{l}\text { 1. Chlorpromazine: dose } 150-600 \mathrm{mg} / \text { day. } \mathrm{N}=13 . \\
\text { 2. Placebo. } \mathrm{N}=15 .\end{array}$ \\
& 3. Chlordiazepoxide: dose $150-700 \mathrm{mg} /$ day. $\mathrm{N}=13$. \\
\hline Outcomes & Behaviour rating scale. \\
& Unable to use- \\
& Leaving the study early (no usable data). \\
\hline Notes & Withdrawals described but unclear. \\
\hline
\end{tabular}

\section{Risk of bias}

\begin{tabular}{l|l} 
Bias & Authors' judgement
\end{tabular}

Random sequence generation (selection Unclear risk bias)
The 45 patients were divided into three matched groups on the basis of age, illness duration and predominant symptomatology" no further details reported

No information reported.

Allocation concealment (selection bias) Unclear risk

"The medication used during the study was

Blinding of participants and personnel Low risk (performance bias)

All outcomes

Blinding of outcome assessment (detection Unclear risk bias)

All outcomes

Incomplete outcome data (attrition bias) Unclear risk All outcomes prepared in identical capsules"

"Neither the patients nor the attending physicians knew what medication was being given. An identifying code was available but not broken until the end of the study."

"Neither the patients nor the attending physicians knew what medication was being given." no further details reported

Two participants lost to follow-up in the chlorpromazine group and two in the clordiazepoxide group, reasons for leaving the 
Smith 1961 (Continued)

study early not reported. Unclear whether there were any losses in the placebo group

\begin{tabular}{l|l|l} 
Selective reporting (reporting bias) & Low risk & All expected outcomes reported. \\
\hline Other bias & Unclear risk & Source of funding not reported.
\end{tabular}

Somerville 1960

Methods

Allocation: matched on symptoms, age, and duration of illness, then allocated 'by random choice' - no further description.

Blinding: 'the two placebos were identical in appearance with the respective active tablets'.

Duration: 6 weeks.

Design: parallel.

Country: Australia.

Participants

Diagnosis: schizophrenia or 'paraphrenic psychoses' $(\mathrm{N}=56)$; manic depression $(\mathrm{N}=4)$.

History: duration of illness, mean 9.5 yrs, range 0.4-29.

$\mathrm{N}=60$.

Sex: $60 \mathrm{~F}$

Age: mean 41 yrs, range 24-58.

Setting: hospital.

Interventions

1. Chlorpromazine: dose 200-800 mg/day. $\mathrm{N}=15$.

2. Placebo. $\mathrm{N}=30$.

3. Thioridazine: dose $200-800 \mathrm{mg} /$ day. $\mathrm{N}=15$.

Outcomes

Leaving study early.

Clinical improvement (own 5-point rating scale).

Behaviour. Fergus Falls Rating Scale.

Adverse effects.

Notes

Risk of bias

\begin{tabular}{l|l|l} 
Bias & Authors' judgement & Support for judgement \\
\hline $\begin{array}{l}\text { Random sequence generation (selection } \\
\text { bias) }\end{array}$ & Unclear risk & $\begin{array}{l}\text { "Random choice" matched on symptoms, } \\
\text { age, and duration of illness, no further de- } \\
\text { tails reported }\end{array}$ \\
\hline Allocation concealment (selection bias) & Unclear risk & $\begin{array}{l}\text { "A doctor who had no duties connected } \\
\text { with the ward concerned allotted each of } \\
\text { the groups to a particular therapy" no fur- } \\
\text { ther details reported }\end{array}$
\end{tabular}


Blinding of participants and personnel Low risk (performance bias)

All outcomes

Blinding of outcome assessment (detection Unclear risk bias)

All outcomes

\begin{tabular}{l|l|l}
\hline $\begin{array}{l}\text { Incomplete outcome data (attrition bias) } \\
\text { All outcomes }\end{array}$ & Low risk & There were no losses to follow-up. \\
\hline Selective reporting (reporting bias) & Low risk & All expected outcomes reported. \\
\hline Other bias & Unclear risk & $\begin{array}{l}\text { Sandoz Australia Proprietary Limited and } \\
\text { May \& Baker (Australia) Proprietary Lim- } \\
\text { ited supplied drugs } \\
\text { Source of funding not reported. }\end{array}$ \\
\hline
\end{tabular}

\section{Spohn 1977}

Methods

Allocation: randomly assigned - no further description.

Blinding: double, used 'chlorpromazine facsimile" placebo.

Duration: "at least six weeks" (preceded by abrupt medication withdrawal \& 6 week washout)

Design: parallel.

Country: USA.

\begin{tabular}{ll} 
Participants & Diagnosis: chronic schizophrenia ('official hospital diagnosis'). \\
& $\begin{array}{l}\text { Ne } 40 . \\
\text { Sex: } 28 \mathrm{M}, 12 \mathrm{~F} . \\
\text { Age: range } 18-55 \text { yrs. } \\
\text { Setting: hospital. }\end{array}$ \\
\hline Interventions & $\begin{array}{l}\text { 1. Chlorpromazine: dose discretionary min. } 200 \mathrm{mg} / \mathrm{day} . \mathrm{N}=20 . \\
\text { 2. Placebo. N=20. } \\
\text { Antiparkinsonian medication for EPS as required; chloral hydrate for insomnia as re- } \\
\text { quired }\end{array}$ \\
\hline Outcomes & $\begin{array}{l}\text { Relapse. } \\
\text { Unable to use - } \\
\text { Global severity of illness: Global Severity Scale (no means or SD). } \\
\text { Global improvement: Global Improvement Scale (no means or SD). } \\
\text { Behaviour: Ward Behavior Rating Scale (no means or SD). }\end{array}$ \\
\hline Notes & \\
\hline
\end{tabular}

Risk of bias

Chlorpromazine versus placebo for schizophrenia (Review)

Copyright ( 2015 The Cochrane Collaboration. Published by John Wiley \& Sons, Ltd. 
Spohn 1977 (Continued)

\begin{tabular}{|c|c|c|}
\hline Bias & Authors' judgement & Support for judgement \\
\hline $\begin{array}{l}\text { Random sequence generation (selection } \\
\text { bias) }\end{array}$ & Unclear risk & $\begin{array}{l}\text { "Random assignment" no further details } \\
\text { reported. }\end{array}$ \\
\hline Allocation concealment (selection bias) & Unclear risk & No information reported. \\
\hline $\begin{array}{l}\text { Blinding of participants and personnel } \\
\text { (performance bias) } \\
\text { All outcomes }\end{array}$ & Unclear risk & $\begin{array}{l}\text { "During the drug treatment period, pa- } \\
\text { tients, project personnel, and hospital per- } \\
\text { sonnel were "blind" to the patients' drug } \\
\text { status" no further details reported }\end{array}$ \\
\hline $\begin{array}{l}\text { Blinding of outcome assessment (detection } \\
\text { bias) } \\
\text { All outcomes }\end{array}$ & Unclear risk & $\begin{array}{l}\text { "During the drug treatment period, pa- } \\
\text { tients, project personnel, and hospital per- } \\
\text { sonnel were "blind" to the patients' drug } \\
\text { status" no further details reported }\end{array}$ \\
\hline $\begin{array}{l}\text { Incomplete outcome data (attrition bias) } \\
\text { All outcomes }\end{array}$ & Unclear risk & Losses to follow-up not reported. \\
\hline Selective reporting (reporting bias) & High risk & $\begin{array}{l}\text { Means and SDs were not reported for the } \\
\text { Global Severity Scale, Global improvement } \\
\text { Scale and the Ward Behaviour Rating Scale }\end{array}$ \\
\hline Other bias & Unclear risk & $\begin{array}{l}\text { Supported by a Public Health Service re- } \\
\text { search grant and a research scientist award } \\
\text { from the National Institute of Mental } \\
\text { Health and by the Ittleson Family Founda- } \\
\text { tion } \\
\text { Chlorpromazine supplied by Smith Kline } \\
\text { and French Laboratories }\end{array}$ \\
\hline
\end{tabular}

Tetreault 1969

Methods

Allocation: randomly assigned - according to a 'random number table'.

Blinding: double, identical capsules.

Duration: 12 weeks (preceded by 19-day wash-out).

Design: parallel.

Country: Canada.

Participants

Diagnosis: schizophrenia (no specified criteria).

History: 'chronic', mean duration of hospitalisation 16.3 yrs.

$\mathrm{N}=45$.

Sex:45 F.

Age: mean 50.5 yrs.

Setting: hospital. 


\section{Tetreault 1969 (Continued)}

\begin{tabular}{|c|c|}
\hline Interventions & $\begin{array}{l}\text { 1. Chlorpromazine: dose } 300 \mathrm{mg} \text { increasing to } 600 \mathrm{mg} / \text { day. } \mathrm{N}=15 \text {. } \\
\text { 2. Placebo: dose } 3 \text { capsules increasing to } 6 \text { capsules/day. } \mathrm{N}=15 \text {. } \\
\text { 3. TPS- } 23 \text { (Mesoridazine): dose } 150 \mathrm{mg} \text { increasing to } 300 \mathrm{mg} / \text { day. } \mathrm{N}=15 \\
\text { Chlorpromazine }(50 \mathrm{mg} \text { im), chloral hydrate }(650 \mathrm{mg}) \text {, ethchlorvynol }(500 \mathrm{mg}) \text {, pro- } \\
\text { cyclidine ( } 5 \mathrm{mg} \mathrm{IM}) \text { as required 'in case of emergency' }\end{array}$ \\
\hline Outcomes & $\begin{array}{l}\text { Leaving study early. } \\
\text { Mental state. BPRS. } \\
\text { Behaviour. Modified Rosenthal Rating Scale. } \\
\text { Extrapyramidal adverse effects. } \\
\text { Adverse effects. }\end{array}$ \\
\hline Notes & \\
\hline
\end{tabular}

Risk of bias

\begin{tabular}{|c|c|c|}
\hline Bias & Authors' judgement & Support for judgement \\
\hline $\begin{array}{l}\text { Random sequence generation (selection } \\
\text { bias) }\end{array}$ & Low risk & $\begin{array}{l}\text { "Patients received one of the tested drugs } \\
\text { according to a random number table" }\end{array}$ \\
\hline Allocation concealment (selection bias) & Unclear risk & No information reported. \\
\hline $\begin{array}{l}\text { Blinding of participants and personnel } \\
\text { (performance bias) } \\
\text { All outcomes }\end{array}$ & Low risk & $\begin{array}{l}\text { "TPS- } 23(50 \mathrm{mg} \text {, chlorpromazine }(100 \mathrm{mg}) \\
\text { and placebo presented in identical white } \\
\text { capsules; they were distributed on the ward } \\
\text { in containers on which only the patient's } \\
\text { name appeared. The double-blind tech- } \\
\text { nique was followed throughout the experi- } \\
\text { ment" }\end{array}$ \\
\hline $\begin{array}{l}\text { Blinding of outcome assessment (detection } \\
\text { bias) } \\
\text { All outcomes }\end{array}$ & Unclear risk & "Double-blind" no further details reported. \\
\hline $\begin{array}{l}\text { Incomplete outcome data (attrition bias) } \\
\text { All outcomes }\end{array}$ & Low risk & There were no losses to follow-up. \\
\hline Selective reporting (reporting bias) & Low risk & All expected outcomes reported. \\
\hline Other bias & High risk & $\begin{array}{l}\text { Partly supported by a grant-in-aid from } \\
\text { Sandoz (Canada) Ltd. who supplied the } \\
\text { drugs }\end{array}$ \\
\hline
\end{tabular}




Methods
Allocation: randomly assigned - no further description.
Blinding: 'the hospital pharmacist alone knowing which patients were receiving CPZ
and which the placebo'.
Duration: not specified.
Design: parallel.
Country: UK.

Diagnosis: not specified; all participants had motor restlessness, psychomotor agitation, and excitement, were 'chronic and intractable', and had a poor prognosis.

History: mean duration of hospitalisation 9.6 yrs.

$\mathrm{N}=48$.

Sex: $48 \mathrm{~F}$.

Age: mean 43 yrs.

Setting: hospital.

1. Chlorpromazine: dose variable $75-450 \mathrm{mg} /$ day. $\mathrm{N}=24$.

2. Placebo. $\mathrm{N}=24$.

Outcomes

Notes
Global improvement.

Reviewers assume short-term outcome - in keeping with other studies of that period

\section{Risk of bias}

\begin{tabular}{|c|c|c|}
\hline Bias & Authors' judgement & Support for judgement \\
\hline $\begin{array}{l}\text { Random sequence generation (selection } \\
\text { bias) }\end{array}$ & Unclear risk & $\begin{array}{l}\text { "By random selection" no further details } \\
\text { reported. }\end{array}$ \\
\hline Allocation concealment (selection bias) & Unclear risk & No information reported. \\
\hline $\begin{array}{l}\text { Blinding of participants and personnel } \\
\text { (performance bias) } \\
\text { All outcomes }\end{array}$ & Unclear risk & $\begin{array}{l}\text { "The hospital pharmacist alone knowing } \\
\text { which patients were receiving chlorpro- } \\
\text { mazine and which the placebo" no further } \\
\text { details reported }\end{array}$ \\
\hline $\begin{array}{l}\text { Blinding of outcome assessment (detection } \\
\text { bias) } \\
\text { All outcomes }\end{array}$ & Unclear risk & $\begin{array}{l}\text { "The hospital pharmacist alone knowing } \\
\text { which patients were receiving chlorpro- } \\
\text { mazine and which the placebo" no further } \\
\text { details reported }\end{array}$ \\
\hline $\begin{array}{l}\text { Incomplete outcome data (attrition bias) } \\
\text { All outcomes }\end{array}$ & Unclear risk & Losses to follow-up not reported. \\
\hline Selective reporting (reporting bias) & High risk & Not all expected outcomes reported. \\
\hline Other bias & Unclear risk & $\begin{array}{l}\text { Messrs May \& Baker supplied the placebo } \\
\text { tablets. } \\
\text { Source of funding not reported. }\end{array}$ \\
\hline
\end{tabular}


Walsh 1959

Allocation: randomly assigned - 'allocation of a preparation to a group was purely arbi-
trary' - matched on age, hospitalisation, adjustment, psychotic behaviour, and activity/
withdrawal.
Blinding: unclear, no. \& size of placebo tablets altered when active preparations altered.
Duration: 8 weeks.
Design: parallel.
Country: not reported

$\begin{array}{ll}\text { Participants } & \text { Diagnosis: schizophrenia (no specified criteria). } \\ & \text { History: 'chronic', mean duration of hospitalisation } 13 \text { yrs, range 1-28. } \\ & \text { N=66. } \\ \text { Sex: } 66 \mathrm{~F} . \\ \text { Age: mean } 40 \text { yrs, range } 27-50 . \\ \text { Setting: hospital. }\end{array}$

Interventions

1. Chlorpromazine: dose $75 \mathrm{mg} /$ day increasing to $300 \mathrm{mg} /$ day. $\mathrm{N}=22$.

2. Placebo. $\mathrm{N}=22$.

3. Triflupromazine: dose $75 \mathrm{mg} /$ day increasing to $300 \mathrm{mg} /$ day. $\mathrm{N}=22$

Outcomes
$\begin{aligned} & \text { Clinical improvement (4-point rating scale). } \\ & \text { Adverse effects. } \\ & \text { Unable to use - } \\ & \text { Mental state: Rowell 'Psychoticism' Rating Scale (no SD). } \\ & \text { Behaviour: Venables Activity-Withdrawal Rating Scale (no SD) }\end{aligned}$

Notes

\section{Risk of bias}

\begin{tabular}{|c|c|c|}
\hline Bias & Authors' judgement & Support for judgement \\
\hline $\begin{array}{l}\text { Random sequence generation (selection } \\
\text { bias) }\end{array}$ & Unclear risk & $\begin{array}{l}\text { "Allocation of a preparation to a group } \\
\text { was purely arbitrary“, participants matched } \\
\text { on age, hospitalisation, adjustment, psy- } \\
\text { chotic behaviour, and activity/withdrawal. } \\
\text { No further details reported }\end{array}$ \\
\hline Allocation concealment (selection bias) & Unclear risk & No information reported. \\
\hline $\begin{array}{l}\text { Blinding of participants and personnel } \\
\text { (performance bias) } \\
\text { All outcomes }\end{array}$ & Low risk & $\begin{array}{l}\text { As this involved periodic changes in the } \\
\text { number and/or size of the tablets, the num- } \\
\text { ber and/or size of the tablets given to the } \\
\text { placebo group was altered simultaneously. } \\
\text { Neither the doctor nor the ward staff were } \\
\text { aware of the nature of the preparation be- } \\
\text { ing given to a particular patient. A sepa- } \\
\text { rate bottle was assigned to each patient and } \\
\text { in this supplies of the specific preparation }\end{array}$ \\
\hline
\end{tabular}


Walsh 1959 (Continued)

were issued at weekly intervals"

Blinding of outcome assessment (detection Unclear risk bias)

"Neither the doctor nor the ward staff were aware of the nature of the preparation being given to a particular patient" no further details reported

All outcomes

There were no losses to follow-up.

Incomplete outcome data (attrition bias) Low risk

All outcomes

\begin{tabular}{l|l|l}
\hline Selective reporting (reporting bias) & High risk & $\begin{array}{l}\text { No SDs were reported for Rowell 'Psychoti- } \\
\text { cism' Rating Scale and the Venables Activ- } \\
\text { ity-Withdrawal Rating Scale }\end{array}$ \\
\hline Other bias & Unclear risk & $\begin{array}{l}\text { ER Squibb and Sons Ltd, London provided } \\
\text { drugs. } \\
\text { Source of funding not reported. }\end{array}$ \\
\hline
\end{tabular}

Weckowicz 1960

\begin{tabular}{|c|c|}
\hline Methods & $\begin{array}{l}\text { Allocation: not stated. } \\
\text { Blinding: double blind. } \\
\text { Duration: } 8 \text { weeks. } \\
\text { Design: parallel. } \\
\text { Country: Canada. }\end{array}$ \\
\hline Participants & $\begin{array}{l}\text { Diagnosis: schizophrenia (criteria not reported). } \\
\mathrm{N}=48 \\
\text { Age: average was } 48 \text { to } 51 \text { in each group. } \\
\text { Sex: F } 48 \text {. } \\
\text { History: Disturbed chronic schizophrenic patients. } \\
\text { Exclusions: not reported. } \\
\text { Setting: hospital. }\end{array}$ \\
\hline Interventions & $\begin{array}{l}\text { 1. Chlorpromazine: dose } 50 \mathrm{mg} / \text { day for } 2 \text { days, } 100 \mathrm{mg} / \text { day for } 3 \text { days and } 150 \mathrm{mg} / \text { day } \\
\text { for the remaining } 28 \text { days. } \mathrm{N}=16 \text {. } \\
\text { 2. Placebo. } \mathrm{N}=16 \text {. } \\
\text { 3. RO5- } 0690 \text {. dose } 50 \mathrm{mg} / \text { day for } 2 \text { days, } 100 \mathrm{mg} / \text { day for } 3 \text { days and } 150 \mathrm{mg} / \text { day for } \\
\text { the remaining } 28 \text { days. } \mathrm{N}=16\end{array}$ \\
\hline Outcomes & $\begin{array}{l}\text { Global impression: no global improvement (rated by nurse). } \\
\text { Adverse effects. } \\
\text { Unable to use - } \\
\text { Weyburn Assessment Scale (no SDs reported). }\end{array}$ \\
\hline Notes & \\
\hline
\end{tabular}

Risk of bias

Chlorpromazine versus placebo for schizophrenia (Review) 
Weckowicz 1960 (Continued)

\begin{tabular}{|c|c|c|}
\hline Bias & Authors' judgement & Support for judgement \\
\hline $\begin{array}{l}\text { Random sequence generation (selection } \\
\text { bias) }\end{array}$ & High risk & $\begin{array}{l}\text { "On the basis of rating they were divided } \\
\text { into three matched groups" no further de- } \\
\text { tails reported }\end{array}$ \\
\hline Allocation concealment (selection bias) & Unclear risk & No information reported. \\
\hline $\begin{array}{l}\text { Blinding of participants and personnel } \\
\text { (performance bias) } \\
\text { All outcomes }\end{array}$ & Low risk & $\begin{array}{l}\text { "Double-blind" } \\
\text { "The patients in the three groups received } \\
\text { respectively from bottles marked "A“, "B" } \\
\text { and "C" } 50 \mathrm{mg} \text { tablets which looked exactly } \\
\text { the same" }\end{array}$ \\
\hline $\begin{array}{l}\text { Blinding of outcome assessment (detection } \\
\text { bias) } \\
\text { All outcomes }\end{array}$ & Unclear risk & "Double-blind" no further details reported. \\
\hline $\begin{array}{l}\text { Incomplete outcome data (attrition bias) } \\
\text { All outcomes }\end{array}$ & Low risk & $\begin{array}{l}\text { For the outcome global impression "the } \\
\text { number [of participants] is less than } 16 \text { in } \\
\text { the groups, because some patients refused } \\
\text { to take their medication" }\end{array}$ \\
\hline Selective reporting (reporting bias) & High risk & $\begin{array}{l}\mathrm{N} \text { and SD not reported for the Weyburn } \\
\text { assessment scale. }\end{array}$ \\
\hline Other bias & Low risk & $\begin{array}{l}\text { Funded by the Rockefeller Foundation and } \\
\text { the Federal Fund. }\end{array}$ \\
\hline
\end{tabular}

\section{Xiong 1994}

\begin{tabular}{|c|c|}
\hline Methods & $\begin{array}{l}\text { Allocation: randomly divided. } \\
\text { Blinding: double. } \\
\text { Duration: } 9 \text { weeks. } \\
\text { Design: parallel. } \\
\text { Country: China. }\end{array}$ \\
\hline Participants & $\begin{array}{l}\text { Diagnosis: chronic schizophrenia (DSM III-R). } \\
\text { History: not reported. } \\
\mathrm{N}=48^{*} \text {. } \\
\text { Sex: all male. } \\
\text { Age: range } 27-46 \text {, mean } 35 \text { years. } \\
\text { Setting: hospital. }\end{array}$ \\
\hline Interventions & $\begin{array}{l}\text { 1. Chlorpromazine: dose mean } 295 \mathrm{mg} / \text { day. } \mathrm{N}=12 \text {. } \\
\text { 2. Placebo. } \mathrm{N}=12 \text {. } \\
\text { 3. Chlorpromazine: dose mean } 143.5 \mathrm{mg} / \text { day + Phenytoin }-155 \mathrm{mg} / \text { day. } \mathrm{N}=12 \text {. } \\
\text { 4. Phenytoin: dose mean } 327 \mathrm{mg} / \text { day. } \mathrm{N}=12 \text {. }\end{array}$ \\
\hline
\end{tabular}




\begin{tabular}{|c|c|c|}
\hline Outcomes & \multicolumn{2}{|c|}{$\begin{array}{l}\text { Leaving the study early. } \\
\text { Unable to use - } \\
\text { Mental state: BPRS, SANS (no data for placebo arm). } \\
\text { Adverse effects (no data for the placebo arm). }\end{array}$} \\
\hline Notes & \multicolumn{2}{|c|}{${ }^{*}$ Only data from groups 1 and 2 used. } \\
\hline \multicolumn{3}{|l|}{ Risk of bias } \\
\hline Bias & Authors' judgement & Support for judgement \\
\hline $\begin{array}{l}\text { Random sequence generation (selection } \\
\text { bias) }\end{array}$ & Unclear risk & Randomly divided. \\
\hline Allocation concealment (selection bias) & Unclear risk & Not stated. \\
\hline $\begin{array}{l}\text { Blinding of participants and personnel } \\
\text { (performance bias) } \\
\text { All outcomes }\end{array}$ & Unclear risk & Double blind. \\
\hline $\begin{array}{l}\text { Blinding of outcome assessment (detection } \\
\text { bias) } \\
\text { All outcomes }\end{array}$ & Unclear risk & Double blind. \\
\hline $\begin{array}{l}\text { Incomplete outcome data (attrition bias) } \\
\text { All outcomes }\end{array}$ & High risk & $\begin{array}{l}\text { Drop outs are unaccounted for in the final } \\
\text { analysis. }\end{array}$ \\
\hline Selective reporting (reporting bias) & Low risk & All measured outcomes were reported. \\
\hline Other bias & Low risk & None obvious. \\
\hline
\end{tabular}

\section{General Abbreviations}

$\mathrm{CPZ}$ - Chlorpromazine

ECT - electroconvulsive therapy

EPS - extrapyramidal symptoms

HCL - hydrochloride

ITT - Intention-to-treat

IM - intra muscular injection

max - maximum

min - minimum

SD - standard deviation

SE - standard error

tds - three times daily

yrs - years

Rating scales

Behaviour -

OBRS - Oklahoma Behaviour Rating Scale 
PBRS - Parkside Behaviour Rating Scale

RRS - Rosenthal Rating Scale

Global impression -

CGI - Clinical Global Impression

\section{Mental state -}

BPRS - Brief Psychiatric Rating Scale

IMPS - Inpatient Multidimensional Psychiatric Rating Scale

MMPI - Minnesota Multiphasic Personality Inventory

MSRPP -Multidimensional Scale for Rating Psychiatric Patient

NOSIE - Nurses Observation Scale for Inpatient Evaluation

PRS - Psychiatric Rating Scale

\section{Adverse effects -}

SAS - Simpson-Angus Scale

TESS - Treatment Emergent Symptoms Scale

\section{Characteristics of excluded studies [ordered by study ID]}

\begin{tabular}{ll}
\hline Study & Reason for exclusion \\
\hline Abse 1960 & Study 1 \\
& Allocation: randomised. \\
& Participants: people with schizophrenia. \\
& Interventions: reserpine versus powdered opium versus placebo \\
& Study 2 \\
Allocation: randomised. & Participants: people with schizophrenia. \\
& Interventions: chlorpromazine versus powdered opium versus placebo \\
& Results of two studies are added and placebo groups are reported as one \\
\hline
\end{tabular}

Acker 1965

Allocation: unclear, not described.

Participants: people with schizophrenia.

Interventions: chlorpromazine or thioridazine versus placebo.

Outcomes: not reported for individual drugs.

Affleck 1966

Allocation: 'balanced order' - unclear if randomised, cross-over.

Participants: any patient with anxiety as a major symptom - unclear if schizophrenia.

Interventions: chlorpromazine + high expectations of effect versus chlorpromazine + low expectations of effect versus placebo + high expectations of effect versus placebo + low expectations of effect.

Outcomes: no usable data before the first cross-over.

Agarwal 1985

Allocation: randomised.

Participants: people with schizophrenia.

Interventions; modified ECT versus simulated ECT, used chlorpromazine in the early stages of the study 
(Continued)

Outcomes: behaviour, mental state - no outcomes for the chlorpromazine versus placebo comparison

\begin{tabular}{l|l} 
Alpert 1966 & Allocation: randomised. \\
& Participants: people with schizophrenia. \\
& $\begin{array}{l}\text { Interventions: chlorpromazine versus placebo. } \\
\text { Outcomes: no data presented by group of allocation, report focused on use of taped recordings to } \\
\text { measure outcomes }\end{array}$ \\
\hline Alpert 1978 & $\begin{array}{l}\text { Allocation: randomised. } \\
\text { Participants: people with schizophrenia. } \\
\text { Interventions: chlorpromazine versus L-dopa, no placebo. }\end{array}$ \\
\hline
\end{tabular}

Alson 1964

Allocation: not randomised, hospitalised patients switched from chlorpromazine to placebo

Aman 1985

Allocation: randomised.

Participants: severely and profoundly retarded adolescents and adults

Amin 1977

Allocation: randomised.

Participants: people with schizophrenia.

Interventions: chlorpromazine versus benzquinamide versus benzquinamide and group therapy, no placebo group

$\begin{array}{ll}\text { Ananth } 1972 & \text { Allocation: randomised. } \\ \text { Participants: people with schizophrenia. } \\ \text { Interventions: nicotinic acid, nicotinamide and placebo. }\end{array}$

Andrews $1976 \quad$ Allocation: randomised.

Participants: people with schizophrenia, stabilised on chlorpromazine.

Interventions: continuing chlorpromazine versus chlorpromazine withdrawal

Ashcroft 1961

Allocation: not randomised.

Participants: people with schizophrenia.

Interventions: chlorpromazine, tetrabenazine and placebo.

\begin{tabular}{l|l} 
Ayers 1984 & Allocation: not randomised, case series. \\
\hline Azima 1954 & Allocation: not randomised, case series. \\
\hline Bagadia 1981 & $\begin{array}{l}\text { Allocation: randomised. } \\
\text { Participants: people with schizophrenia. } \\
\text { Interventions: chlorpromazine and simulated ECT vers }\end{array}$ \\
\hline Ban 1977 & $\begin{array}{l}\text { Allocation: unclear, 'double-blind study'. } \\
\text { Participants: people with chronic schizophrenia. }\end{array}$ \\
\hline Interventions: chlorpromazine and placebo versus ch \\
\hline Beech 1990 & $\begin{array}{l}\text { Allocation: unclear, 'double-blind, cross-over study'. } \\
\text { Participants: healthy volunteers. }\end{array}$
\end{tabular}

Chlorpromazine versus placebo for schizophrenia (Review)

Copyright () 2015 The Cochrane Collaboration. Published by John Wiley \& Sons, Ltd. 
(Continued)

\begin{tabular}{ll}
\hline Benaim 1960 & $\begin{array}{l}\text { Allocation: not described. } \\
\text { Participants: people with schizophrenia. } \\
\text { Interventions: insulin versus insulin with chlorpromazine versus insulin with chlorpromazine and } \\
\text { phenytoin }\end{array}$ \\
\hline Bennett 1956 & $\begin{array}{l}\text { Allocation: alternate allocation. } \\
\text { Participants: people with schizophrenia and other diagnoses. } \\
\text { Interventions: chlorpromazine versus reserpine. }\end{array}$ \\
\hline Blumberg 1964 & $\begin{array}{l}\text { Allocation: 'random assignment'. } \\
\text { Participants: people with non chronic mental disorder, majority with schizophrenia. } \\
\text { Interventions: chlorpromazine with procyclidine, imipramine and placebo. } \\
\text { Outcomes: blood pressure data were not supported with SD's. }\end{array}$ \\
\hline
\end{tabular}

Blumberg 1969

Allocation: randomised.

Participants: voluntary co-operative psychiatric patients on an open ward, not schizophrenia

\begin{tabular}{l|l}
\hline Boullin 1975 & Allocation: not randomised, case control study. \\
\hline Bowes 1956 & $\begin{array}{l}\text { Allocation: quasi-randomised. } \\
\text { Participants: people with schizophrenia. } \\
\text { Interventions: frenkel versus placebo, not chlorpromazine. }\end{array}$ \\
\hline Bressler 1971 & $\begin{array}{l}\text { Allocation: randomised. } \\
\text { Participants: people with schizophrenia. } \\
\text { Interventions: chlorpromazine versus thiothixene. }\end{array}$ \\
\hline
\end{tabular}

Brizer 1985

Allocation: randomised.

Participants: people with treatment-resistant schizophrenia.

Interventions: placebo versus methadone, chlorpromazine equivalents calculated

Burnett 1975

Allocation: randomised, cross-over design.

Participants: people with schizophrenia.

Interventions: chlorpromazine versus thiothixene, placebo used for washout only

Cabrera Gomez 1994

Allocation: randomised.

Participants: people with schizophrenia.

Interventions: recombinant alpha-interferon versus placebo, chlorpromazine used as needed but not randomised

Caffey 1963

Allocation: randomised.

Participants: people with chronic schizophrenia.

Interventions: chlorpromazine or thioridazine (maintenance dose) versus chlorpromazine or thioridazine (3/7 of dose) versus placebo, withdrawal study.

Outcomes: data not reported for individual drug.

Caffey 1975

Allocation: not randomised, non-systematic review of other studies (confirmed by Russian translator)

Chlorpromazine versus placebo for schizophrenia (Review)

Copyright ( 2015 The Cochrane Collaboration. Published by John Wiley \& Sons, Ltd. 
(Continued)

\begin{tabular}{|c|c|}
\hline Campbell 1972 & Allocation: non-randomised double-blind, cross-over trial. \\
\hline Cardone 1969 & $\begin{array}{l}\text { Allocation: unclear, 'one group was given ...'. } \\
\text { Participants: people with chronic schizophrenia. } \\
\text { Interventions: chlorpromazine versus placebo versus nothing. } \\
\text { Outcomes: psychological tests of body image, no clinical data }\end{array}$ \\
\hline Carrillo 1971 & $\begin{array}{l}\text { Allocation: randomised. } \\
\text { Participants: 'emotionally unstable character disorder', not schizophrenia }\end{array}$ \\
\hline Casey 1960 & $\begin{array}{l}\text { Allocation: randomised. } \\
\text { Participants: people with schizophrenia. } \\
\text { Interventions: chlorpromazine versus promazine versus phenobarbital versus placebo. } \\
\text { Outcomes: numbers allocated to each group not reported. } \\
\text { US veterans association contacted for archived data - none available }\end{array}$ \\
\hline Casey 1961 & $\begin{array}{l}\text { Allocation: randomised. } \\
\text { Participants: people with chronic schizophrenia. } \\
\text { Interventions: d-amphetamine versus isocarboxazid versus imipramine versus trifluoperazine versus } \\
\text { placebo, chlorpromazine given to everyone }\end{array}$ \\
\hline Chacon 1972 & $\begin{array}{l}\text { Allocation: 'randomly selected'. } \\
\text { Participants: people with schizophrenia. } \\
\text { Interventions: chlorpromazine, fluphenazine decanoate and placebo for 'washout' }\end{array}$ \\
\hline Childers 1961 & $\begin{array}{l}\text { Allocation: not randomised - 'assigned sequentially as they were admitted'. } \\
\text { Participants: people with schizophrenia. } \\
\text { Interventions: chlorpromazine versus trifluoperazine versus placebo versus nothing }\end{array}$ \\
\hline Chouinard 1977 & $\begin{array}{l}\text { Allocation: randomised. } \\
\text { Participants: people with schizophrenia. } \\
\text { Interventions: chlorpromazine and penfluridol -placebo used for washout period }\end{array}$ \\
\hline
\end{tabular}

Chouinard-G 1983

Allocation: 'randomly assigned'.

Participants: people with schizophrenia.

Interventions: chlorpromazine, fluspirilene and placebo.

Outcomes: data not related to placebo.

Claghorn 1983

Allocation: randomised.

Participants: people with schizophrenia.

Interventions: chlorpromazine versus clozapine, placebo used for washout period only

Clark 1970c

Allocation: unclear.

Participants: unclear.

Interventions: chlorpromazine versus placebo versus a 'thioxanthene and a butyrophenone'.

Outcomes: no data reported. 
(Continued)

\begin{tabular}{ll} 
Clark 1970d & $\begin{array}{l}\text { Allocation: randomised. } \\
\text { Participants: people with schizophrenia. } \\
\text { Interventions: chlorpromazine versus placebo. } \\
\text { Outcomes: body weight, serum cholesterol - no usable data (study } 5 \text { in cited report.) }\end{array}$ \\
\hline Clark 1975 & $\begin{array}{l}\text { Allocation: randomised. } \\
\text { Participants: people with schizophrenia. } \\
\text { Interventions: chlorpromazine versus placebo. } \\
\text { Outcomes: numbers allocated to each group not reported. }\end{array}$ \\
\hline Cobb 1956 & Allocation: not randomised. \\
\hline
\end{tabular}

Cole 1967

Allocation: 'randomly assigned to one of the three drug treatments'

Participants: people with schizophrenia.

Interventions: chlorpromazine, fluphenazine and acetophenazine

Coons 1962 Allocation: 'randomly assigned'.

Participants: "long term mental hospital patients".

Interventions: chlorpromazine, trifluoperazine and placebo.

Outcomes: no SD's used.

Cowden 1956

Allocation: participants assigned on basis of behavioural rating scale and average hospitalisation of different groups - not random

Crane 1970

Allocation: randomised.

Participants: people with chronic mental illness and tardive dyskinesia.

Interventions: trifluoperazine and placebo.

Crane 1971

Allocation: not randomised, review.

Crow 1986

Allocation: randomised.

Participants: people with non-affective psychosis.

Interventions: continuing drug (chlorpromazine or fluphenazine or haloperidol or pimozide or trifluoperazine) versus placebo (drug withdrawal).

Results not broken down by individual drug, and withdrawal study

Curry 1972

Allocation: randomised.

Participants: people with schizophrenia.

Interventions: chlorpromazine versus fluphenazine decanoate; placebo used for blinding purposes only ('double-dummy')

Cutler 1957

Allocation: 'divided into three groups'

Participants: people with schizophrenia.

Interventions: reserpine and placebo.

Dally 1966

Allocation: not described.

Participants: people with anorexia nervosa.

Chlorpromazine versus placebo for schizophrenia (Review)

Copyright ( 2015 The Cochrane Collaboration. Published by John Wiley \& Sons, Ltd. 
(Continued)

\begin{tabular}{ll}
\hline Danion 1992 & $\begin{array}{l}\text { Allocation: randomised. } \\
\text { Participants: healthy volunteers. }\end{array}$ \\
\hline Daston 1958 & Allocation: not randomised, 'stylus maze performance test'. \\
\hline Daston 1959 & $\begin{array}{l}\text { Allocation: unclear, 'double blind, cross-over trial'. } \\
\text { Participants: people with schizophrenia. } \\
\text { Interventions: chlorpromazine versus promazine versus phenobarbital versus placebo. } \\
\text { Outcomes: psychological tests, no clinical outcomes, no dropout data }\end{array}$ \\
\hline Davies 1973 & $\begin{array}{l}\text { Allocation: unclear, 'patients were divided into groups' - likely non-random. } \\
\text { Participants: people with schizophrenia. } \\
\text { Interventions: chlorpromazine versus placebo. } \\
\text { Outcomes: no data presented. }\end{array}$ \\
\hline
\end{tabular}

Dean 1967

Allocation: randomised.

Participants: 50 people with prophyria variegata, not schizophrenia

Den Boer $2000 \quad$ Allocation: randomly assigned.

Participants: people with schizophrenia.

Interventions: ritanserin and placebo.

Denber 1955

Allocation: "selected at random".

Participants: people with schizophrenia.

Interventions: mescaline sulphate and chlorpromazine hydrochloride

Denber 1956

Denber 1957

Desager 1988

Douglas 1969

Downing 1963
Allocation: not randomised, case study.

Allocation: quasi-random, 'assigned in rotation' during consecutive admissions

Allocation: double blind Latin-square design.

Participants: healthy volunteers, not people with schizophrenia

Allocation: 'double blind'.

Participants: 64 people with functional psychiatric disability.

Interventions: chlorpromazine versus mesoridazine, not placebo

Allocation: 'randomly assigned'.

Participants: people with schizophrenia.

Interventions: chlorpromazine, fluphenazine and thioridazine.

Outcomes: no SD's used.

Allocation: 'randomly administered'.

Participants: people with schizophrenia.

Interventions: lithium, chlorpromazine and placebo washout. 
(Continued)

Eitan 1991

Allocation: 'were assigned' - no further description.

Participants: people with schizophrenia.

Interventions: chlorpromazine versus thioridazine versus trifluoperazine versus placebo.

Outcomes: cognitive function not reported for individual arms of cross-over

Ekdawi 1966

Allocation: randomised.

Participants: people with chronic schizophrenia.

Interventions: methixene hydrochloride versus orphenadrine versus procyclidine, all on antipsychotics including chlorpromazine

Elkes 1954

Allocation: unclear if randomised - 'double blind, cross-over trial'.

Participants: chronically over-active psychotic people.

Interventions: chlorpromazine versus placebo.

Outcomes: first arm of cross-over not reported.

Feldman 1956

Allocation: 'a staff psychiatrist (not involved in the project) who cross-matched the patients into two similar groups' - not randomised

Fink 1958

Allocation: randomised.

Participants: people with schizophrenia.

Interventions: chlorpromazine versus insulin coma therapy, no placebo group

Fink 1965

Allocation: "randomly assigned".

Participants: "classified as affective disorder".

Interventions: chlorpromazine with procyclidine, imipramine and placebo.

Outcomes: no usable data.

Fleischhacker 1995

Allocation: not randomised.

Participants: not described.

Interventions: seroquel, chlorpromazine and placebo.

Outcomes: no usable data.

Fleming 1958

Allocation: randomised, cross-over design.

Participants: people with schizophrenia and manic-depressive illness.

Interventions: chlorpromazine versus B.W.203 versus placebo.

Outcomes: data not reported for individual arms of cross-over

Foote 1958

Allocation: randomised

Participants: people with schizophrenia.

Interventions: chlorpromazine-reserpine combination versus placebo

Forrest $1967 \quad$ Allocation: randomised.

Participants: healthy volunteers.

Freed 1956

Allocation: not randomised.

Participants: "primary behaviour disorders, psychoneurotic, schizophrenic, reactive behaviour disorders".

Interventions: chlorpromazine. 


\begin{tabular}{ll}
\hline Freedman 1965 & $\begin{array}{l}\text { Allocation: randomised. } \\
\text { Participants: people with schizophrenia. } \\
\text { Interventions: chlorpromazine, promazine and placebo. } \\
\text { Outcomes: no usable data. }\end{array}$ \\
\hline Freeman 1956 & $\begin{array}{l}\text { Allocation: 'divided into two groups matched primarily on the basis of their rating scores and, sec- } \\
\text { ondarily, on the basis of age, duration of hospitalisation, and years since lobotomy' - not randomised }\end{array}$ \\
\hline Freeman 1973 & $\begin{array}{l}\text { Allocation: "randomly assigned”. } \\
\text { Participants: people with schizophrenia. } \\
\text { Interventions: mesoridazine, chlorpromazine and placebo. } \\
\text { Outcomes: chlorpromazine data not evaluated against placebo. }\end{array}$ \\
\hline Friedhoff 1960 & Allocation: 'divided into two sub-groups by alternation of patients" \\
\hline
\end{tabular}

Fromm 1956

Allocation: 'Dr Forsberg matched the patients and decided whether they were to receive chlorpromazine or placebo' - not randomised

Gaitz 1955

Allocation: "assigned randomly to 3 groups".

Participants: "actively psychotic having a schizophrenic reaction".

Interventions: group A was an artificial hibernation group, group B received chlorpromazine and group $\mathrm{C}$ receiving their usual treatment without chlorpromazine

Galbrecht 1968

Allocation: randomised.

Participants: people with schizophrenia.

Interventions: chlorpromazine versus fluphenazine versus thioridazine, no placebo

Galdi $1988 \quad$ Allocation: randomised.

Participants: people with schizophrenia.

Interventions: chlorpromazine versus fluphenazine versus perphenazine, no placebo

Gallant 1963

Allocation: randomised - "divided at random" - no further details.

Participants: people with chronic schizophrenia.

Interventions: chlorpromazine versus methysergide (UML-491) versus placebo.

Outcomes: no usable data as number in each group unspecified

Gallant $1967 \quad$ Allocation: randomised.

Participants: people with schizophrenia.

Interventions: chlorpromazine + placebo versus chlorpromazine + BL-KR140

Gardner 1955

Allocation: no evidence of randomisation.

Gardos 1968

Allocation: divided into two groups- 'withdrawn' and 'agitated'.

Participants: "psychotic".

Interventions: trifluoperazine, chlorpromazine, (placebo used for 'wash out')

Gardos 1976

Allocation: not randomised, review article of other trials performing withdrawal studies

Chlorpromazine versus placebo for schizophrenia (Review)

Copyright ( 2015 The Cochrane Collaboration. Published by John Wiley \& Sons, Ltd. 
(Continued)

\begin{tabular}{l} 
Garfield $1962 \quad \begin{array}{l}\text { Allocation: random assignment. } \\
\text { Participants: “adjustment reaction of childhood }(\mathrm{n}=6) \text {, psychoneurotic disorder }(\mathrm{n}=5) \text {, schizophrenic } \\
\text { reaction childhood type }(\mathrm{n}=5) \text {, personality trait disturbance }(\mathrm{n}=2) \text {, chronic brain disturbance with } \\
\text { psychosis }(\mathrm{n}=1) \text {. } \\
\text { Interventions: chlorpromazine versus placebo. } \\
\text { Outcomes: no usable data. }\end{array}$ \\
\hline
\end{tabular}

Garmezy 1969

Allocation: "randomly assigned".

Participants: people with schizophrenia.

Interventions: chlorpromazine and placebo.

Outcomes: no usable data (no SD).

Gauthier 1967

Allocation: random numbers table used.

Participants: not described from french translation.

Interventions: trifluperidol versus trifluoperazine.

Gendron 1973

Allocation: "randomly assigned“.

Participants: people with schizophrenia.

Interventions: chlorpromazine and $\mathrm{Al}-1021$

Gibbs 1956

Allocation: 'assigned by an unbiased, alternating method' and 'assigned to one of the three treatment groups on an alternating basis as they entered the study' - not randomised.

Participants: heterogeneous diagnoses, "27 were diagnosed psychoneurotic and the remaining 12 psychotic"

Gilgash 1957

Allocation: unclear, 'two groups .... matched on the basis of admission diagnosis, age, sex and IQ'. Participants: patients with catatonic schizophrenia.

Interventions: chlorpromazine versus placebo.

Outcomes: cognitive function; no clinical measures.

Goldberg $1968 \quad$ Allocation: "random assignment".

Participants: people with schizophrenia, based on two separate hospital studies.

Interventions: Acetophenazine, chlorpromazine, thioridazine fluphenazine and placebo.

Outcomes: data based on prediction equations and are unusable

Goldberg 1970

Allocation: "allocated at random to a group".

Participants: people with schizophrenia.

Interventions: oxypertine and chlorpromazine with 3-week washout with placebo

Goldberg 1972

Allocation: randomised.

Participants: people with schizophrenia.

Interventions: chlorpromazine versus acetophenazine versus placebo.

Outcomes: no usable data - unclear how many allocated to each group

Goldman 1955

Allocation: not randomised, review.

Good 1958

Allocation: randomised.

Participants: people with schizophrenia stabilised on chlorpromazine.

Chlorpromazine versus placebo for schizophrenia (Review)

Copyright @ 2015 The Cochrane Collaboration. Published by John Wiley \& Sons, Ltd. 
(Continued)

Interventions: continued chlorpromazine versus placebo, withdrawal study

Goodwin-Austin 1971

Allocation: randomised.

Participants: people with dementia and movement disorders, not schizophrenia

Goyne 1958

Allocation: not described.

Participants: people with schizophrenia.

Interventions: vesperin versus chlorpromazine.

Graupner 1972

Allocation: randomised.

Participants: healthy volunteers.

Green 1996

Allocation: balanced Latin-square randomisation.

Participants: healthy volunteers.

Green 1998

Allocation: not described.

Participants: healthy volunteers.

Greenberg 1966

Allocation: unclear if randomised.

Participants: people with schizophrenia.

Interventions: chlorpromazine versus withdrawal of chlorpromazine to placebo

Griffiths 1979

Allocation: 'double blind'.

Participants: people with a history of sedative drug abuse, not people with schizophrenia

Guy 1978

Allocation: not randomised, review.

Hammond 1978

Allocation: A-B-A design, not randomised.

Hamner 1996

Allocation: randomised.

Participants: people with schizophrenia.

Interventions: chlorpromazine and ICI 204636.

Hankoff $1960 \quad$ Allocation: randomised.

Participants: people with schizophrenia.

Interventions: chlorpromazine versus promazine versus placebo.

Outcomes: chlorpromazine and promazine data combined - no usable outcomes

Hanlon 1958

Allocation: not described- cross over study.

Participants: people with psychosis.

Hanlon 1960

Allocation: not randomised, survey.

Harper 1976

Allocation: unclear, 'double-blind, cross-over'.

Participants: people with schizophrenia.

Interventions: chlorpromazine versus fluphenazine decanoate. 
(Continued)

\begin{tabular}{ll}
\hline Hartley 1978 & $\begin{array}{l}\text { Allocation: 'Latin square counterbalanced design' } \\
\text { Participants: healthy volunteers, not people with schizophrenia }\end{array}$ \\
\hline Hartley 1987 & $\begin{array}{l}\text { Allocation: randomised. } \\
\text { Participants: 'normals'. } \\
\text { Interventions: chlorpromazine versus placebo. } \\
\text { Outcomes: physiological tests. }\end{array}$ \\
\hline
\end{tabular}

Hartley 1989 Allocation: implied randomisation.

Participants: healthy volunteers.

Hartley $1991 \quad$ Allocation: 'double blind'.

Participants: healthy volunteers, not people with schizophrenia

Hartmann 1973 Allocation: "balanced cross-over design“.

Participants: healthy volunteers.

Haskell $1974 \quad$ Allocation: randomised.

Participants: anxious and depressed people, not schizophrenia

Heilizer 1959 Allocation: randomised.

Participants: people with schizophrenia.

Interventions: chlorpromazine versus placebo.

Outcomes: no usable data - unclear how many people allocated to each group

Hekimian 1967

Allocation: 'assigned in rotation' - quasi-randomised.

Herrera 1988

Allocation: not randomised.

Participants: people with schizophrenia.

Interventions: haloperidol with benztropine versus chlorpromazine with benztropine (placebo used for 'wash out')

Herrmann 1991a

Allocation: randomised, cross-over design.

Participants: healthy men.

Interventions: chlorpromazine versus savoxepine versus placebo

Herrmann 1991b

Allocation: randomised, cross-over design.

Participants: healthy men.

Interventions: chlorpromazine versus imipramine versus placebo

Herz $1991 \quad$ Allocation: randomised.

Participants: people with schizophrenia.

Interventions: maintenance phenothiazines, including chlorpromazine versus intermittent drug treatment

Hoffer 1975

Allocation: randomised.

Participants: people with schizophrenia.

Interventions: niacin versus placebo. 
(Continued)

\begin{tabular}{|c|c|}
\hline Hogarty 1976 & Allocation: not randomised, discontinuation study. \\
\hline Hollis 1968 & Allocation: not randomised, case report. \\
\hline Hollister 1955 & $\begin{array}{l}\text { Allocation: no evidence of randomisation (five studies). } \\
\text { Participants: people with chronic schizophrenia. } \\
\text { Interventions: chlorpromazine versus placebo. }\end{array}$ \\
\hline Holt 1984 & $\begin{array}{l}\text { Allocation: 'matched', no further description - likely not randomised. } \\
\text { Participants: 'male psychiatric inpatients'. } \\
\text { Interventions: chlorpromazine versus haloperidol versus fluphenazine decanoate versus no drug } \\
\text { therapy. } \\
\text { Outcomes: platelet levels. }\end{array}$ \\
\hline Hong 1996a & $\begin{array}{l}\text { Allocation: randomised, four parallel groups. } \\
\text { Participants: people with schizophrenia. } \\
\text { Interventions: ICI 204, 636, chlorpromazine. } \\
\text { Outcomes: no data provided for chlorpromazine and placebo. }\end{array}$ \\
\hline Hong 1996b & $\begin{array}{l}\text { Allocation: not described. } \\
\text { Participants: people with schizophrenia. } \\
\text { Interventions: ICI 204, } 636 \text { and placebo. }\end{array}$ \\
\hline Hopkin 1954 & $\begin{array}{l}\text { Allocation: not randomised, case series. } \\
\text { Participants: people in need of analgesia. }\end{array}$ \\
\hline Hrushka 1966 & $\begin{array}{l}\text { Allocation: "random basis“. } \\
\text { Participants: people with psychosis. } \\
\text { Interventions: chlorpromazine combined with placebo. }\end{array}$ \\
\hline Huang 1967 & Allocation: A-B design, not randomised. \\
\hline Hughes 1967 & Allocation: not randomised, before and after design. \\
\hline Hurst 1960 & $\begin{array}{l}\text { Allocation: 'assigned to } 3 \text { groups ... alternately, in order of their admission to hospital' - quasi- } \\
\text { random. double-blind, cross-over design. } \\
\text { Participants: people with schizophrenia. } \\
\text { Interventions: chlorpromazine versus pecazine versus placebo. } \\
\text { Outcome: no usable data. }\end{array}$ \\
\hline Hurst 1996 & Allocation: not randomised, review . \\
\hline Hussar 1969 & $\begin{array}{l}\text { Allocation: not described. } \\
\text { Participants: people with schizophrenia and psychiatric patients without schizophrenia. } \\
\text { Interventions: chlorpromazine and no treatment. }\end{array}$ \\
\hline
\end{tabular}

Chlorpromazine versus placebo for schizophrenia (Review)

Copyright () 2015 The Cochrane Collaboration. Published by John Wiley \& Sons, Ltd. 


\begin{tabular}{|c|c|}
\hline IRCT138811022935N32010 & $\begin{array}{l}\text { Allocation: randomised. } \\
\text { Participants: people with schizophrenia. } \\
\text { Interventions: Chlorpromazine plus placebo versus chlorpromazine plus omega-3 }\end{array}$ \\
\hline Itil 1968 & $\begin{array}{l}\text { Allocation: 'random order', cross-over design. } \\
\text { Participants: 'normals', people with psychoneurotic disorders and those with schizophrenia. } \\
\text { Interventions: chlorpromazine versus imipramine versus chlordiazepoxide versus placebo. } \\
\text { Outcomes: physiological tests; not reported for first arm of cross-over }\end{array}$ \\
\hline Itil 1971 & Allocation: not randomised, review. \\
\hline Jia 2004 & $\begin{array}{l}\text { Allocation: randomised. } \\
\text { Participants: people with schizophrenia. } \\
\text { Interventions: chlorpromazine plus TCM drugs versus chlorpromazine plus placebo }\end{array}$ \\
\hline Johnstone 1978 & $\begin{array}{l}\text { Allocation: randomly allocated. } \\
\text { Participants: people with schizophrenia. } \\
\text { Interventions: alpha-flupenthixol, 3-flupenthixol and placebo. chlorpromazine added to the active } \\
\text { drugs }\end{array}$ \\
\hline Jones 1969 & Allocation: not randomised, A-B design. \\
\hline Jones 1971 & $\begin{array}{l}\text { Allocation: unclear. } \\
\text { Participants: people with schizophrenia. } \\
\text { Interventions: chlorpromazine versus trifluoperazine; placebo for 'washout' only }\end{array}$ \\
\hline
\end{tabular}

Joseph 1979 Allocation: randomised.

Participants: people with schizophrenia.

Interventions: alpha-flupenthixol, beta-flupenthixol and placebo

Joshi $1980 \quad$ Allocation: randomised.

Participants: people with acute schizophrenia.

Interventions: each of four groups received chlorpromazine (different doses) with either placebo or adjunctive $B$ vitamins

Kabes 1982

Allocation: 'randomly distributed'.

Participants: people with schizophrenia.

Interventions: chlorpromazine, haloperidol, clorothepine and placebo.

Outcomes: no data provided for chlorpromazine.

Kammerer 1968

Allocation: unclear.

Participants: people mainly with affective disorders.

Interventions: possibly Pertofran (Geigy) but not chlorpromazine versus placebo

Kaplan 1974

Allocation: A-B-A design, not randomised.

Keskiner 1970

Allocation: not randomised, placed into groups according to pre-study medication

Chlorpromazine versus placebo for schizophrenia (Review)

Copyright $\odot 2015$ The Cochrane Collaboration. Published by John Wiley \& Sons, Ltd. 
King 1959

Allocation: randomised.

Participants: people with schizophrenia.

Interventions: prochlorperazine, chlorpromazine and placebo.

Outcomes: no usable data.

King 1994

Allocation: randomised, cross-over design.

Participants: healthy volunteers.

Interventions: chlorpromazine versus remoxipride (immediate release) versus remoxipride (controlled release) versus lorazepam versus placebo

Klein 1974

Allocation: randomised.

Participants: "some form of psychotic disturbance".

Interventions: imipramine or chlorpromazine, self administered with or without instruction versus imipramine or chlorpromazine, nurse administered with or without instruction

Kopell 1968

Allocation: cross-over design, no mention of randomisation.

Participants: people with schizophrenia and other psychotic disorders.

Interventions: chlorpromazine versus methamphetamine versus placebo.

Outcomes: signal detection, no clinically meaningful outcomes

Kordas 1968

Allocation: not randomised, 'allocated to three groups', and 'double-blind controlled trial' - no further information.

Participants: people with chronic schizophrenia.

Interventions: clopenthixol versus chlorpromazine versus placebo.

Outcomes: no usable data (individual participant data, or means and SD)

Kornetsky 1957

Allocation: unclear, 'Latin square', cross-over design.

Participants: normal volunteers.

Interventions: chlorpromazine versus secobarbital versus meperidine hydrochloride versus lysergic acid diethylamide, placebo used between arms of cross-over

Kornetsky 1958

Allocation: unclear.

Participants: normal volunteers.

Interventions: chlorpromazine versus secobarbital, placebo for 'washout' only

Kornetsky 1959

Allocation: unclear, 'modified Latin square', cross-over design.

Participants: people with schizophrenia.

Interventions: chlorpromazine versus secobarbital versus placebo.

Outcomes: various psychological tests, results not reported for individual arms of cross-over 
(Continued)

Korol 1965

Allocation: randomised.

Participants: people with schizophrenia, stabilised on chlorpromazine.

Interventions: continuing chlorpromazine versus chlorpromazine withdrawal

Kovitz 1955

Allocation: no evidence of randomisation, cross-over design.

Participants: people with chronic schizophrenia, and other psychoses.

Interventions: chlorpromazine versus reserpine versus placebo

Kramer 1975 Allocation: randomised.

Participants: people with acute schizophrenia.

Interventions: chlorpromazine versus metiapine versus placebo.

Outcomes: various relevant outcomes, but study rejected because placebo group was withdrawn

after the first 13 were randomised - no data for chlorpromazine at this point in the study

Kugler 1980

Allocation: unclear, double-blind, Latin-square design.

Participants: healthy volunteers.

Interventions: chlorpromazine versus amylobarbitone versus placebo

Kupfer 1971

Allocation: not randomised, A-B cross-over design.

Kurland 1981

Allocation: randomised.

Participants: people with schizophrenia.

Interventions: chlorpromazine or haloperidol supplemented with either viloxazine or placebo.

Outcomes: no usable data.

Lampe 1969 Allocation: randomised.

Participants: people with schizophrenia.

Interventions: clomacran versus placebo.

Latz 1965

Allocation: no evidence of randomisation, Latin-square cross-over design.

Participants: people with schizophrenia.

Interventions: chlorpromazine versus secobarbital versus placebo.

Outcomes: tests of cognitive function; no usable data (no $\mathrm{N}$ or SD, and results not reported for individual arms of cross-over)

Laurian 1981

Allocation: randomised.

Participants: healthy volunteers, not people with schizophrenia

Leff 1971

Allocation: randomised (to drug group vs placebo), but allocation to different drugs not randomised (based on pre-study medication).

Interventions: trifluoperazine or chlorpromazine versus placebo.

Outcomes: not broken down by drug group.

Leszek 1991

Allocation: not described.

Participants: people with schizophrenia.

Interventions: interferon and placebo, chlorpromazine used to control symptoms

Chlorpromazine versus placebo for schizophrenia (Review)

Copyright $(2015$ The Cochrane Collaboration. Published by John Wiley \& Sons, Ltd. 

the use of a major tranquillising drug'.

Interventions: haloperidol versus chlorpromazine versus placebo.

Outcomes: no usable data; information from each arm not separated 
(Continued)

period between arms of cross-over)

Mahal 1976

Allocation: randomised.

Participants: people with schizophrenia.

Interventions: tagara, brahmyadi yoga, chlorpromazine and placebo.

Outcomes: no usable data (no SD).

Allocation: no evidence of randomisation (translation by Polish speaker)

Marjerrison 1969

Allocation: randomised, cross-over design.

Participants: people newly admitted with acute schizophrenia.

Interventions: chlorpromazine versus haloperidol versus chlorprothixene versus placebo.

Placebo only compared with haloperidol and chlorprothixene.

Marrazzi 1972

Allocation: unclear if randomised, A-B-C design.

Participants: people with schizophrenia.

Interventions: chlorpromazine versus placebo with LSD challenge

Mason-Browne $1957 \quad$ Allocation: no evidence of randomisation.

Participants: 'chronic patients'; no indication of diagnosis.

Interventions: chlorpromazine versus perphenazine versus placebo

Mathur 1981

Allocation: randomised.

Participants: people with chronic schizophrenia stabilized on chlorpromazine.

Interventions: continuing chlorpromazine versus placebo (withdrawal study)

Mattila $1994 \quad$ Allocation: Latin-square cross-over.

Participants: healthy volunteers, not people with schizophrenia

McClelland $1990 \quad$ Allocation: randomised, cross-over design.

Participants: healthy volunteers.

Interventions: chlorpromazine versus haloperidol versus sulpiride versus placebo

Melnyk 1966

Allocation: randomised.

Participants: people with schizophrenia.

Interventions: thioridazine, chlorpromazine and placebo.

Outcomes: no usable data (no SD).

Merry 1957

Allocation: unclear.

Participants: people with chronic neurotic tension (no schizophrenia or psychoses).

Interventions: chlorpromazine versus placebo.

Michaux 1966

Allocation: randomised.

Participants: 181 people with schizophrenia.

Interventions: chlorpromazine and placebo versus chlorpromazine and chlordiazepoxide versus chlorpromazine and imipramine

Chlorpromazine versus placebo for schizophrenia (Review)

Copyright @ 2015 The Cochrane Collaboration. Published by John Wiley \& Sons, Ltd. 
(Continued)

Millar 1963

Allocation: "divided into random groups".

Participants: people with schizophrenia.

Interventions: fluphenazine and placebo.

Milne 1960

Allocation: quasi-randomised, 'divided arbitrarily into four groups'.

Participants: people with chronic schizophrenia.

Interventions: chlorpromazine versus prochlorperazine versus methotrimeprazine versus placebo.

Outcomes: improvement, behaviour; no usable data (no mean, $\mathrm{N}$ or SD)

Milstein 1994

Allocation: randomised.

Participants: people with schizophrenia.

Interventions: Iloperidone versus chlorpromazine versus placebo

Outcomes: EEG - no clinical outcomes.

Milton $1978 \quad$ Allocation: randomised.

Participants: people with delusions.

Interventions: confrontation versus belief modification, also on chlorpromazine or clozapine but not randomised to these drugs

Mitchell 1956

Allocation: quasi-randomised (used surnames beginning A-L for first group).

Participants: people with schizophrenia.

Interventions: chlorpromazine versus placebo.

Outcomes: no usable data (no means, N, or SD).

Mitchell 1960

Allocation: assigned by matching variables.

Participants: "psychiatric patients"

Interventions: chlorpromazine.

Monteleone 1999

Allocation: randomised.

Participants: people with schizophrenia and healthy particpants.

Interventions: D-fenfluramine and placebo.

Morgenstern 1960

Allocation: not described.

Participants: "acutely disturbed patients".

Interventions: triflupromazine, chlorpromazine, placebo with ECT being administered concurrently with the drug interventions

Morton 1968

Allocation: randomised.

Participants: people with schizophrenia.

Interventions: continued maintenance therapy (chlorpromazine or trifluoperazine) versus placebo (withdrawal study)

Moss 1958

Allocation: not randomised - appears to be A-B-A design.

Participants: people with schizophrenia.

Interventions: chlorpromazine versus placebo. 


\begin{tabular}{ll}
\hline Neal 1969 & $\begin{array}{l}\text { Allocation: randomised. } \\
\text { Participants: people with chronic schizophrenia. }\end{array}$ \\
& $\begin{array}{l}\text { Interventions: chlorpromazine versus oxypertine; placebo given during first } 4 \text { weeks of trial (for } \\
\text { washout) }\end{array}$ \\
\hline Newbold 1956 & $\begin{array}{l}\text { Allocation: not described. } \\
\text { Participants: "patients undergoing thorazine treatment }-3 \text { with a form of schizophrenia“ } \\
\text { Interventions: chlorpromazine and placebo. } \\
\text { Outcomes: no usable data. }\end{array}$ \\
\hline
\end{tabular}

Okuma 1979

Allocation: randomised.

Participants: 63 people with mania, not schizophrenia.

Orzack 1969 Allocation: 'randomly determined treatment"'.

Participants: people with schizophrenia and normal volunteers.

Interventions: chlorpromazine, and placebo used 'at two appropriate intervals'

Outcomes: no usable data.

Osmakova 1972

Allocation: not randomised, review article (translated by native Russian speaker)

$\begin{array}{ll}\text { Pai } 2001 & \text { Allocation: randomised. } \\ \text { Participants: people with schizophrenia. } \\ \text { Interventions: risperidone and placebo. }\end{array}$

Paredes 1966

Allocation: randomised.

Participants: people with schizophrenia.

Interventions: chlorpromazine and placebo.

Outcomes: no usable data (no SD).

Park 1981

Allocation: randomised.

Participants: people with acute schizophrenia.

Interventions: chlorpromazine + triiodothyronine versus chlorpromazine + placebo

Pasamanick 1967

Allocation: randomised.

Participants: people with schizophrenia.

Interventions: home (drugs) versus home (placebo) versus hospital treatment; data not split by drug (chlorpromazine or trifluoperazine or thioridazine)

Patterson $1981 \quad$ Allocation: unclear, Latin-square design.

Participants: healthy male volunteers, not schizophrenia.

Peet 1980

Allocation: randomised, cross-over design.

Participants: people with schizophrenia.

Interventions: chlorpromazine versus chlorpromazine + propranolol

Allocation: not randomised, case series.

Pietzcker 1978

Allocation: not randomised, review.

Chlorpromazine versus placebo for schizophrenia (Review)

Copyright $\odot 2015$ The Cochrane Collaboration. Published by John Wiley \& Sons, Ltd. 
(Continued)

Pigache 1973

Allocation: randomised, cross-over design.

Participants: people with schizophrenia, maintained on chlorpromazine.

Interventions: chlorpromazine versus placebo; withdrawal study

Pigache 1993

Allocation: randomised, cross-over design.

Participants: people with schizophrenia.

Interventions: chlorpromazine (300-600 mg/day) versus chlorpromazine (600-1200 mg/day) versus chlorpromazine (900-1800 mg/day); no placebo period or placebo group (identical placebo tablets used for maintaining double-blind procedure)

Platz 1967

Allocation: randomised.

Participants: people with schizophrenia.

Interventions: chlorpromazine versus carphenazine versus trifluoperazine; placebo given during first 3 weeks of trial (for washout)

Pleasure $1956 \quad$ Allocation: not randomised, alternately allocated.

Pollack $1956 \quad$ Allocation: not randomised, case series.

$\begin{array}{ll}\text { Pollard } 1959 & \text { Allocation: not described. }\end{array}$

Participants: people with schizophrenia.

Interventions: chlorpromazine with meprobamate and placebo.

Outcomes no usable data.

Quigley 1996

Allocation: unclear if randomised, Latin-square design.

Participants: healthy volunteers, not schizophrenia.

Quinn 1960

Allocation: no evidence of randomisation - "the pharmacist ... allocated the treatment to the three groups".

Participants: people with schizophrenia.

Interventions: chlorpromazine versus placebo versus methotrimeprazine

Raaska $2000 \quad$ Allocation: randomised.

Participants: people with schizophrenia.

Interventions: ciprofloxacin and placebo.

Ragland 1968

Allocation: randomised.

Participants: people with chronic schizophrenia.

Interventions: chlorpromazine versus placebo.

Outcomes: no usable data (no individual patient outcomes, or means reported for continuous outcomes)

Raja 2000

Allocation: non-randomised study.

Rappaport 1967

Allocation: randomised.

Participants: people with schizophrenia.

Interventions: chlorpromazine versus perphenazine versus sodium pentobarbital versus placebo.

Outcomes: auditory attention tasks, no clinical data. 
(Continued)

\begin{tabular}{ll}
\hline Rappaport 1968 & $\begin{array}{l}\text { Allocation: randomised. } \\
\text { Participants: people with schizophrenia. } \\
\text { Interventions: chlorpromazine versus perphenazine versus dextroamphetamine versus } \\
\text { methylphenidate versus placebo. } \\
\text { Outcomes: auditory attention tests, no clinical data. }\end{array}$ \\
\hline Rathod 1958 & $\begin{array}{l}\text { Allocation: randomised, cross-over design. } \\
\text { Participants: 'disturbed psychotic patients'. } \\
\text { Interventions: chlorpromazine versus placebo. } \\
\text { Outcomes: results not reported for individual arms of cross-over }\end{array}$ \\
\hline Raymond 1957 & $\begin{array}{l}\text { Allocation: randomised, cross-over design. } \\
\text { Participants: a 'heterogeneous group of psychoneurotic disorders' all with a 'tension component' - } \\
\text { no mention of schizophrenia or psychosis }\end{array}$ \\
\hline Remr 1970 & $\begin{array}{l}\text { Allocation: no evidence of randomisation, 'single-blind, placebo-controlled, cross-over design'. } \\
\text { Participants: people with schizophrenia. } \\
\text { Interventions: chlorpromazine versus placebo. } \\
\text { Outcomes: various psychomotor tasks; results not reported for individual arms of cross-over }\end{array}$ \\
\hline Rifkin 1978 & $\begin{array}{l}\text { Allocation: 'randomised unequally'. } \\
\text { Participants: 'patients receiving a maintenance dose of antipsychotic medication'. } \\
\text { Interventions: procyclidine and placebo. }\end{array}$ \\
\hline
\end{tabular}

Rinaldi 1956

Allocation: 'double blind crosover'.

Participants: people with schizophrenia.

Interventions: chlorpromazine versus placebo versus azacyclonol versus reserpine.

Outcomes: no data reported for the chlorpromazine versus placebo comparison

Rivera-Calimlim 1973

Allocation: not randomised, case series.

Rojo-Sierra 1971

Rosen 1972

Rosenheck 2000

Rosner 1955
Allocation: not randomised, review.

Allocation: randomised.

Participants: people with schizophrenia.

Interventions: chlorpromazine versus placebo versus promazine.

Outcomes: no usable data.

Allocation: randomised.

Participants: people with schizophrenia.

Interventions: clozapine and haloperidol.

Allocation: quasi-randomised; 'placed on one of the drugs or a placebo in strict order of admission'. Participants: people with various psychotic, neurotic or character disorders.

Interventions: chlorpromazine versus reserpine versus phenobarbital versus placebo

Rudy 1957 
(Continued)

\begin{tabular}{ll} 
Rudy 1958 & $\begin{array}{l}\text { Allocation: 'double blind cross-over'. } \\
\text { Participants: people with chronic psychotic illnesses. } \\
\text { Interventions: trifluoperazine versus placebo, not chlorpromazine }\end{array}$ \\
\hline Sainz 1955 & $\begin{array}{l}\text { Allocation: not described. } \\
\text { Participants: people with schizophrenia, alcoholism, birth trauma, anxiety reactions, obsessive com- } \\
\text { pulsive reactions }\end{array}$ \\
\hline
\end{tabular}

\begin{tabular}{l|l}
\hline Saletu 1972 & $\begin{array}{l}\text { Allocation: randomised. } \\
\text { Participants: healthy volunteers. }\end{array}$ \\
\hline Salisbury 1957 & $\begin{array}{l}\text { Allocation: unclear, Latin-square design. } \\
\text { Participants: people with chronic schizophrenia. } \\
\text { Interventions: chlorpromazine versus 'control' (placebo) versus ritalin (at two dose levels). } \\
\text { Outcomes: behaviour and mental state outcomes not reported for individual arms of cross-over }\end{array}$ \\
\hline Schiele 1959 & Allocation: divided into 2 matched groups of 19, not randomised \\
\hline
\end{tabular}

Schmidt 1957 Allocation: no evidence of randomisation.

Participants: people with chronic schizophrenia.

Interventions: combination of chlorpromazine + reserpine versus placebo

\begin{tabular}{|c|c|}
\hline Schooler 1976 & $\begin{array}{l}\text { Allocation: randomised. } \\
\text { Participants: people with schizophrenia. } \\
\text { Interventions: chlorpromazine versus placebo. } \\
\text { Outcomes: preliminary report of larger study. }\end{array}$ \\
\hline Seager 1955 & $\begin{array}{l}\text { Allocation: no evidence of randomisation, cross-over design. } \\
\text { Participants: people with schizophrenia (thirteen), depression (six), or dementia (twenty-nine). } \\
\text { Interventions: chlorpromazine versus inert control. }\end{array}$ \\
\hline Serafetinides 1973 & Allocation: not randomised, review. \\
\hline Shaskan 1975 & $\begin{array}{l}\text { Allocation: randomised. } \\
\text { Participants: people with schizophrenia. } \\
\text { Interventions: chlorpromazine + imipramine versus placebo + thiothixine }\end{array}$ \\
\hline Shawver 1959 & $\begin{array}{l}\text { Allocation: randomised. } \\
\text { Participants: people with schizophrenia. } \\
\text { Interventions: continuing chlorpromazine versus reserpine versus placebo; a withdrawal study }\end{array}$ \\
\hline Shopsin 1978 & $\begin{array}{l}\text { Allocation: unclear, 'double-blind controlled comparison'. } \\
\text { Participants: people with schizophrenia. } \\
\text { Interventions: chlorpromazine versus clozapine versus placebo. } \\
\text { Outcomes: no usable data reported. } \\
\text { NB: some evidence in this report suggests that this trial is the same as Shopsin } 1979 .\end{array}$ \\
\hline
\end{tabular}

Chlorpromazine versus placebo for schizophrenia (Review)

Copyright () 2015 The Cochrane Collaboration. Published by John Wiley \& Sons, Ltd. 
Allocation: randomised.

Participants: patients with schizophrenia.

Interventions: chlorpromazine versus clozapine versus placebo. However, 'all of the placebo-treated patients were prematurely terminated from study because of continued aggravation of psychopathology ... and it was mutually agreed that this study group be dissolved'.

Outcomes: no comparison with placebo group possible, data from chlorpromazine group was never compared with placebo group at the point where allocation to placebo was terminated

Silver 2000

Allocation: randomised.

Participants: people with schizophrenia.

Interventions: fluvoxamine and placebo.

Simopoulos 1971

Allocation: randomised.

Participants: people with schizophrenia.

Interventions: dilantin versus placebo, no chlorpromazine group

Simpson 1974 Allocation: no evidence of randomisation; double-blind cross-over trial.

Participants: people with schizophrenia.

Interventions: chlorpromazine (generic) versus chlorpromazine (Thorazine branded); placebo administered during washout period

Simpson 1980

Allocation: no evidence of randomisation; 'double-blind split cross-over trial'.

Participants: people with schizophrenia.

Interventions: chlorpromazine + trihexyphenidyl hydrochloride versus chlorpromazine + placebo

Singh 1974

Allocation: no evidence of randomisation, cross-over design.

Participants: people with schizophrenia.

Interventions: chlorpromazine versus haloperidol versus benzotropine versus placebo, results not reported for placebo arms of cross-over (placebo used for baseline and washout periods)

Singh 1990

Allocation: randomised.

Participants: people with schizophrenia, meeting criteria for supersensitivity psychosis.

Interventions: neuroleptic medication versus placebo (withdrawal of usual medication) - neuroleptic drugs (haloperidol, fluphenazine, chlorpromazine, thioridazine, thiothixene or loxapine) not analysed separately

Small 1987

Allocation: no evidence of randomisation.

Participants: people with treatment resistant schizophrenia.

Interventions: chlorpromazine + benzotropine versus clozapine + placebo; placebo used in washout periods and as double-dummy to maintain blinding.

Outcomes: EEG - no clinical outcomes.

Smith 1958

Allocation: no evidence of randomisation, cross-over design.

Participants: people with chronic schizophrenia.

Interventions: chlorpromazine versus triflupromazine versus placebo.

Outcomes: results not reported for individual arms of cross-over 
(Continued)

Smith 1960

Allocation: no evidence of randomisation, matched groups.

Participants: people with chronic schizophrenia or manic-depression.

Interventions: chlorpromazine versus chlordiazepoxide versus placebo

Smith 1967

Allocation: randomisation implied but not mentioned.

Participants: people with schizophrenia.

Interventions: chlorpromazine versus chlorpromazine and ECT, no placebo

Sommerness $1957 \quad$ Allocation: no evidence of randomisation.

Participants: people with schizophrenia, manic-depression, and various other psychoses.

Interventions: chlorpromazine versus placebo.

Outcomes: no usable data reported (no means, $\mathrm{N}$ or SD).

South-East 1961

Allocation: 'allocation to groups A and B'.

Participants: people with schizophrenia.

Interventions: chlorpromazine, prochlorperazine and placebo.

Outcomes: no usable data (no SD).

Soyka 1968

Allocation: not described.

Participants: people with psychosis, depression and neurosis

Spiegel 1967

Allocation: randomised.

Participants: people with chronic schizophrenia.

Interventions: chlorpromazine versus trifluoperazine versus carphenazine, placebo for 'washout' only

Spohn 1974

Allocation: randomised, cross-over.

Participants: healthy volunteers.

Sugerman 1964

Allocation: no evidence of randomisation, cross-over design.

Participants: people with schizophrenia.

Interventions: chlorpromazine versus placebo versus perphenazine versus deanol.

Outcomes: EEG; no data for clinical outcomes; no data given per arm of cross-over

Sun 2006

Allocation: randomised.

Participants: people with chronic schizophrenia.

Interventions: Chlopromazine plus placebo versus chlorpromazine plus venlafaxine

Syvalahti $1997 \quad$ Allocation: randomised.

Participants: people with schizophrenia.

Interventions: citalopram or placebo given as an adjuvant to neuroleptic medication

Talbot 1964

Allocation: randomised.

Participants: people with schizophrenia.

Interventions: chlorpromazine versus trifluoperazine versus chlorpromazine + trifluoperazine;

placebo used to maintain double-blind conditions 
(Continued)

Tang 2005

Allocation: randomised.

Participants: people with schizophrenia.

Interventions: chlorpromazine plus placebo versus chlorpromazine plus herb mixture

Tang 2005a

Allocation: randomised.

Participants: people with schizophrenia.

Interventions: chlorpromazine plus placebo versus chlorpromazine plus Chinese medicine

Tang 2006

Allocation: randomised.

Participants: people with schizophrenia.

Interventions: chlorpromazine plus placebo versus chlorpromazine plus TCM herbs

Tassis 1959

Allocation: not described.

Participants: people with schizophrenia.

Interventions: insulin, ECT and chlorpromazine.

Teja 1975

Allocation: randomised.

Participants: people with schizophrenia.

Interventions: chlorpromazine versus trifluoperazine versus thiothixine versus haloperidol versus placebo.

Outcomes: no usable data.

Tenenblatt 1956

Allocation: no evidence of randomisation.

Terminska 1989

Allocation: unclear.

Participants: people with paranoid schizophrenia.

Interventions: chlorpromazine versus perazine versus fluphenazine versus trifluoperazine versus haloperidol; no placebo group (confirmed by Polish speaker)

Tetreault 1969a

Allocation: randomised.

Participants: people with schizophrenia.

Intervention: fluphenazine in enanthate, fluphenazine bichlorhydrate and placebo

Thorpe 1956

Allocation: randomised.

Participants: people with schizophrenia.

Interventions: chlorpromazine versus pacatal versus no treatment versus placebo.

Outcomes: no usable data.

Tourlentes 1958

Allocation: "randomly assigned".

Participants: people with schizophrenia.

Interventions: chlorpromazine versus placebo.

Outcomes: no usable data.

Troshinsky 1962

Allocation: randomised.

Participants: people with schizophrenia.

Interventions: placebo versus 'active medication' (phenothiazine); phenothiazines were chlorpromazine, trifluoperazine, triflupromazine, thioridazine

Outcomes: results not reported for individual drugs - withdrawal study 
(Continued)

\begin{tabular}{ll} 
Turner 1956 & $\begin{array}{l}\text { Allocation: not described. } \\
\text { Participants: "people neurosis, psychosis and epilepsy". } \\
\text { Interventions: chlorpromazine. }\end{array}$ \\
\hline Turner 1966 & $\begin{array}{l}\text { Allocation: random order Latin-square design. } \\
\text { Participants: healthy volunteers, not people with schizophrenia }\end{array}$ \\
\hline Urquhart 1959 & $\begin{array}{l}\text { Allocation: randomised. } \\
\text { Participants: people with schizophrenia. } \\
\text { Interventions: stage 1: placebo versus acetyl promazine versus promazine hydrochloride, cross-over } \\
\text { design; stage 2: chlorpromazine versus reserpine, cross-over design; no arm comparing chlorpro- } \\
\text { mazine versus placebo }\end{array}$ \\
\hline
\end{tabular}

van Praag 1975

Allocation: randomised.

Participants: people with acute psychotic disorders.

Interventions: chlorpromazine versus oxypertine, placebo used to maintain blinding during dose changes

Vestre $1961 \quad$
$\begin{aligned} & \text { Allocation: not described. } \\ & \text { Participants: people with schizophrenia. } \\ & \text { Interventions: chlorpromazine and placebo. } \\ & \text { Outcomes: no usable data. }\end{aligned}$

Vinar 1973 Allocation: randomised, a 'continuous controlled trial'.

Participants: people with functional psychoses.

Interventions: chlorpromazine versus 'control'.

Outcomes: no usable data, multivariate analysis of Brief Psychiatric Rating Scale and 1-year outcomes of total group, no comparisons between chlorpromazine and control

Vinar $1976 \quad$ Allocation: not randomised.

Volavka 1983 Allocation: randomised, cross-over design.

Participants: people with schizophrenia.

Interventions: (Des-tyr)-gamma-endorphin versus placebo.

Warner 1996

Allocation: unclear.

Participants: people with schizophrenia and other diagnoses.

Interventions: unspecified neuroleptic medications versus unmedicated controls

Weir 1968

Allocation: randomised.

Participants: disturbed, 'mentally subnormal' people, not people with schizophrenia

Welbel $1980 \quad$ Allocation: unclear.

Participants: people with schizophrenia.

Interventions: chlorpromazine versus clozapine versus levopromazine versus triflupromazine versus pimozide versus sulpiride, no placebo group (confirmed by Polish-speaker) 
(Continued)

\begin{tabular}{l|l} 
Whitehead 1958 & $\begin{array}{l}\text { Allocation: randomised. } \\
\text { Participants: people with chronic psychoses. } \\
\text { Interventions:chlorpromazine versus placebo, unclear how many people assigned to each group }\end{array}$ \\
\hline Wilcott 1962 & $\begin{array}{l}\text { Allocation: not described. } \\
\text { Participants: emotionally disturbed children. }\end{array}$ \\
\hline
\end{tabular}

Wilson 1961 Allocation: unclear, 'Latin square', cross-over design.

Participants: people with paranoid schizophrenia.

Interventions: chlorpromazine versus prochlorperazine versus trifluoperazine versus placebo

Winkelman 1957

Allocation: not described- case report series.

Winter 1956

Allocation: randomised.

Participants: people with a 'variety of diagnostic categories', and 'acutely disturbed'.

Interventions: chlorpromazine versus placebo.

Outcomes: chlorpromazine and placebo groups not reported separately

Wode-Helgodt $1977 \quad$ Allocation: randomised.

Participants: those with psychoses, and 'schizophrenic symptomology'.

Interventions: chlorpromazine $200 \mathrm{mg} /$ day versus chlorpromazine $400 \mathrm{mg} /$ day versus chlorpromazine $600 \mathrm{mg} /$ day, placebo used for washout only

Wold 1959

Allocation: not described.

Participants: people with schizophrenia.

Interventions: chlorpromazine and placebo.

Outcomes: no usable data.

Wolpert 1969

Allocation: 'assigned at random'.

Participants: people with schizophrenia.

Interventions: chlorpromazine, triiodothyronine and placebo.

Outcomes: no usable data.

Wyatt $1997 \quad$ Allocation: randomised.

Participants: people with schizophrenia.

Interventions: milieu therapy versus psychotherapy versus ECT versus antipsychotic medications (including chlorpromazine amongst others) versus antipsychotic medication + psychotherapy

Outcomes: not possible to separate chlorpromazine data from totals

Wykes 1994

Allocation: randomised.

Participants: people with schizophrenia and cognitive difficulties.

Interventions: cognitive remediation versus treatment as usual

Yan 2004

Allocation: randomised.

Participants: people with schizophrenia.

Interventions: chlorpromazine plus placebo versus chlorpromazine plus ferrous sulphate 


\begin{tabular}{|c|c|}
\hline Yang 2005 & $\begin{array}{l}\text { Allocation: randomised. } \\
\text { Participants: people with schizophrenia. } \\
\text { Interventions: psychological rehabilitation therapy versus general rehabilitation }\end{array}$ \\
\hline Yorkston 1977 & $\begin{array}{l}\text { Allocation: randomised. } \\
\text { Participants: people with schizophrenia. } \\
\text { Interventions: propranolol versus placebo, all on antipsychotics, doses expressed as chlorpromazine } \\
\text { equivalents }\end{array}$ \\
\hline Yuan-guang 1994 & $\begin{array}{l}\text { Allocation: randomised. } \\
\text { Participants: } 41 \text { people with schizophrenia. } \\
\text { Interventions: three different doses of chlorpromazine, no placebo }\end{array}$ \\
\hline Zeller 1956 & $\begin{array}{l}\text { Allocation: possibly randomised, 'selected at random'. } \\
\text { Participants: mainly people with schizophrenia. } \\
\text { Interventions: continuing chlorpromazine or reserpine versus placebo, withdrawal study }\end{array}$ \\
\hline 王强, 1995 & $\begin{array}{l}\text { Allocation: randomised. } \\
\text { Participants: people with schizophrenia. } \\
\text { Interventions: cross-over trial, chlorpromazine plus lithium versus chlorpromazine plus placebo }\end{array}$ \\
\hline 金建烽, 2008 & $\begin{array}{l}\text { Allocation: randomised. } \\
\text { Participants: people with schizophrenia. } \\
\text { Interventions: chlorpromazine plus placebo versus chlorpromazine plus aripiprazole }\end{array}$ \\
\hline
\end{tabular}

$\mathrm{CPZ}$ - chlorpromazine

ECT - electroconvulsive therapy

EEG - electroencephalogram

$\mathrm{SD}$ - standard deviation

TCM - traditional Chinese medicine 
DATA AND ANALYSES

\section{Comparison 1. CHLORPROMAZINE versus PLACEBO}

\begin{tabular}{|c|c|c|c|c|}
\hline Outcome or subgroup title & $\begin{array}{l}\text { No. of } \\
\text { studies }\end{array}$ & $\begin{array}{c}\text { No. of } \\
\text { participants }\end{array}$ & Statistical method & Effect size \\
\hline 1 Death & 1 & 14 & Risk Ratio (M-H, Fixed, 95\% CI) & $0.0[0.0,0.0]$ \\
\hline 2 Relapse & 7 & & Risk Ratio (M-H, Random, 95\% CI) & Subtotals only \\
\hline 2.1 short term $(0-8$ weeks $)$ & 2 & 74 & Risk Ratio (M-H, Random, 95\% CI) & $0.24[0.01,5.49]$ \\
\hline $\begin{array}{l}2.2 \text { medium term (9 weeks - } 6 \\
\text { months) }\end{array}$ & 4 & 809 & Risk Ratio (M-H, Random, 95\% CI) & $0.61[0.21,1.72]$ \\
\hline $\begin{array}{l}2.3 \text { long term ( } 6 \text { months - } 2 \\
\text { years) }\end{array}$ & 3 & 512 & Risk Ratio (M-H, Random, 95\% CI) & $0.65[0.47,0.90]$ \\
\hline $2.42-5$ years & 2 & 394 & Risk Ratio (M-H, Random, 95\% CI) & $0.74[0.51,1.09]$ \\
\hline $\begin{array}{l}3 \text { Global state: 1a. No } \\
\text { overall improvement } \\
\text { (psychiatrist-rated) }\end{array}$ & 27 & & Risk Ratio (M-H, Random, 95\% CI) & Subtotals only \\
\hline 3.1 short term $(0-8$ weeks $)$ & 13 & 728 & Risk Ratio (M-H, Random, 95\% CI) & $0.61[0.46,0.82]$ \\
\hline $\begin{array}{l}3.2 \text { medium term (9 weeks - } 6 \\
\text { months) }\end{array}$ & 14 & 1164 & Risk Ratio (M-H, Random, 95\% CI) & $0.71[0.58,0.86]$ \\
\hline $\begin{array}{l}4 \text { Global state: } 1 \mathrm{~b} . \text { No overall } \\
\text { improvement (nurse-rated) }\end{array}$ & 4 & & Risk Ratio (M-H, Fixed, 95\% CI) & Subtotals only \\
\hline 4.1 short term (0-8 weeks) & 1 & 29 & Risk Ratio (M-H, Fixed, 95\% CI) & $0.91[0.65,1.27]$ \\
\hline $\begin{array}{l}4.2 \text { medium term (9 weeks- } 6 \\
\text { months) }\end{array}$ & 3 & 84 & Risk Ratio (M-H, Fixed, 95\% CI) & $0.48[0.35,0.66]$ \\
\hline $\begin{array}{l}5 \text { Global state: } 2 \text {. Average endpoint } \\
\text { score - short term (CGI, high } \\
\text { score=worse) }\end{array}$ & 1 & 19 & Mean Difference (IV, Fixed, 95\% CI) & $0.10[-0.35,0.55]$ \\
\hline $\begin{array}{l}6 \text { Global state: } 3 a \text {. Severity } \\
\text { of illness, severely ill or } \\
\text { worse (CGI 5+ points, } \\
\text { psychiatrist-rated) }\end{array}$ & 4 & & Risk Ratio (M-H, Fixed, 95\% CI) & Subtotals only \\
\hline 6.1 short term $(0-8$ weeks $)$ & 1 & 44 & Risk Ratio (M-H, Fixed, 95\% CI) & $0.46[0.16,1.30]$ \\
\hline $\begin{array}{l}6.2 \text { medium term (9 weeks - } 6 \\
\text { months) }\end{array}$ & 3 & 694 & Risk Ratio (M-H, Fixed, 95\% CI) & $0.80[0.74,0.86]$ \\
\hline $\begin{array}{l}7 \text { Global state: } 3 \text { b. Severity of } \\
\text { illness, severely ill or worse - } \\
\text { medium term (CGI 5+ points, } \\
\text { nurse-rated) }\end{array}$ & 2 & 66 & Risk Ratio (M-H, Fixed, 95\% CI) & $0.63[0.45,0.90]$ \\
\hline 8 Leaving the study early & 45 & & Risk Ratio (M-H, Fixed, 95\% CI) & Subtotals only \\
\hline 8.1 short term $(0-8$ weeks $)$ & 17 & 1065 & Risk Ratio (M-H, Fixed, 95\% CI) & $0.76[0.63,0.92]$ \\
\hline $\begin{array}{l}8.2 \text { medium term (9 weeks - } 6 \\
\text { months) }\end{array}$ & 27 & 1831 & Risk Ratio (M-H, Fixed, 95\% CI) & $0.64[0.53,0.78]$ \\
\hline $\begin{array}{l}8.3 \text { long term (>6 months }-2 \\
\text { years) }\end{array}$ & 2 & 492 & Risk Ratio (M-H, Fixed, 95\% CI) & $1.06[0.71,1.59]$ \\
\hline $8.4>2-5$ years & 1 & 374 & Risk Ratio (M-H, Fixed, 95\% CI) & $0.68[0.35,1.36]$ \\
\hline $\begin{array}{l}9 \text { Mental state: } 1 . \text { Improved - short } \\
\text { term (BPRS, } 50 \% \text { change) }\end{array}$ & 1 & 106 & Risk Ratio (M-H, Fixed, 95\% CI) & $1.25[0.36,4.40]$ \\
\hline
\end{tabular}

Chlorpromazine versus placebo for schizophrenia (Review)

Copyright (๑) 2015 The Cochrane Collaboration. Published by John Wiley \& Sons, Ltd. 
10 Mental state: 2. Average endpoint scores (BPRS, high score $=$ worse)

10.1 short term (0-8 weeks)

10.2 medium term (9 weeks 6 months)

11 Behaviour: 1. Deteriorated/ disturbed/un-cooperative

11.1 short term - (0-8 weeks)

11.2 medium term (9 weeks 6 months)

12 Behaviour: 2. Unchanged 12.1 short term (0-8 weeks)

12.2 medium term (9 weeks 6 months)

13 Behaviour: 3. Average endpoint scores (RRS, high score $=$ worse) 13.1 short term (0-8 weeks) 13.2 medium term (9 weeks 6 months)

14 Behaviour: 4. Average endpoin score - short term (PBRS, high score $=$ good)

15 Behaviour: 5. Average endpoint scores - medium term (Fergus Falls Behavioural rating scale)

16 Adverse effects: 1 . Movement disorders

16.1 acute movement disorders (dystonia)

16.2 parkinsonism (includes EPS)

16.3 tremor

16.4 rigidity

16.5 akathisia

16.6 chronic movement

disorders (tardive dyskinesia)

16.7 ataxia

17 Adverse effects: 2. Movement disorders: Average endpoint scores (Extrapyramidal Bilan, high score $=$ worse)

17.1 short term (0-8 weeks)

17.2 medium term (9 weeks 6 months)

18 Adverse effects: 1. Central nervous system

18.1 sleepiness

18.2 fits / loss of consciousness

18.3 weakness

18.4 convulsions

Subtotals only

49
Mean Difference (IV, Fixed, 95\% CI)

Mean Difference (IV, Fixed, 95\% CI)

Risk Ratio (M-H, Random, 95\% CI)

Mean Difference (IV, Fixed, 95\% CI)

Risk Ratio (M-H, Fixed, 95\% CI)

Risk Ratio (M-H, Fixed, 95\% CI)

Mean Difference (IV, Fixed, 95\% CI)

Risk Ratio (M-H, Fixed, 95\% CI)

Risk Ratio (M-H, Fixed, 95\% CI)

Risk Ratio (M-H, Fixed, 95\% CI)

Risk Ratio (M-H, Fixed, 95\% CI)

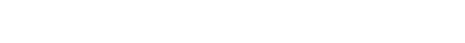

Risk Ratio (M-H, Fixed, 95\% CI)

Risk Ratio (M-H, Fixed, 95\% CI)

Risk Ratio (M-H, Fixed, 95\% CI)

Risk Ratio (M-H, Fixed, 95\% CI)
$-4.82[-8.48,-1.15]$

$-7.70[-14.77,-0.63]$

Subtotals only

$0.67[0.34,1.35]$

$0.49[0.24,1.00]$

Subtotals only

$0.63[0.25,1.58]$

$1.15[0.64,2.07]$

Subtotals only

$-2.90[-6.74,0.94]$

$-4.60[-9.47,0.27]$

$6.0[1.97,10.03]$

$-2.36[-6.11,1.39]$

Subtotals only

3.47 [1.50, 8.03]

$2.11[1.59,2.80]$

$1.66[1.01,2.73]$

$2.24[1.42,3.54]$

$0.78[0.54,1.11]$

1.5 [0.32, 6.94]

8.64 [0.94, 79.31]

Subtotals only

$-1.40[-3.22,0.42]$

$-1.80[-4.19,0.59]$

Subtotals only

$2.79[2.25,3.45]$

3.11 [1.05, 9.18]

3.33 [1.02, 10.88]

0.33 [0.01, 7.82]

Chlorpromazine versus placebo for schizophrenia (Review) 
19 Adverse effects: 3. Blood, skin, liver, eyes

19.1 blood problems (agranulocytosis, leukopenia)

19.2 rashes/itching/skin disorders

19.3 liver problems

19.4 photosensitivity

19.5 eye opacity / eye pigment problems

20 Adverse effects: 4. Other

20.1 blood pressure - low +/-

dizziness/syncope

20.2 constipation

20.3 urinary problems

20.4 blurred vision

20.5 dry mouth

20.6 weight increase

20.7 weight decrease

20.8 nausea/vomiting

20.9 salivation

20.10 menorrhagia / abnormal menstruation

20.11 amenorrhea

20.12 lactation

21 SUBGROUP ANALYSIS: 1.

MEN vs WOMEN: Behaviour:

Deteriorated/disturbed/un-

cooperative

21.1 only men

21.2 only women

22 SUBGROUP ANALYSIS: 2.

ACUTE vs CHRONIC

22.1 acute - Relapse (9 wks -

6 months)

22.2 chronic - Relapse (9 wks

-6 months)

22.3 acute - Global state 1 . No

overall improvement (0-8 wks)

22.4 chronic - Global state 1 .

No overall improvement (0-8

wks)

22.5 acute - Global state 2 .

No overall improvement (9

wks-6 months)

22.6 chronic - Global state

2. No overall improvement (9 wks-6 months)

22.7 acute - Behaviour deteriorated/disturbed/uncooperative
40

158

127

682

149

459

23
Risk Ratio (M-H, Fixed, 95\% CI)

Risk Ratio (M-H, Fixed, 95\% CI)

Risk Ratio (M-H, Fixed, 95\% CI)

Risk Ratio (M-H, Fixed, 95\% CI)

Risk Ratio (M-H, Fixed, 95\% CI)

Risk Ratio (M-H, Fixed, 95\% CI)

Risk Ratio (M-H, Fixed, 95\% CI)

Risk Ratio (M-H, Fixed, 95\% CI)

Risk Ratio (M-H, Fixed, 95\% CI)

Risk Ratio (M-H, Fixed, 95\% CI)

Risk Ratio (M-H, Fixed, 95\% CI)

Risk Ratio (M-H, Fixed, 95\% CI)

Risk Ratio (M-H, Fixed, 95\% CI)

Risk Ratio (M-H, Fixed, 95\% CI)

Risk Ratio (M-H, Fixed, 95\% CI)

Risk Ratio (M-H, Fixed, 95\% CI)

Risk Ratio (M-H, Fixed, 95\% CI)

Risk Ratio (M-H, Fixed, 95\% CI)

Risk Ratio (M-H, Fixed, 95\% CI)

Risk Ratio (M-H, Fixed, 95\% CI)

Risk Ratio (M-H, Random, 95\% CI)

Risk Ratio (M-H, Random, 95\% CI)

$0.74[0.64,0.86]$

Risk Ratio (M-H, Fixed, 95\% CI)

Risk Ratio (M-H, Fixed, 95\% CI)

Risk Ratio (M-H, Random, 95\% CI)

Risk Ratio (M-H, Random, 95\% CI)

Risk Ratio (M-H, Random, 95\% CI)

Risk Ratio (M-H, Random, 95\% CI)

Risk Ratio (M-H, Random, 95\% CI)

$0.57[0.39,0.84]$

$0.18[0.03,1.28]$

$0.46[0.29,0.73]$

Subtotals only

$1.21[0.94,1.55]$

$0.46[0.18,1.15]$

$0.68[0.44,1.05]$

Risk Ratio (M-H, Random, 95\% CI)

$0.88[0.60,1.29]$ 
22.8 chronic - Behaviour

deteriorated/disturbed/unco-

operative

23 SUBGROUP ANALYSIS: 3.

HIGH vs LOW DOSE

23.1 high - Relapse (9 wks- 6 Months)

23.2 low - Relapse (9 wks-6

Months)

23.3 high - Global state 1. No

overall improvement (0-8 wks)

23.4 low - Global state 1. No overall improvement (0-8 wks)

23.5 high - Global state 1 . No overall improvement ( 9 wks- 6 months)

23.6 low - Global state 1. No overall improvement (9 wks-6 months)

23.7 high - Behaviour 1.

Deteriorated/disturbed/uncooperative

23.8 low - Behaviour 1.

Deteriorated/disturbed/unco-

operative

24 SUBGROUP ANALYSIS: 4.

DIAGNOSTIC CRITERIA

vs NO DIAGNOSTIC

CRITERIA

24.1 diagnostic criteria -

Relapse (0-8 wks)

24.2 no diagnostic criteria -

Relapse (0-8 wks)

24.3 diagnostic criteria -

Relapse (9 wks-6 months)

24.4 no diagnostic criteria -

Relapse ( 9 wks- 6 months)

24.5 diagnostic criteria -

Global state 1. No overall

improvement (0-8 wks)

24.6 no diagnostic criteria

- Global state 1. No overall improvement (0-8 wks)

24.7 diagnostic criteria -

Global state 1. No overall improvement (9 wks-6 months)

24.8 no diagnostic criteria

- Global state 1. No overall

improvement (9 wks-6 months)

11
Risk Ratio (M-H, Random, 95\% CI)

Subtotals only

Risk Ratio (M-H, Random, 95\% CI)

$0.14[0.08,0.26]$

$0.51[0.26,0.98]$

$0.48[0.18,1.25]$

$0.72[0.52,1.01]$

$0.69[0.51,0.94]$

$0.83[0.60,1.16]$

$0.50[0.04,6.21]$

$0.39[0.27,0.56]$

Subtotals only

Risk Ratio (M-H, Random, 95\% CI)

$0.75[0.26,2.19]$

$0.05[0.00,0.76]$

$0.34[0.13,0.90]$

$1.03[0.66,1.60]$

$0.63[0.40,0.99]$

$0.64[0.46,0.90]$

$0.77[0.57,1.05]$

475

Risk Ratio (M-H, Random, 95\% CI)
$0.71[0.59,0.85]$ 
24.9 diagnostic criteria Global state 3. Severity of illness (9 wks-6 months)

24.10 no diagnostic criteria

- Global state 3. Severity of illness (9 wks-6 months)

24.11 diagnostic criteria Behaviour 1. deteriorated/ disturbed/unco-operative

24.12 no diagnostic criteria - Behaviour 1. deteriorated/ disturbed/unco-operative

25 SUBGROUP ANALYSIS:

5. STUDIES PRE-1990 vs

STUDIES 1990-2007

25.1 Pre-1990 - Global state

1 . No overall improvement (08 wks)

25.21990 to 2002 -

Global state 1. No overall

improvement (0-8 wks)

25.3 Pre-1990 - Global state

1. No overall improvement (9

wks-6 months)

25.41990 to 2002 -

Global state 1. No overall

improvement (9 wks-6 months)

25.5 Pre-1990 - Behaviour 1. deteriorated/disturbed/uncooperative

25.61990 to 2002 -

Behaviour 1. deteriorated/

disturbed/unco-operative

26 SENSITIVITY ANALYSIS: 1. RANDOMISATION

26.1 not stated - Global state:

1. No overall improvement (9 weeks - 6 months)

26.2 stated - Global state: 1.

No overall improvement (9

weeks - 6 months)

27 SENSITIVITY ANALYSIS: 2. ASSUMPTIONS FOR LOST BINARY DATA

27.1 LOCF - Global state: 1. No overall improvement (0-8 weeks)

27.2 not LOCF - Global state:

1. No overall improvement (08 weeks)
Risk Ratio (M-H, Random, 95\% CI)

$0.56[0.33,0.97]$ 


\section{Analysis I.I. Comparison I CHLORPROMAZINE versus PLACEBO, Outcome I Death.}

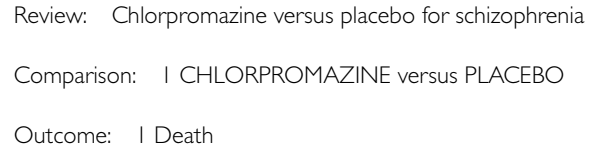

\begin{tabular}{|c|c|c|c|c|c|}
\hline \multirow[t]{2}{*}{ Study or subgroup } & Chlorpromazine & Placebo & Risk Ratio & Weight & Risk Ratio \\
\hline & $\mathrm{n} / \mathrm{N}$ & $\mathrm{n} / \mathrm{N}$ & M-H,Fixed,95\% Cl & & M-H,Fixed,95\% Cl \\
\hline
\end{tabular}

Total (95\% CI) 7

Total events: 0 (Chlorpromazine), 0 (Placebo)

Heterogeneity: not applicable

Test for overall effect: not applicable

Test for subgroup differences: Not applicable 


\section{Analysis I.2. Comparison I CHLORPROMAZINE versus PLACEBO, Outcome 2 Relapse.}

Review: Chlorpromazine versus placebo for schizophrenia

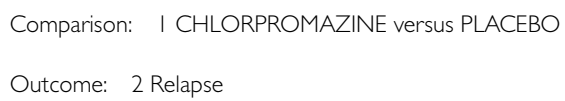

Total events: 87 (Chlorpromazine), 144 (Placebo)

Heterogeneity: $\mathrm{Tau}^{2}=1.04 ; \mathrm{Chi}^{2}=68.53, \mathrm{df}=3(\mathrm{P}<0.0000 \mathrm{I}) ; \mathrm{I}^{2}=96 \%$

Test for overall effect: $Z=0.94(P=0.35)$

3 long term (6 months - 2 years)

$\begin{array}{lrr}\text { Engelhardt 1960 } & 28 / 62 & 35 / 56 \\ \text { Hogarty 1973 } & 70 / 192 & 131 / 182 \\ \text { Nishikawa 1982 } & 8 / 10 & 10 / 10 \\ \text { Subtotal (95\% CI) } & \mathbf{2 6 4} & \mathbf{2 4 8}\end{array}$

Total events: 106 (Chlorpromazine), 176 (Placebo)

Heterogeneity: $\mathrm{Tau}^{2}=0.06 ; \mathrm{Chi}^{2}=7.13, \mathrm{df}=2(\mathrm{P}=0.03) ; \mathrm{I}^{2}=72 \%$

Test for overall effect: $Z=2.62(P=0.0089)$

42 - 5 years

$$
\begin{array}{lrr}
\text { Hogarty } 1973 & 99 / 192 & 149 / 182 \\
\text { Nishikawa } 1982 & 9 / 10 & 10 / 10
\end{array}
$$

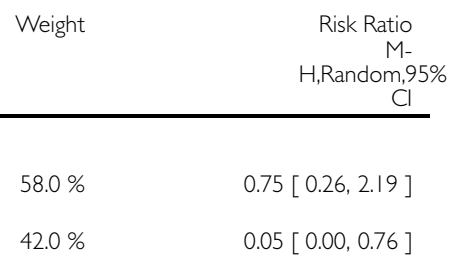

$58.0 \%$

$42.0 \%$

$0.75[0.26,2.19]$

$0.05[0.00,0.76]$

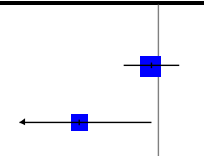

$100.0 \%$

$0.24[0.01,5.49$ ]

$25.1 \%$

$0.75[0.41,1.36]$

$21.6 \%$

$26.5 \%$

$26.8 \%$

$100.0 \%$

$0.64[0.23,1.80]$

$0.23[0.17,0.33]$

$1.21[0.94,1.55]$

$0.61[0.21,1.72$ ]

$30.6 \%$

$0.72[0.51,1.02]$

$39.1 \%$

$0.5 \mid[0.41,0.62]$

$30.3 \%$

$100.0 \%$

$0.81[0.57,1.14]$

$0.65[0.47,0.90]$

$54.1 \%$

$45.9 \%$

$0.63[0.54,0.73]$

$0.90[0.69,1.18]$

$100.0 \%$ 
Analysis I.3. Comparison I CHLORPROMAZINE versus PLACEBO, Outcome 3 Global state: Ia. No overall improvement (psychiatrist-rated).

Review: Chlorpromazine versus placebo for schizophrenia

Comparison: I CHLORPROMAZINE versus PLACEBO

Outcome: 3 Global state: Ia. No overall improvement (psychiatrist-rated)

Study or subgroup

Chlorpromazine Placebo

Placebo

Risk Ratio

$M$ -

H,Random,95\%

Weight

Risk Ratio

H,Random, $95 \%$

$\mathrm{n} / \mathrm{N}$

$n / N$

Cl

H,Random,95\%

I short term (0-8 weeks)

Baker 1959

Chouinard 1990 (I)

$7 / 7$

6/7

$-$

$10.5 \%$

$1.15[0.79,1.68]$

Clark 197I (2)

$9 / 21$

$13 / 2$ |

Cooper 2000

$3 / 23$

$|1 / 2|$

Fink 1963

$26 / 53$

$35 / 53$

Hankoff 1962

|0/5 |

$30 / 44$

Kurland 196I

$12 / 16$

$65 / 68$

Ramu 1999

9/33

30/74

Reschke 1974

$6 / 27$

18/27

Reschke 1974

$7 / 10$

$4 / 11$

Shepherd 1956

Somerville 1960

$3 / 8$

$10 / 16$

Vaughan 1955

$7 / 15$

$23 / 30$

Walsh 1959

$8 / 24$

$19 / 24$

2/22

$8 / 22$

Subtotal (95\% CI)

310

418

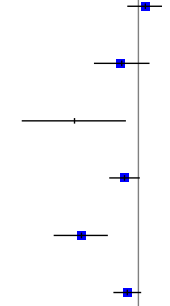

$8.3 \%$

$0.69[0.38,1.26]$

$4.4 \%$

$0.25[0.08,0.77]$

$11.0 \%$

$8.4 \%$

$0.74[0.53,1.04]$

$0.29[0.16,0.52]$

$11.4 \%$

$0.78[0.59,1.05]$

$8.1 \%$

$6.9 \%$

$0.67[0.36,1.25]$

$0.33[0.16,0.71]$

$5.9 \%$

$1.93[0.80,4.64]$

$5.3 \%$

$8.5 \%$

$0.60[0.23,1.59]$

$0.61[0.34,1.08]$

$8.3 \%$

$0.42[0.23,0.77]$

$3.1 \%$

$0.25[0.06,1.05]$

Total events: 109 (Chlorpromazine), 272 (Placebo)

Heterogeneity: Tau $^{2}=0.17 ; \mathrm{Chi}^{2}=38.79, \mathrm{df}=12(\mathrm{P}=0.000 \mathrm{II}) ; \mathrm{I}^{2}=69 \%$

Test for overall effect: $Z=3.33(P=0.00087)$

2 medium term ( 9 weeks -6 months)

Ban 1975

$6 / 10$

Bishop 1963

$2 / 10$

$8 / 10$

$10 / 10$

Clark 196I

$13 / 19$

$19 / 19$

Clark 1968a

$10 / 18$

$30 / 36$

Clark 1970a

$8 / 15$

$9 / 14$

Clark 1972

$10 / 19$

$14 / 18$

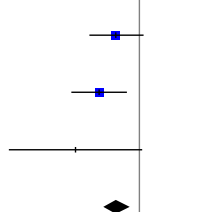

$100.0 \%$

$0.61[0.46,0.82$ ]

$5.9 \%$

$2.6 \%$

$9.4 \%$

$7.7 \%$

$5.7 \%$

$7.0 \%$

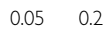

Favours CPZ

Favours placebo
(Continued ... )

$0.75[0.41,1.36]$

$0.24[0.08,0.71]$

$0.69[0.51,0.95$ ]

$0.67[0.43,1.03]$

$0.83[0.45,1.53]$

$0.68[0.41,1.11]$ 


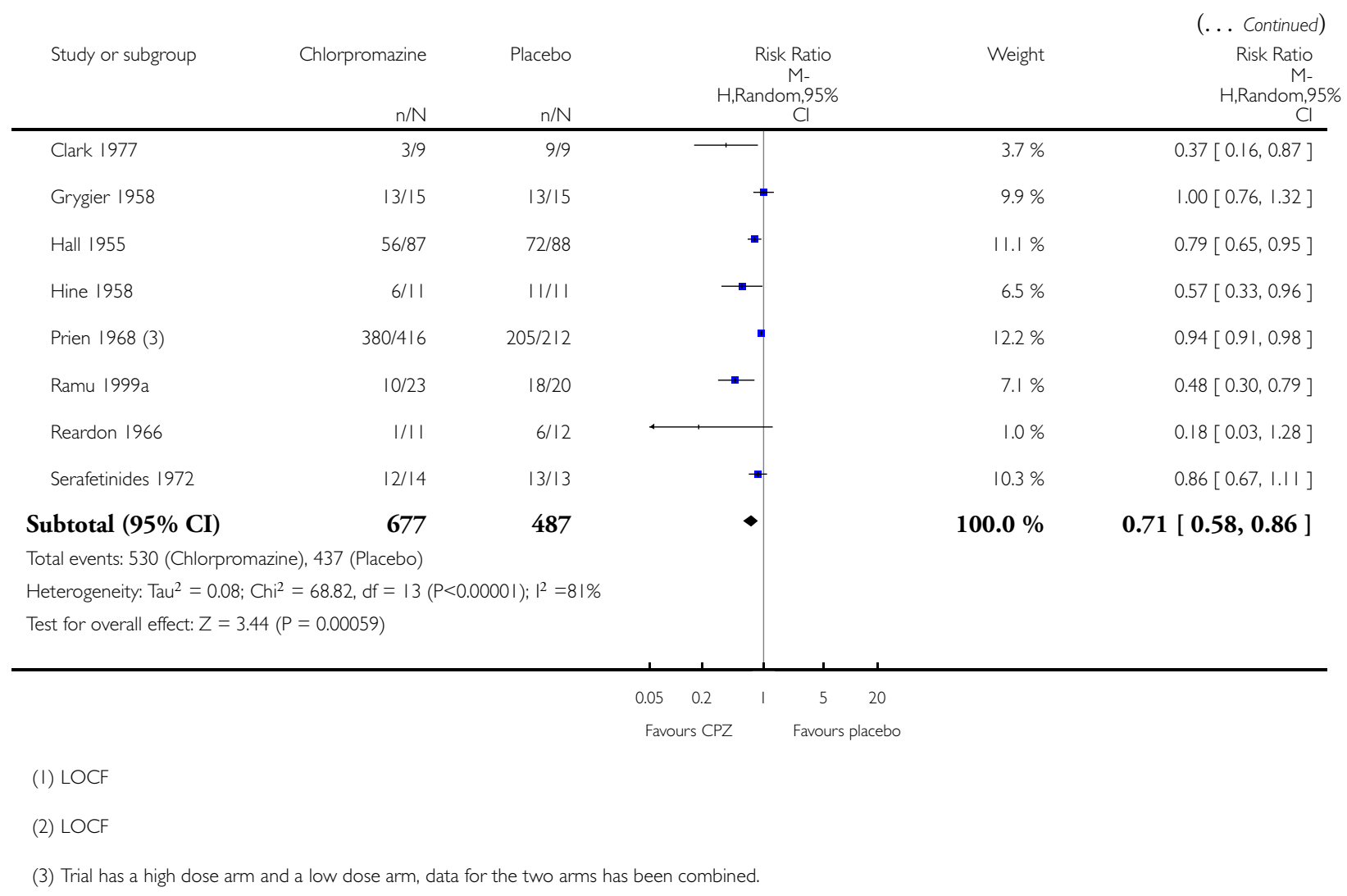


Analysis I.4. Comparison I CHLORPROMAZINE versus PLACEBO, Outcome 4 Global state: Ib. No overall improvement (nurse-rated).

Review: Chlorpromazine versus placebo for schizophrenia

Comparison: I CHLORPROMAZINE versus PLACEBO

Outcome: 4 Global state: Ib. No overall improvement (nurse-rated)

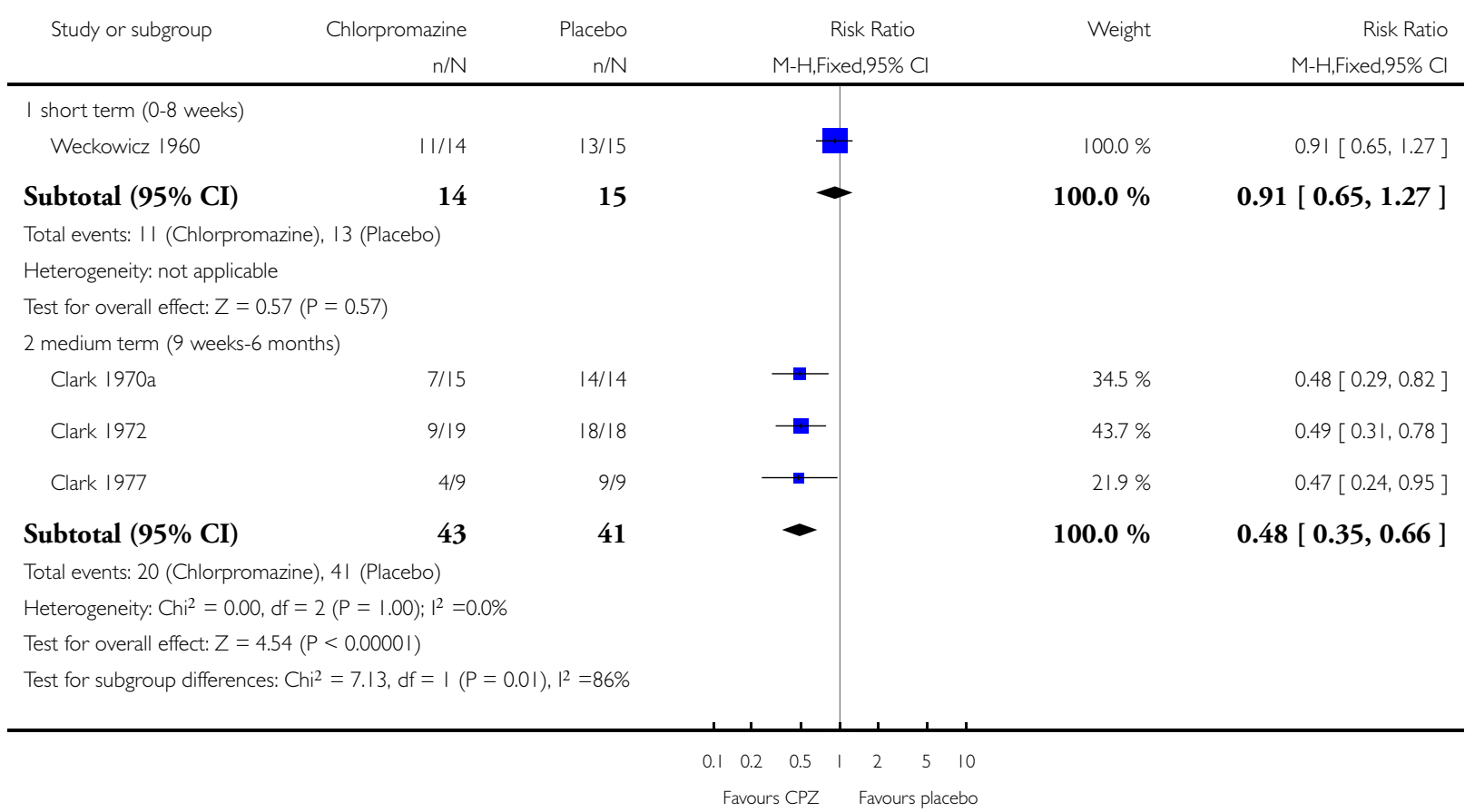


Analysis I.5. Comparison I CHLORPROMAZINE versus PLACEBO, Outcome 5 Global state: 2. Average endpoint score - short term (CGI, high score=worse).

Review: Chlorpromazine versus placebo for schizophrenia

Comparison: I CHLORPROMAZINE versus PLACEBO

Outcome: 5 Global state: 2. Average endpoint score - short term (CGl, high score=worse)

\begin{tabular}{|c|c|c|c|c|c|c|c|c|}
\hline \multirow[t]{2}{*}{ Study or subgroup } & Chlorpromazine & \multicolumn{2}{|c|}{ Placebo } & \multicolumn{3}{|r|}{$\begin{array}{r}\text { Mean } \\
\text { Difference }\end{array}$} & Weight & $\begin{array}{r}\text { Mean } \\
\text { Difference }\end{array}$ \\
\hline & $\mathrm{N}$ & Mean(SD) & $N$ & Mean(SD) & & IV,Fixed,95\% Cl & & IV,Fixed,95\% Cl \\
\hline Borison 1991 & 9 & $4.4(0.5)$ & 10 & $4.3(0.5)$ & & & $100.0 \%$ & $0.10[-0.35,0.55]$ \\
\hline Total (95\% CI) & 9 & & 10 & & & - & $100.0 \%$ & $0.10[-0.35,0.55]$ \\
\hline \multicolumn{9}{|c|}{ Heterogeneity: not applicable } \\
\hline \multicolumn{9}{|c|}{ Test for overall effect: $Z=0.44(P=0.66)$} \\
\hline \multicolumn{9}{|c|}{ Test for subgroup differences: Not applicable } \\
\hline & & & & & -1 & -0.5 & 1 & \\
\hline & & & & & $\mathrm{Fa}$ & irs CPZ & cebo & \\
\hline
\end{tabular}


Analysis I.6. Comparison I CHLORPROMAZINE versus PLACEBO, Outcome 6 Global state: 3a. Severity of illness, severely ill or worse (CGI 5+ points, psychiatrist-rated).

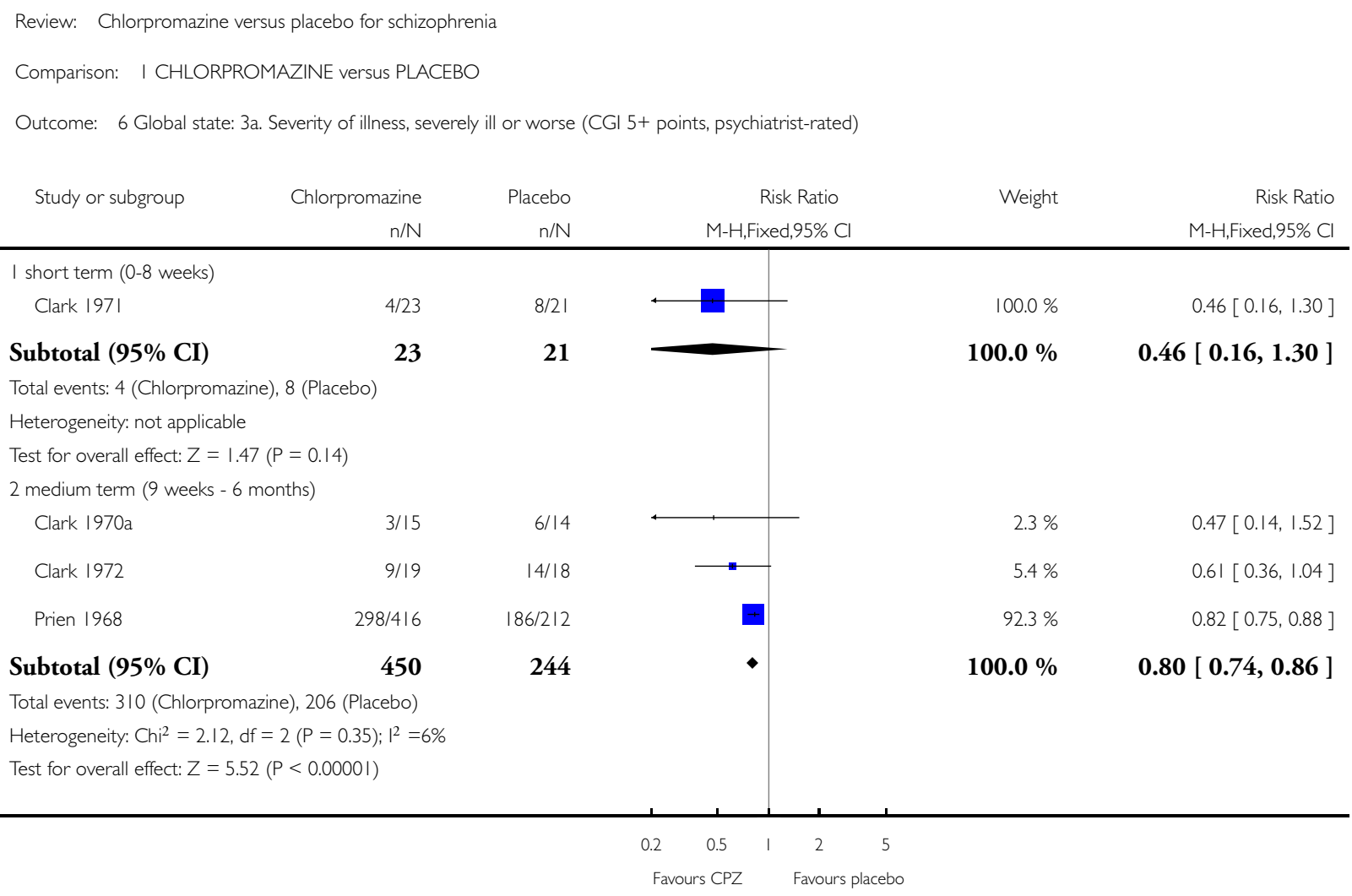


Analysis I.7. Comparison I CHLORPROMAZINE versus PLACEBO, Outcome 7 Global state: 3b. Severity of illness, severely ill or worse - medium term (CGI 5+ points, nurse-rated).

\begin{tabular}{|c|c|c|c|c|c|}
\hline \\
\hline \multicolumn{6}{|c|}{ Outcome: 7 Global state: 3b. Severity of illness, severely ill or worse - medium term (CGI 5+ points, nurse-rated) } \\
\hline \multirow[t]{2}{*}{ Study or subgroup } & Chlorpromazine & Placebo & & \multirow[t]{2}{*}{ Weight } & Risk Ratio \\
\hline & $\mathrm{n} / \mathrm{N}$ & $\mathrm{n} / \mathrm{N}$ & M-H,Fix & & M-H,Fixed,95\% Cl \\
\hline Clark 1970a & $8 / 15$ & $14 / 14$ & $\longrightarrow$ & $52.9 \%$ & $0.55[0.34,0.88]$ \\
\hline Clark 1972 & $10 / 19$ & $13 / 18$ & - & $47.1 \%$ & $0.73[0.44,1.22]$ \\
\hline Total $(95 \% \mathrm{CI})$ & 34 & 32 & $\longrightarrow$ & $100.0 \%$ & $0.63[0.45,0.90]$ \\
\hline \multicolumn{6}{|c|}{ Total events: 18 (Chlorpromazine), 27 (Placebo) } \\
\hline \multicolumn{6}{|c|}{ Heterogeneity: $\mathrm{Ch}^{2} \mathrm{I}^{2}=0.64, \mathrm{df}=\mathrm{I}(P=0.42) ; \mathrm{I}^{2}=0.0 \%$} \\
\hline \multicolumn{6}{|c|}{ Test for overall effect: $Z=2.57(P=0.010)$} \\
\hline Test for subgroup diffe & Not applicable & & & & \\
\hline
\end{tabular}

$\begin{array}{ccccc}0.2 & 0.5 & \text { I } & 2 & 5 \\ \text { Favours } & \text { CPZ } & & \text { Favours placebo }\end{array}$


Analysis I.8. Comparison I CHLORPROMAZINE versus PLACEBO, Outcome 8 Leaving the study early.

Review: Chlorpromazine versus placebo for schizophrenia

Comparison: I CHLORPROMAZINE versus PLACEBO

Outcome: 8 Leaving the study early

Study or subgroup

Chlorpromazine

Placebo

Risk Ratio

Weight

Risk Ratio

$\mathrm{n} / \mathrm{N}$

$\mathrm{n} / \mathrm{N}$

M-H,Fixed,95\% Cl

M-H,Fixed,95\% Cl

I short term (0-8 weeks)

Baker 1959

0/7

$0 / 7$

Chouinard 1990

$4 / 21$

$7 / 21$

Clark 197I

$3 / 23$

$4 / 21$

Cole 1964

$10 / 112$

$37 / 125$

Cooper 2000

$25 / 53$

$25 / 53$

Fink 1963

$0 / 12$

0/7

Hamill 1975

$6 / 22$

$5 / 22$

Hamilton 1960

$0 / 18$

$0 / 18$

Hankoff 1962

$8 / 25$

23/95

Klein 1973

0/46

0/42

Kurland 1961

$24 / 33$

63/74

Peet |98|

$6 / 16$

$8 / 18$

Reschke 1974

$0 / 10$

0/1 I

Shepherd 1956

$0 / 8$

$0 / 16$

Simon 1958

$0 / 20$

$0 / 20$

Somerville 1960

$0 / 15$

$0 / 30$

Walsh 1959

$0 / 22$

Subtotal (95\% CI)

463

Total events: 86 (Chlorpromazine), 172 (Placebo)

Heterogeneity: Chi $^{2}=14.19, \mathrm{df}=7(\mathrm{P}=0.05) ; \mathbf{1}^{2}=51 \%$

Test for overall effect: $Z=2.76(P=0.0059)$

2 medium term ( 9 weeks -6 months)

Abrams 1958

$$
\text { 2/20 }
$$

Ban 1975

Bishop 1963

$0 / 10$

$0 / 10$

$|1 / 5|$

$0 / 22$

602

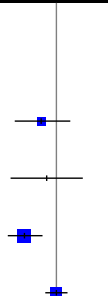

$+\quad 18.9 \%$

$5.3 \%$

$3.2 \%$

$26.5 \%$

Not estimable

Clark 1967

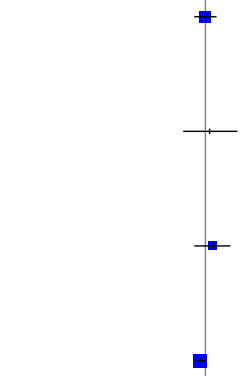

$3.8 \%$
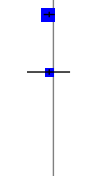

$7.3 \%$

$29.4 \%$

$5.7 \%$

$2.2 \%$

$0.50[0.10,2.43]$

Not estimable

Not estimable

$0.4 \%$

$9.73[0.60,157.98]$ 


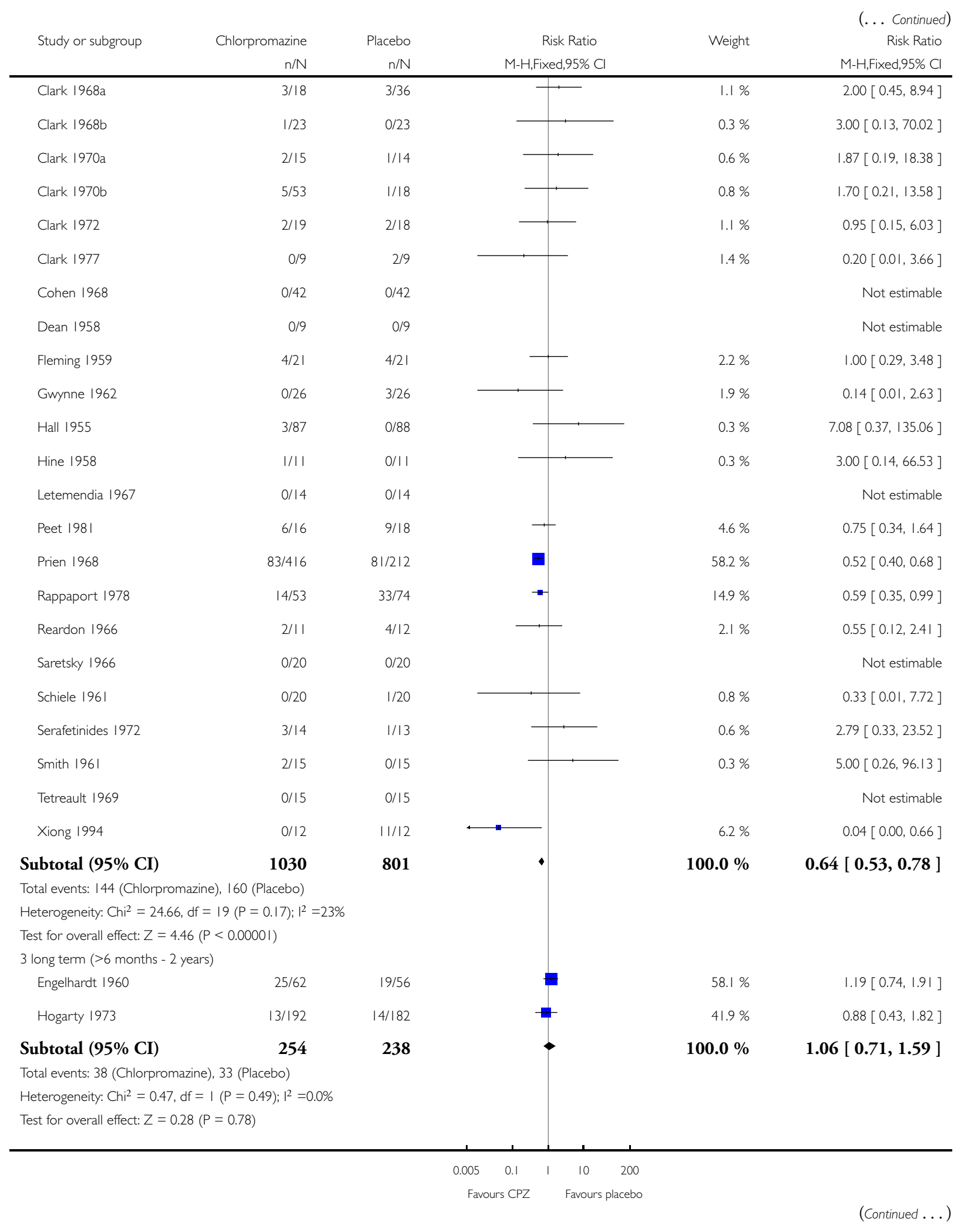

Chlorpromazine versus placebo for schizophrenia (Review) 


\begin{tabular}{|c|c|c|c|c|c|c|}
\hline \multirow[t]{2}{*}{ Study or subgroup } & Chlorpromazine & Placebo & \multicolumn{2}{|r|}{ Risk Ratio } & Weight & $\begin{array}{c}\text { (... Continued) } \\
\text { Risk Ratio }\end{array}$ \\
\hline & $\mathrm{n} / \mathrm{N}$ & $\mathrm{n} / \mathrm{N}$ & \multicolumn{2}{|r|}{ M-H,Fixed,95\% Cl } & & M-H,Fixed,95\% Cl \\
\hline \multicolumn{7}{|l|}{$4>2-5$ years } \\
\hline Hogarty 1973 & $13 / 192$ & $18 / 182$ & & 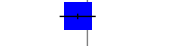 & $100.0 \%$ & $0.68[0.35,1.36]$ \\
\hline Subtotal $(95 \% \mathrm{CI})$ & 192 & 182 & & - & $100.0 \%$ & $0.68[0.35,1.36]$ \\
\hline \multicolumn{7}{|c|}{ Total events: 13 (Chlorpromazine), 18 (Placebo) } \\
\hline \multicolumn{7}{|c|}{ Heterogeneity: not applicable } \\
\hline \multicolumn{7}{|c|}{ Test for overall effect: $Z=1.09(P=0.28)$} \\
\hline & & & 0.005 & 10 & 200 & \\
\hline & & & Favo & Favours & acebo & \\
\hline
\end{tabular}

Analysis I.9. Comparison I CHLORPROMAZINE versus PLACEBO, Outcome 9 Mental state: I. Improved - short term (BPRS, $50 \%$ change).

Review: Chlorpromazine versus placebo for schizophrenia

Comparison: I CHLORPROMAZINE versus PLACEBO

Outcome: 9 Mental state: I. Improved - short term (BPRS, 50\% change)

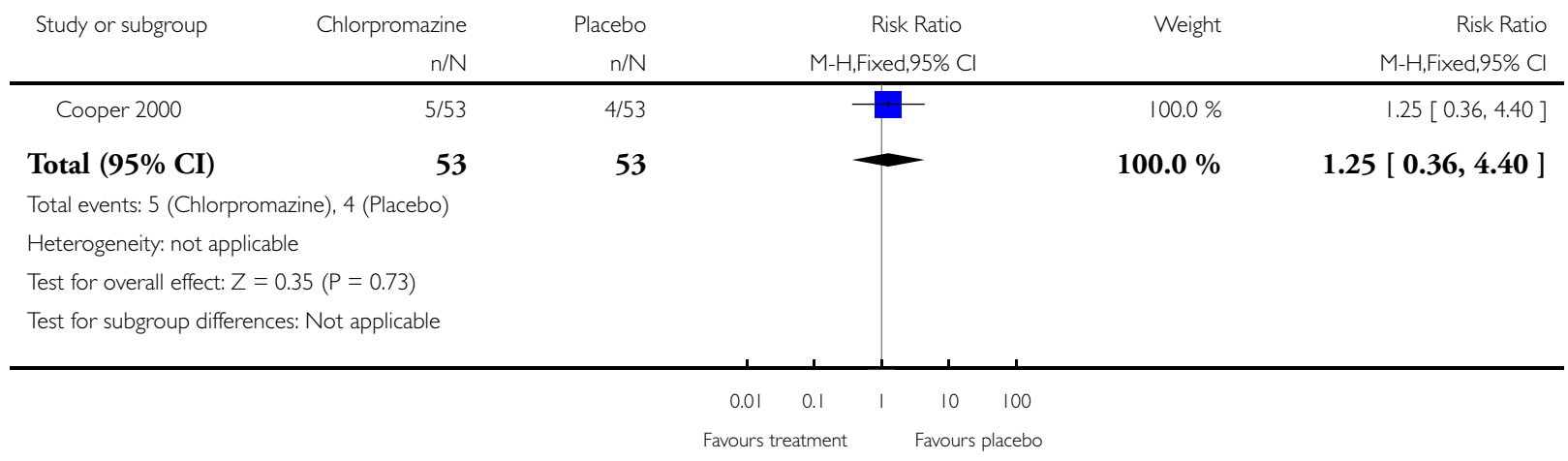




\section{Analysis I.10. Comparison I CHLORPROMAZINE versus PLACEBO, Outcome I0 Mental state: 2. Average}

endpoint scores (BPRS, high score=worse).

Review: Chlorpromazine versus placebo for schizophrenia

Comparison: I CHLORPROMAZINE versus PLACEBO

Outcome: 10 Mental state: 2. Average endpoint scores (BPRS, high score=worse)

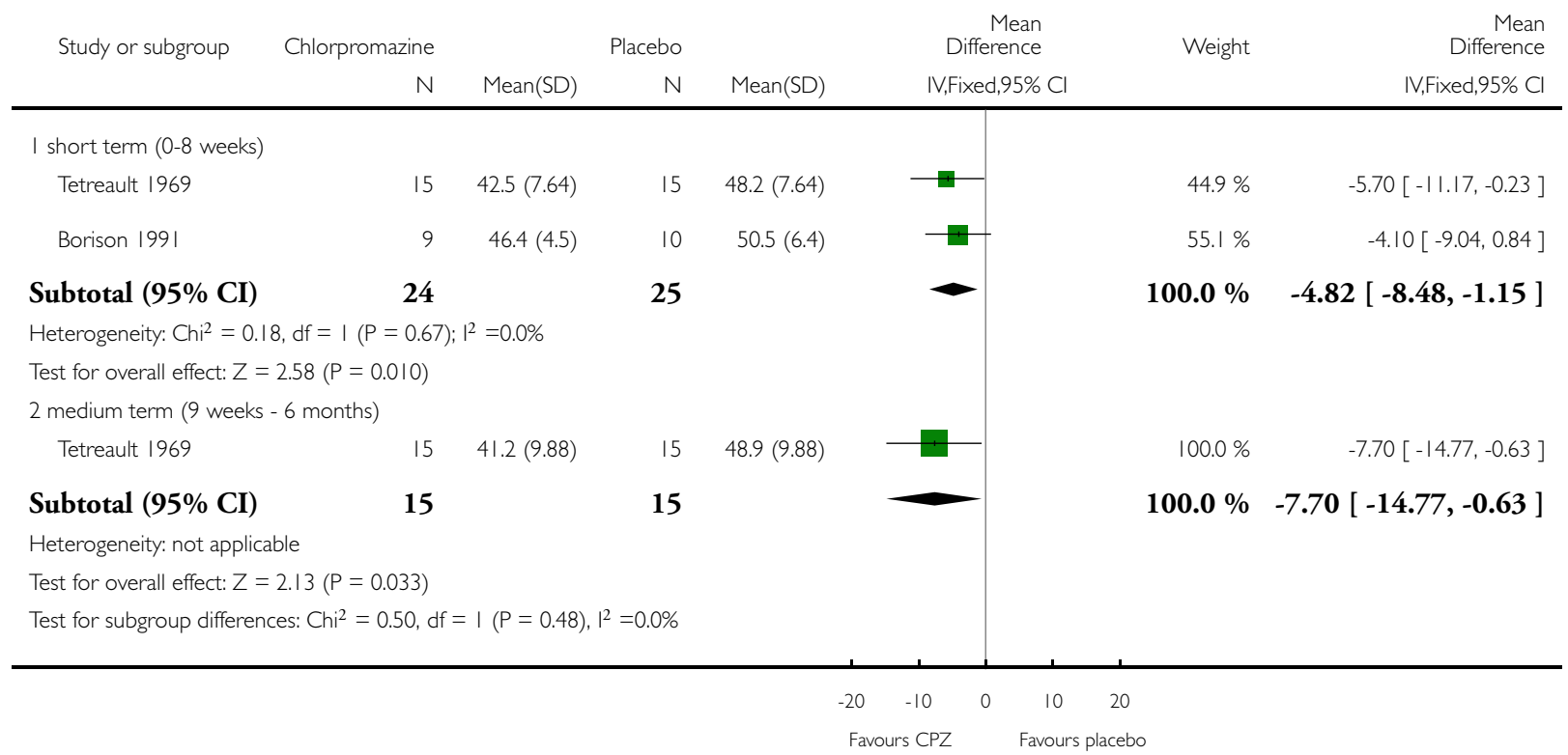


Analysis I.II. Comparison I CHLORPROMAZINE versus PLACEBO, Outcome I I Behaviour: I. Deteriorated/ disturbed/un-cooperative.

Review: Chlorpromazine versus placebo for schizophrenia

Comparison: I CHLORPROMAZINE versus PLACEBO

Outcome: II Behaviour: I. Deteriorated/ disturbed/un-cooperative

Risk Ratio

H.Random- $95 \%$

Weight

Risk Ratio

H,Random,95\%

$n / N \quad n / N$

Cl

I short term - (0-8 weeks)

Chouinard 1990

|4/2|

$16 / 21$

Somerville 1960

$5 / 15$

$22 / 30$

r-

Subtotal (95\% CI)

36

51

Total events: 19 (Chlorpromazine), 38 (Placebo)

Heterogeneity: $\operatorname{Tau}^{2}=0.17 ; \mathrm{Chi}^{2}=2.83, \mathrm{df}=\mathrm{I}(\mathrm{P}=0.09) ; \mathrm{I}^{2}=65 \%$

Test for overall effect: $Z=1.12(P=0.26)$

2 medium term ( 9 weeks -6 months)

Clark 1970 a

$2 / 15$

Clark $1970 b$

$10 / 53$

Fleming 1959

$5 / 21$

Hall 1955

$65 / 87$

Prien 1968

Schiele 1961

$37 / 416$

Serafetinides 1972

0/20

$6 / 14$

$4 / 13$

639

$5 \quad 5 / 14$

Smith 1961

$6 / 18$

$13 / 2 \mid$

$70 / 88$

$70 / 212$

$12 / 20$

$3 / 13$

$10 / 15$

Subtotal (95\% CI)

Total events: 129 (Chlorpromazine), 189 (Placebo)

401

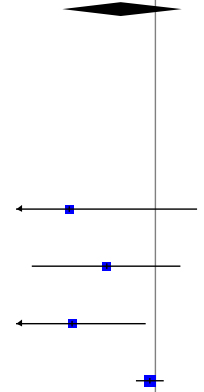

$9.8 \%$

$0.37[0.09,1.62]$

$13.6 \%$

$13.7 \%$

$16.8 \%$

$16.2 \%$

$4.8 \%$

$11.7 \%$

$13.4 \%$

$100.0 \%$

Heterogeneity: $\mathrm{Tau}^{2}=0.78 ; \mathrm{Chi}^{2}=70.98, \mathrm{df}=7(\mathrm{P}<0.0000 \mathrm{I}) ; \mathrm{I}^{2}=90 \%$

Test for overall effect: $Z=1.97(P=0.049)$ 
Analysis I.12. Comparison I CHLORPROMAZINE versus PLACEBO, Outcome I2 Behaviour: 2. Unchanged.

\begin{tabular}{|c|c|c|c|c|c|}
\hline \multicolumn{6}{|c|}{ Comparison: I CHLORPROMAZINE versus PLACEBO } \\
\hline \multicolumn{6}{|c|}{ Outcome: 12 Behaviour: 2. Unchanged } \\
\hline \multirow[t]{2}{*}{ Study or subgroup } & Chlorpromazine & Placebo & Risk Ratio & Weight & Risk Ratio \\
\hline & $\mathrm{n} / \mathrm{N}$ & $\mathrm{n} / \mathrm{N}$ & M-H,Fixed,95\% Cl & & M-H,Fixed,95\% Cl \\
\hline \multicolumn{6}{|l|}{ I short term (0-8 weeks) } \\
\hline Schiele 1961 & $5 / 20$ & $8 / 20$ & & $100.0 \%$ & $0.63[0.25,1.58]$ \\
\hline Subtotal $(95 \% \mathrm{CI})$ & 20 & 20 & & $100.0 \%$ & $0.63[0.25,1.58]$ \\
\hline \multicolumn{6}{|c|}{ Total events: 5 (Chlorpromazine), 8 (Placebo) } \\
\hline \multicolumn{6}{|c|}{ Heterogeneity: not applicable } \\
\hline \multicolumn{6}{|c|}{ Test for overall effect: $Z=0.99(P=0.32)$} \\
\hline \multicolumn{6}{|c|}{2 medium term ( 9 weeks -6 months) } \\
\hline Schiele 1961 & $6 / 20$ & $8 / 20$ & & $63.3 \%$ & $0.75[0.32,1.77]$ \\
\hline Smith 1961 & $8 / 13$ & $5 / 15$ & + & $36.7 \%$ & $1.85[0.80,4.25]$ \\
\hline Subtotal (95\% CI) & 33 & 35 & - & $100.0 \%$ & $1.15[0.64,2.07]$ \\
\hline \multicolumn{6}{|c|}{ Total events: 14 (Chlorpromazine), I3 (Placebo) } \\
\hline \multicolumn{6}{|c|}{ Heterogeneity: $\mathrm{Ch}^{2}=2.19, \mathrm{df}=1(P=0.14) ;\left.\right|^{2}=54 \%$} \\
\hline \multicolumn{6}{|c|}{ Test for overall effect: $Z=0.48(P=0.63)$} \\
\hline
\end{tabular}


Analysis I.13. Comparison I CHLORPROMAZINE versus PLACEBO, Outcome I3 Behaviour: 3. Average endpoint scores (RRS, high score=worse).

Review: Chlorpromazine versus placebo for schizophrenia

Comparison: I CHLORPROMAZINE versus PLACEBO

Outcome: 13 Behaviour: 3. Average endpoint scores (RRS, high score=worse)

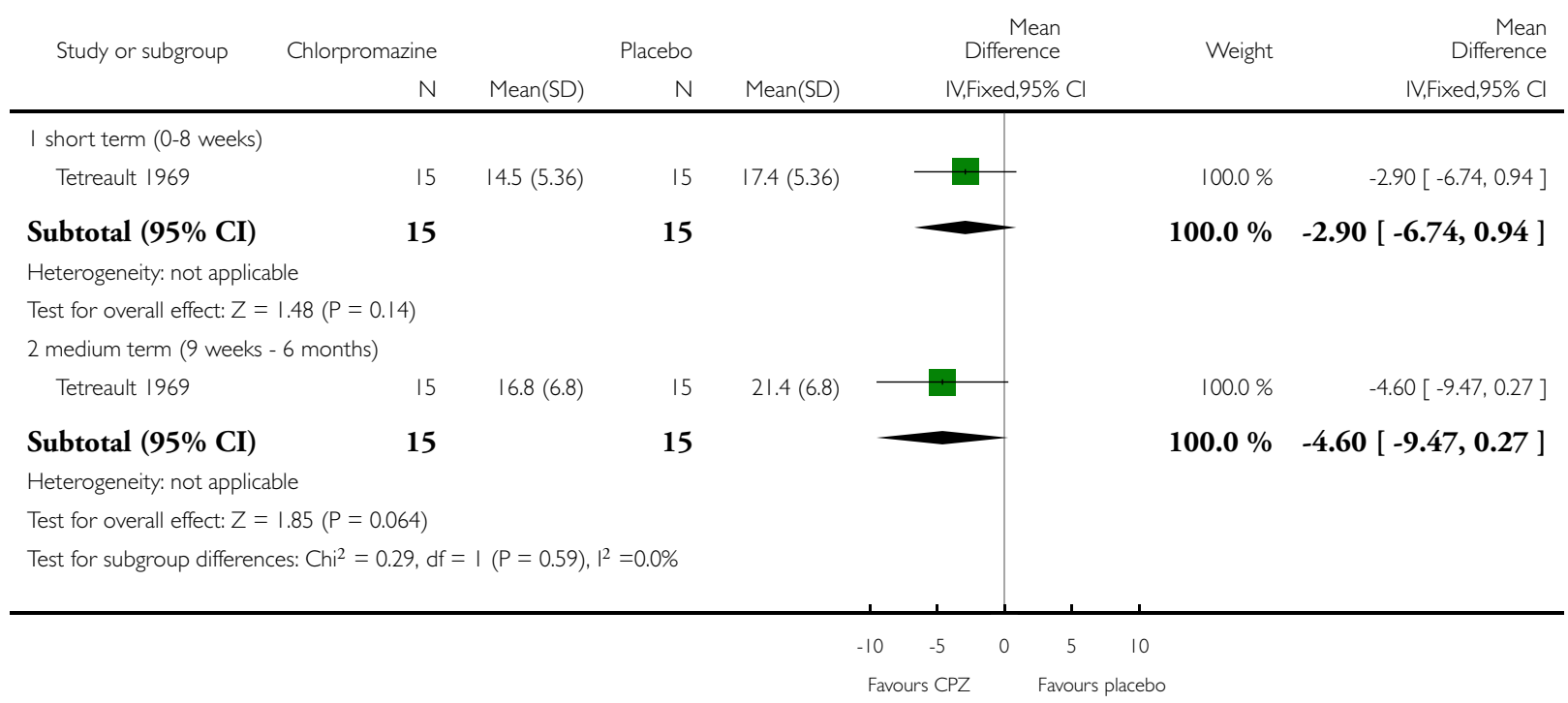


Analysis I.14. Comparison I CHLORPROMAZINE versus PLACEBO, Outcome I4 Behaviour: 4. Average endpoint score - short term (PBRS, high score=good).

Review: Chlorpromazine versus placebo for schizophrenia

Comparison: I CHLORPROMAZINE versus PLACEBO

Outcome: 14 Behaviour: 4. Average endpoint score - short term (PBRS, high score=good)

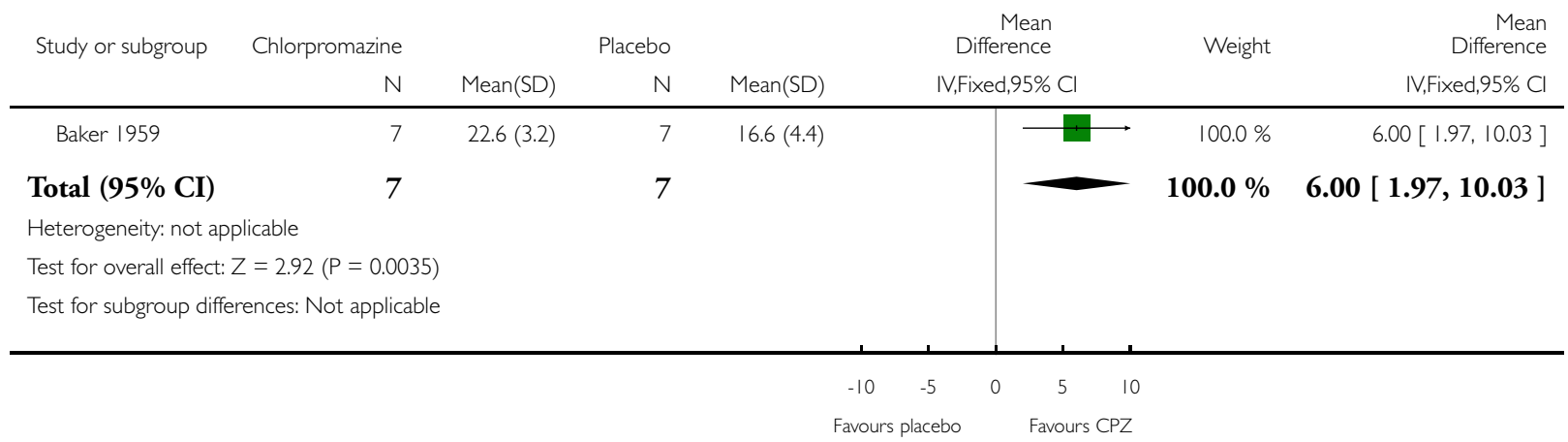

Analysis I.I5. Comparison I CHLORPROMAZINE versus PLACEBO, Outcome I5 Behaviour: 5. Average endpoint scores - medium term (Fergus Falls Behavioural rating scale).

Review: Chlorpromazine versus placebo for schizophrenia

Comparison: I CHLORPROMAZINE versus PLACEBO

Outcome: 15 Behaviour: 5. Average endpoint scores - medium term (Fergus Falls Behavioural rating scale)

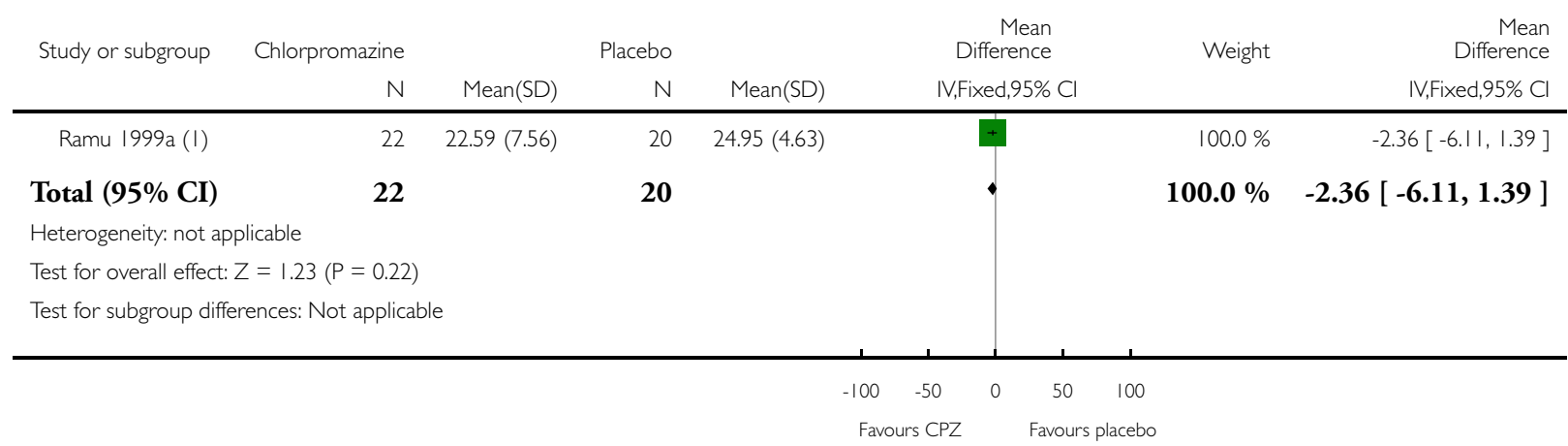

(I) N not reported, assumed to be the number reported in each group after losses to follow-up. 
Analysis I.16. Comparison I CHLORPROMAZINE versus PLACEBO, Outcome I6 Adverse effects: I. Movement disorders.

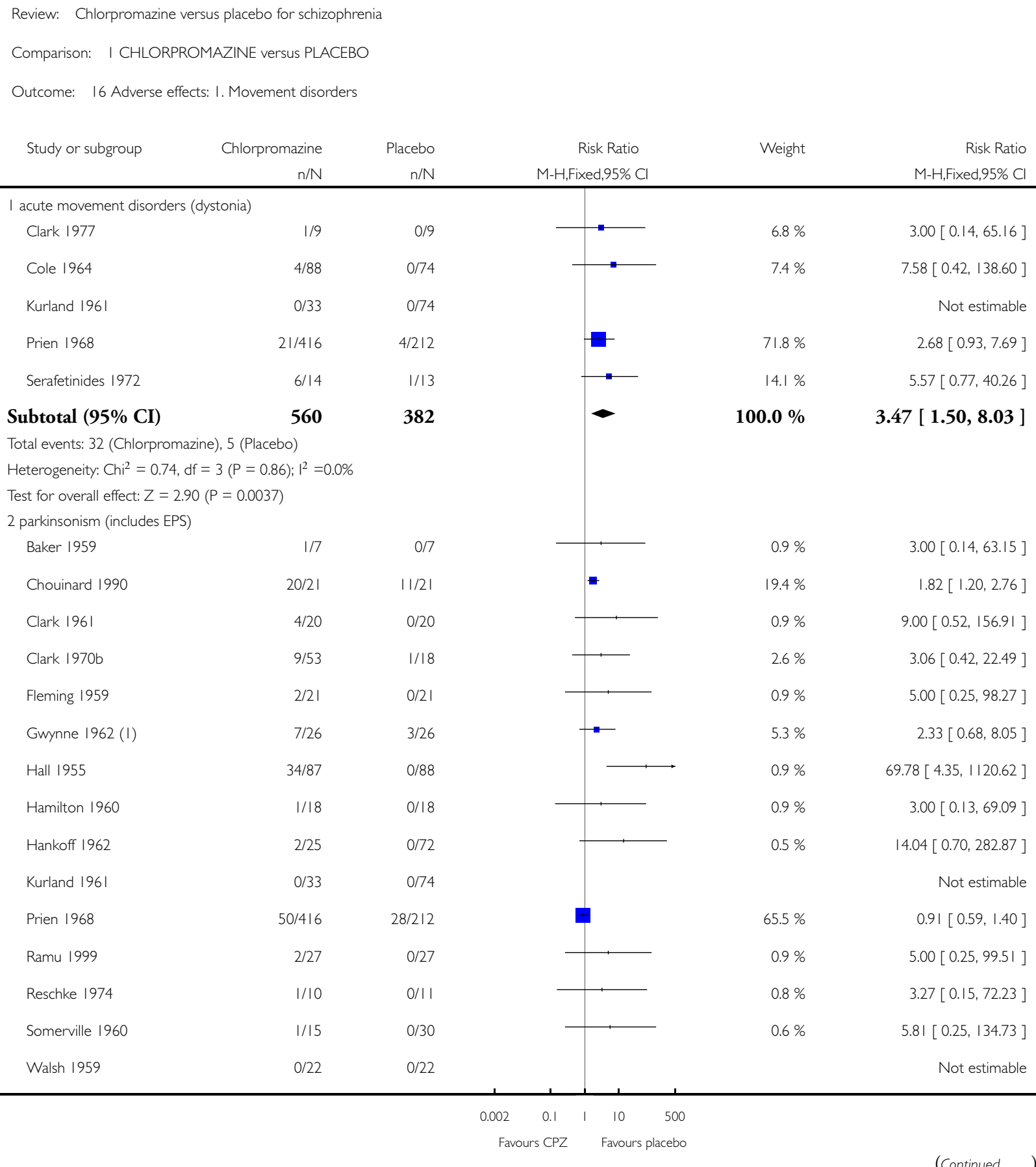

(Continued...) 


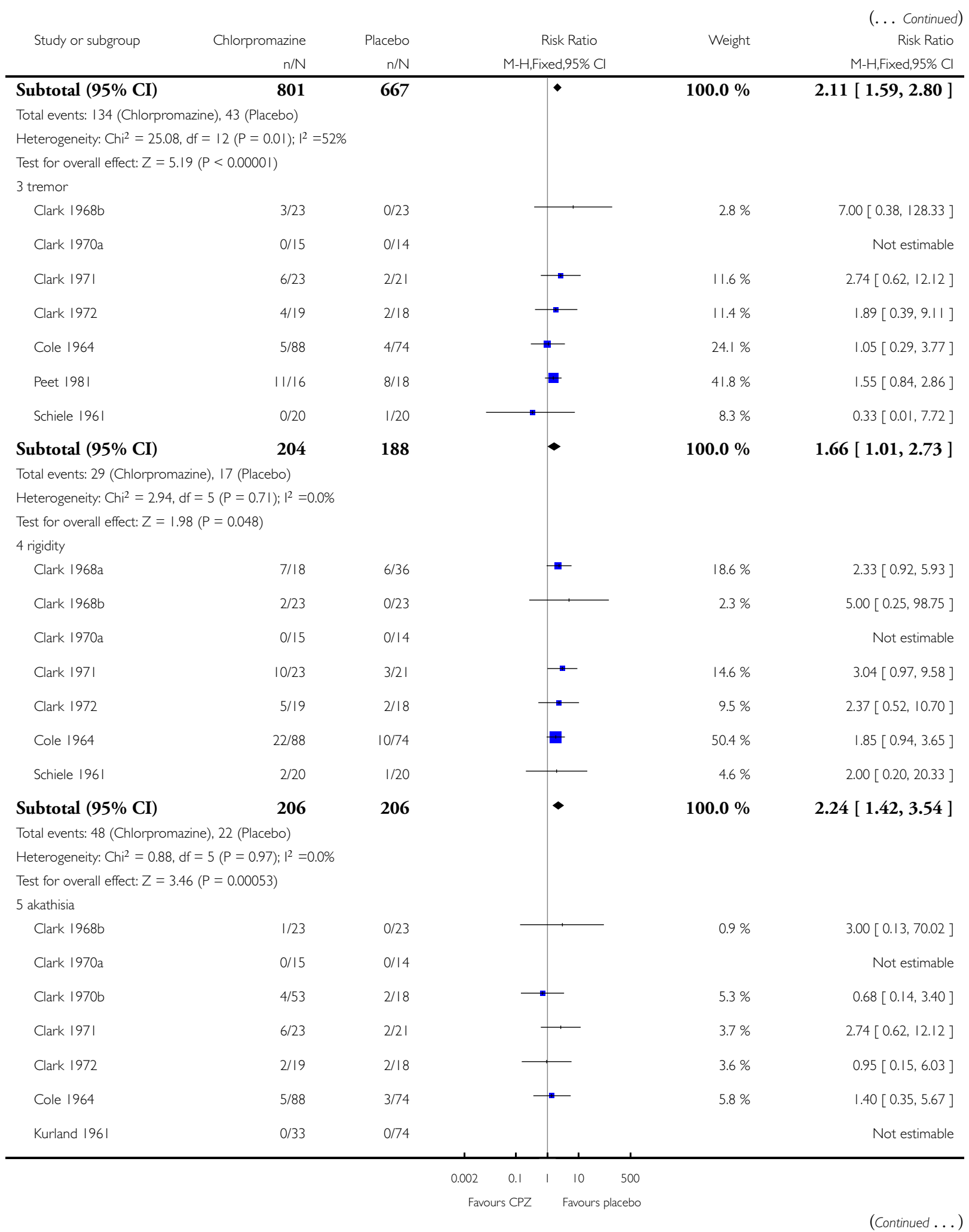

Chlorpromazine versus placebo for schizophrenia (Review)

Copyright $\odot 2015$ The Cochrane Collaboration. Published by John Wiley \& Sons, Ltd. 


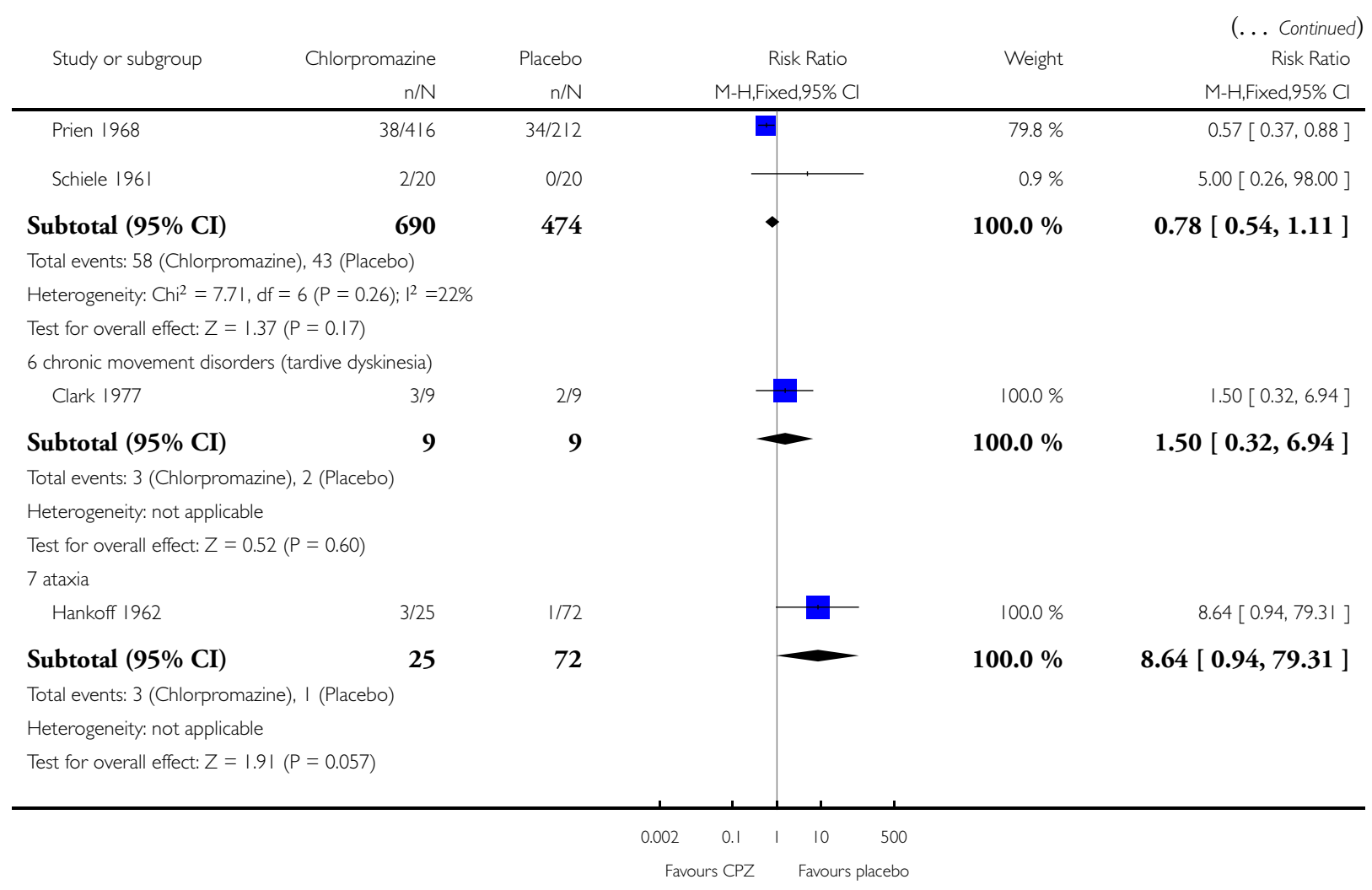

(I) N not reported, assumed to be $\mathrm{N}$ randomised. 
Analysis I.I7. Comparison I CHLORPROMAZINE versus PLACEBO, Outcome I7 Adverse effects: 2. Movement disorders: Average endpoint scores (Extrapyramidal Bilan, high score=worse).

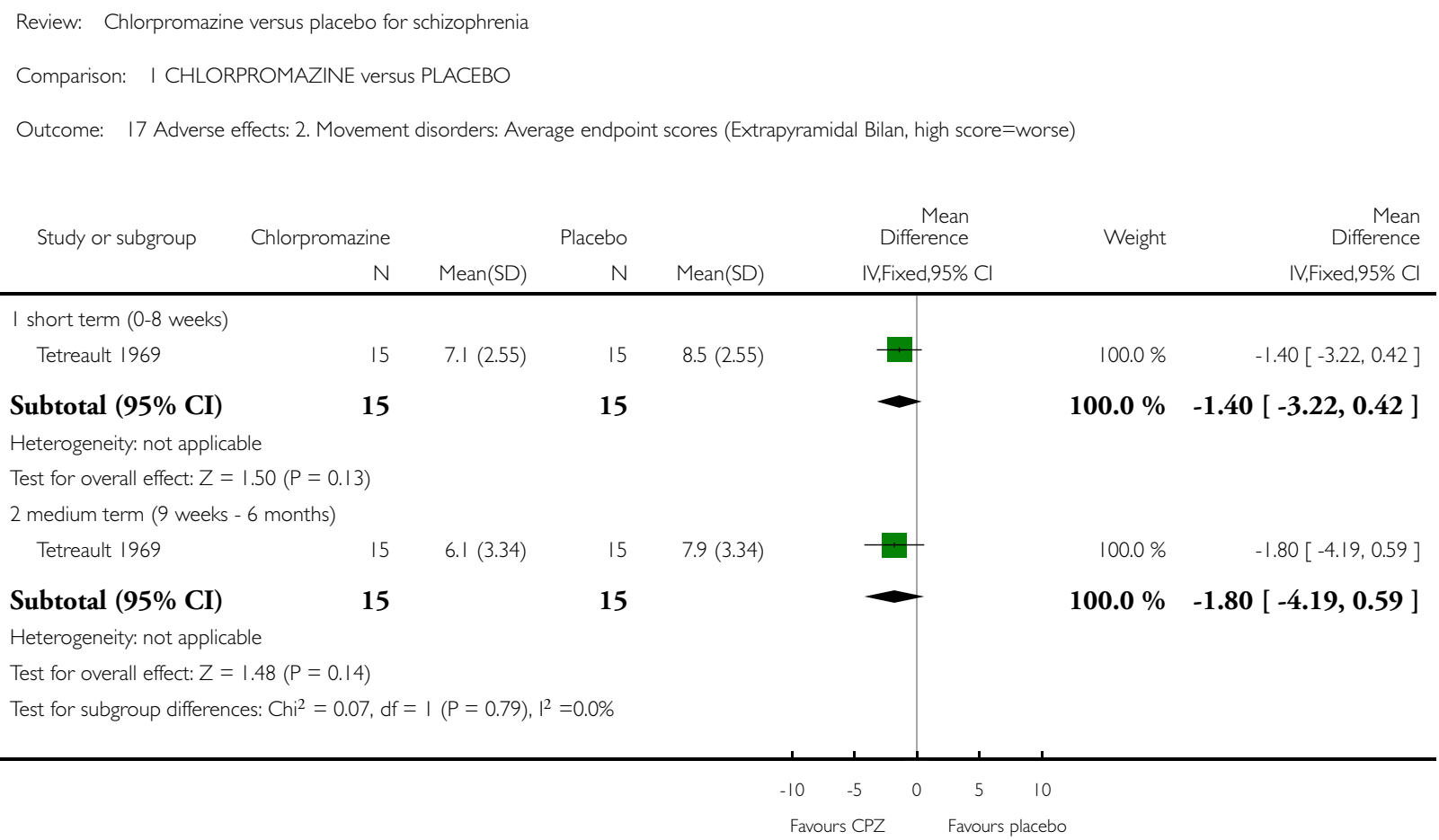


Analysis I.I8. Comparison I CHLORPROMAZINE versus PLACEBO, Outcome I 8 Adverse effects: I. Central nervous system.

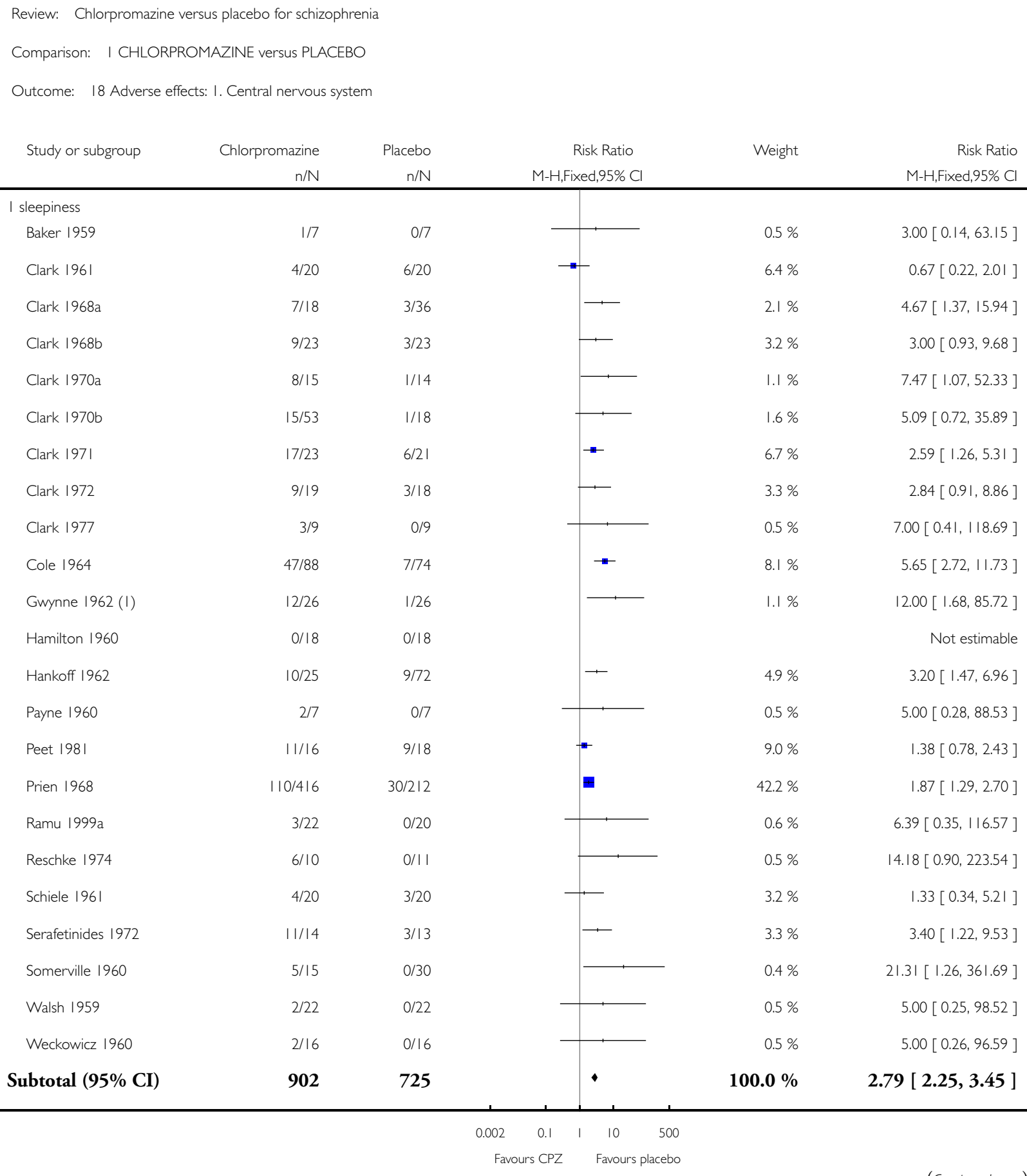

(Continued....) 


\begin{tabular}{|c|c|c|c|c|c|c|c|c|}
\hline \multirow[t]{2}{*}{ Study or subgroup } & Chlorpromazine & Placebo & \multicolumn{4}{|c|}{ Risk Ratio } & Weight & $\begin{array}{c}\text { (... Continued) } \\
\text { Risk Ratio }\end{array}$ \\
\hline & $\mathrm{n} / \mathrm{N}$ & $\mathrm{n} / \mathrm{N}$ & \multicolumn{4}{|c|}{ M-H,Fixed,95\% Cl } & & M-H,Fixed,95\% Cl \\
\hline \multicolumn{9}{|c|}{ Total events: 298 (Chlorpromazine), 85 (Placebo) } \\
\hline \multicolumn{9}{|c|}{ Heterogeneity: $\mathrm{Ch}^{2}=30.61, \mathrm{df}=21 \quad(P=0.08) ; 1^{2}=31 \%$} \\
\hline \multicolumn{9}{|c|}{ Test for overall effect: $Z=9.45(P<0.0000 \mathrm{I})$} \\
\hline \multicolumn{9}{|c|}{2 fits / loss of consciousness } \\
\hline Clark 1972 & $2 / 19$ & $3 / 18$ & & & & & $65.0 \%$ & $0.63[0.12,3.35]$ \\
\hline Prien 1968 & $14 / 4 \mid 6$ & $0 / 212$ & & & $\square$ & & $14.0 \%$ & $|4.8|[0.89,247.12]$ \\
\hline Tetreault 1969 & $3 / 15$ & 1/15 & & & $\mp$ & & $21.1 \%$ & $3.00[0.35,25.68]$ \\
\hline Subtotal $(95 \% \mathrm{CI})$ & 450 & 245 & & & - & & $100.0 \%$ & $3.11[1.05,9.18]$ \\
\hline \multicolumn{9}{|c|}{ Total events: 19 (Chlorpromazine), 4 (Placebo) } \\
\hline \multicolumn{9}{|c|}{ Heterogeneity: $\mathrm{Chi}^{2}=4.69, \mathrm{df}=2(\mathrm{P}=0.10) ; 1^{2}=57 \%$} \\
\hline \multicolumn{9}{|c|}{ Test for overall effect: $Z=2.05(P=0.040)$} \\
\hline \multicolumn{9}{|c|}{3 weakness } \\
\hline Hine 1958 & $1 / 11$ & $0 / 11$ & & & 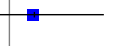 & & $16.7 \%$ & $3.00[0.14,66.53]$ \\
\hline Schiele 1961 & $1 / 20$ & 0/20 & & & $=$ & & $16.7 \%$ & $3.00[0.13,69.52]$ \\
\hline Tetreault 1969 & $7 / 15$ & 2/15 & & & + & & $66.7 \%$ & $3.50[0.86,14.18]$ \\
\hline Subtotal $(95 \% \mathrm{CI})$ & 46 & 46 & & & - & & $100.0 \%$ & $3.33[1.02,10.88]$ \\
\hline \multicolumn{9}{|c|}{ Total events: 9 (Chlorpromazine), 2 (Placebo) } \\
\hline \multicolumn{9}{|c|}{ Heterogeneity: $\mathrm{Chi}^{2}=0.0 \mathrm{I}, \mathrm{df}=2(\mathrm{P}=0.99) ; \mathrm{I}^{2}=0.0 \%$} \\
\hline \multicolumn{9}{|c|}{ Test for overall effect: $Z=1.99(P=0.046)$} \\
\hline \multicolumn{9}{|c|}{4 convulsions } \\
\hline Gwynne $1962(2)$ & $0 / 26$ & 1/26 & & & - & & $100.0 \%$ & $0.33[0.01,7.82]$ \\
\hline Subtotal $(95 \% \mathrm{CI})$ & 26 & 26 & & & 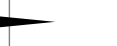 & & $100.0 \%$ & $0.33[0.01,7.82]$ \\
\hline \multicolumn{9}{|c|}{ Total events: 0 (Chlorpromazine), I (Placebo) } \\
\hline \multicolumn{9}{|c|}{ Heterogeneity: not applicable } \\
\hline \multicolumn{9}{|c|}{ Test for overall effect: $Z=0.68(P=0.50)$} \\
\hline & & & 0.002 & 0.1 & 10 & 500 & & \\
\hline & & & & irs $\mathrm{CPZ}$ & Favours pl & lacebo & & \\
\hline
\end{tabular}


Analysis I.19. Comparison I CHLORPROMAZINE versus PLACEBO, Outcome I9 Adverse effects: 3. Blood, skin, liver, eyes.

Review: Chlorpromazine versus placebo for schizophrenia

Comparison: I CHLORPROMAZINE versus PLACEBO

Outcome: 19 Adverse effects: 3. Blood, skin, liver, eyes

\begin{tabular}{|c|c|c|c|c|c|}
\hline \multirow[t]{2}{*}{ Study or subgroup } & Chlorpromazine & Placebo & \multirow{2}{*}{$\begin{array}{c}\text { Risk Ratio } \\
\text { M-H,Fixed,95\% Cl }\end{array}$} & \multirow[t]{2}{*}{ Weight } & \multirow{2}{*}{$\begin{array}{r}\text { Risk Ratio } \\
\text { M-H,Fixed,95\% Cl }\end{array}$} \\
\hline & $\mathrm{n} / \mathrm{N}$ & $\mathrm{n} / \mathrm{N}$ & & & \\
\hline \multicolumn{6}{|c|}{ I blood problems (agranulocytosis, leukopenia) } \\
\hline Clark 1961 & $1 / 20$ & $0 / 20$ & & $10.0 \%$ & $3.00[0.13,69.52]$ \\
\hline Clark 1968b & $1 / 23$ & $0 / 23$ & $\longrightarrow$ & $10.0 \%$ & $3.00[0.13,70.02]$ \\
\hline Clark 1970b & $4 / 53$ & $1 / 18$ & $\longrightarrow$ & $29.7 \%$ & $1.36[0.16,11.38]$ \\
\hline Fleming 1959 & $\mid / 21$ & $0 / 21$ & $=$ & $10.0 \%$ & $3.00[0.13,69.70]$ \\
\hline Kurland 196| & 1/33 & $0 / 74$ & $=$ & $6.2 \%$ & $6.62[0.28,158.32]$ \\
\hline Prien 1968 & $1 / 42$ & $0 / 16$ & $\rightarrow$ & $14.3 \%$ & $1.19[0.05,27.70]$ \\
\hline Tetreault 1969 & $1 / 15$ & 1/15 & $\longrightarrow$ & $19.9 \%$ & $1.00[0.07,14.55]$ \\
\hline Subtotal $(95 \%$ CI $)$ & 207 & 187 & - & $100.0 \%$ & $2.08[0.74,5.83]$ \\
\hline \multicolumn{6}{|c|}{ Total events: 10 (Chlorpromazine), 2 (Placebo) } \\
\hline \multicolumn{6}{|c|}{ Heterogeneity: $\mathrm{Ch}^{2}=1.23, \mathrm{df}=6(\mathrm{P}=0.98) ; \mathrm{I}^{2}=0.0 \%$} \\
\hline \multicolumn{6}{|c|}{ Test for overall effect: $Z=1.39(P=0.16)$} \\
\hline \multicolumn{6}{|c|}{2 rashes/itching/skin disorders } \\
\hline Clark 196| & 2/20 & $0 / 20$ & & $1.8 \%$ & $5.00[0.26,98.00]$ \\
\hline Clark 1968a & $4 / 18$ & $3 / 36$ & - & $7.1 \%$ & $2.67[0.67,10.66]$ \\
\hline Clark 1968b & $1 / 23$ & $0 / 23$ & & $1.8 \%$ & $3.00[0.13,70.02]$ \\
\hline Clark 1970b & $5 / 53$ & $1 / 18$ & $=$ & $5.3 \%$ & $1.70[0.21,13.58]$ \\
\hline Clark 197I & $4 / 23$ & $2 / 21$ & $\longrightarrow$ & $7.5 \%$ & $1.83[0.37,8.96]$ \\
\hline Clark 1972 & $4 / 19$ & $2 / 18$ & - & $7.3 \%$ & $1.89[0.39,9.11]$ \\
\hline Cole 1964 & $3 / 88$ & $2 / 74$ & $=$ & $7.8 \%$ & $1.26[0.22,7.35]$ \\
\hline Dean 1958 & 0/9 & $0 / 9$ & & & Not estimable \\
\hline Hine 1958 & $1 / 11$ & $0 / 11$ & & $1.8 \%$ & $3.00[0.14,66.53]$ \\
\hline Kurland 1961 & $2 / 33$ & $1 / 74$ & & $2.2 \%$ & $4.48[0.42,47.74]$ \\
\hline Prien 1968 & $17 / 416$ & $11 / 212$ & 畐 & $52.0 \%$ & $0.79[0.38,1.65]$ \\
\hline Schiele 1961 & $1 / 20$ & $1 / 20$ & 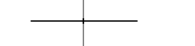 & $3.6 \%$ & $1.00[0.07,14.90]$ \\
\hline Walsh 1959 & $1 / 22$ & $0 / 22$ & $\longrightarrow$ & $1.8 \%$ & $3.00[0.13,69.87]$ \\
\hline Subtotal $(95 \%$ CI) & 755 & 558 & - & $100.0 \%$ & $1.45[0.92,2.29]$ \\
\hline
\end{tabular}

(Continued ...) 


\begin{tabular}{|c|c|c|c|c|c|}
\hline Study or subgroup & $\begin{array}{r}\text { Chlorpromazine } \\
n / N\end{array}$ & $\begin{array}{r}\text { Placebo } \\
\mathrm{n} / \mathrm{N} \\
\end{array}$ & $\begin{array}{c}\text { Risk Ratio } \\
\text { M-H,Fixed,95\% Cl }\end{array}$ & \multicolumn{2}{|r|}{$\begin{array}{c}\text { (... Continued) } \\
\text { Risk Ratio }\end{array}$} \\
\hline \multicolumn{6}{|c|}{ Total events: 45 (Chlorpromazine), 23 (Placebo) } \\
\hline \multicolumn{6}{|c|}{ Heterogeneity: $\mathrm{Chi}^{2}=5.83, \mathrm{df}=1|(P=0.88) ;|^{2}=0.0 \%$} \\
\hline \multicolumn{6}{|c|}{ Test for overall effect: $Z=1.59(P=0.11)$} \\
\hline \multicolumn{6}{|l|}{3 liver problems } \\
\hline Clark 1970a & $2 / 15$ & $0 / 14$ & + & $25.2 \%$ & $4.69[0.24,89.88]$ \\
\hline Dean 1958 & 0/9 & 0/9 & & & Not estimable \\
\hline Hall 1955 & $3 / 87$ & 0/88 & $\longrightarrow$ & $24.2 \%$ & $7.08[0.37,135.06]$ \\
\hline Serafetinides 1972 & $3 / 14$ & $1 / 13$ & - & $50.6 \%$ & $2.79[0.33,23.52]$ \\
\hline Subtotal $(95 \% \mathrm{CI})$ & 125 & 124 & - & $100.0 \%$ & $4.31[0.98,18.95]$ \\
\hline \multicolumn{6}{|c|}{ Total events: 8 (Chlorpromazine), I (Placebo) } \\
\hline \multicolumn{6}{|c|}{ Heterogeneity: Chi $^{2}=0.27, d f=2(P=0.87) ; I^{2}=0.0 \%$} \\
\hline \multicolumn{6}{|c|}{ Test for overall effect: $Z=1.93(P=0.053)$} \\
\hline \multicolumn{6}{|c|}{4 photosensitivity } \\
\hline Clark 197I & $7 / 23$ & $2 / 21$ & - & $18.5 \%$ & $3.20[0.75,13.70]$ \\
\hline Clark 1972 & $8 / 19$ & $2 / 18$ & - & $18.1 \%$ & $3.79[0.93,15.51]$ \\
\hline Clark 1977 & $1 / 9$ & $0 / 9$ & + & $4.4 \%$ & $3.00[0.14,65.16]$ \\
\hline Prien 1968 & $50 / 416$ & $4 / 212$ & + & $46.8 \%$ & $6.37[2.33,17.40]$ \\
\hline Serafetinides 1972 & $5 / 14$ & $1 / 13$ & $\because$ & $9.2 \%$ & $4.64[0.62,34.65]$ \\
\hline Somerville 1960 & $10 / 15$ & 0/30 & $\longrightarrow$ & $3.0 \%$ & $40.69[2.54,650.71]$ \\
\hline Subtotal (95\% CI) & 496 & 303 & $\bullet$ & $100.0 \%$ & $6.04[3.22,11.32]$ \\
\hline \multicolumn{6}{|c|}{ Total events: 81 (Chlorpromazine), 9 (Placebo) } \\
\hline \multicolumn{6}{|c|}{ Heterogeneity: $\mathrm{Ch}^{2} \mathrm{I}^{2}=3.25, \mathrm{df}=5(\mathrm{P}=0.66) ; \mathrm{I}^{2}=0.0 \%$} \\
\hline \multicolumn{6}{|c|}{ Test for overall effect: $Z=5.6 \mathrm{I}(P<0.0000 \mathrm{I})$} \\
\hline \multicolumn{6}{|c|}{5 eye opacity / eye pigment problems } \\
\hline Clark 1970a & $0 / 15$ & $0 / 14$ & & & Not estimable \\
\hline Prien 1968 & $97 / 416$ & $16 / 212$ & $\square$ & $100.0 \%$ & $3.09[1.87,5.11]$ \\
\hline Subtotal $(95 \% \mathrm{CI})$ & 431 & 226 & $\bullet$ & $100.0 \%$ & $3.09[1.87,5.11]$ \\
\hline \multicolumn{6}{|c|}{ Total events: 97 (Chlorpromazine), 16 (Placebo) } \\
\hline \multicolumn{6}{|c|}{ Heterogeneity: not applicable } \\
\hline Test for overall effect: $Z=$ & $P=0.000011)$ & & & & \\
\hline
\end{tabular}


Analysis I.20. Comparison I CHLORPROMAZINE versus PLACEBO, Outcome 20 Adverse effects: 4. Other.

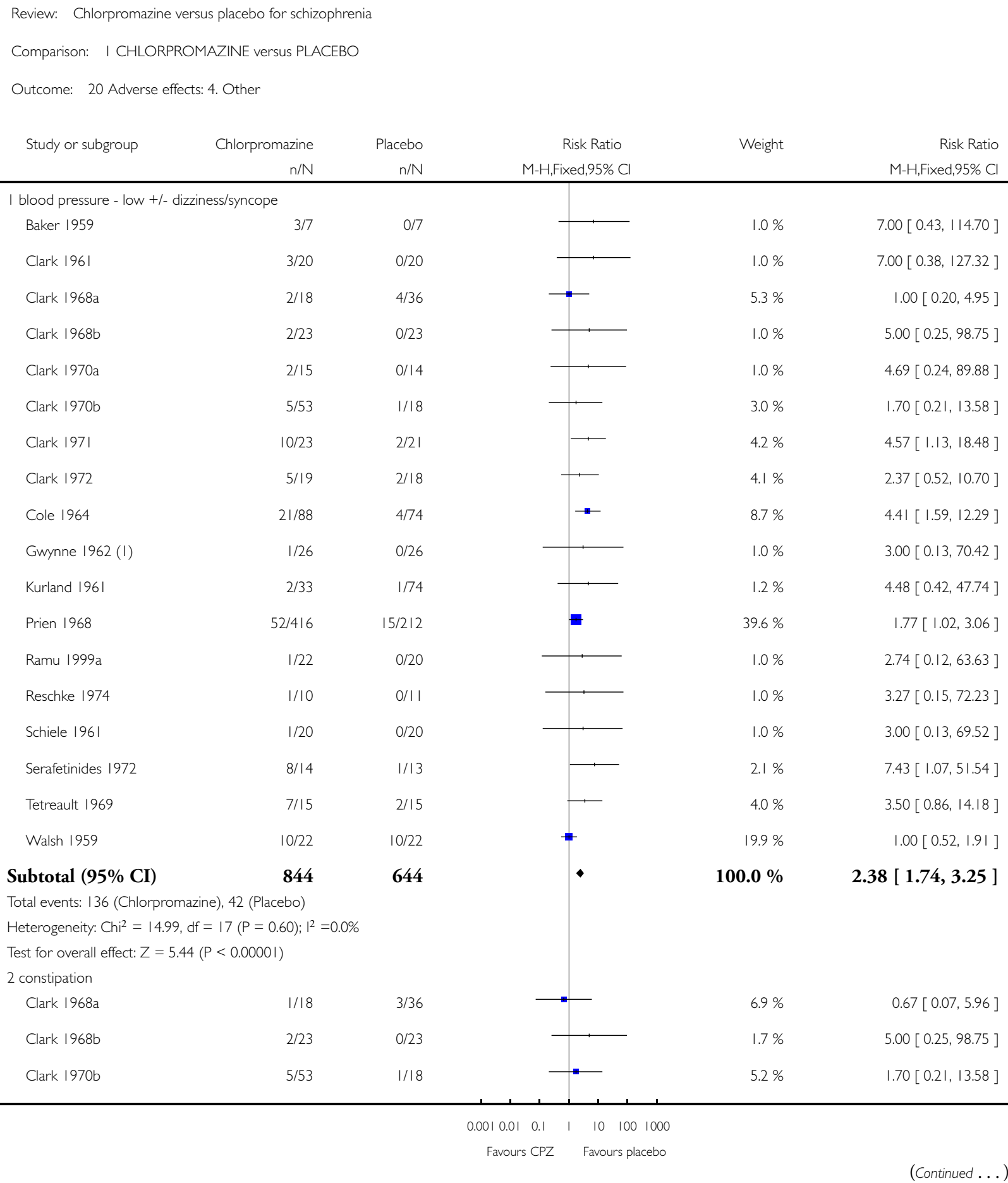




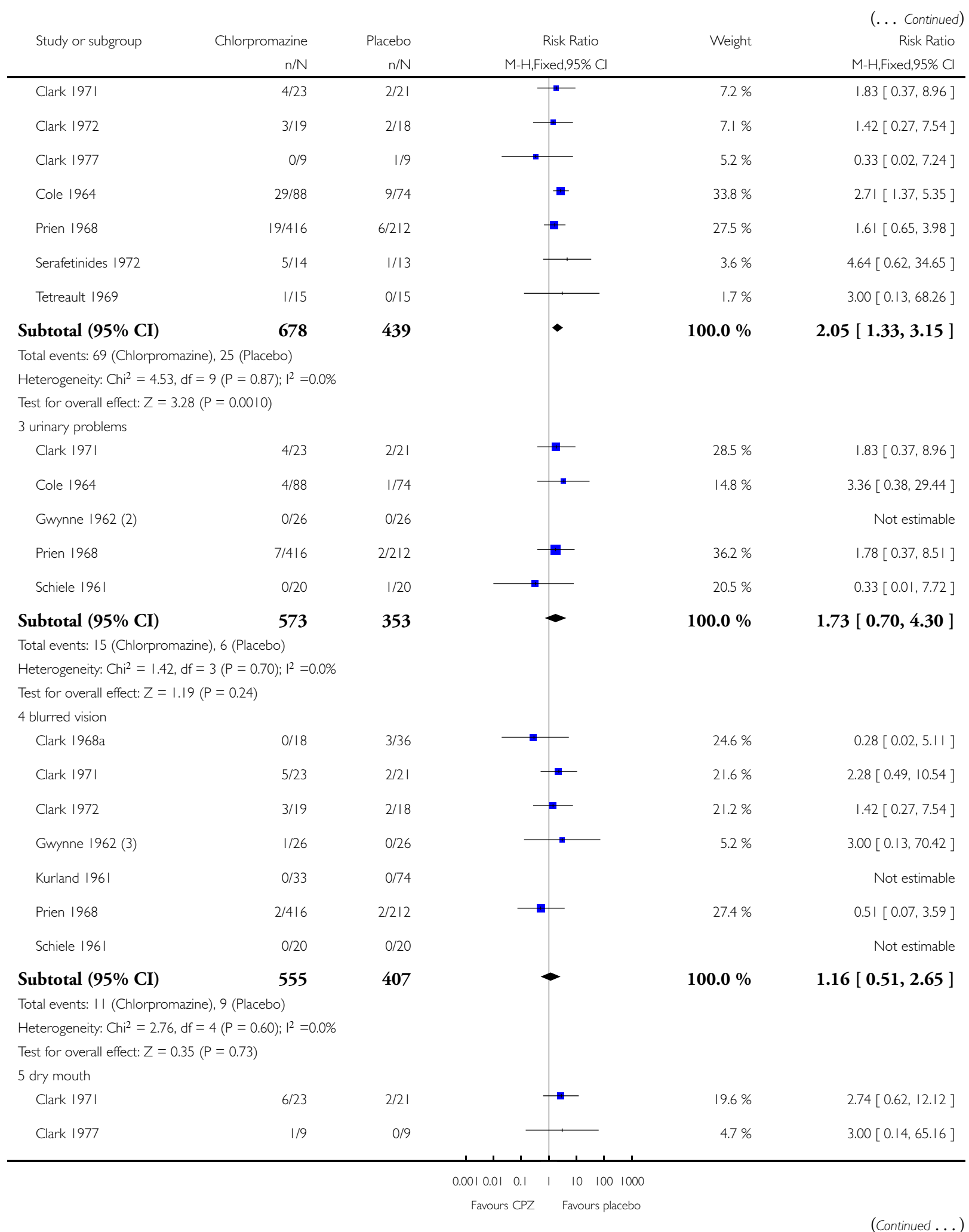

Chlorpromazine versus placebo for schizophrenia (Review)

Copyright () 2015 The Cochrane Collaboration. Published by John Wiley \& Sons, Ltd. 


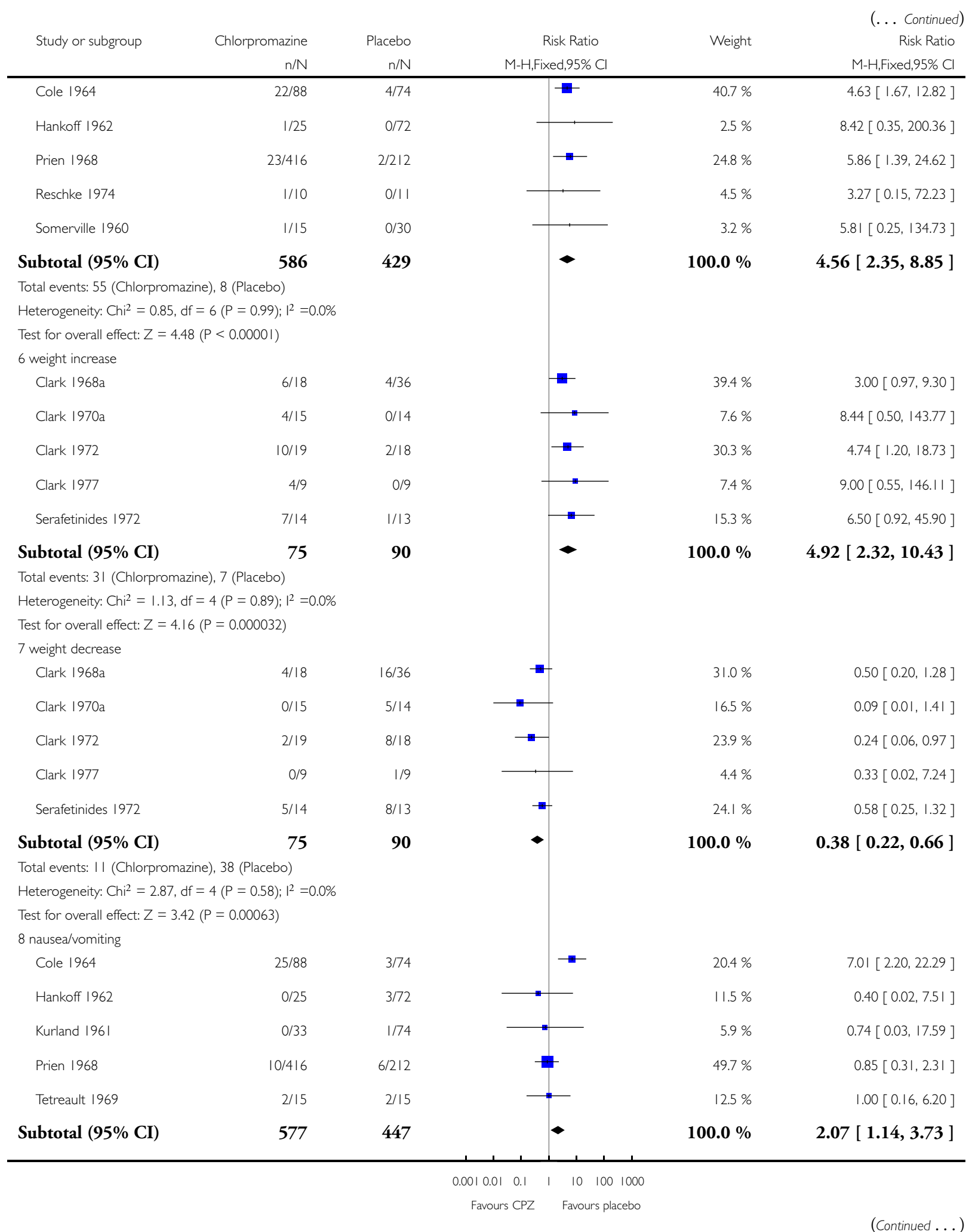




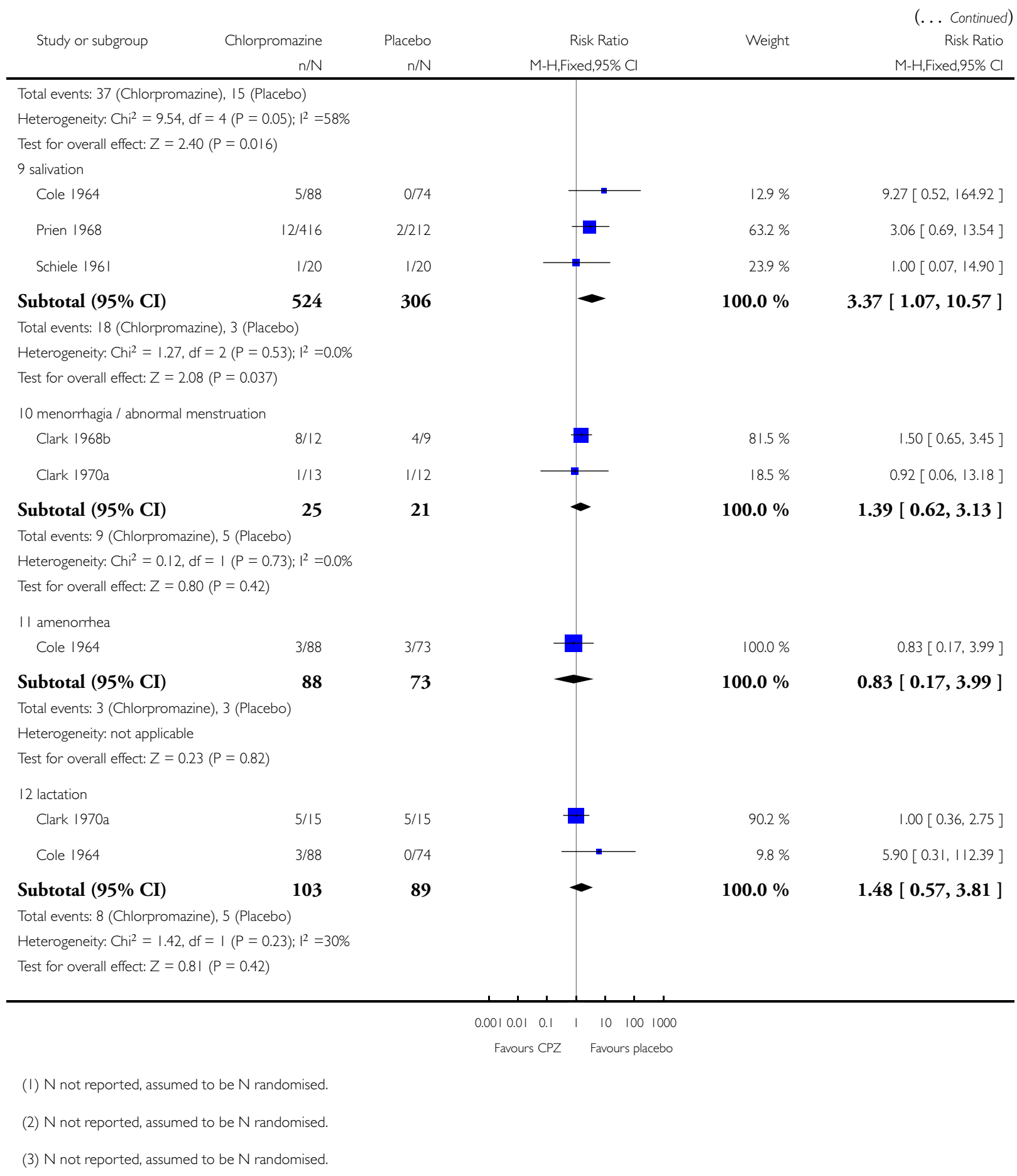




\section{Analysis I.2I. Comparison I CHLORPROMAZINE versus PLACEBO, Outcome 2 I SUBGROUP}

ANALYSIS: I. MEN vs WOMEN: Behaviour: Deteriorated/disturbed/un-cooperative.

Review: Chlorpromazine versus placebo for schizophrenia

Comparison: I CHLORPROMAZINE versus PLACEBO

Outcome: 2 I SUBGROUP ANALYSIS: I. MEN vs WOMEN: Behaviour: Deteriorated/disturbed/un-cooperative

Study or subgroup Chlorpromazine Placebo Risk Ratio Risk Ratio

\section{I only men}

Schiele 1961

$0 / 20$

12/20

$+2$

Subtotal (95\% CI)

20

20

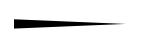

Total events: 0 (Chlorpromazine), 12 (Placebo)

Heterogeneity: not applicable

Test for overall effect: $Z=2.28(P=0.022)$

2 only women

$\begin{array}{ll}\text { Clark } 1970 b & \text { 10/53 } \\ \text { Fleming } 1959 & 5 / 21 \\ \text { Somerville } 1960 & 5 / 15\end{array}$

89

$\begin{array}{ll}10 / 53 & 6 / 18 \\ 5 / 21 & \mid 3 / 21\end{array}$

$6 / 18$

$3 / 21$

$22 / 30$

69

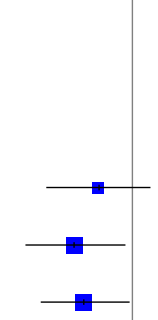

Subtotal (95\% CI)

89

Total events: 20 (Chlorpromazine), 4 I (Placebo)

Heterogeneity: $\mathrm{Chi}^{2}=0.40, \mathrm{df}=2(\mathrm{P}=0.82) ; \mathrm{I}^{2}=0.0 \%$

Test for overall effect: $Z=3.29(P=0.0010)$

Test for subgroup differences: $C^{2} i^{2}=2.91, d f=I(P=0.09),\left.\right|^{2}=66 \%$

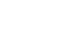

$100.0 \%$

$0.04[0.00,0.63]$

$100.0 \%$

$0.04[0.00,0.63]$

$24.5 \%$

$35.5 \%$

$0.57[0.24,1.34]$

$0.38[0.17,0.89]$

$40.0 \%$

$0.45[0.22,0.96]$ 


\section{Analysis I.22. Comparison I CHLORPROMAZINE versus PLACEBO, Outcome 22 SUBGROUP ANALYSIS: 2. ACUTE vS CHRONIC.}

Review: Chlorpromazine versus placebo for schizophrenia

Comparison: I CHLORPROMAZINE versus PLACEBO

Outcome: 22 SUBGROUP ANALYSIS: 2. ACUTE vs CHRONIC

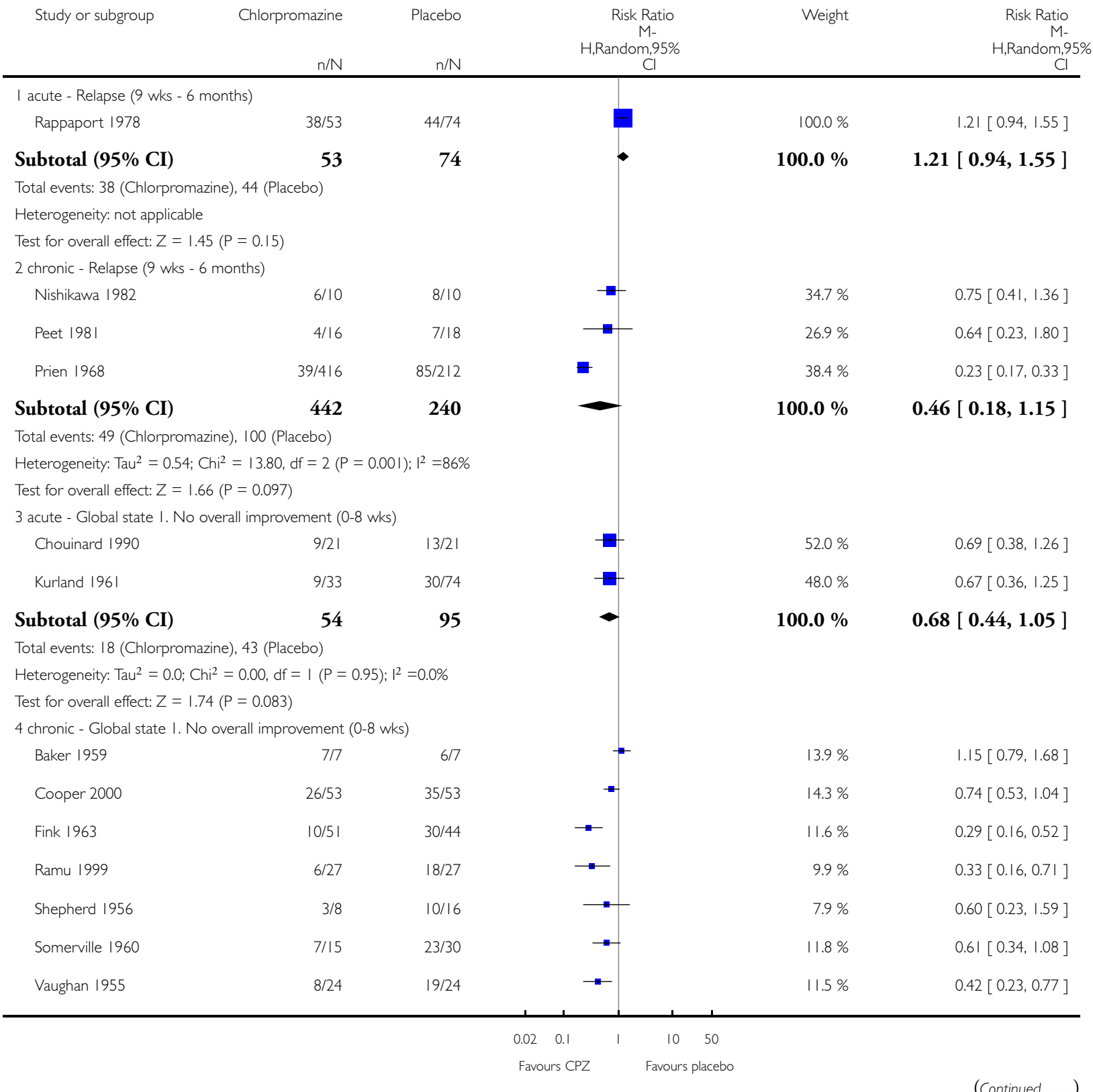




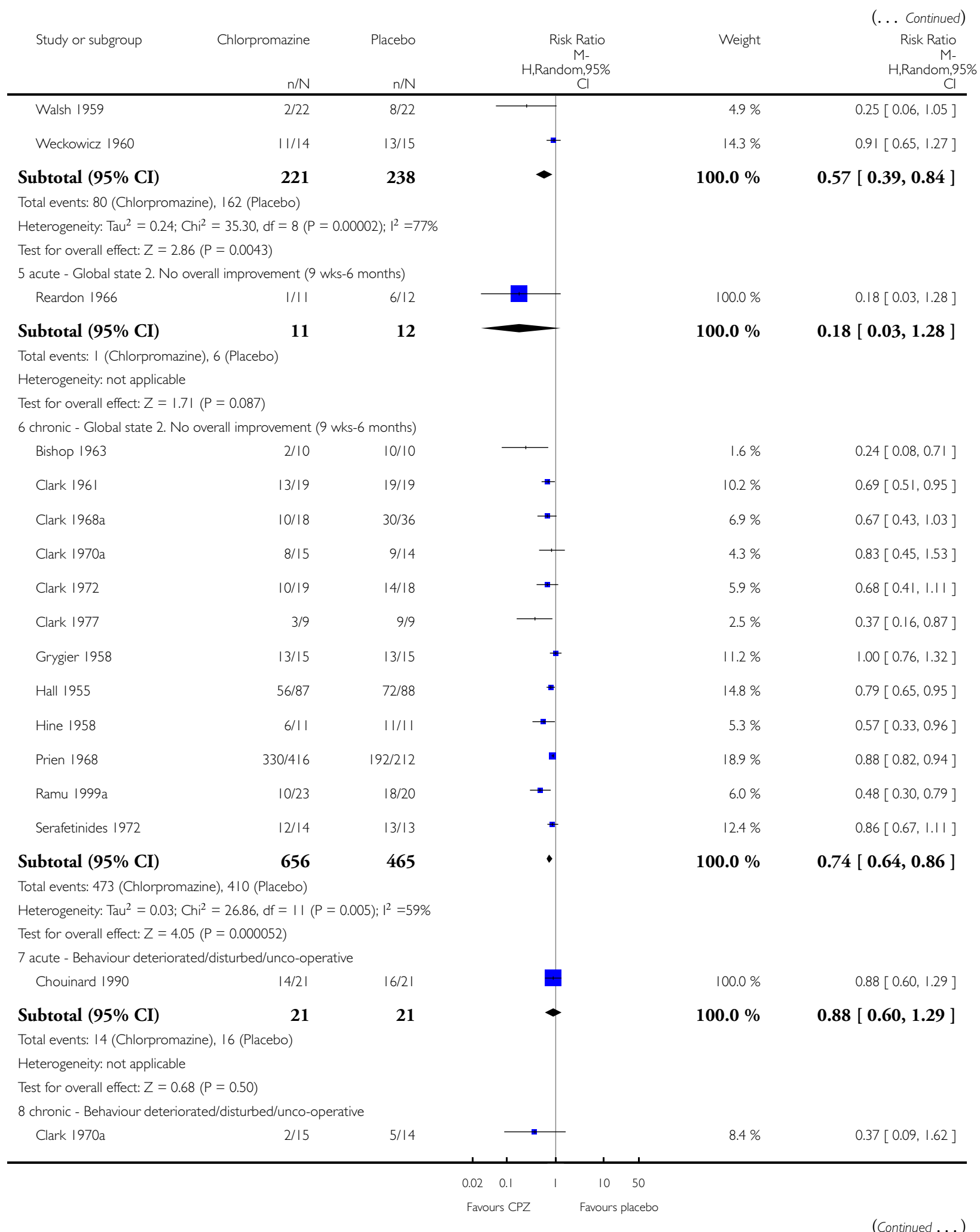

Chlorpromazine versus placebo for schizophrenia (Review) 


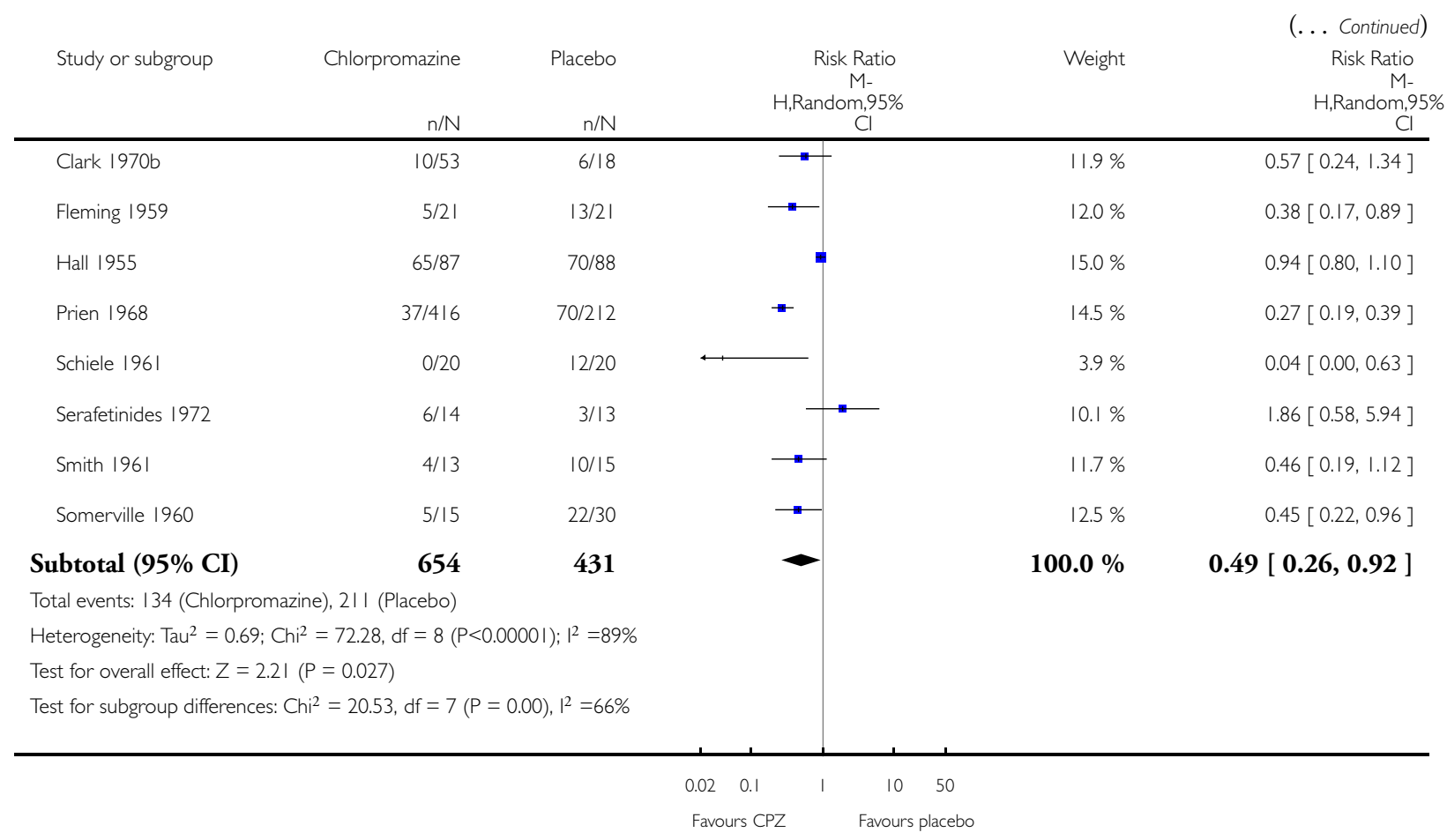




\section{Analysis I.23. Comparison I CHLORPROMAZINE versus PLACEBO, Outcome 23 SUBGROUP ANALYSIS: 3. HIGH vs LOW DOSE.}

Review: Chlorpromazine versus placebo for schizophrenia

Comparison: I CHLORPROMAZINE versus PLACEBO

Outcome: 23 SUBGROUP ANALYSIS: 3. HIGH vs LOW DOSE

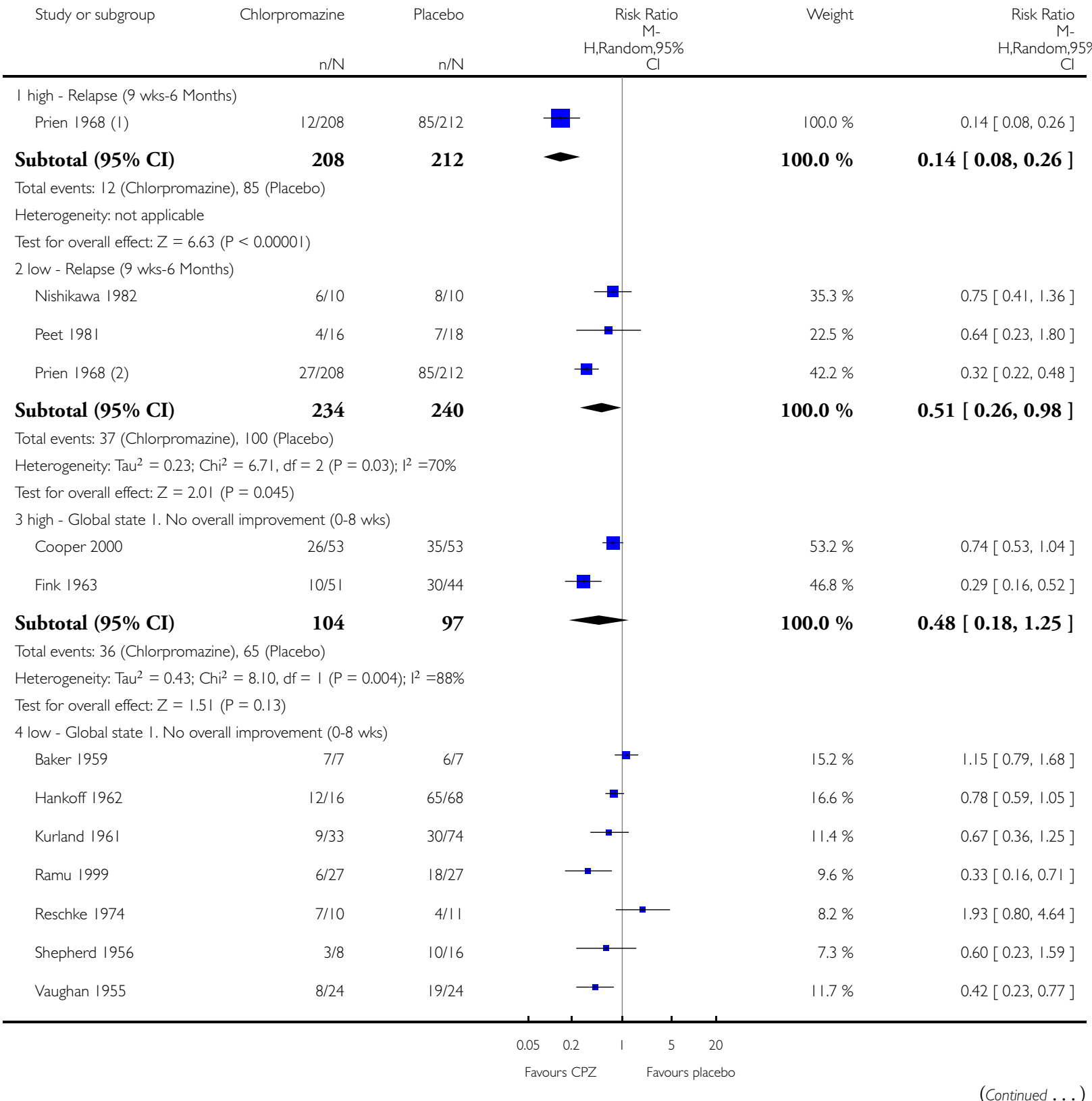




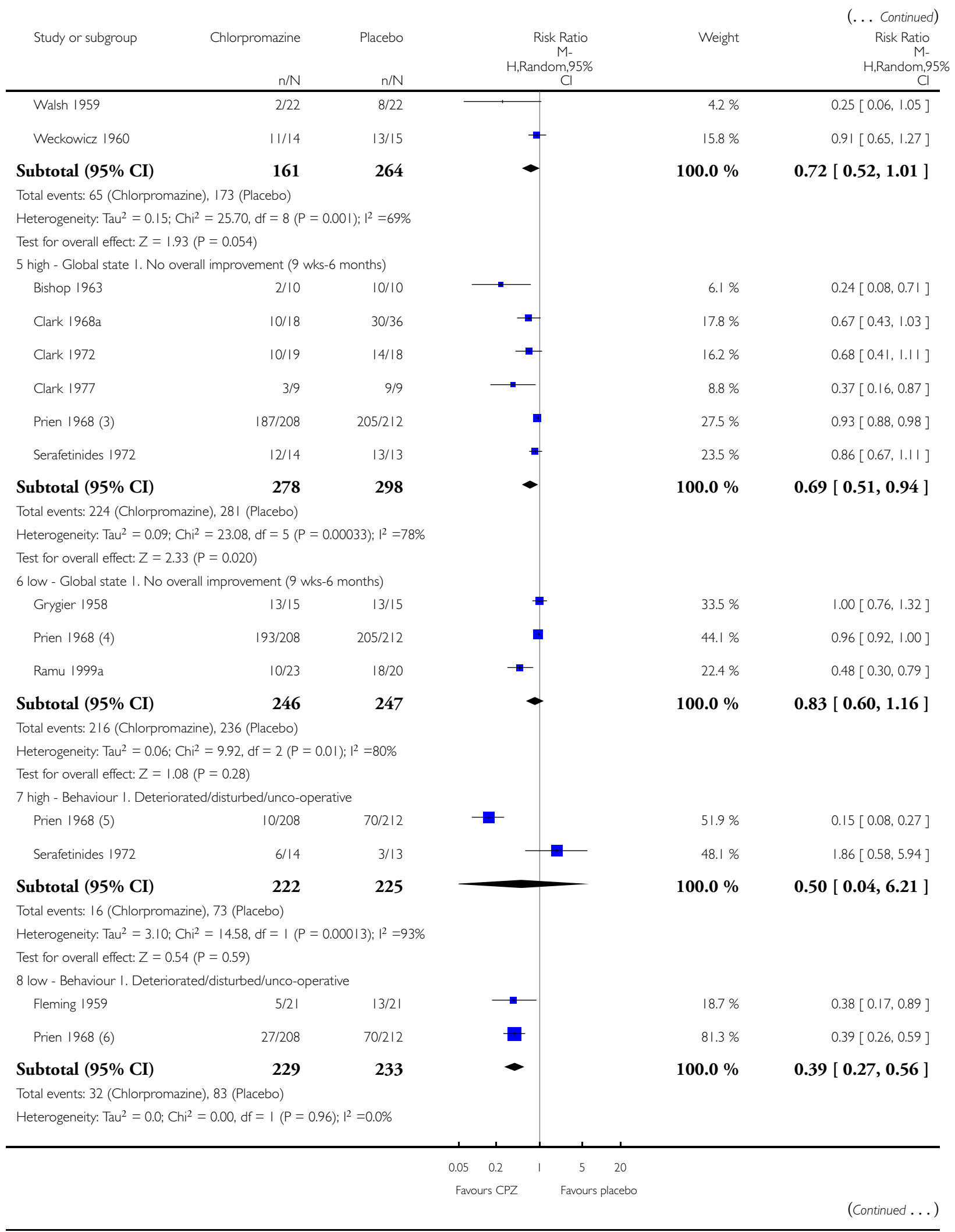

Chlorpromazine versus placebo for schizophrenia (Review) 


Study or subgroup
Test for overall effect: $\mathrm{Z}=5.09(\mathrm{P}<0.0000 \mathrm{I})$
Test for subgroup differences: $\mathrm{Ch} \mathrm{i}^{2}=35.2 \mathrm{I}, \mathrm{df}=7(\mathrm{P}=0.00), \mathrm{I}^{2}=80 \%$
(I) Trial had a high dose and low dose arm.
(2) Trial had a high dose and low dose arm.
(3) Trial had a high dose and low dose arm. Data provided as percentages and numbers are calculated based on all participants randomised.
(4) Trial had a high dose and low dose arm. Data provided as percentages and numbers are calculated based on all participants randomised.
(5) Trial had a high dose and low dose arm.
(6) Trial had a high dose and low dose arm.

\section{Analysis I.24. Comparison I CHLORPROMAZINE versus PLACEBO, Outcome 24 SUBGROUP ANALYSIS: 4. DIAGNOSTIC CRITERIA vs NO DIAGNOSTIC CRITERIA.}

Review: Chlorpromazine versus placebo for schizophrenia

Comparison: I CHLORPROMAZINE versus PLACEBO

Outcome: 24 SUBGROUP ANALYSIS: 4. DIAGNOSTIC CRITERIA vs NO DIAGNOSTIC CRITERIA

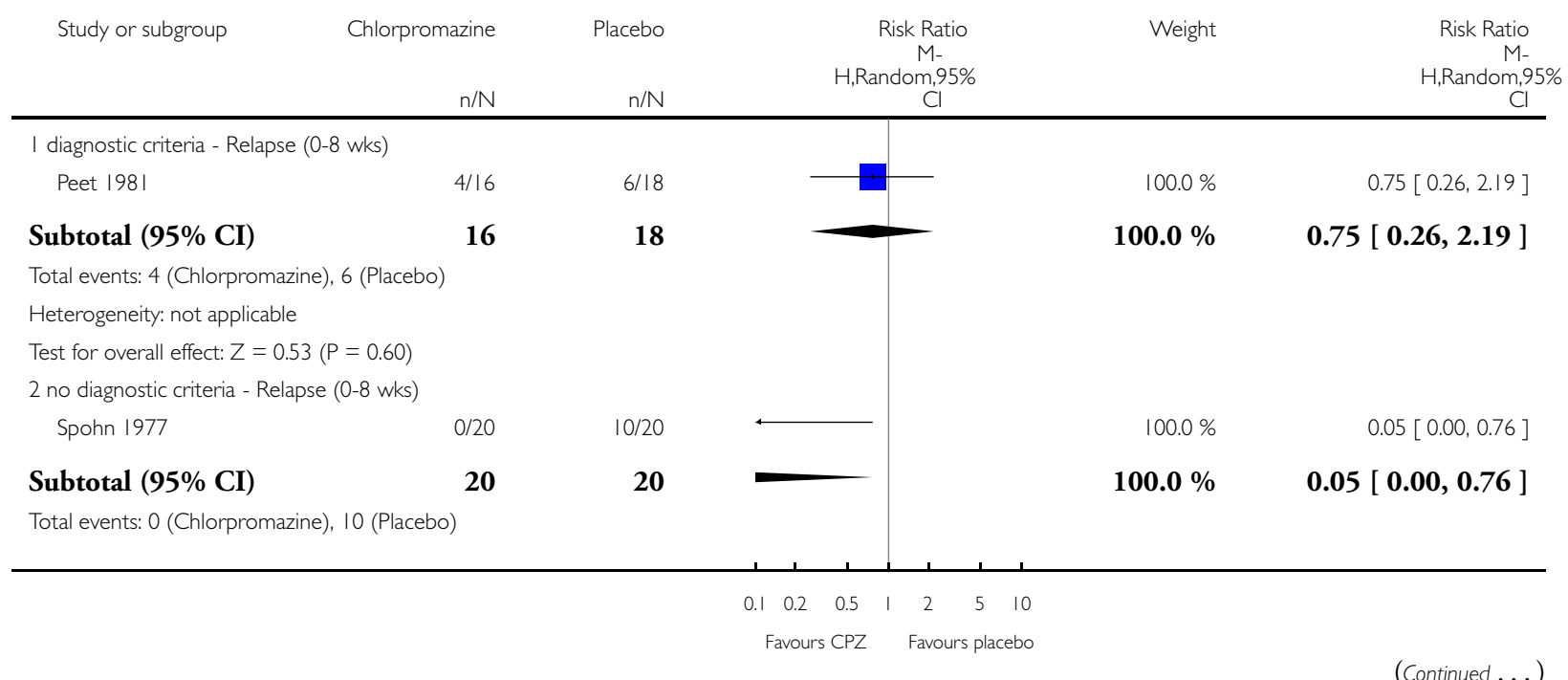




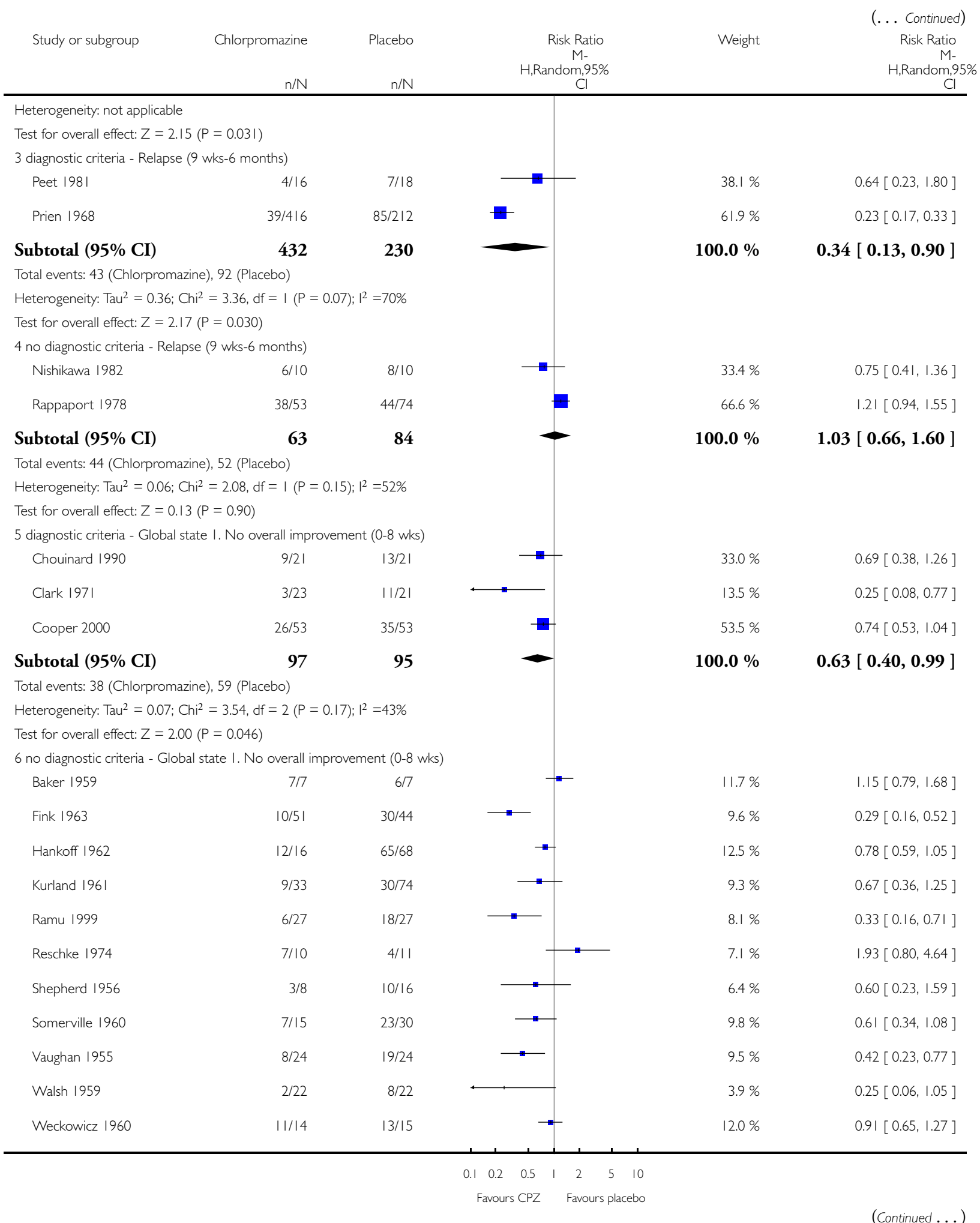

Chlorpromazine versus placebo for schizophrenia (Review)

Copyright $\odot 2015$ The Cochrane Collaboration. Published by John Wiley \& Sons, Ltd. 


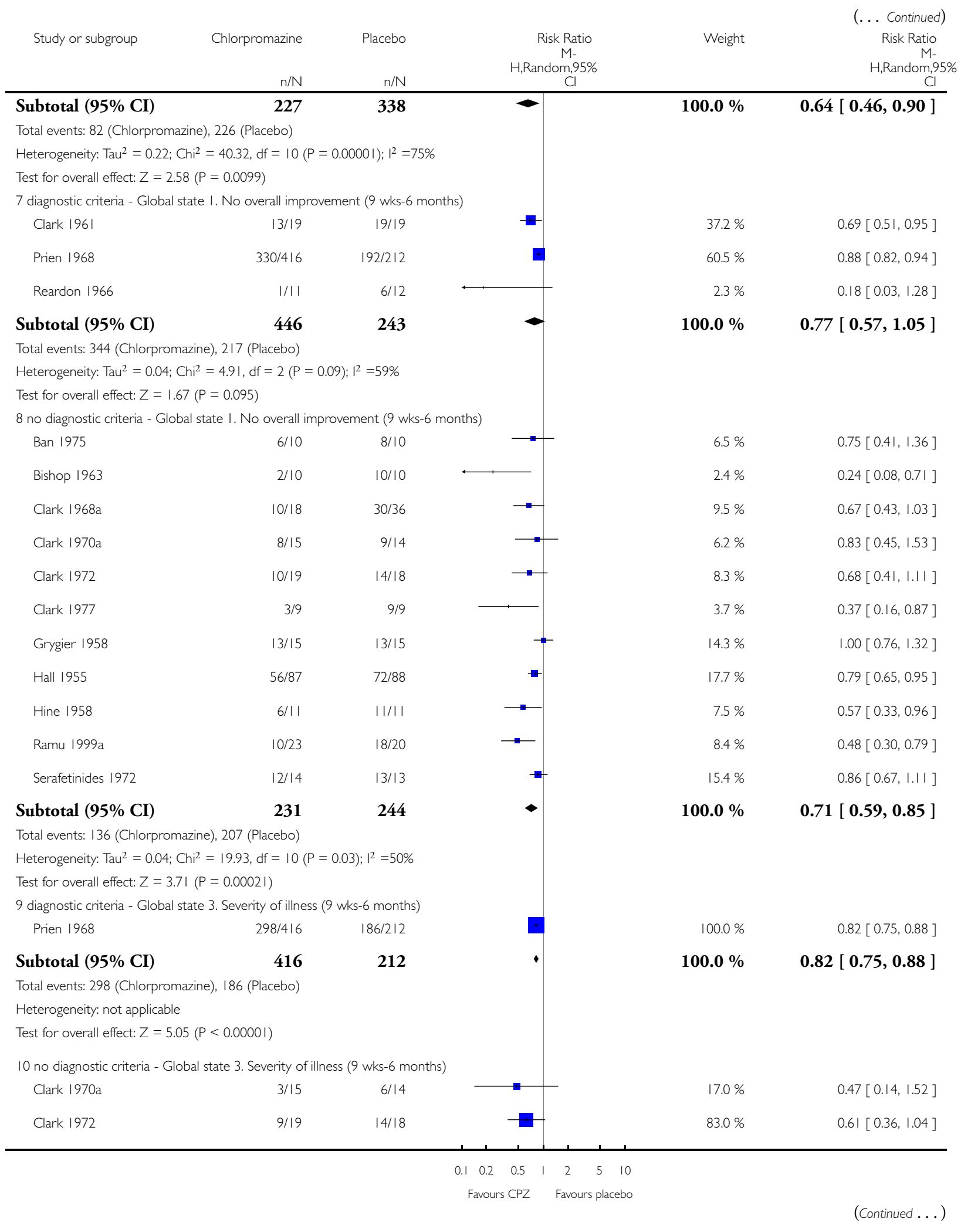

Chlorpromazine versus placebo for schizophrenia (Review) 


\begin{tabular}{|c|c|c|c|c|c|}
\hline Study or subgroup & Chlorpromazine & $\mathrm{n} / \mathrm{N}$ & $\begin{array}{c}\text { Risk Ratio } \\
\text { M- } \\
\mathrm{H}, \text { Random,95\% } \\
\mathrm{Cl} \\
\end{array}$ & Weight & $\begin{array}{c}\text { (... Continued) } \\
\text { Risk Ratio } \\
\text { M- } \\
\text { H,Random,95\% } \\
\text { Cl } \\
\end{array}$ \\
\hline Subtotal $(95 \% \mathrm{CI})$ & 34 & 32 & - & $100.0 \%$ & $0.58[0.36,0.95]$ \\
\hline \multicolumn{6}{|c|}{ Total events: 12 (Chlorpromazine), 20 (Placebo) } \\
\hline \multicolumn{6}{|c|}{ Heterogeneity: Tau $^{2}=0.0 ; \mathrm{Chi}^{2}=0.17, \mathrm{df}=\mathrm{I}(\mathrm{P}=0.68) ; \mathrm{I}^{2}=0.0 \%$} \\
\hline \multicolumn{6}{|c|}{ Test for overall effect: $Z=2.18(P=0.029)$} \\
\hline \multicolumn{6}{|c|}{ I I diagnostic criteria - Behaviour I. deteriorated/disturbed/unco-operative } \\
\hline Chouinard 1990 & $14 / 21$ & $16 / 2 \mid$ & & $49.9 \%$ & $0.88[0.60,1.29]$ \\
\hline Prien 1968 & $37 / 416$ & $70 / 212$ & & $50.1 \%$ & $0.27[0.19,0.39]$ \\
\hline Subtotal $(95 \% \mathrm{CI})$ & 437 & 233 & & $100.0 \%$ & $0.48[0.14,1.72]$ \\
\hline \multicolumn{6}{|c|}{ Total events: 5 I (Chlorpromazine), 86 (Placebo) } \\
\hline \multicolumn{6}{|c|}{ Heterogeneity: Tau $^{2}=0.80 ; \mathrm{Chi}^{2}=22.97, \mathrm{df}=\mathrm{I}(\mathrm{P}<0.0000 \mathrm{I}) ; \mathrm{I}^{2}=96 \%$} \\
\hline \multicolumn{6}{|c|}{ Test for overall effect: $Z=1.12(P=0.26)$} \\
\hline \multicolumn{6}{|c|}{ I2 no diagnostic criteria - Behaviour I. deteriorated/disturbed/unco-operative } \\
\hline Clark 1970a & $2 / 15$ & $5 / 14$ & & $8.3 \%$ & $0.37[0.09,1.62]$ \\
\hline Clark 1970b & $10 / 53$ & $6 / 18$ & & $13.9 \%$ & $0.57[0.24,1.34]$ \\
\hline Fleming 1959 & $5 / 21$ & $13 / 2 \mid$ & - & $14.2 \%$ & $0.38[0.17,0.89]$ \\
\hline Hall 1955 & $65 / 87$ & $70 / 88$ & \# & $20.8 \%$ & $0.94[0.80,1.10]$ \\
\hline Schiele 1961 & 0/20 & 12/20 & & $3.3 \%$ & $0.04[0.00,0.63]$ \\
\hline Serafetinides 1972 & $6 / 14$ & $3 / 13$ & & $10.8 \%$ & $1.86[0.58,5.94]$ \\
\hline Smith 1961 & $4 / 13$ & $10 / 15$ & & $13.5 \%$ & $0.46[0.19,1.12]$ \\
\hline Somerville 1960 & $5 / 15$ & $22 / 30$ & —- & $15.2 \%$ & $0.45[0.22,0.96]$ \\
\hline Subtotal $(95 \% \mathrm{CI})$ & 238 & 219 & & $100.0 \%$ & $0.56[0.33,0.97]$ \\
\hline \multicolumn{6}{|c|}{ Total events: 97 (Chlorpromazine), 14I (Placebo) } \\
\hline \multicolumn{6}{|c|}{ Heterogeneity: $\mathrm{Tau}^{2}=0.36 ; \mathrm{Ch}^{2}=25.14, \mathrm{df}=7(\mathrm{P}=0.00072) ; \mathrm{I}^{2}=72 \%$} \\
\hline \multicolumn{6}{|c|}{ Test for overall effect: $Z=2.06(P=0.039)$} \\
\hline Test for subgroup differen & $2=|6.01, \mathrm{df}=1|$ & 4), $\left.\right|^{2}=31 \%$ & & & \\
\hline
\end{tabular}




\section{Analysis I.25. Comparison I CHLORPROMAZINE versus PLACEBO, Outcome 25 SUBGROUP ANALYSIS: 5. STUDIES PRE-I990 vs STUDIES I990-2007.}

Review: Chlorpromazine versus placebo for schizophrenia

Comparison: I CHLORPROMAZINE versus PLACEBO

Outcome: 25 SUBGROUP ANALYSIS: 5. STUDIES PRE-1990 vs STUDIES 1990-2007

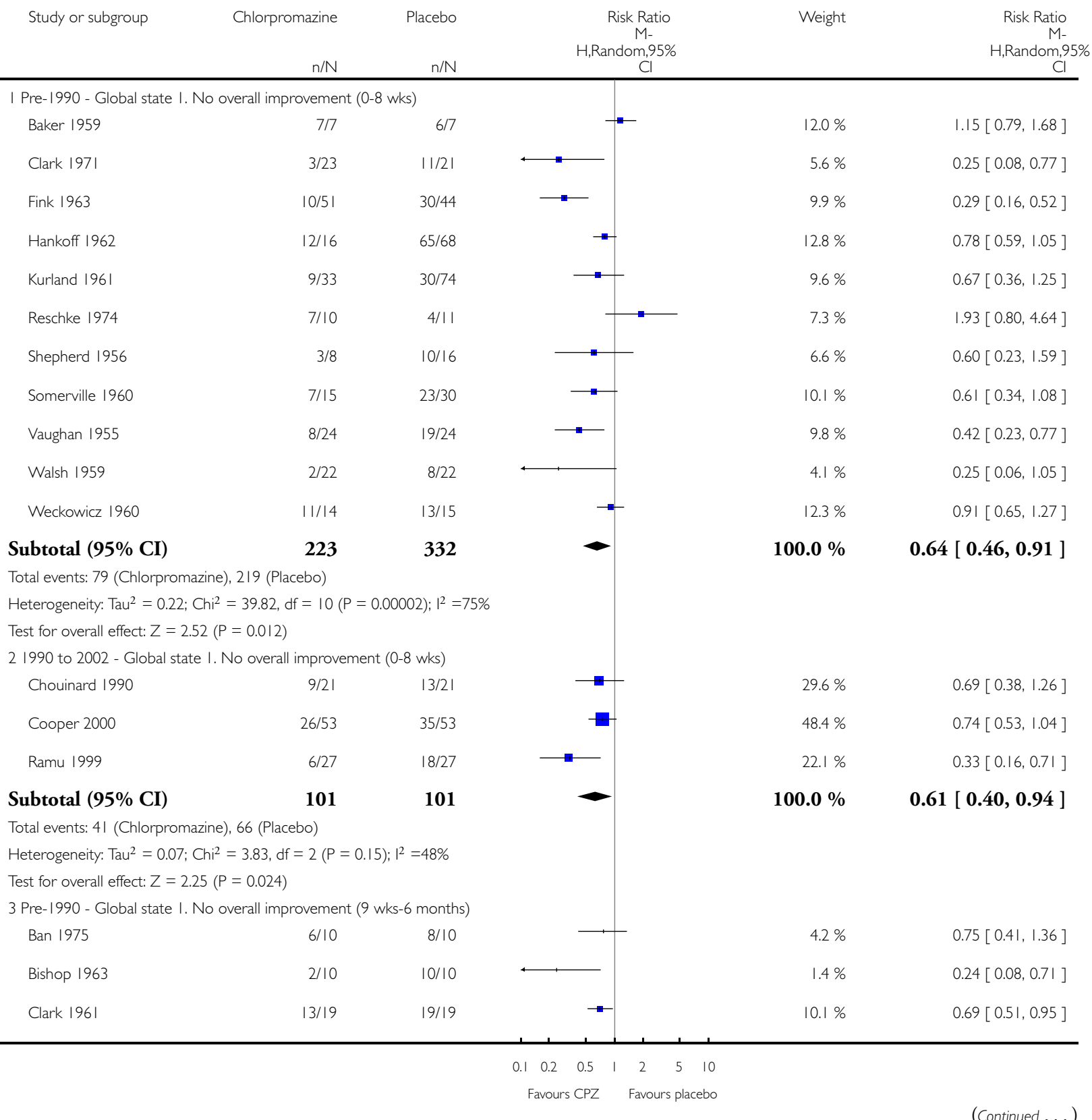




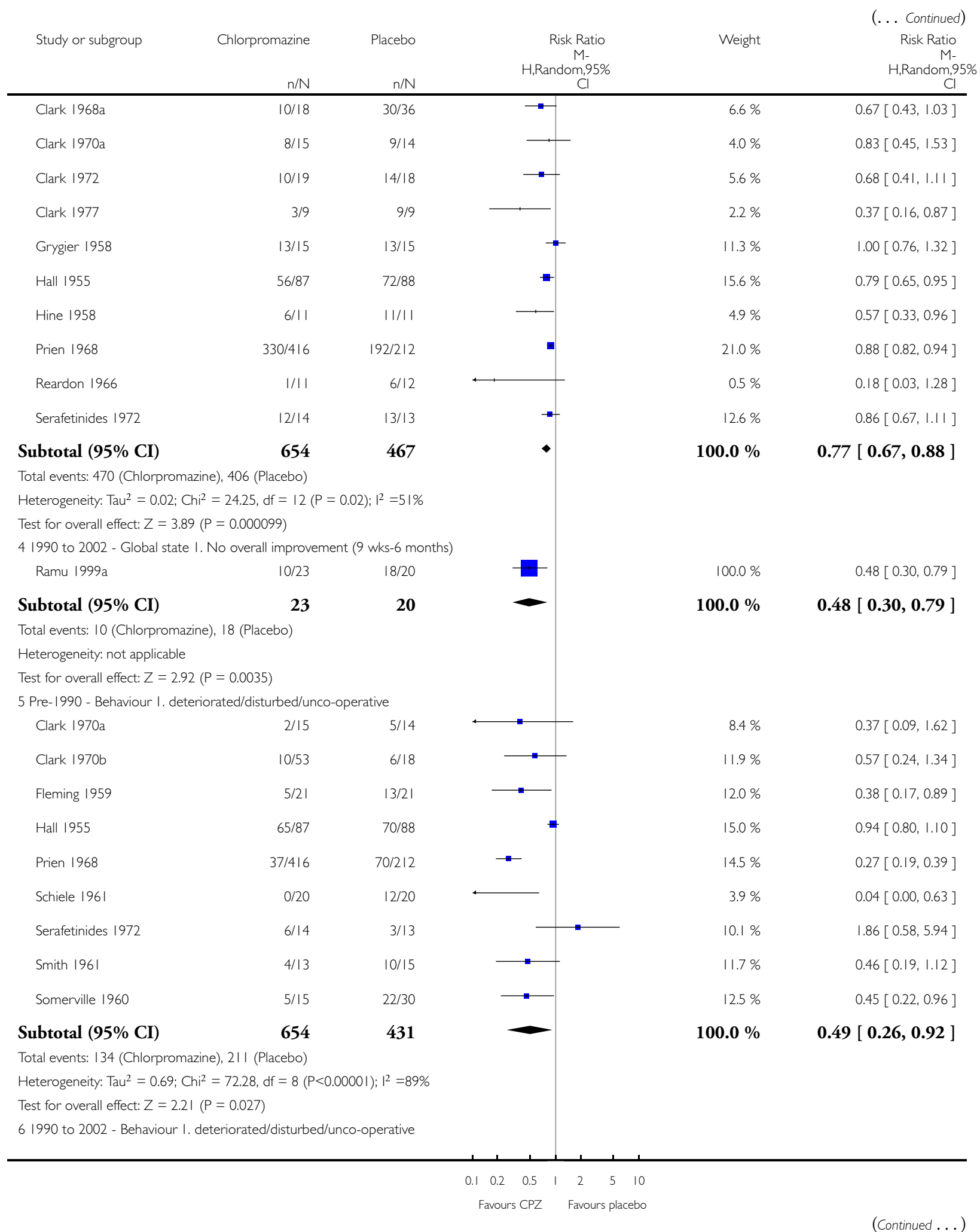

Chlorpromazine versus placebo for schizophrenia (Review) 


\begin{tabular}{|c|c|c|c|c|c|}
\hline Study or subgroup & Chlorpromazine & $\begin{array}{r}\text { Placebo } \\
n / N \\
\end{array}$ & $\begin{array}{c}\text { Risk Ratio } \\
\text { M- } \\
\text { H,Random,95\% } \\
\text { Cl } \\
\end{array}$ & Weight & $\begin{array}{c}\text { (... Continued) } \\
\text { Risk Ratio } \\
\text { M- } \\
\text { H,Random,95\% } \\
\text { Cl } \\
\end{array}$ \\
\hline Chouinard 1990 & $|4 / 2|$ & $16 / 21$ & 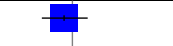 & $100.0 \%$ & $0.88[0.60,1.29]$ \\
\hline Subtotal $(95 \% \mathrm{CI})$ & 21 & 21 & $\longrightarrow$ & $100.0 \%$ & $0.88[0.60,1.29]$ \\
\hline \multicolumn{6}{|c|}{ Total events: 14 (Chlorpromazine), 16 (Placebo) } \\
\hline \multicolumn{6}{|c|}{ Heterogeneity: not applicable } \\
\hline \multicolumn{6}{|c|}{ Test for overall effect: $Z=0.68(P=0.50)$} \\
\hline \multicolumn{6}{|c|}{ Test for subgroup differences: $\mathrm{Chi}^{2}=6.77, \mathrm{df}=5(P=0.24), \mathrm{I}^{2}=26 \%$} \\
\hline
\end{tabular}

$\begin{array}{lllllll}0.1 & 0.2 & 0.5 & 1 & 2 & 5 & 10\end{array}$

Favours CPZ Favours placebo

\section{Analysis I.26. Comparison I CHLORPROMAZINE versus PLACEBO, Outcome 26 SENSITIVITY} ANALYSIS: I. RANDOMISATION.

Review: Chlorpromazine versus placebo for schizophrenia

Comparison: I CHLORPROMAZINE versus PLACEBO

Outcome: 26 SENSITIVITY ANALYSIS: I. RANDOMISATION

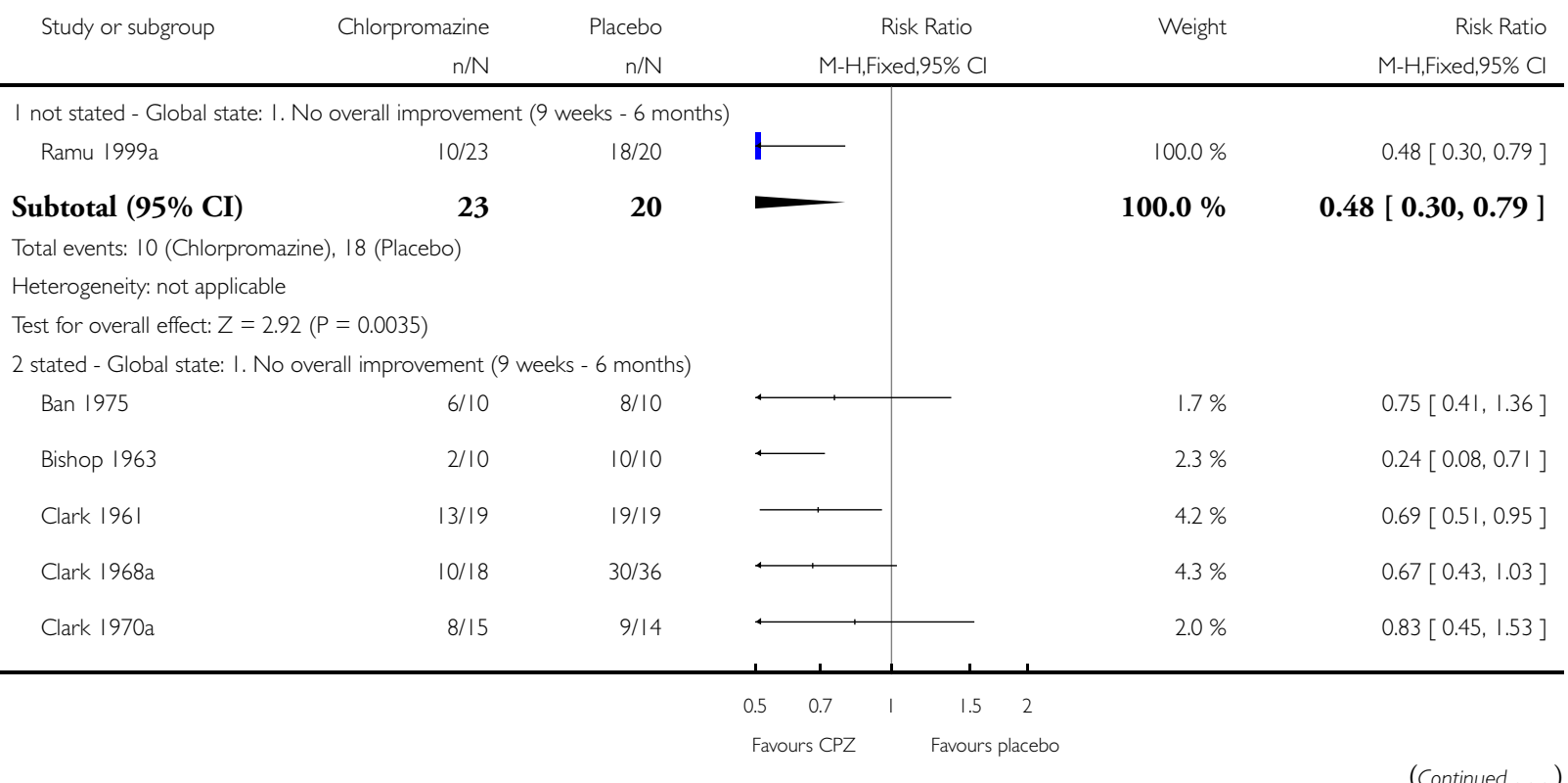




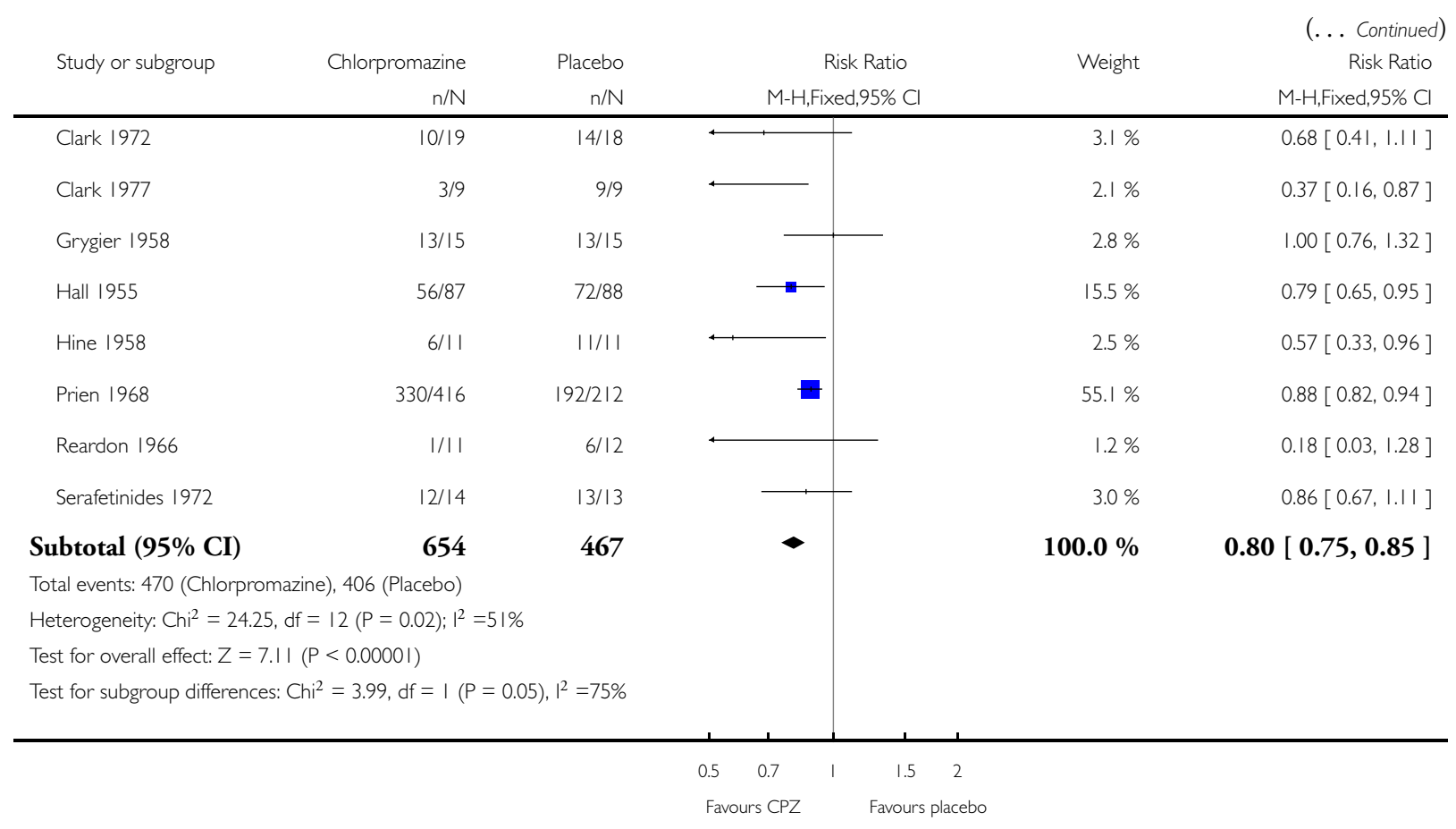




\section{Analysis I.27. Comparison I CHLORPROMAZINE versus PLACEBO, Outcome 27 SENSITIVITY}

ANALYSIS: 2. ASSUMPTIONS FOR LOST BINARY DATA.

Review: Chlorpromazine versus placebo for schizophrenia

Comparison: I CHLORPROMAZINE versus PLACEBO

Outcome: 27 SENSITIVITY ANALYSIS: 2. ASSUMPTIONS FOR LOST BINARY DATA

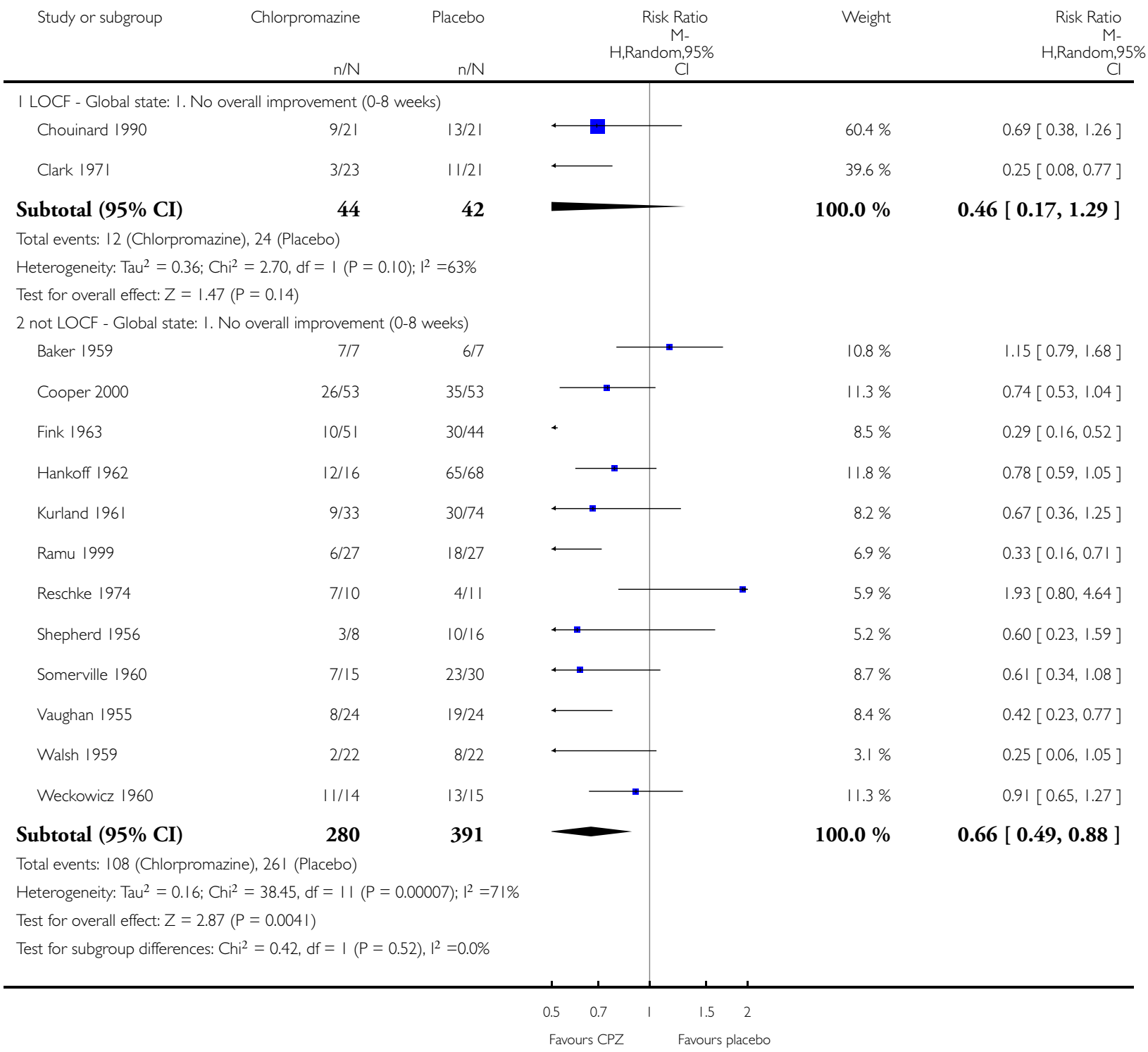




\section{ADDITIONAL TABLES}

Table 1. Mental state: 3. Average BPRS change score (large decline=best)

\begin{tabular}{|c|c|c|c|c|c|c|}
\hline Study & $\begin{array}{l}\text { Chlorpro- } \\
\text { mazine mean }\end{array}$ & $\begin{array}{l}\text { Chlorpro- } \\
\text { mazine SD }\end{array}$ & $\begin{array}{l}\text { Chlorpro- } \\
\text { mazine } N\end{array}$ & Placebo mean & Placebo SD & Placebo N \\
\hline Cooper 2000 & -4.3 & 19.1 & 53 (LOCF) & -2.9 & 16.3 & 53 (LOCF) \\
\hline
\end{tabular}

\section{A P P E N D I C E S}

\section{Appendix I. Previous plain language summary}

\section{Chlorpromazine versus placebo for schizophrenia}

Schizophrenia is a long-term illness with a worldwide lifetime prevalence of about one per cent. Many people who suffer from schizophrenia live with considerable disability. Chlorpromazine was one of the first drugs discovered to be effective in its treatment back in the 1950s - and is still used extensively today. This review updates the information available from trials in which chlorpromazine was compared with placebo. In addition it attempts to look at outcomes in smaller sub-groups of people, by sex, by age, by length of illness, by dose of chlorpromazine, by criteria of diagnosis or by whether they were diagnosed before or after 1990 . This update adds five studies giving a total of 55 studies and the included data have been divided as to whether they refer to short, medium or longterm treatment. When looking at chlorpromazine versus placebo for schizophrenia since the first review in 1995 , 370 trials have been considered but 315 have been excluded, many because of flaws in the research methods or the reporting of the data. This is a shame and much opportunity has been lost to report outcomes of interest to the reviewers and others.Chlorpromazine has been shown to improve both a person's symptoms and functioning in 14 trials containing 1164 people. Chlorpromazine reduces relapse in the short, medium and long term. Many trials, however, have demonstrated that chlorpromazine has a number of adverse effects when compared with placebo important ones being movement disorders, sleepiness, skin sensitivity to sunlight, low blood pressure and constipation. The main weakness of these trials is that the majority are conducted on people who are in hospital. The results, therefore, may, at best, be only partially applicable to people in the community.(Plain language summary prepared for this review by Janey Antoniou of RETHINK, UK www.rethink.org).

\section{Appendix 2. Previous search strategies}

1.2 Details of previous electronic search:

1.2.1 We searched The Cochrane Schizophrenia Group Trials Register (June 2002) using the phrase:

$\left\{\left[\left({ }^{*}\right.\right.\right.$ anadep ${ }^{*}$ or ${ }^{*}$ chloractil ${ }^{*}$ or ${ }^{*}$ chlorazin* or ${ }^{*}$ chlorpromados* or ${ }^{*}$ chlorpromazine* or ${ }^{*}$ chlorprom-ez-ets* or ${ }^{*}\left(\text { chlor }^{*} \text {-z }\right)^{*}$ or ${ }^{*}$ chromedazine* or ${ }^{*} \mathrm{cpz}^{*}$ or *elmarine* or *esmind* or ${ }^{*}$ fenactil* or *hibanil* or *hibernal* or *klorazin* or *klorproman* or *klor-

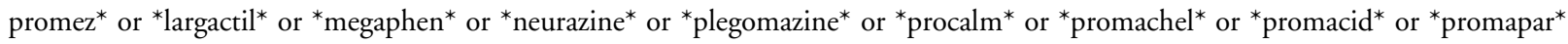
or * promexin* or *promosol* or *prozil* or *psychozine* or *psylactil* or *serazone* or *sonazine* or *thoradex* or *thorazine* or *tranzine*) in title, abstract, index terms of REFERENCE] or [chlorpromazine* in interventions of STUDY]\}

Chlorpromazine is known by many names and we constructed the following search phrase in order to try to aid identification: (chlorpromazine-phrase) $=($ anadep or chloractil or chlorazin or chlorpromados or chlorpromazine or chlorprom-ez-ets or (chlor p-z) or chromedazine or cpz or elmarine or esmind or fenactil or hibanil or hibernal or klorazin or klorproman or klorpromez or largactil

Chlorpromazine versus placebo for schizophrenia (Review)

Copyright (c) 2015 The Cochrane Collaboration. Published by John Wiley \& Sons, Ltd. 
or megaphen or neurazine or plegomazine or procalm or promachel or promacid or promapar or promexin or promosol or prozil or psychozine or psylactil or (RP near1 4560) or serazone or sonazine or thoradex or thorazine or tranzine).

1.2.2 We searched The Cochrane Schizophrenia Group Trials Register (October 1999) using the phrase:

(((chlorpromazine-phrase) or $(\# 42=5))$ and (placebo* or $(\# 42=4)))$

\#42 is the 'Intervention' field and 5 is the code for chlorpromazine; 4 is the code for placebo

1.2.3 We searched Biological Abstracts (January 1982 to May 1995) using The Cochrane Schizophrenia Group's phrase for both randomised controlled trials and schizophrenia (see: Group search strategy) combined with the phrase:

((chlorpromazine-phrase) and placebo*)

1.2.4 We searched The Cochrane Library (1999, Issue 2) using the phrase:

((chlorpromazine-phrase) and placebo)

1.2.5 We searched EMBASE (January 1980 to May 1995) using The Cochrane Schizophrenia Group's phrase for both randomised controlled trials and schizophrenia (see Group search strategy) combined with the phrase:

(and (chlorpromazine-phrase) and placebo*)

1.2.6 We searched MEDLINE (January 1966 to May 1995) using The Cochrane Schizophrenia Group's phrase for both randomised controlled trials and schizophrenia (see Group search strategy) combined with the phrase:

(and (chlorpromazine-phrase) and placebo*)

1.2.7 We searched PsycLIT (January 1974 to May 1995) using The Cochrane Schizophrenia Group's phrase for both randomised controlled trials and schizophrenia (see Group search strategy) combined with the phrase:

(and (chlorpromazine-phrase) and placebo*)

1.2.8 We searched local library listings of books/university series/dissertations relating to chlorpromazine using the phrase:

(and (chlorpromazine-phrase) and placebo*)

1.2.9 We searched Scisearch Citation Index database using each citation from the included studies. We inspected reports of articles that had cited these studies in order to identify further trials.

\section{Cochrane Schizophrenia Group Trials Register (January 2007)}

We searched The Cochrane Schizophrenia Group Trials Register (January 2007) using the phrase:

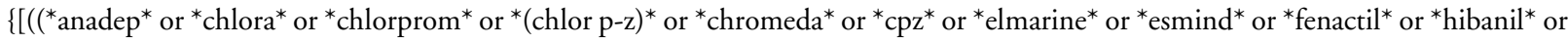
*hibernal* or *klorazin* or *klorpro* or *largactil* or *megaphen* or *neurazin* or * plegomaz* or * procalm* or * proma* or * promexin* or *promosol* or *prozil* or *psychozin* or *psylactil* or *serazon* or *sonazin* or *thoradex* or *tranzine*) and placebo*) in title, abstract, index terms of REFERENCE] or [)chlorpromazine* and placebo*) in interventions of STUDY]\}

\section{Appendix 3. Previous data collection}

1. Study selection

We (BT, CEA and JR) independently inspected citations from the searches and identified relevant abstracts. GA independently reinspected a random $10 \%$ sample to ensure reliability. Where disputes arose, we acquired the full report for more detailed scrutiny. We (BT and JR) obtained and inspected full reports of the abstracts meeting the review criteria. Again, a random $10 \%$ of reports were reinspected by CEA and GA in order to ensure reliable selection. Where it was not possible to resolve disagreement by discussion, an attempt was made to contact the authors of the study for clarification. For the 2007 update, we independently inspected and selected citations from the search results.

2. Assessment of methodological quality

We (BT, JR) assessed the methodological quality of included trials in this review using the criteria described in The Cochrane Handbook (Higgins 2005). It is based on the evidence of a strong relationship between allocation concealment and direction of effect (Schulz 1995). When disputes arose as to which category a trial should be allocated, again we attempted resolution by discussion. When this was not possible, we did not enter the data and added the trial to the list of those awaiting assessment until further information could be obtained. The categories are defined below:

A. Low risk of bias (adequate allocation concealment)

B. Moderate risk of bias (some doubt about the results)

C. High risk of bias (inadequate allocation concealment).

In addition, for the first version of this review, we rated studies using the Jadad Scale (Jadad 1996) but this was not applied for the updates, as it was found to add little to the initial version. The reliability of quality-rating was checked by CEA and GA who re-rated a $10 \%$ sample of the selected studies.

Chlorpromazine versus placebo for schizophrenia (Review)

Copyright (C) 2015 The Cochrane Collaboration. Published by John Wiley \& Sons, Ltd. 
3. Data management

3.1. Data extraction

We (BT and JR) independently extracted data and, where further clarification was needed we contacted the authors of trials to provide missing data. CEA and GA independently checked a 10\% sample for reliability. Any disagreements were discussed and decisions documented. For the 2007 update, JR independently extracted data and contacted authors of trials for missing data.

4. Data synthesis

4.1 Data types: We assessed outcomes using continuous (e.g. average changes on a behaviour scale), categorical (e.g. one of three categories on a behaviour scale, such as 'little change', 'moderate change' or 'much change') or dichotomous measures, e.g. either 'no important change' or 'important change' in a person's behaviour. RevMan software does not currently support categorical data, so we only presented these in the text of the review.

4.2 Binary data

For binary outcomes we calculated the relative risk (RR) and its $95 \%$ confidence interval (CI) based on the fixed-effect model. Relative Risk is more intuitive (Boissel 1999) than odds ratios and odds ratios tend to be interpreted as RR by clinicians (Deeks 2000). This misinterpretation then leads to an overestimate of the impression of the effect. When the overall results were significant we calculated the number needed to treat (NNT) and the number needed to harm (NNH). Where people were lost to follow-up at the end of the study, we assumed that they had had a poor outcome and once they were randomised we included them in the analysis (intention-totreat /ITT analysis).

Where possible, we attempted to convert outcome measures to binary data. This can be done by identifying cut-off points on rating scales and dividing participants accordingly into "clinically improved" or "not clinically improved". It was generally assumed that if there had been a 50\% reduction in a scale-derived score such as the Brief Psychiatric Rating Scale (BPRS, Overall 1962) or the Positive and Negative Syndrome Scale (PANSS, Kay 1986), this could be considered as a clinically significant response (Leucht 2005a; Leucht 2005b). It was recognised that for many people, especially those with chronic or severe illness, a less rigorous definition of important improvement (e.g. $25 \%$ on the BPRS) would be equally valid. If individual patient data were available, we used the $50 \%$ cut-off for the definition in the case of non-chronically ill people and $25 \%$ for those with chronic illness. If data based on these thresholds were not available, we used the primary cut-off presented by the original authors.

4.3 Continuous data

4.3.1 Normal distribution

Continuous data on outcomes in trials relevant to mental health issues are often not normally distributed. To avoid the pitfall of applying parametric tests to non-parametric data we applied the following standards to continuous final value endpoint data before inclusion: (a) standard deviations and means were reported in the paper or were obtainable from the authors; (b) when a scale started from zero, the standard deviation, when multiplied by two, should be less than the mean (otherwise the mean is unlikely to be an appropriate measure of the centre of the distribution, Altman 1996); In cases with data that are greater than the mean we entered these into 'Other data' table as skewed data. If a scale starts from a positive value (such as PANSS, which can have values from 30 to 210 ) the calculation described above in (b) should be modified to take the scale starting point into account. In these cases skewness is present if $2 \mathrm{SD}>(\mathrm{S}-\mathrm{Smin})$, where $\mathrm{S}$ is the mean score and $\mathrm{Smin}$ is the minimum score.

For change data (mean change from baseline on a rating scale) it is impossible to tell whether or not data are non-normally distributed (skewed) unless individual patient data are available. After consulting the ALLSTAT electronic statistics mailing list, we presented change data in RevMan graphs to summarise available information. In doing this, we assumed either that data were not skewed or that the analysis could cope with the unknown degree of skew.

4.3.2 Final endpoint value versus change data

Where both final endpoint data and change data were available for the same outcome category, we only presented endpoint data. We acknowledge that by doing this much of the published change data may be excluded, but argue that endpoint data is more clinically relevant and that if change data were to be presented along with endpoint data, it would be given undeserved equal prominence.

4.4 Rating scales: A wide range of instruments are available to measure mental health outcomes. These instruments vary in quality and many are not valid, and are known to be subject to bias in trials of treatments for schizophrenia (Marshall 2000). Therefore we only included continuous data from rating scales if the measuring instrument had been described in a peer-reviewed journal.

4.5 Cross-over design

We expected that some trials would use a cross-over design. In order to exclude the potential additive effect in the second or later stages in these trials we only analysed data from the first stage.

4.6 Cluster trials

Studies increasingly employ "cluster randomisation" (such as randomisation by clinician or practice) but analysis and pooling of clustered data poses problems. Firstly, authors often fail to account for intra class correlation in clustered studies, leading to a "unit of analysis"

Chlorpromazine versus placebo for schizophrenia (Review)

Copyright ( 2015 The Cochrane Collaboration. Published by John Wiley \& Sons, Ltd. 
error (Divine 1992) whereby P values are spuriously low, confidence intervals unduly narrow and statistical significance overestimated. This causes type 1 errors (Bland 1997; Gulliford 1999).

Where clustering was not accounted for in primary studies, we presented the data in a table, with a $\left(^{*}\right)$ symbol to indicate the presence of a probable unit of analysis error. in subsequent versions of this review we will seek to contact first authors of studies to obtain intraclass correlation co-efficients of their clustered data and to adjust for this using accepted methods (Gulliford 1999). Where clustering has been incorporated into the analysis of primary studies, we will also present these data as if from a non-cluster randomised study, but adjusted for the clustering effect.

We have sought statistical advice and have been advised that the binary data as presented in a report should be divided by a "design effect". This is calculated using the mean number of participants per cluster $(\mathrm{m})$ and the intraclass correlation co-efficient (ICC) [Design effect $\left.=1+(\mathrm{m}-1)^{*} \mathrm{ICC}\right]$ (Donner 2002). If the ICC was not reported it was assumed to be 0.1 (Ukoumunne 1999).

If cluster studies had been appropriately analysed taking into account intra-class correlation coefficients and relevant data documented in the report, synthesis with other studies would have been possible using the generic inverse variance technique.

5. Investigation for heterogeneity

Firstly, we considered all the included studies within any comparison to judge for clinical heterogeneity then we visually inspected the graphs to investigate the possibility of statistical heterogeneity. This was supplemented using, primarily, the I-squared statistic. This provides an estimate of the percentage of variability due to heterogeneity rather than chance alone. Where the I-squared estimate was greater than or equal to $75 \%$, we interpreted this as indicating the presence of high levels of heterogeneity (Higgins 2003). If heterogeneity was found, we re-analysed the data using a random-effects model to see if this made a substantial difference. If it did, we did not add the studies responsible for heterogeneity to the main body of homogeneous trials, but summated and presented them separately and investigated reasons for heterogeneity.

6. Addressing publication bias

We undertook funnel plots (trial affect versus trial size) for outcomes where more than five trials reported usable data and no clear asymmetry was apparent.

7. Sensitivity analysis

We anticipated that this would be a large review in comparison to many within the field of mental health. As a result this gave an opportunity for several sensitivity analyses to be undertaken. These sensitivity analyses are listed (see: in Objectives). BT, CEA and JR selected relevant trials at the data extraction stage of the review. The synthesised results of the groups of trials were inspected for overlap of the $95 \%$ confidence intervals.

8. General

Where possible we presented data so that results shown to the left of the line of no effect favoured chlorpromazine.

\section{F E E D B A C K}

\section{Methods and results}

\section{Summary}

Methods - summary statistic

I think it would be helpful if you were to include in your review additional measures of effect size. While you report the relative risk and number needed to treat, many of us not in medical or epidemiological fields tend to use effect size analysis (Cohen 1983), in standard deviation, units to evaluate strength of effect. For binary outcomes, we also tend to use the difference in the percentage of those having the desired outcome in the experimental treatment minus the percentage having the desired effect in the control treatment. Using your study to illustrate, if the percentage of the placebo treated group showing symptomatic remission is 40 and the NNT is 7, then the percentage of drug treated participants showing symptom remission is $52.5(100 /(7+1)=.125+.40=.525)$. Then the effect size is 12.5 percent, or a small to moderate effect size. I think that adding this type of layman-accessible translation will enhance the utility and breadth of appeal of your analysis.

Results - sensitivity analysis

Are there differences between early (first and second) episode patients and those with a more chronic course? I think it reasonable to expect a higher proportion of placebo remissions in early episodes, and perhaps a different (smaller or larger) effect size for the drugs. 
In looking through the titles of the articles included in your review, it seems that most studies are of the more chronic group. If you can segregate the early episode studies form the more chronic ones, I think the field could learn a great deal about whether the drug has different effects at these different stages of illness. In relation to the Rappaport (1978) first episode study, you might consider a comment on the portion of the placebo treated group that appeared to do better without drugs. If there is such a subgroup, this would be important to know.

Results and conclusions - the interaction of drug effects and study design

From what we know of the conventional antipsychotic effect, there is a dopamine blocking action that appears correlated with the effect. The body responds to this blocking by generating additional dopamine receptors. Subsequent withdrawing of antipsychotics can thus increase the likelihood of a subsequent episode of psychosis to be greater than if drugs were never given (Chouinard 1978, Chouinard 1980, Warner 1985). In relation to study design, this effect can operate in a number of ways, potentially introducing bias into study results. If the study is of first episode patients and the control group does not receive antipsychotics, then there is no problem. Warner (1985) calls this design 'initial assignment'. But if, while waiting for participants to be collected, early recruits are given medication that for some of them (subsequently assigned to the control group) is later withdrawn, effect size estimates, particularly those using 'relapse' as the dependent variable, will be biased in favour of the drug treated group. This is due to the increased likelihood of 'supersensitivity' psychosis (Chouinard 1978, Chouinard 1980) associated with drug withdrawal. Warner (1985) calls this design 'drug withdrawal'. These issues become more complex when studying a more chronic population (virtually all of whom have been previously medicated). Certainly a sudden drug withdrawal will insert this bias, but most studies you cite seem to use 'wash-out periods' of varying lengths. The real question here is whether the length of the wash out period is sufficient to conduct a fair test. If it's not, there is a bias favouring the drug treatment group in the design. If there is a way, in your analysis, to control for length of wash-out period, it might produce 'clean' estimates of drug-effect for chronically ill people. It would also help to clarify empirically whether the length of the wash-out period is a significant issue (by whether the effect size changes when length of wash-out is included as a control variable).

\section{Reply}

The reviewers would first like to thank Dr Bola for his detailed comment and patience. It has taken us a shamefully long time to address the issues he raised.

Methods - summary statistic

We have taken advice on this comment as regards the use of an additional effect size statistic. The two statisticians consulted suggested that accessibility is best served by the NNT statistic and the effect size adds little. Although it is now well recognised that there are difficulties with the NNT in meta-analysis it is still thought to be of use. The reviewers have tried to reword were necessary and clarify the numbers without decreasing readability.

Results - sensitivity analysis

Dr Bola highlighted that we had not completed the review. We had intended to undertake several additional sensitivity analyses. One of these was to compare, for primary outcomes, if any clear differences were suggested for the effect of chlorpromazine compared with placebo, when a group of people whose illnesses were not chronic were included in the study, as against people with more chronic illnesses. We too expected to see a difference but data were so limited that nothing could be said with confidence. For the outcome of medium term relapse the results of the Rappaport 1978 study (acutely ill people) are different from the synthesised findings of three studies dealing with a more chronic population. This difference was not, however, statistically significant. The other outcomes in this sensitivity analysis do not show any suggestion of a difference. We agree that it would have been important to know with certainty if a portion of the placebo treated group that appeared to do better without drugs. This review generates some hypotheses that could be worth testing. The data are very far from being strong enough to all any clear conclusions to be drawn.

Results and conclusions - the interaction of drug effects and study design

We completely accept Dr Bola's comment about the possible interaction of length of washout and effect of chlorpromazine. There is just not enough data to be able to control for this in the current analyses. Taking this into account, along with the other potential biases that could be operating, often favouring the chlorpromazine group, gives all the more reason to treat the current estimates of the size of the effect of this drug with caution.

\section{Contributors}

Comment by John Bola, Los Angeles, CA, USA, March 2000.

References

Chouinard G, Jones BD. Neuroleptic-induced supersensitivity psychosis: Clinical and pharmacological characteristics. American Journal of Psychiatry 1980;137(1):16-21.

Chlorpromazine versus placebo for schizophrenia (Review)

Copyright @ 2015 The Cochrane Collaboration. Published by John Wiley \& Sons, Ltd. 
Chouinard G, Jones BD, Annable L. Neuroleptic-induced supersensitivity psychosis. American Journal of Psychiatry 1978;135(11): 1409-10.

Cohen J, Cohen P. Applied multiple regression/correlation analysis for the behavioral sciences:2nd ed. Hillsdale, NJ: Lawrence Erlbaum Associates, 1980.

Rappaport M, Hopkins HK, Hall K, Belleza T, Silverman J. Are there schizophrenics for whom drugs may be unnecessary or contraindicated? International Pharmacopsychiatry 1978:13(2):100-11.

Warner R. Recovery from schizophrenia: psychiatry and political economy. London: Routledge and Kegan Paul, 1985.

\section{Feedback received, 18 August 2015}

\section{Summary}

Comment \#1: The authors mention in the abstract of this huge review ((55 trials and 5,506 patients) without any reservation that akathisia didn't occur more often in the chlorpromazine group than in the placebo group. The largest trial that contributed data to this outcome even found significantly less akathisia in the active group than in the placebo group, relative risk $0.57,95 \% \mathrm{CI} 0.37$ to 0.88. Since we know that antipsychotics cause akathisia and that placebo cannot cause akathisia, this result speaks volumes about how flawed trials in schizophrenia generally are. What was seen in the placebo group were cold turkey symptoms caused by withdrawal of the antipsychotics the patients had received before randomisation.

Comment \#2: I [Professor Gøtzsche] believe this fundamental problem renders the review unreliable

Comment \#3 : I [Professor Gøtzsche] refer readers to another review. The most reliable placebo controlled trials are those of first episode schizophrenia where none of the patients have ever received drugs before. There is a Cochrane review that approaches this ideal, but even this review is biased, as the trials are not limited to first episode patients; the review includes studies "with a majority of first and second episode schizophrenia spectrum disorders" (4). The authors of that Cochrane review pointed out that the available evidence doesn't support a conclusion that antipsychotic treatment in an acute early episode of schizophrenia is effective. They felt this was worrying given the widespread use of antipsychotics in the acute treatment of early episode schizophrenia-type psychoses, and also because the use of antipsychotics for millions of people with an early episode appears based on the trials for those with multiple previous episodes (which we know are highly flawed). What does this mean for use of antipsychotics more generally, also for multiple episodes of psychoses? Doesn't it mean that we don't have the evidence to support using antipsychotics at all? In fact, despite the trials being flawed by the cold turkey design, what was seen in recent placebo controlled trials in submissions to the FDA was only a 6 point improvement on the Positive and Negative Syndrome Scale (PANSS) (5,6), far below the minimally relevant clinical effect on this scale, which is about 15 points (7).

\section{Reply}

Response \#1: Thank you for this comment. The abstract is accurate in that we found, for akathisia, for these trials RR was 0.78 (CI 0.54 to $1.11,9$ RCTs, $n=1164$ ). Professor Gøtzsche says that "we know that that antipsychotics cause akathisia and that placebo cannot cause akathisia." Antipsychotics can cause akathisia, but these symptoms are well recognised to also occur in people who have never been on medication. Even a cursory search of the literature highlights study after study illustrating this odd fact ${ }^{1-3}$. It is indeed possible that the akathisia people displayed in these trials was due to preceding medications, but also a whole raft of other factors that are not speculated upon in a balanced argument. Professor Gøtzsche goes on to say that his statement "speaks volumes" about how flawed trials in schizophrenia generally are”. Professor Gøtzsche's statement is poorly-supported and - even if it had been supported - generalising his perception of nine trials conducted between 1961 and 1970 to all of trials in schizophrenia is unscientific and not appropriate.

Response \#2: The authors of the review make effort to provide a balanced appraisal of the best available evidence and have made efforts within the review to be transparent. Every one of the studies has been rated in detail regarding risk of bias and pre-defined outcomes given particular scrutiny for the Summary of Findings table. Professor Gøtzsche has selected one outcome which he finds fault with, speculates as to its cause, generalises to all of trials relevant to people with schizophrenia, and dismisses the review. We feel this is unwarranted.

Response \#3: There is much in this comment that does not relate to this review. Important for this review is the statement "The most reliable placebo controlled trials are those of first episode schizophrenia where none of the patients have ever received drugs before." Professor Gøtzsche does not explain what he means by reliable. It seems likely that he is suggesting the explanatory exploration of the effects of medications - and is right in saying that trials in the group of people who have not had any medication before may help this 
exploration. It does not, however, help exploration of the effects of drugs for the great majority of people who have the illness in realworld circumstances. Professor Gøtzsche goes on to make statements about another review which we also feel are equally unwarranted but are not relevant to this evidence within the Chlorpromazine versus placebo review. Professor Gøtzsche is right in saying that the Chlorpromazine versus placebo review was "huge". He has chosen to comment on one outcome amongst hundreds, has not evidence to support his speculative interpretation of the finding and then used this as a basis for developing the argument across another review and well beyond. His final statements are a rallying call and not relevant to the Chlorpromazine versus placebo review and consistent with his recent statements to the press where he advertises his book attempting to discredit all psychiatry drugs (Daily Mail) to which others have reacted ( Royal College of Psychiatrists 2015).

1. Prevalence and clinical correlates of extrapyramidal signs and spontaneous dyskinesia in never-medicated schizophrenic patients. Am J Psychiatry. 1995 Dec 1;152(12):1724-9.

2. Peralta V, de Jalón EG, Campos MS, Basterra V, Sanchez-Torres A, Cuesta MJ. Risk factors, pre-morbid functioning and episode correlates of neurological soft signs in drug-naive patients with schizophrenia-spectrum disorders. Psychol Med. 2011 Jun;41(06):127989.

3.

Extrapyramidal

Signs

and

Clinical Symptoms in First-Episode. Journal of Clinical Psychopharmacology [Internet]. LWW. [cited 2015 Sep 30]. Available from: http://journals.lww.com/psychopharmacology/Fulltext/1997/08000/Extrapyramidal_Signs_and_Clinical_Symptoms_in.11.aspx

4. Bola J, Kao D, Soydan H, et al. Antipsychotic medication for early episode schizophrenia. Cochrane Database Syst Rev 2011;6: CD006374.

5. Moncrieff J. The bitterest pills. Basingstoke: Palgrave Macmillan; 2013.

6. Khin NA, Chen YF, Yang Y, et al. Exploratory analyses of efficacy data from schizophrenia trials in support of new drug applications submitted to the US Food and Drug Administration. J Clin Psychiatry 2012;73:856-64.

7. Leucht S, Kane JM, Etschel E, et al. Linking the PANSS, BPRS, and CGI: clinical implications. Neuropsychopharmacology 2006; 31:2318-25.

\section{Contributors}

Feedback comment: Peter C Gøtzsche: Director Nordic Cochrane Centre.

Reply: Clive E Adams. Author, Cochrane Schizophrenia Group.

\section{WHAT'S NEW}

\begin{tabular}{l|l|l}
\hline Date & Event & Description \\
\hline 30 October 2015 & Amended & Reply to Feedback received 18 August 2015
\end{tabular}

\section{H I S T O R Y}

Protocol first published: Issue 3, 1996

Review first published: Issue 1, 1998

Chlorpromazine versus placebo for schizophrenia (Review)

Copyright @ 2015 The Cochrane Collaboration. Published by John Wiley \& Sons, Ltd. 


\begin{tabular}{|c|c|c|}
\hline Date & Event & Description \\
\hline 7 September 2015 & Amended & New Feedback received. \\
\hline 3 December 2013 & $\begin{array}{l}\text { New citation required but conclusions have not } \\
\text { changed }\end{array}$ & $\begin{array}{l}\text { Results of update search added to review, no substantial } \\
\text { change to overall conclusions }\end{array}$ \\
\hline 5 November 2012 & New search has been performed & $\begin{array}{l}\text { Update search carried out November 2012. Five new } \\
\text { trials added to the review }\end{array}$ \\
\hline 15 May 2012 & Amended & $\begin{array}{l}\text { Update search of Cochrane Schizophrenia } \\
\text { Group's Trial Register (see Search methods for } \\
\text { identification of studies), } 26 \text { studies added to awaiting } \\
\text { classification. }\end{array}$ \\
\hline 14 March 2012 & Amended & Additional table(s) linked to text. \\
\hline 18 January 2012 & Amended & Contact details updated. \\
\hline 24 April 2009 & Amended & New plain language summary added. \\
\hline 23 April 2008 & Amended & Converted to new review format. \\
\hline 30 January 2007 & New citation required and conclusions have changed & Substantive amendment \\
\hline
\end{tabular}

\section{CONTRIBUTIONS OFAUTHORS}

Clive Adams - protocol development, searching, data extraction, analysis, data interpretation, writing the final report and maintaining the review.

John Rathbone - study selection, data extraction, analysis, writing the report for the update of 2002. Update 2007, study selection, data extraction, data analysis, writing final report.

George Awad - protocol development, data interpretation.

Ben Thornley - completion of earlier versions of this review.

Karla Soares-Weiser - completion of 2012 update.

Nicola Maayan - completion of 2012 update. 


\section{DECLARATIONSOF INTEREST}

None known.

\section{SOURCES OF SUPPORT}

\section{Internal sources}

- University of Toronto, Canada.

- University of Leeds, UK.

\section{External sources}

- NHS Executive Anglia and Oxford R\&D Directorate, UK.

\section{DIFFERENCES BETWEEN PROTOCOLANDREVIEW}

We have updated the methods section since the last publication of this review to reflect changes in the Cochrane Schizophrenia Group's methodology.

We have re-ordered some of the outcomes.

\section{INDEX TERMS}

\section{Medical Subject Headings (MeSH)}

Antipsychotic Agents [adverse effects; * therapeutic use]; Chlorpromazine [adverse effects; *therapeutic use]; Placebo Effect; Randomized Controlled Trials as Topic; Schizophrenia [*drug therapy; prevention \& control]; Secondary Prevention

\section{MeSH check words}

Humans 